E January - February 1994
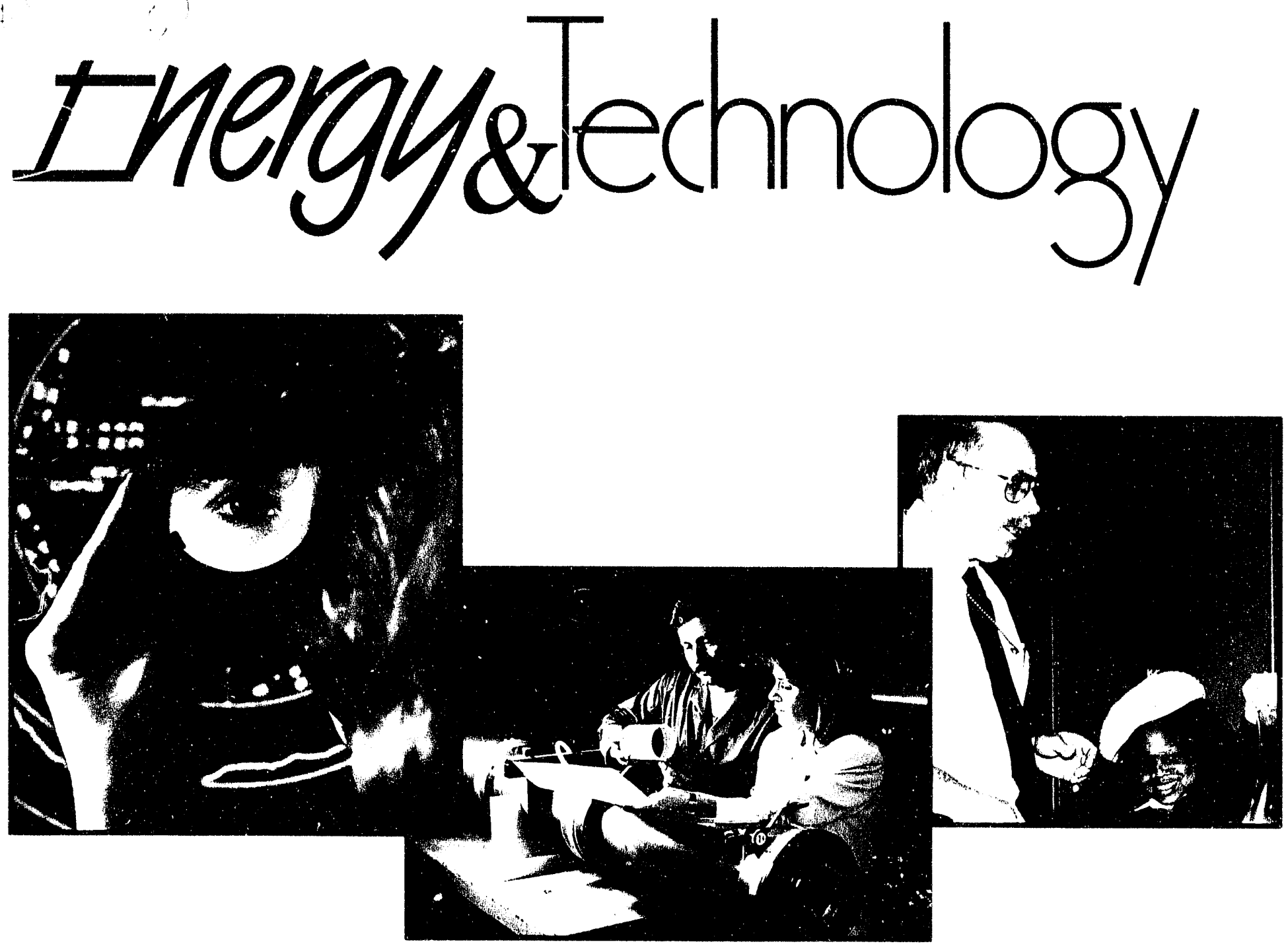

The State of the Laboratory 


\section{About the Issue}

The Lawrence Livermore National Laboratory (LLNL) was founded 41 years ago to push the limits of science and technology for national security and defense. Research was driven by the demands of the Cold War and focused primarily on the design and development of nuclear weapons. Today, however, the world situation has changed dramatically, and it is clear that U.S. national security depends as much on a strong economy and an educated populace as it does on military strength. As we prepare for the 21 st century, the highest priority missions for LLNL and the other two national weapons laboratories, Los Alamos and Sandia, are enhancing U.S. economic competitiveness and countering the proliferation of weapons of mass destruction.

This issue of Energy and Technology Revien highlights the Laboratory's 1993 accomplishments in our mission areas and core programs--economic competitiveness, national security, energy, the environment, lasers, biology and biotechnology. engineering, physics, chemistry and materials science, computers and computing, and science and math education. LLNL is a major national resource of science and technology expertise, and we are committed to applying this expertise to meet vital national needs.

Photographs: (left) Senior technologist Marsha Kellam examines a highly polished, multilayer $x$-ray mirror; in the background is a profilometer plot of the smoothness of the mirror surface. (center) Mechanical engineer Monya Lane and lead mechanical technician Tom Stone confer in the development of a now high-power, coppervapor laser amplifier head that provides a $25 \%$ increase in power output over preceding designs. (right) Dennis Chakedis, a mechanical technician supervisor. demonstrates the effect of liquid nitrogen on an inflated balloon to a group of young students in a "traveling science show," one of the Laboratory's many activities to help schools improve math and science education.

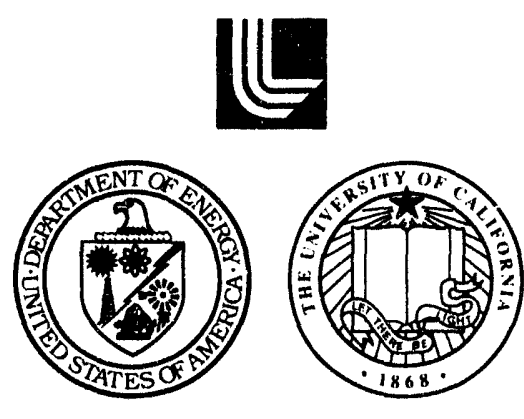

Prepared for DOE under contract No. W-7405-Eng-48

\begin{abstract}
About the Journal
The Lawrence Livermore National Laboratory, operated by the University of California for the United States Department of Energy, was established in 1952 to do research on nuclear weapons and magnetic fusion energy. Since then, in response to new national needs, we have added other major programs, including economic competiveness, laser science (fusion, isotope separation, materials processing), biology and biotechnology, environmental research, restoration and protection, arms control and nonproliferation. advanced defense technology, and applied energy technology. These programs, in turn, require research in basic scientific disciplines, including chemistry and materials science, computing science and technology, engineering, and physics. The Laboratory also carries out a variety of projects for other federal agencies. Energy and Technology Review is published monthly to report on unclassified work in all our programs. Please address any correspondence concerning Energy and Techmology Revien (including name and address changes) to Mail Stop L-3, Lawrence Livermore National Laboratory. P.O. Box 808, Livermore, CA 94551, or telephone us at (510) $422-4859$
\end{abstract}




\section{Q Jamuary · February 1994}

Scientific Editor

William J. Quirk

Editorial Staff

June Canada

Lauren de Vore

Kevin Gleason

Robert D. Kirvel

Harriet Kroopnick

Lori McElroy

Art Staff

Kathryn Tinsley Lynn M. Costa

Janet Crampton-Pipes Paul M. Harding

Treva Carey George Kitrinos

Compositor

Louisa Cardoza

This document was prepared as an account of work sponsored by an agency of the United States Government. Neither the United States Government nor the University of California nor any of their employees makes any warranty, express or implied, or assumes any legal liability or responsibility for the accuracy, completeness, or usefulness of any information, apparatus, product, or process disclosed, or represents that its use would not infringe privately owned rights. Reference herein to any specific commercial product, process, or service by trade name, trademark, manufacturer, or otherwise, does not necessarily constitute or imply its endorsement, recommendation, or favoring by the United States Government or the University of California. The views and opinions of authors expressed herein do siot necessarily state or reflect those of the United States Government or the University of Califomia and shall not be used for advertising or product endorsement purposes.

Printed in the United States of America Available from

National Technical Information Service U.S. Department of Commerce 5285 Port Royal Road

Springfield, Virginia 22161

UCRL-52000-94-1/2

Distribution Category UC-700 January - February 1994

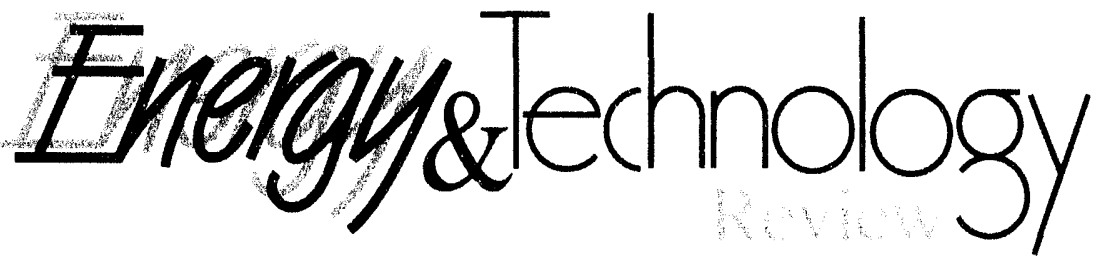

The State of the Laboratory 1

Economic Competitiveness $\quad 4$

$\begin{array}{ll}\text { National Security } & 10\end{array}$

Nonproliferation, Arrns Control, and International Security 12

$\begin{array}{lr}\text { Defense Systems } & 18\end{array}$

Nuclear Testing and Experimental Science 24

$\begin{array}{ll}\text { Lasers } & 30\end{array}$

$\begin{array}{ll}\text { Environment } & 36\end{array}$

Environmental Research and Technology Development 38

Environmental Restoration, Protection, and Waste Management 44

$\begin{array}{ll}\text { Energy } & 50\end{array}$

Biology and Biotechnology $\quad 56$

Engineering $\quad 62$

$\begin{array}{ll}\text { Physics } & 68\end{array}$

Chemistry and Materials Science $\quad 74$

Computers and Computing $\quad \mathbf{8 0}$

$\begin{array}{lr}\text { Education } & 86\end{array}$

Administration and Institutional Services $\quad 92$

Awards 
Studies with powerful lasers like Nova will be an important component of stockpile stewardship in the absence of nuclear testing.
In the post-Cold War era, the President and Congress are defining new national priorities, many of which are in LLNL mission areas. Sweeping internal changes are under way as the Laboratory shifts its human and material resources to meet these new national priorities.

President Clinton has emphasized two high-priority missions for LLNL and our two sister DOE weapons laboratories, Los Alamos and Sandia:

- In the commercial area, to enhance U.S. economic competitiveness. - In the defense area, to help counter the proliferation of weapons of mass destruction and to make possible the stewardship of the U.S. nuclear weapons stockpile without nuclear testing.

In a September 1993 speech to the United Nations, the President focused on emerging problems of the management and storage of plutonium and other special materials resulting from the dismantlement of the U.S. and former Soviet Union (FSU) nuclear stockpiles.

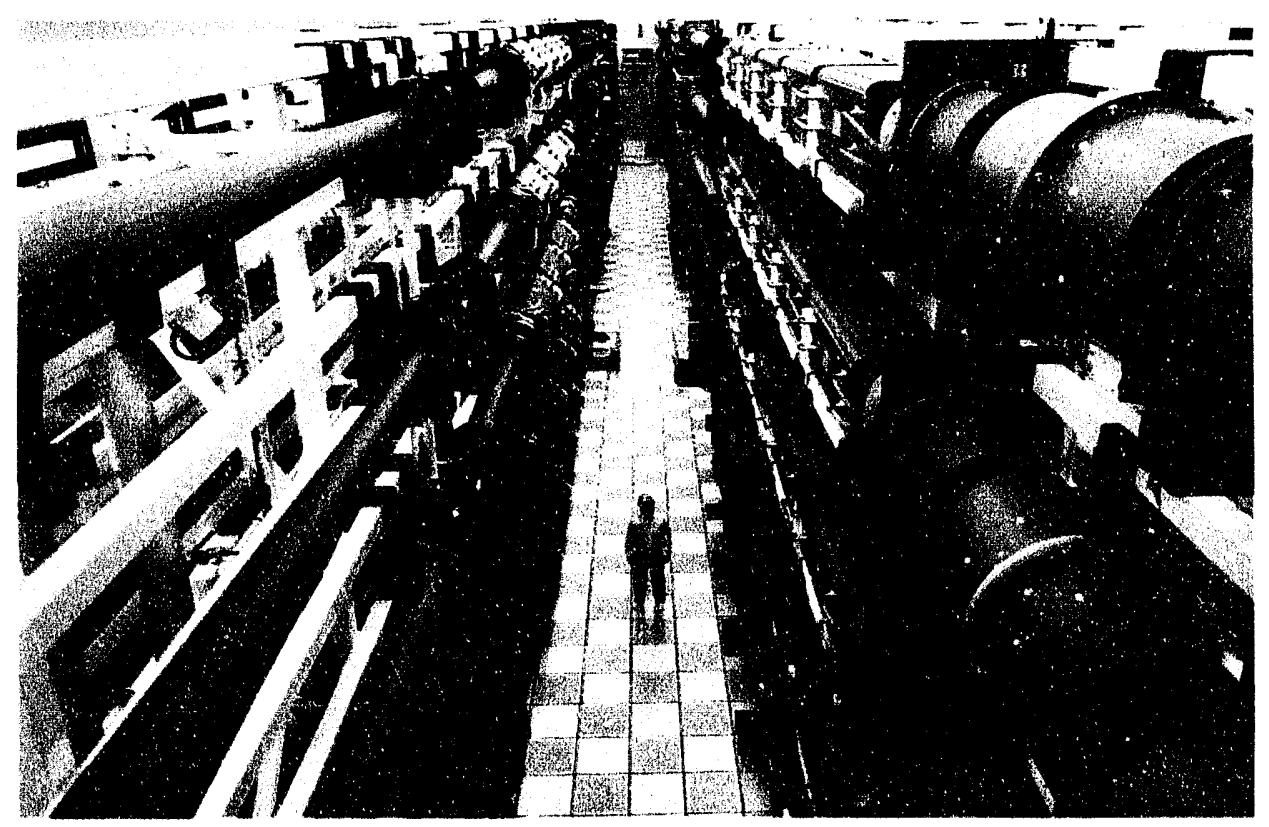


In this period of global disorder and nuclear proliferation, several of these high-leverage tasks are pressing and require the combined efforts of the weapons laboratories.

The President's commercial mission for the weapons laboratories also provides an extraordinary challenge. Funding of this mission area is rapidly increasing. We are in a learning phase where many approaches are being tested. In five years, it is projected that up to $20 \%$ of LLNL will be funded to enhance U.S. economic competitiveness. A substantial part of the remaining $80 \%$ of our funding will also contribute through programmatic dual-use/dual-benefit activities conducted in partnership with industry. The great challenge for the weapons laboratories in the commercial area is to help effect technologically a significant increase in the rate of growth of the U.S. economy. Over time, an increase in the economic growth rate could compound exponentially to result in a substantial increase in U.S. economic strength.

In addition to these national security and commercial challenges, the Laboratory is committed to meeting vital long-range national needs within our civilian mission areas.

- In energy, we are focused on harnessing virtually inexhaustible fusion energy and on establishing the feasibility of a 21 stcentury hydrogen energy system. - In environment, we are focused on understanding the threat of global warming, developing a sound scientific foundation for risk-based environmental protection and cleanup, and developing and applying "smart" technologies to achieve environmental cleanup at greatly reduced costs.
- In health and biomedicine, our principal focus is on mapping the human genome and then applying the knowledge generated to revolutionize health care.

- Funding for our science and math education program is relatively small but growing. This program includes a substantial volunteer effort by Laboratory employees.

The Laboratory's approach to accomplishing our mission activities includes a strong focus on partnerships with the University of California, other laboratories, and the private sector. Internally, this fundamental change in approach is being facilitated by the introduction of total-quality-management principles.

Through these transformations in mission and capability, LLNL, with DOE's support and encouragement, is reinventing itself to meet the challenges of the 21 st century. Our vision is to continue to excel in creating and applying science and technology to meet vital national needs.

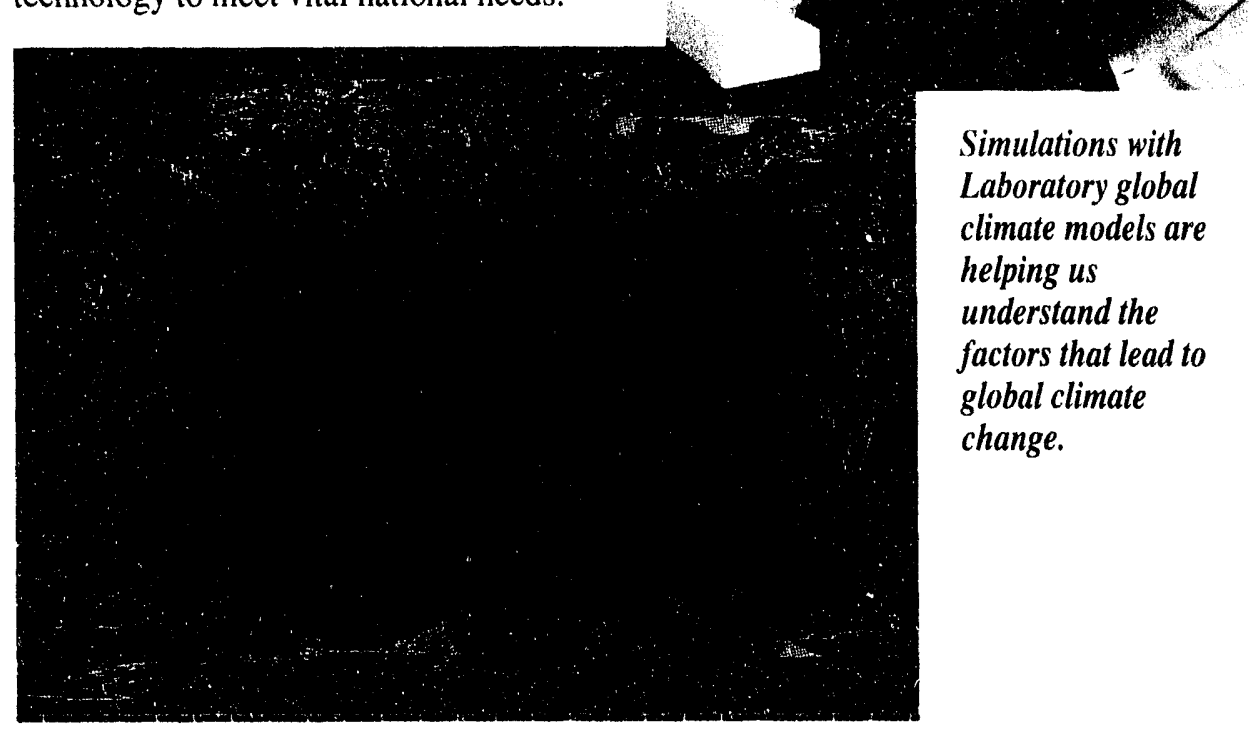

Fundamental knowledge about the human genome will have revolutionary

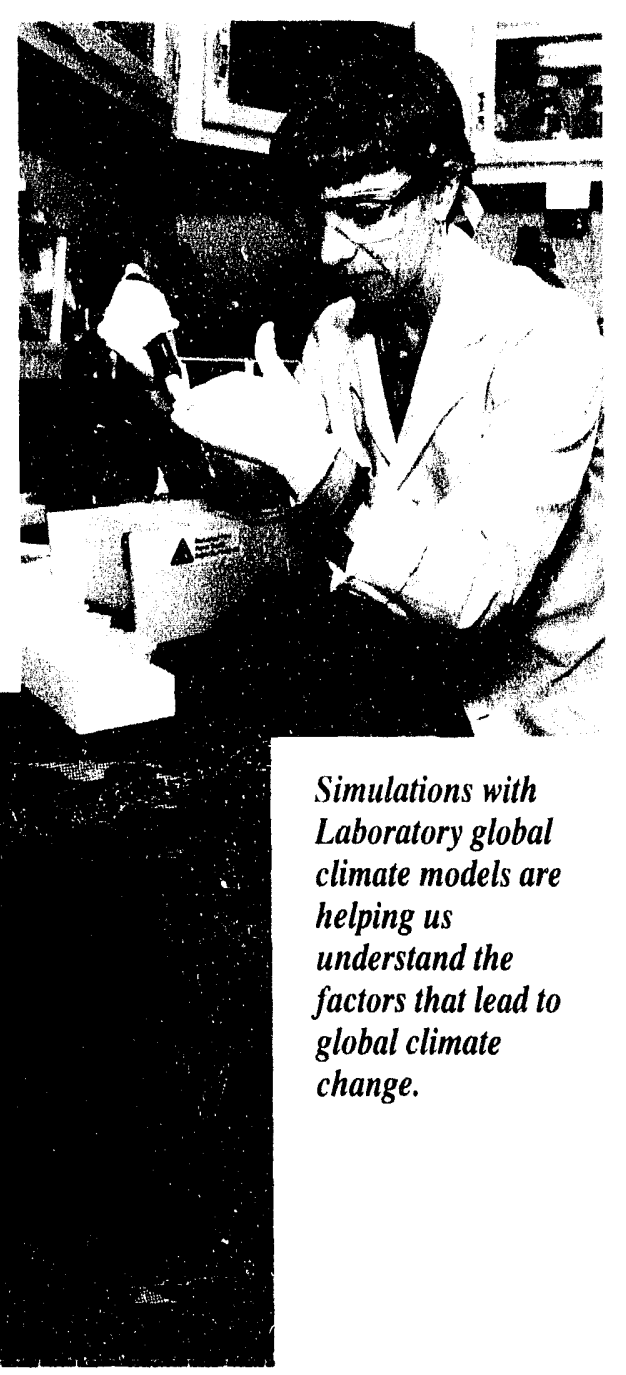
applications to human health care. 


\title{
omic Competifiveness
}

\author{
Through cooperative efforts with business, industry, universities, and other government \\ agencies, we are developing products and processes that will improve the economy and secure \\ the nation a strong competitive position in the international market.
}

L

$\checkmark$ LNL was founded 41 years ago to push the limits of science and technology for national security and defense. Today, we know that national security depends as much on economic strength as it does on military might. Thus, we have a new mission-to push the limits of science and technology for the nation's economic well-being. This new mission requires collaboration between the national laboratories and U.S. business and industry to transfer existing technologies and to rapidly develop new products and processes.

Congress and the DOE have authorized and funded us to pursue the commercialization of Laboratorydeveloped technologies that strengthen our ability to accomplish our primary missions. As a result, we are reaching out aggressively to American business and industry in an effort to understand and match their needs with our resources and capabilities. We bring to them a unique ability to solve large-scale problems through interdisciplinary research, development, demonstration, and testing; an impressive array of state-of-the-art

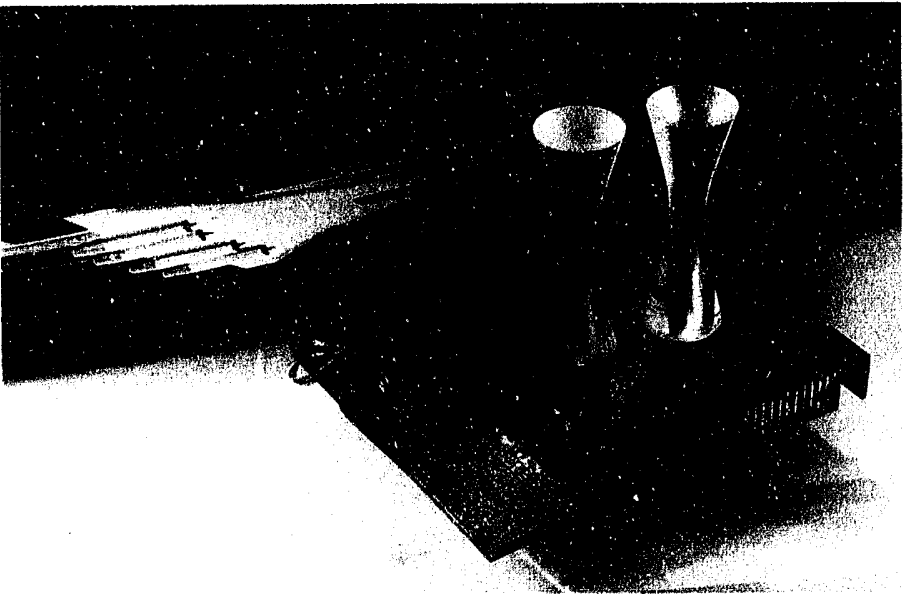

equipment and experimental facilities; and our skill, expertise, and achievements in such critical technology-producing areas as high-performance computing, lasers, optics, precision engineering, advanced materials, biomedicine, and energy.

We see technology transfer occurring at several levels. At one level, we are working with industry to market our "spinoff" technologies-those products, processes, or technical resources (expertise, equipment, facilities) developed during thie normal course of defense research that also have significant commercial value. At another level, we are working with industry to develop new technologies that can be used now or within the next three to five years for specific commercial applications. At the most challenging level, we are working with industry to create breakthrough technologies-those revolutionary products or processes that either change the emphasis of an existing market or become the starting point for an entirely new one. Breakthrough technologies entail higher risk and a longer-term commitment of resources, but they also have a higher potential payoff.

This year, we established partnerships with a number of U.S. companies for a variety of projects. For each project, the method of transfer varied according to the nature and complexity of the technology, its degree of development, its perceived applications, its proprietary status, and the time and effort needed to effect the transfer. Some of these projects were set up as cooperative research and development agreements (CRADAs), others as licensing agreements, others as memoranda of agreement, and still others as employee consulting or exchange programs. ${ }^{1}$ 


\section{Materials for Supersonic Aircraft}

In August 1993, we signed a five-year, \$18.5-million CRADA with Boeing Commercial Airplane Group and Vought Aircraft Co., to evaluate the long-term performance of the high-temperature polymer composites to be used to build the High-Speed Civil Transport, the world's first economically viable, supersonic passenger plane. According to Boeing, the plane will be operational in the early part of the 21 st century. It will accommodate 300 passengers and fly from California to Australia in about seven hours, half the time it takes to fly that route by subsonic commercial jet.

We are developing accelerated aging models that will predict the long-term strength and durability of the polymer composites to be used on the plane. We are also conducting thermal-mechanical tests to see how the materials age. Boeing and Vought are testing the materials in realtime to determine how they will function over the next five years.

The data from the thermal-mechanical tests will be used to compare a polymer's accelerated aging with its real-time aging. These data will also be used to develop computer models that predict how the mechanical properties of a polymer change over time so that aircraft designers can determine its useful life span.

Predicting the structural lifetime of a composite material currently is a difficult, costly process that requires more than 10 years of real-time testing. As a result, very few polymer composites have been used for long-term, high-performance, structural applications, even though they might perform better and cost less. With our models and thermal-mechanical aging tests, Boeing and Vought hope to reduce more than 10 years of testing to $1-2$ years and thereby encourage the use of the best materials for the best possible product.

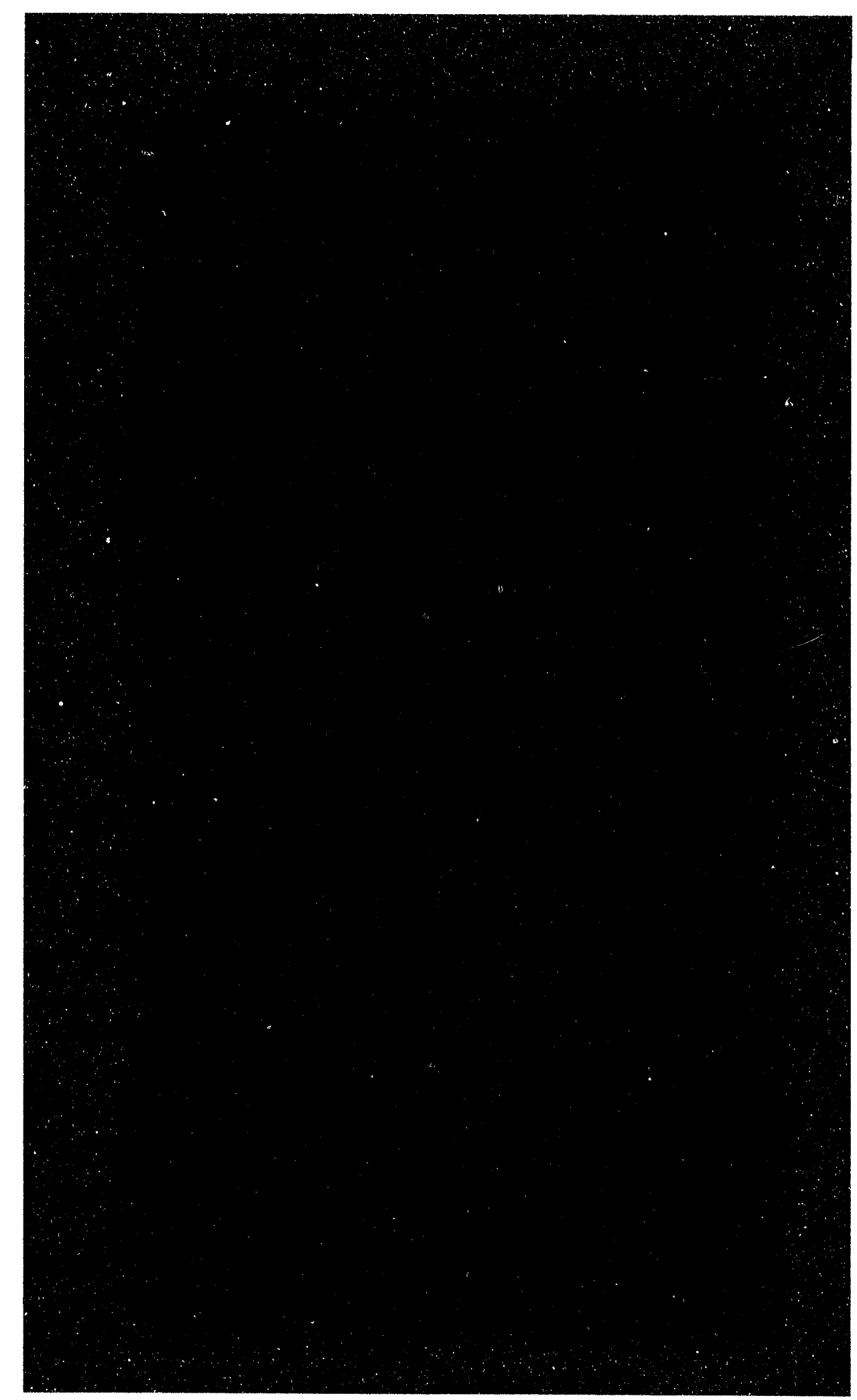




\section{Correcting Vision Problems}

The microthin lens dwarfed by a dime. Researchers from Phoenix Laser Systems, Inc., and the Laboratory are studying the use of this thin plastic membrane in correcting human vision problems.

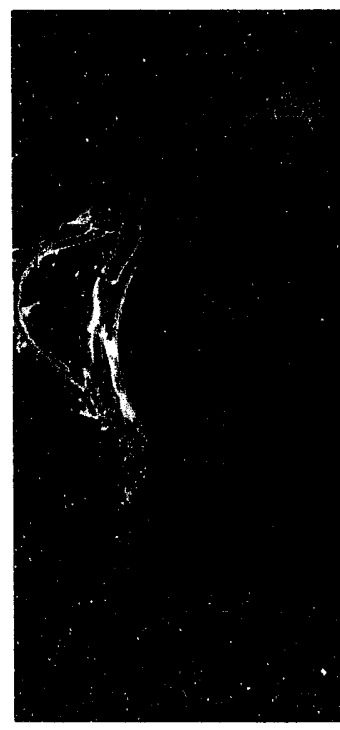

Laboratory physicist

Steve Falabella poses with the vacuum chamber and cathodic arc ion source used for cathodic arc deposition, a technique he developed for applying thin diamond film to various surfaces. SI Diamond Technology, Inc, , together with Commonwealth Scientific and $L L N L$, will evaluate the feasibility of using this technique to coat its new flat panel displays with thin diamond film.
This year, we began working with Phoenix Laser Systems, Inc. (Fremont, California), to examine possible applications for the microthin lens, a very thin (thinner than a human hair), plastic, diffractive membrane developed by the Laboratory and the University of California, San Francisco, in 1989. The microthin lens combines the thinness of a diffractive lens with the optical properties of a refractive lens, solving the problem of chromatic aberration and thus enabling the use of a diffractive lens to correct vision. We are developing the optics and fabrication technologies for the lens and will be responsible for its demonstration. Phoenix Laser Systems is evaluating its optical performance and assessing its biological compatibility for approval by the Food and Drug Administration.

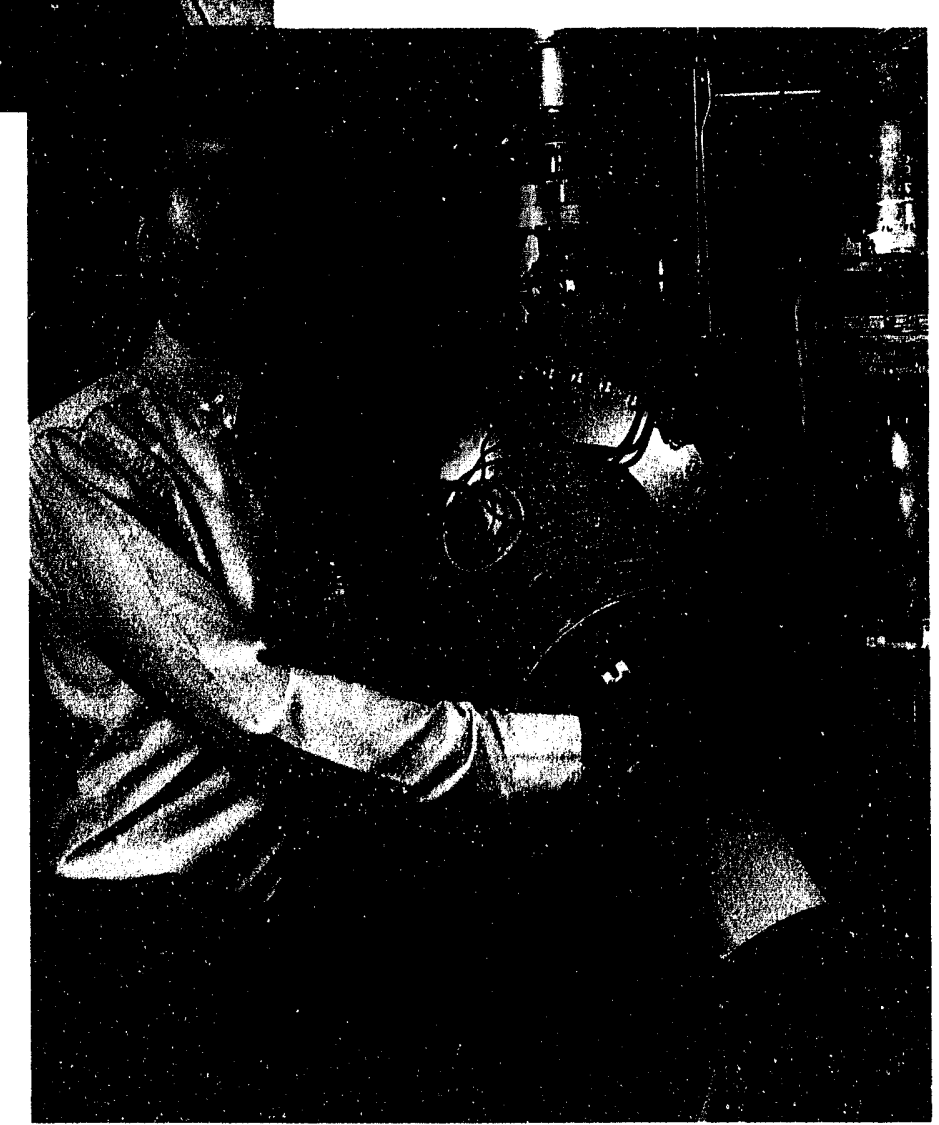

The goal of this joint venture, funded by a \$15.2 million CRADA, is to use the lens in correcting four common vision problems: presbyopia (the eye's lens loses elasticity and therefore its ability to vary focal length, a problem corrected now by bifocal glasses); hyperopia, or farsightedness; myopia, or nearsightedness; and cataracts, a clouding or fogging of the lens that prevents the passage of light and results in either greatly diminished vision or blindness.

Currently, project researchers are studying two ways to emplace the microthin lens in corrective cataract surgery. The first is to remove the eye's natural lens through a small incision made by laser light or ultrasound and then roll or fold the microthin lens into the eye through the same incision. Once in the eye, the microthin lens would unfold into its original shape. The second way is to remove the eye's natural lens and epithelium (the thin layer of cells covering the cornea) by laser light or ultrasound and place the microthin lens over the cornea so that, once the epithelium grows back, it covers and secures the microthin lens in place. These methods could reduce the cost of cataract surgery as well as the potential for infection afterwards.

\section{Depositing Thin Diamond Film}

SI Diamond Technology, Inc. (Houston, Texas), and Commonwealth Scientific (Alexandria, Virginia), a manufacturer of ion beam sources, are collaborating with us to determine whether our technique for depositing thin diamond film can be used in the development of SI Diamond's new flat panel displays. These new displays could be used with portable computers, in aircraft cockpits, and for home entertainment and computer systems and, by some estimates, could expand the market for flat panel displays to over $\$ 50$ billion a year by the beginning of the next decade. They are better than their predecessors because they produce light directly (precluding the need for a backlight source), have high enough resolution for 
use with high-definition television, and can be viewed over a wide range of angles.

A major difficulty in making a flat panel display is the accurate deposition of a layer of diamond that is $0.2 \mu \mathrm{m}$ thick. To do this, SI Diamond had been using laser ablationvaporizing carbon from a graphite source rod with a powerful beam of laser light and then depositing the vapor as a thin film on the substrate where it will be used. Although laser ablation provides adequate accuracy, it is an expensive process for a small company. Thus, SI Diamond has chosen to use a Laboratory-developed process called cathodic arc deposition.

In cathodic arc deposition, a large current arc is induced between a graphite cathode and an anode in a vacuum chamber. The current vaporizes the graphite and creates a plasma of carbon ions that are then guided to the substrate for coating. Since ions have a charge, their path can be directed magnetically to their destination. The carbon ions condense on the surface of the substrate in a hard, glassy state known as "amorphous diamond." Because cathodic arc deposition is faster, easier to control, and less expensive to operate than laser ablation, it could prove to be an important part of manufacturing display panels.

\section{New Diamond-Powder Composite}

In October 1993, we began delivering samples of our new diamond-powder composite, Dymalloy, to Sun Microsystems (Mountain View, California), and Sun began evaluating the material's use as a substrate on which to build the multichip modules used in high-speed computers. These advanced modules combine many microprocessors and electronic components on a single chip to increase computing speed.

Dymalloy, a combination of powdered diamond and copper, is particularly desirable as a substrate for advanced computer chips because it conducts heat faster than most conventional electronic packaging materials and because it expands and contracts at the same rate as the electronic components attached to it.
Sun Microsystems is building more and more high-speed microprocessors. Unfortunately, along with the achievement of high speed comes the problem of overheating. The company believes that using the Dymalloy substrate for its multichip modules will solve this problem; the new substrate will conduct heat away from the electronic component, allowing the microprocessor to run cooler.

The work we accomplish under this one-year, $\$ 350,000$ CRADA with Sun Microsystems could eventually lead to the use of Dymalloy substrates for the electronic components of high-speed workstations and personal computers.

\section{Digital Mammography}

Two years ago, we proposed applying our expertise in weapons $x$-ray measurement and imaging to the detection of breast cancer through digitization and computer analysis of film mammograms. Our early experimental work on digitized film images showed that an automated,

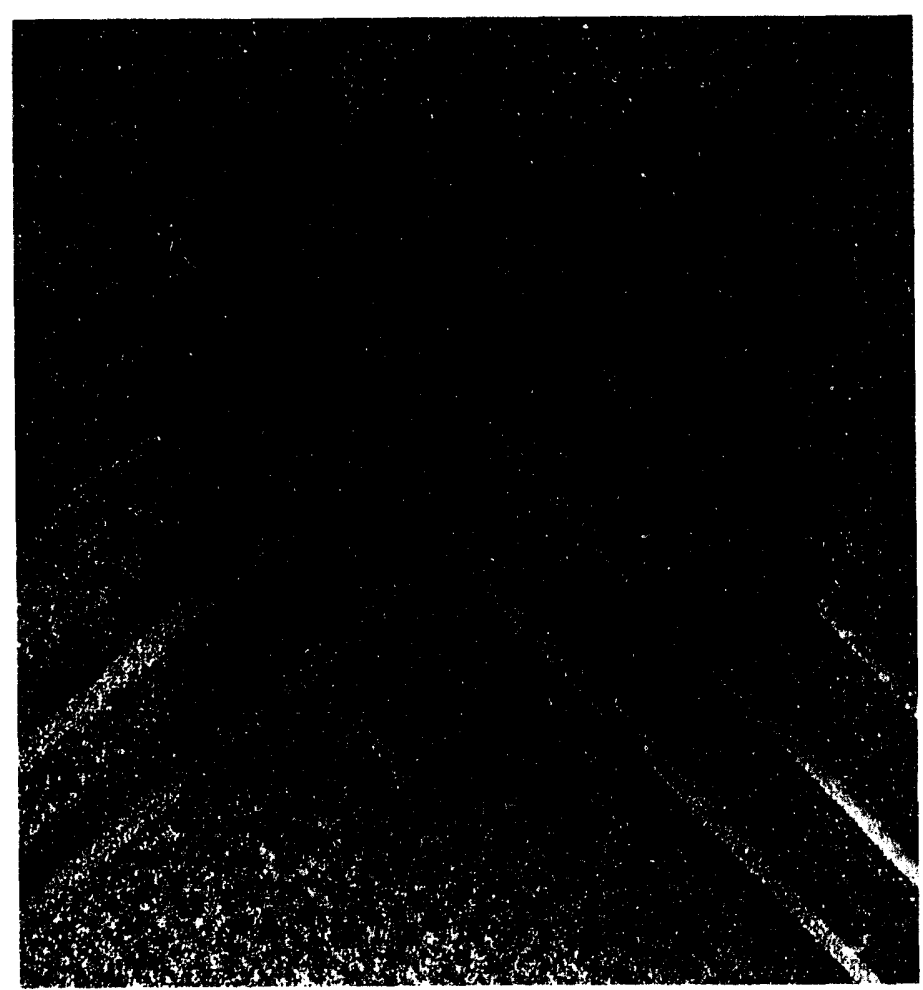

computer-based method for identifying anomalies in breast tissue would allow a more accurate reading of the image, eliminate the difficult and tedious task of searching traditional $x$-ray film images, and provide a timely diagnosis. ${ }^{2}$

This year, we made the transition from experimental work to commercial product development and application. We are working with Fischer Imaging Corp. (Denver, Colorado) to develop a digital mammography device that will produce clearer images, use less radiation, and detect even the smallest cancers, minimizing invasive surgery to the removal of a lump (lumpectomy) rather than an entire breast (mastectomy).

The device being developed under the \$3.38 million CRADA with Fischer Imaging Corporation dispenses with $\mathrm{x}$-ray film altogether and uses sophisticated $\mathrm{x}$-ray detectors to record the image directly. The detector array employs charge-coupled devices (extremely sensitive light detectors used in surveillance, space exploration, and camcorders) to record 20 million individual

Three pieces of Dymalloy, our new diamond-powder composite. The reddish background in this photograph is the composite's surface magnified 1000 times. Sun Microsystems is evaluating this material for use as a substrate on which to build the multichip modules used in its high-speed computers. 
pixels. The result is a digital image that can be further enhanced by computer.

Because it will have a low-dose $x$-ray source with an adjustable wavelength, the new device will have greater flexibility than conventional mammography machines. It will be able to produce the highest quality images of breasts of all sizes and densities using the least radiation possible. Commercialization of this technology will improve the understanding of hundreds of millions of breast images each year and enable an earlier and more accurate detection of cancers.

\section{Magnetron Sputtering Source}

Last year we licensed a technology for magnetron sputtering (that is, for depositing multilayer coatings of metal on glass, plastic, or metal surfaces in a vacuum) to US Thin Film Products, Inc. (Campbell, California). This technology, originally developed for $\mathrm{x}$-ray optic experiments, was modified for commercial use (such as for coating compact disks or integrated circuits) by researchers from US Thin Film Products and the Laboratory, and has recently become available in the form of a small sputtering source called the MightyMAK. According to both parties, the joint effort was smooth and effective and is an excellent example of how technology developed at the national laboratories can be efficiently transferred to the private sector.

US Thin Film Products, Inc. expects that their 1.3- and 3-in. MightyMAK sources will replace the 2- and 4-in. magnetron sputtering sources available now because they are more reliable, easier to operate, and achieve better deposition rates for more uniform coating thicknesses. These new sources are also smaller and more compact than the existing ones, so more of them can be mounted in a vacuum chamber to allow greater flexibility in applying different material coatings. Because of their simple design, the MightyMAK sources can be

A magnetron
sputtering
technology, modified
for commercial use
(e.g., for coating
compact disks or
integrated circuits)
by the Laboratory
and US Thin Film
Products, has
recently become
available as a small
source called the
MightyMAK. Here
we see three
MightyMAKs in a
vacuum chamber.
Laboratory
technician Phil
Ramsey, one of the
inventors of the
source, is operating
the shutter to the
vacuum chamber.

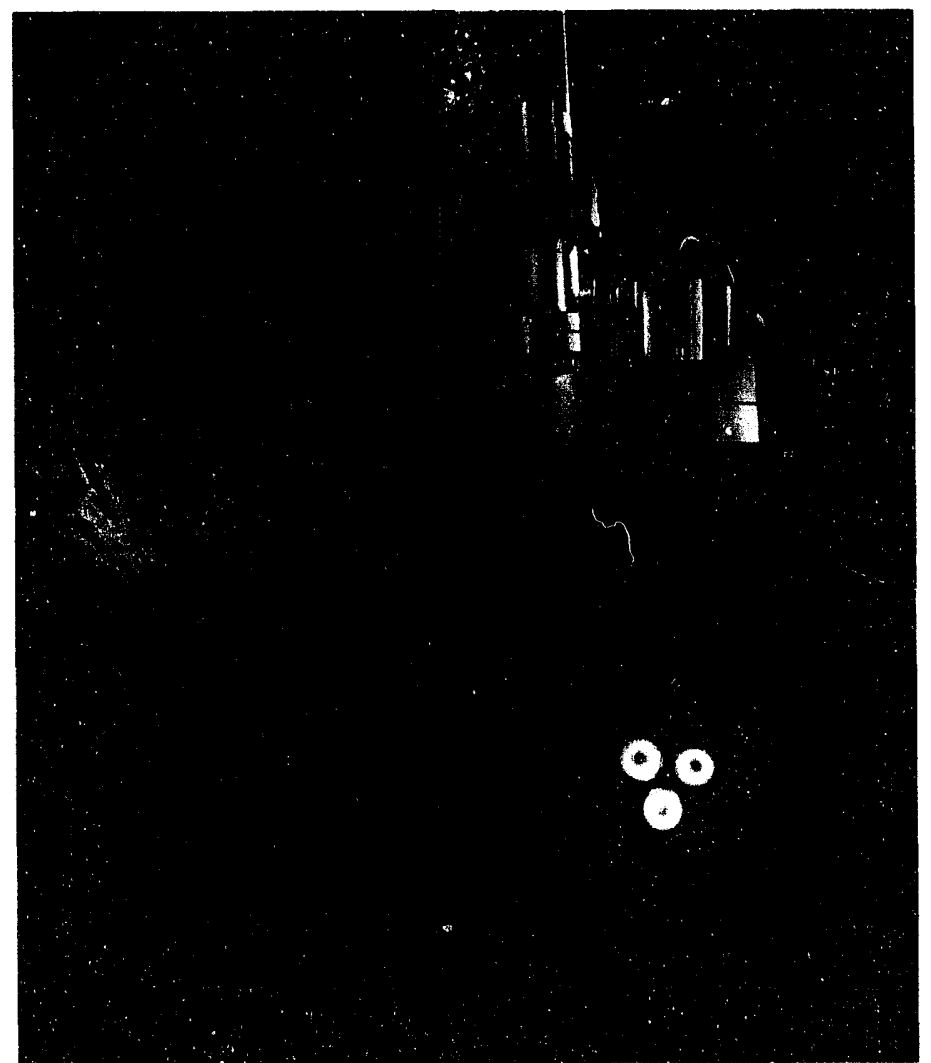

manufactured at a lower cost than current sources and therefore sold at a lower price. The company has already received orders for the sources and expects to sell 250 units in the first year.

\section{The Small Business Initiative}

The Small Business Initiative, formed by LLNL and other national laboratories, is designed to help small companies (those with 500 or fewer employees) overcome technological barriers by giving them access to resources at the national laboratories. In essence, the laboratories provide the companies with the technical assistance or facilities they need to develop products that will enable them to compete successfully in domestic and foreign markets. Funded by an $\$ 8$ million grant from the DOE, the initiative targets small companies in nanufacturing and advanced technology development, especially those trying to make the transition from defense to commercial markets.

This year, Compression Labs, Inc. (San Jose, California), a small manufacturer of video-conferencing systems, began working with LLNL under the Small Business Initiative to extend its desktop video products for use on local area networks. By using LLNL's Ethernet network, the company hopes to determine how a local area network will be affected by one or more video sources and how the video will be affected by the Ethernet data.

\section{Ties with the California Manufacturing Technology Center}

A DOE memorandum of agreement with the California Manufacturing Technology Center (CMTC) represents another opportunity for LLNL to help manufacturers gain a competitive edge. Under this agreement, members of the CMTC and other small and medium-sized manufacturing firms throughout the state will have access to our expertise, equipment, 
and facilities. This collaboration will help the Laboratory identi y what manufacturing technologies are needed in the state and what resources it can apply to meet those needs.

\section{Improving Banking Service}

The goal of a three-year CRADA with Citibank Corporation is to improve the bank's customer service by improving the availability of its current computer and communications systems. Citibank believes that if it can make these systems easier to use and less prone to down time, it will be able to retain more customers and therefore increase its profits.

To determine how Citibank can get the highest availability of its systems cost effectively, we are using the expertise we have gained from analyzing and improving the reliability of nuclear power plants. We are generating models to determine how a given computer architecture responds under different situations and then validating the models with data from Citibank. The results will show how to improve old architectures, develop new ones, and migrate from the old to the new.

\section{Optics for X-Ray Lithography}

We are working with Tinsley Laboratories (Richmond, California), a small firm that manufactures optics, to develop the optics for the next generation of steppers-the machines that produce silicon computer chips. Existing steppers use visible or ultraviolet light to etch the fine lines on a computer chip. The new steppers will use $x$ rays, in a process called $x$-ray lithography, to etch even finer lines and thus allow the chip to accommodate more information and perform faster.

The goal of the three-year, $\$ 2.4$ million CRADA with Tinsley is to develop a strong technology base for manufacturing the optical surfaces required for use in $\mathrm{X}$-ray lithography steppers. Tinsley is providing the basic technology for manufacturing the highly precise and complex optics, and we are providing the technologies to help develop better methods for predicting the interactions of the polishing machine, the polishing tools, and the optical surface. Other areas of LLNL expertise that will prove helpful to this effort include machine tool design, precision engineering, measurement capabilities, the grinding and polishing of optics, and mathematical and computer modeling.

This cooperative research should enhance Tinsley's ability to understand, measure, and control the subtle processes that introduce error into complex and sophisticated optics. Although it will probably take more than a decade for $\mathrm{x}$-ray lithography steppers to come into general use, Tinsley wants to be ready with the upgraded optics needed to develop them.

$\mathrm{X}$-ray lithography is an outstanding example of a breakthrough technology. The U.S. controlled the lithography market in the 1970s but lost it to Japan in the 1980s. Our goal is to help the U.S. recapture the market by exploiting the $\mathrm{x}$-ray optic technology we have developed. Our work with Tinsley is a step toward doing this.

\section{Super-Accurate Slicing Machine}

In a project with Industrial Tools, Inc. (Ojai, California), we developed a slicing machine that cuts hard-to-machine materials, such as ceramics, carbides, glass, and plastics, to within an accuracy of $0.5 \mu \mathrm{m}$. According to Industrial Tools, this new tool not only is twice as accurate as the company's previous machine but is also the most precise production unit in the world. Manufacturers of computer disk-drive recording heads are using the slicing machine to cut disk-drive heads of aluminum-titanium carbide. The slicing machine can also be used in the semiconductor business to cut large silicon wafers into chips. One of our contributions was the design of an airbearing slide system that provides very precise movement of the part being machined. Another contribution was errorbudgeting analysis, in which we systematically examined every potential design error and predicted its effects. This approach demonstrated the importance of maintaining a consistent room temperature, showing that even the machine operator's body heat could change the temperature enough to exceed machine tolerances.

\section{Summary}

Although a number of our technology transfer projects have had successful conclusions, experience shows that we still have a lot to learn about working with the private sector. However, with close attention to our successes and failures and a better understanding of the commercial side of product development, we will be able to zero in on what works and what doesn't.

\section{Notes and References}

1. Chartered in the National Competitiveness Technology Transfer Act of 1989, CRADAs encourage the national laboratories to seek out U.S. industries for mutually beneficial research and development projects; each partner contributes personnel, facilities, equipment, or other resources. We can also transfer technology to a private company through exclusive or nonexclusive licensing agreements; under such agreements, we can provide scientific or technical expertise to fit the technology to a particular application.

2. C. M. Logan, "Digital Mammography" Energy and Technology Review' (October-November-December 1992; UCRL-52000-93-10/11/12), pp. 27-36.

\section{For further information contact Roger W. Werne (510) 422-8351 or Gilbert R. Marguth (510) 423-1341.}




\section{mal Security}

\section{We are addressing a host of urgent issues related to nuclear weapons that have arisen, in part, as a consequence of the end of the Cold War.}

nt, near Amarillo, Texas, ty in the U.S. for the iantlement of nuclear ork with Pantex personnel ment of LLNL-designed

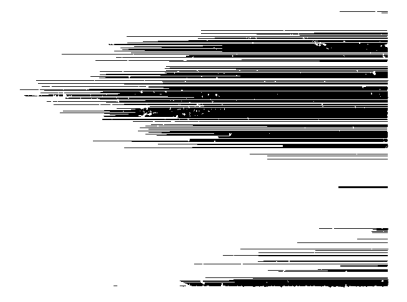
acquisition, and deployment of nuclear weapons.

The weapons laboratories will be the stewards of a reduced nuclear stockpile. Preserving the credibility of that stockpile will be a major challenge. In his speech of July 3,1993 , extending the nuclear testing the Warsaw Pact and the Soviet Union itself. As a result, tensions between the U.S. and its former adversaries have relaxed dramatically, and the arms competition that dominated relations between the superpowers has turned into a race to disarm. The U.S. and the former Soviet Union (FSU) have already crafted treaties that cal! ior mutual reductions in our nuclear arsenals. In addition, each party has undertaken a variety of unilateral measures to temper the development,
HE Cold War is over, and the Laboratory's Weapons Program has a new agenda. In one of the most remarkable episodes of our century, the world has seen the political disintegration of both

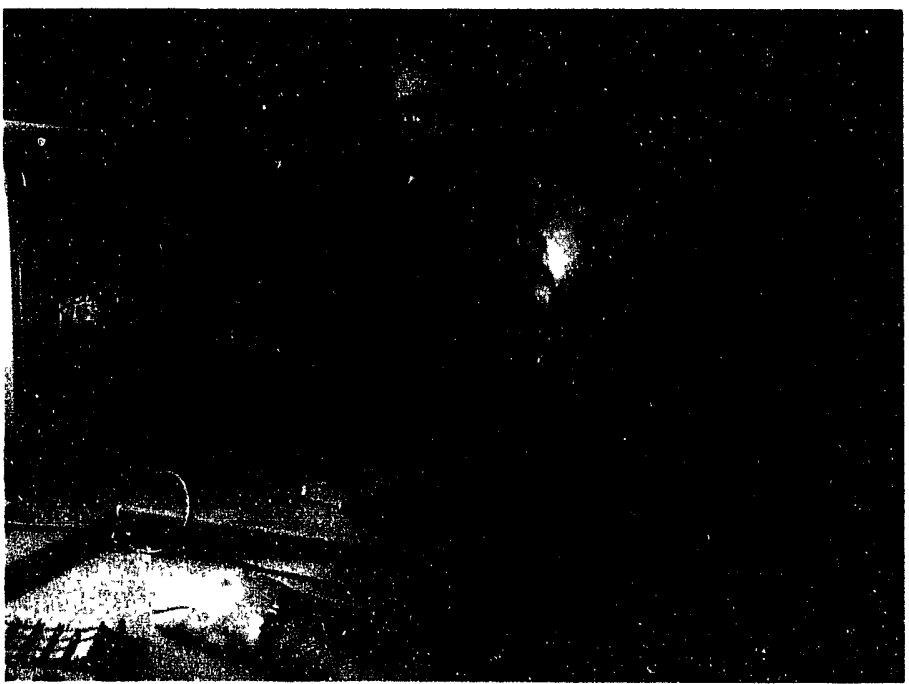

moratorium, President Clinton said: "To assure that our nuclear deterrent remains unquestioned under a test ban, we will explore other means of maintaining our confidence in the safety, the reliability, and performance of our own weapons. We will also refocus much of the talent and resources of our nation's nuclear labs on new technologies to curb the spread of nuclear weapons and verify arms control treaties."

LLNL is responding to the President's directive. We have greatly expanded our efforts to deal with the problems of proliferation. We are seeking other ways to maintain confidence in the stockpile. To this end, we are developing new capabilities and facilities and are enhancing existing ones. A major issue is ensuring that the U.S. nuclear weapons complex can handle the dismantlement of thousands of retired weapons.

A new dimension to this threat involves the ultimate disposition of weapons of mass destruction and technologies that were inherited by the FSU republics, where depressed economic conditions and political instabilities dominate the scene. One way to provide assurance to these republics is for the U.S. to commit to rapid dismantlement of our own retired nuclear weapons and to assist with the dismantlement of the FSU stockpile. We are also working to assist our counterparts in the FSU to refocus their technological capabilities toward peaceful applications.

Against this background is increased concern over the proliferation of nuclear, chemical, and biological weapons. Many Third World nations seeking to enhance 
their military power or prestige have all-too-ready access to the requisite technologies.

Thus, the challenges facing the weapons laboratories are unique in their history. We at LLNL are determined to meet them effectively and responsibly. We will be addressing a host of urgent issues related to nuclear weapons that have arisen, in part, as a consequence of the end of the Cold War.

However, national security rests on issues that are broader than those of defense alone. A crucial concern is the continued vitality of the U.S. economy in an increasingly competitive global marketplace. The defense-related technologies developed by the national laboratories, as well as the skills and the expertise that produced them, can make important contributions to the nation's economic strength.

Specifically, we are addressing the following challenges:

- Maintaining the technical expertise and skills needed to ensure the safety, security, and reliability of a reduced nuclear stockpile under a nuclear test ban.

- Developing sat a procedures to accelerate the dismantlement of U.S. warheads, and addressing the long-term disposition of plutonium from such weapons.

- Providing technical assistance to hasten the dismantlement of weapons controlled by states of the FSU.

- Developing technical options to help counter the dangers of proliferating weapons of mass destruction.

- Seeking ways to consolidate and integrate the remaining U.S. weapons production and $R \& D$ activities, reduce costs, and ensure compliance with increasingly stringent environmental regulations and health standards.

- Expanding our efforts to ensure that, in shifting from defense-related research to civilian research, we contribute to the enhancement of the nation's technological and economic competitiveness.

- Leading the way for our counterparts in the FSU who face an even greater challenge in converting their R\&D from defense to domestic purposes.

- Applying the expertise gained from our nuclear weapons work to problems in conventional defense.

In the sections that follow, we describe the work and recent accomplishments of our programs in nonproliferation, arms control, and international security; defense systems; and nuclear testing and experimental science. All three programs are making important contributions to national and international security. They focus on ensuring a strong U.S. defense, strengthening the nation's competitive position in the world marketplace, assisting in the dismantlement of the nuclear arsenals of the U.S. and the FSU, and countering the proliferation of weapons of mass destruction.

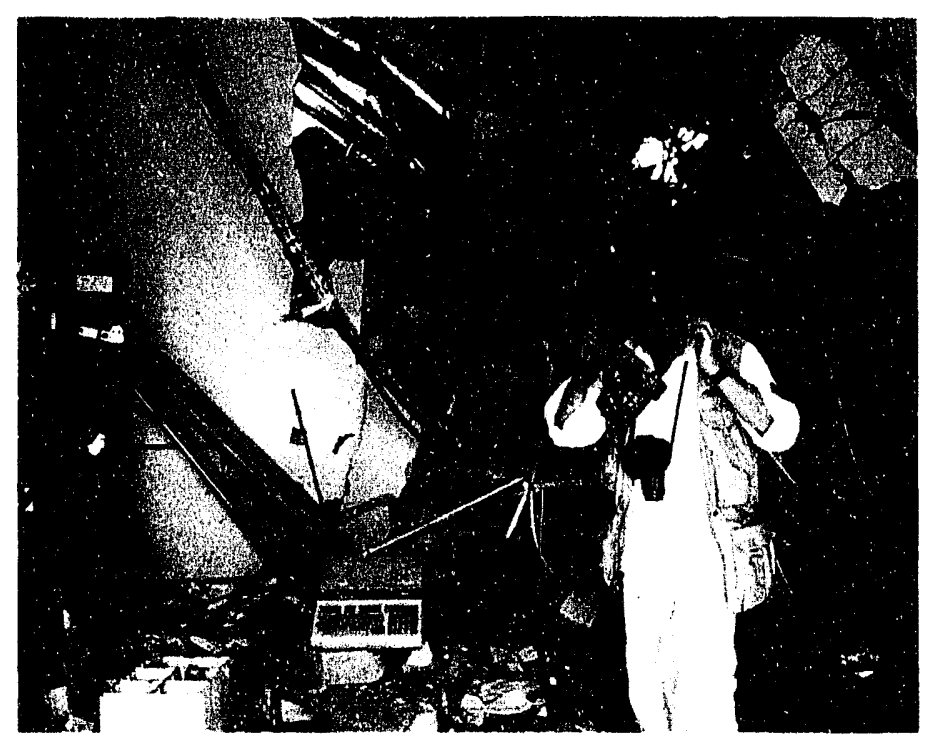

A number of Laboratory scientists (physicist Jay Davis, above, and engineer William Nelson, left) served on International Atomic Energy Agency inspection teams that investigated Iraq's nuclear weapon capabilities. An urgent mission for LLNL is to develop technologies to help counter the proliferation of weapons of mass destruction. 


\title{
iroliferation, Arms Control, ernational Security
}

\begin{abstract}
The goal of our work in nonproliferation, arms control, and international security is to provide the U.S. government with advanced technologies and scientific expertise to detect, assess, and respond to national and civilian security threats.
\end{abstract}

, an LLNL physicist, served 1 inspections in Iraq in ratory supports the IAEA entific expertise and he inspections and by lyzing data obtained during
T and International Security (NAI) directorat was formed in July 1992 to strengthen LLNL's support of the nation's changing defense needs. Two recent events have shifted defense priorities. One was the end of the Cold War; the other was the discovery, in the wake of Operation Desert Storm, of Iraq's heavy commitment to a nuclear weapons program. The result has been greater U.S. involvement with the international community in preventing the proliferation of weapons of mass destruction and U.S. cooperation with the former Soviet Union on nuclear weapons dismantlement, economic goals, and environmental issues.

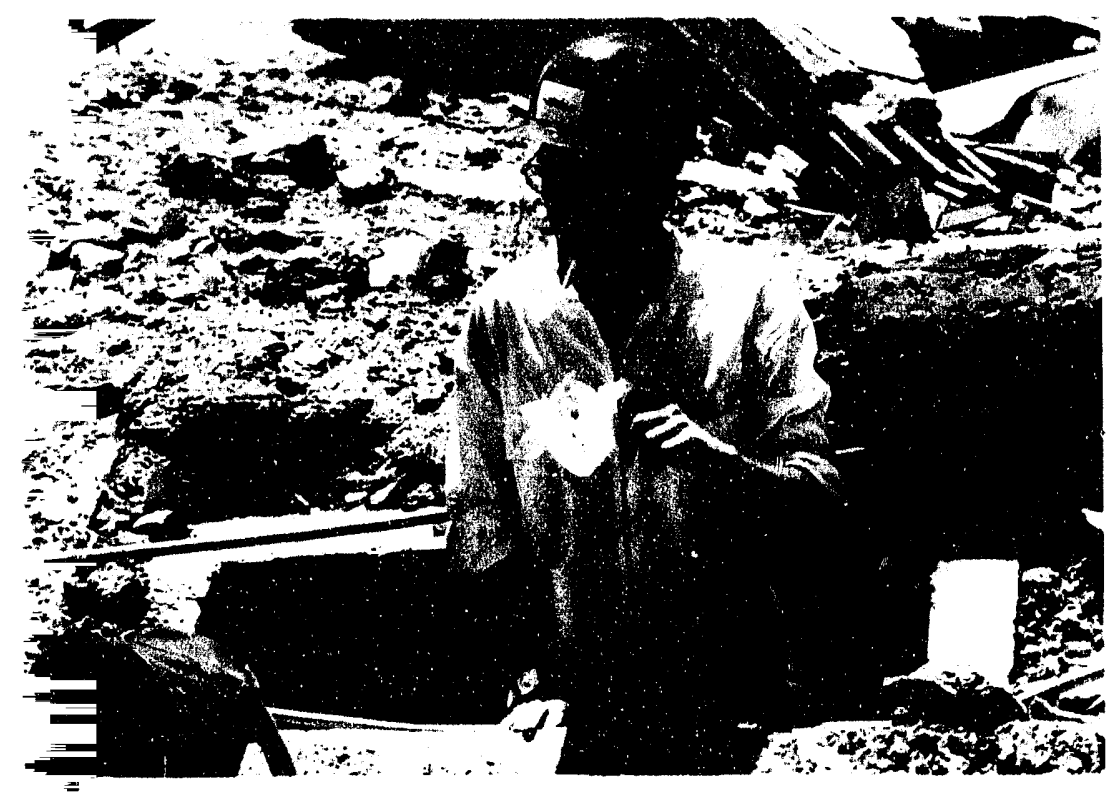

\section{Nonproliferation}

Our objectives in nonproliferation are threefold: (1) to provide technical assessments in support of the nation's nonproliferation policy, (2) to develop technologies for detecting, monitoring, and inspecting proliferation-related activities, and (3) to suggest strategies and means for responding to proliferation activities. Within these broad mandates, we are developing advanced technologies and capabilities for direct use in nonproliferation efforts, including:

- Improved detection systems with the range and sensitivity to target critical information gaps from ground-, air-, and space-based platforms.

- Expansion of our nationally recognized program in nonproliferation intelligence assessment, which will enable us to identify more accurately all proliferant countries, their suppliers, and related issues.

- Equipment to support nonproliferation inspections.

- Technologies and tactics for searching out and disabling covertly delivered nuclear explosives (see also p. 22).

Support of UN and IAEA Inspections

The Laboratory continues to provide experts and equipment to assist the United Nations (UN) Special Commission and the International Atomic Energy Agency (IAEA) in conducting inspections in Iraq and in analyzing data and documents 
obtained during inspections. We have sent inspectors to help account for confiscated equipment, to witness the destruction of designated facilities, to assist in translating Iraqi technical documents, to participate in analyzing reports and in advising on followon activities, and to assist in installing remote monitoring equipment at selected Iraqi facilities.

During 1992 and 1993, the IAEA also visited and inspected sites in Iran, North Korea, and South Africa that had never been inspected. The case of South Africa illustrates some of the new demands facing the IAEA. Before South Africa signed the Non-Proliferation Treaty in 1991, it had already produced quantities of enriched uranium that had gone uninspected. As South Africa later stated publicly, it had designed, fabricated, and stockpiled nuclear weapons and had prepared a nuclear test site. South Africa has also stated that all the weapons have since been destroyed. The IAEA is tasked with verifying that no weapons remain and with accounting for all nuclear materials. As an IAEA member state, the U.S. provides assistance on request, including advice on how to inspect sites related to nuclear weapons and on how to verify the dismantlement, decommissioning, or conversion of such weapons. LLNL personnel provided advice on inspection and dismantlement procedures for South Africa's nuclear weapons program.

\section{Security of Foreign Nuclear Weapons}

Political instability in the FSU and the Middle East has sparked interest in examining the security of nuclear weapons against theft by paramilitary forces. We have used combat simulation codes developed in our Conflict Simulation Laboratory to study this issue (see the box on p. 14). Hypothetical yet plausible scenarios include an assault by a military force against a fixed storage site, an ambush of a train transporting nuclear weapons, and a paramilitary attack on an
SS-25 mobile ICBM unit. These studies were commissioned to estimate the force level needed to wrest physical control of nuclear weapons, the required duration of an attack, and the prospects of a successful attacker in evading a reaction force searching the area of the attack.

\section{Remote Sensing Technologies}

The DOE has tasked the national laboratories with developing remote sensors that can detect signs of an existing or emerging capability to produce weapons of mass destruction. In response, we have developed several new detection systems: - ROMAC (Remote Optical Measurement and Calibration) uses passive detectors to identify and monitor airborne chemicals. The main component of this system is a stable infrared spectrometer that exploits recent developments in infrared detectors and 
grating-fabrication technology. This spectrometer promises an order-ofmagnitude improvement over current systems.
- WTVC (Wavelength-Tunable Video Camera) is a compact system that uses multispectral imaging to capture groundreflectivity data in near real time. It is
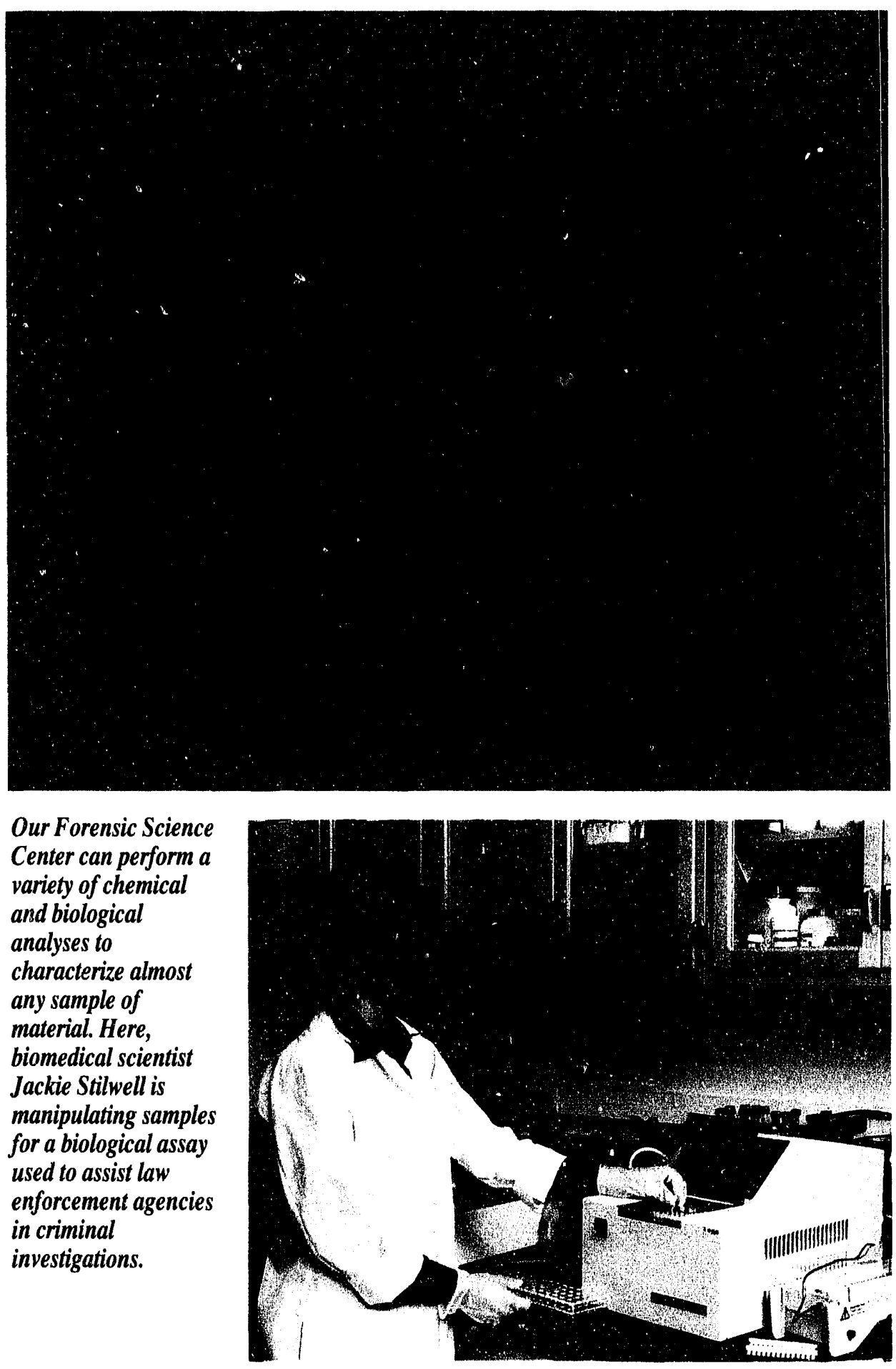

designed to carry out airborne lowaltitude surveys of suspected proliferant sites. The WTVC can search for such indications as stressed foliage and waterborne materials produced by chemical plants; it is also applicable to environmental monitoring and pollution assessment.

- TAISIR (Temperature and Imaging System Infrared) is an advanced research program to study several concepts for obtaining enhanced thermal imagery. These concepts include the use of superresolving techniques to enhance diffractionlimited imagery and the use of highresolution spectroscory to enhance system robustness to various atmospheric effects that degrade thermal imagery. TAISIR ultimately will be carried on a compact airborne or small space-based platform; it will contribute to threat assessments based on thermal measurements of suspected nuclear facilities (such as smoke stacks and cooling ponds). TAISIR may provide a substantial improvement over current systems, such as LANDSAT, in performance (spatial and temperature resolution) and robustness. We will evaluate TAISIR concepts in a series of balloon demonstration flights over the next two years.

- CALIOPF is a new project assigned by the DOE to the Brookhaven, Lawrence Livermore, Los Alamos, Pacific Northwest, and Sandia national laboratories. The goal is to develop technologies that use laser illumination from ultraviolet to infrared spectral regions to detect chemicals. The systems developed for CALIOPE, although focused on detecting nuclear proliferation, will also te able to identify proscribed chemical and biological warfare activities; they may also be applied to detecting illegal drug production and to environmental monitoring.

\section{Forensic Science Center}

The production of nuclear, chemical, or biological weapons generates a variety of unique chemicals and other materials. When 
fully characterized, such artifacts can "fingerprint" specific clandestine activities. Analyses of chemicals in water, air, soil, and vegetation have helped to confirm suspected sites and operations associated with the production of weapons of mass destruction.

Our Forensic Science Center coordinates a suite of analytical technologies to characterize a broad range of samples. These include computerguided gas-chromatograph/mass spectrometers, high-performance liquid clromatography and capillary electrophoresis units, an inductively coupled plasma mass spectrometer, an electron-scattering analysis probe, and a portable x-ray fluorescence analyzer. Available forensic biology methods are DNA purification, hybridization, visualization, and amplification (using the polymerase chain reaction). To date, the substances we have analyzed for clients include high explosives, compounds related to chemical weapons, genetic material, narcotics, and radionuclear species.

In one investigation, done as a public service to the State of California, we analyzed debris from a fatal explosion at another research facility. We were able to identify minute quantities of machine-shop lubricating oil as a potential contributor to the accident, a result that was completely unanticipated.

\section{Arms Control and International Security}

We are continuing our traditional armscontrol activities, which include providing technical support to treaty negotiators and developing equipment to monitor compliance. In a major new thrust, we are supporting the government in its interactions with the weapons laboratories and institutions in the states of the FSU. The goal is to help speed weapon dismantlement and defense conversion and to build confidence between the U.S. and the new Russian republics.

\section{Distinguishing Low-Yield Explosions from Earthquakes}

Monitoring compliance with a comprehensive test ban is expected to be more difficult than monitoring compliance with the current Threshold Test Ban Treaty (TTBT). Many thousands of low-magnitude earthquakes and chemical explosions (such as those in mining) occur each year. Such events are hard to discriminate from a low-yield nuclear test.

We have developed computer-automated techniques for processing seismic signals to determine whether a signal has been produced by an underground nuclear explosion or by some other source. This discrimination technique can be combined with other technologies to monitor a suspected nuclear test site. (The same discrimination techniques have commercial
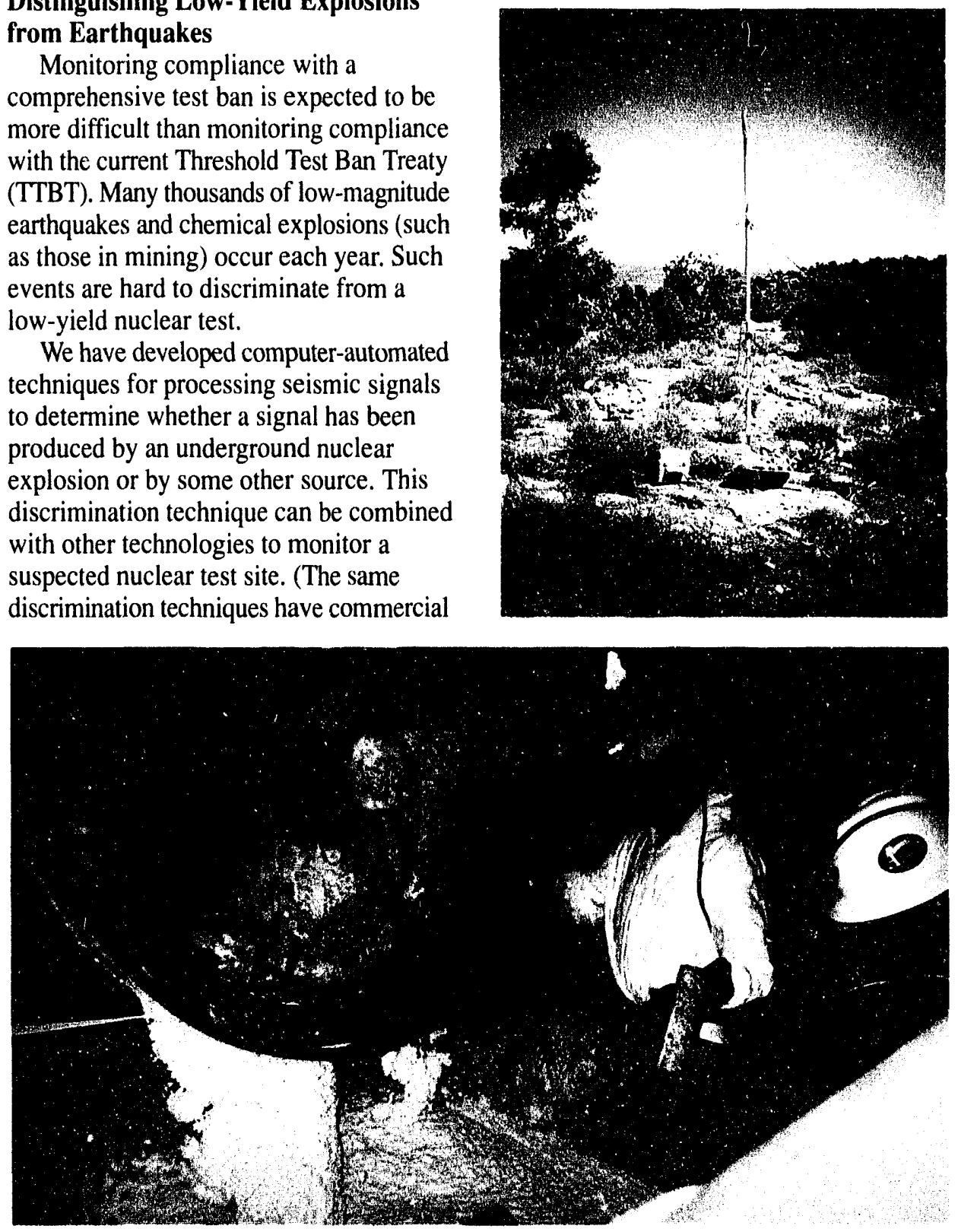

In September 1993, we conducted a 1-kt underground chemical-explosion experiment at the Nevada Test Site. The photograph at top shows one of the aboveground sensor emplacements; the photograph at bottom shows the chemical explosive being mixed. We applied various techniques that were developed to discriminate the seismic signals generated by underground nuclear explosions from other sources. From this experiment, it appears that it may be difficult to discriminate between low-yield nuclear and concentrated chemical explosions on the basis of seismic data alone. 
applications ranging from detecting blood oxygen levels to analyzing electroencephalographic data from epileptic seizures.) We are also examining the use of electromagnetic signals, electrical resistivity of soil, and chemical "sniffing" to identify suspect events.

In September 1993, LLNL conducted a 1-kt chemical-explosion experiment at the Nevada Test Site. The results indicate that it may be difficult to discriminate between low-yield nuclear and chemical explosions on the basis of seismic data alone. Further analysis and follow-on experiments are expected to be valuable during deliberations by the U.S. and other nations on how best to monitor compliance under a comprehensive nuclear test ban.

\section{Nuclear Weapons in the Former Soviet Republics}

The breakup of the Soviet Union has greatly reduced the threat of nuclear war, and the resulting relaxation of tensions has produced far-reaching new agreements between the U.S. and Russia to drastically reduce nuclear stockpiles. However, it will take at least a decade to dismantle all the nuclear weapons covered by current agreements. During this process, large quantities of weaponsgrade nuclear materials will be

In June I993,
Laboratory physicist
William Hogan
observed a laser
experiment at a
branch of the
Kurchatov Institute
(near Moscow). This
formerly closed
Soviet installation
now has contracts
with LLVL for
collaborative work in
laser science and has
made proposals to
the ISTC.
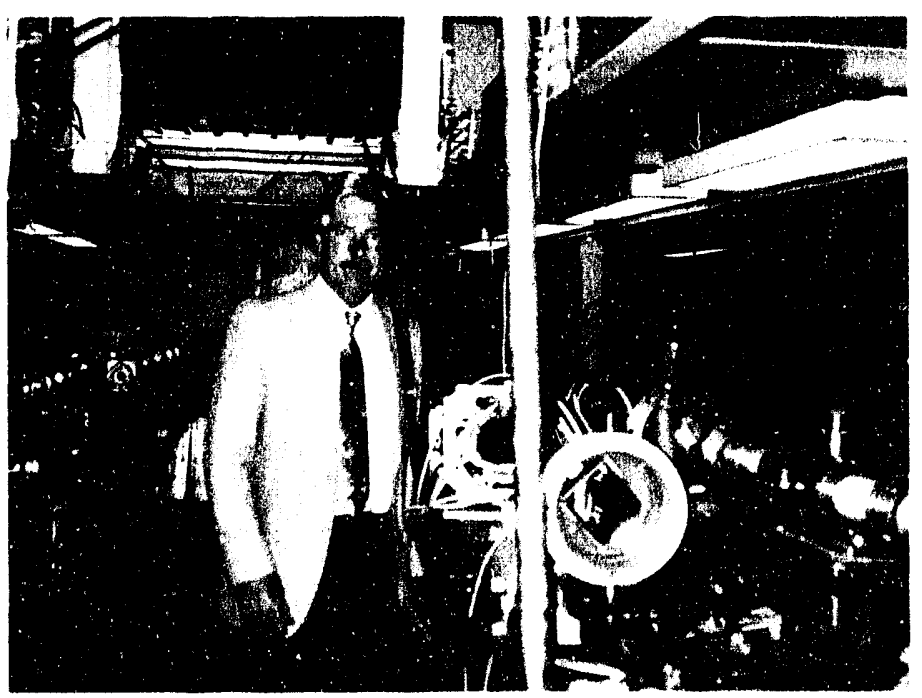

\section{International Science and Technology Center}

In November 1992, the U.S., Japan, Russia, and the European Community agreed to establish an International Science and Trchnology Center (ISTC) in Moscow. The ISTC will give Russian scientists and engineers opportunities to apply their talents to civilian of national or international interest. The ISTC agreement was provisionally ratified in December 1993. Selection of the projects to be funded is scheduled for early 1994. However, the ISTC has begun to solicit and process proposals. Two Laboratory staff members representing the DOE have already worked at the ISTC, and 20 some project proposals include LLNL scientists as collaborators.

\section{Electronic Tags and Seals}

Secure transportation, storage, and processing of nuclear weapons components require that each item be precisely identified and accounted for. During the past year, we identified candidate technologies for electronic seals needed to track and keep account of containers of highly enriched uranium. We have developed two types of electronic seal. One screws onto the bolt that secures the retainer ring on a standard shipping container. The other is an optical-fiber loop. They are tamper-proof, provide unambiguous validation and evidence of any unauthorized attempt to breach the seal, and feature encryption capabilities. Both were demonstrated to a visiting Russian delegation at the Portsmouth Gaseous Diffusion Plant in June 1993.

We are also developing communication devices that use infrared and radiofrequency signals to query sealed units at distances up to about $50 \mathrm{~m}$. Such technologies can be used in situations when it is necessary to limit exposure to hazardous chemicals or radioactive materials. Together with Argonne National Laboratory and QUALCOM (a commercial satellite communications company), we have 
established an interface with a satellite system and can now remotely track a container sealed with an electronic identification unit.

The availability of encrypted information about location and security status makes possible a global accounting system in which electronic tags and seals are applied to items such as weapons components and containers of nuclear materials. Their locations can then be monitored by satellite.

\section{Civilian Security}

We are increasing our efforts to make technologies developed for nonproliferation and arms-control applications available for commercial and civilian needs.

\section{Automatic Vehicle Identification}

We are assisting the California Department of Transportation (Caltrans) in developing automatic vehicle identification (AVI) equipment. The AVI system will be used initially to automate and simplify the process of collecting tolls from commercial users of toll highways. Eventually, the equipment might be used throughout the state to collect tolls electronically. The principal elements of the AVI system are a toll agency reader and an on-vehicle transponder that is "tagged" with an identification number. A toll is collected in three stages: (1) the toll agency reader "wakes up" the vehicle transponder and identifies the toll agency, (2) the tag responds with its identification number, and (3) the reader acknowledges the successful transaction. The complete transaction takes only $1.1 \mathrm{~ms}$. The vehicle owner is billed periodically for tolls charged to that vehicle. Within the first five months of this project, we designed the hardware systems for the proof-of-concept tag and reader and successfully demonstrated them at highway speeds.

\section{Unattended Sensor Systems}

Thousands of archaeological sites located on military bases, national park lands, and other remote areas are falling prey to treasure hunters and vandals. We are developing a system, called HIPROTECT, to detect trespassers and alert military or park authorities. (This project, a joint undertaking of the Laboratory and UC Riverside, is sponsored by the DOD's Legacy Resource Management Program.) HIPROTECT uses a variety of sensors that are triggered by the approach of a person or a vehicle. When activated, the system transmits alarm messages to local authorities via a cellular phone link. A video and audio system at the site verifies the intrusion and enables authorities to communicate with the trespasser. HIPROTECT can detect persons walking or bicycling as well as motorcycles and automobiles. The direction of entry is indicated by passive magnetic and infrared sensors. Because the sensors are wireless and battery-powered, they can be easily deployed, and their low power consumption gives their batteries a longer lifetime. The HIPROTECT system has many other potential applications. including protection of outlying facilities for commercial institutions or for residential security.

We have developed another unattended ground sensor system for the Immigration and Naturalization Service. Known as INSENS, it is designed to detect illegal land entry of aliens and contraband such as prohibited drugs into the U.S. The system includes a sensor that processes signals from multiple probes, a repeater to transmit data, and a hand-held monitor. Seismic, passive infrared, and magnetic probes are currently supported. Key to the utility of this new system is its modular architecture, which can easily accommodate software and hardware enhancements.

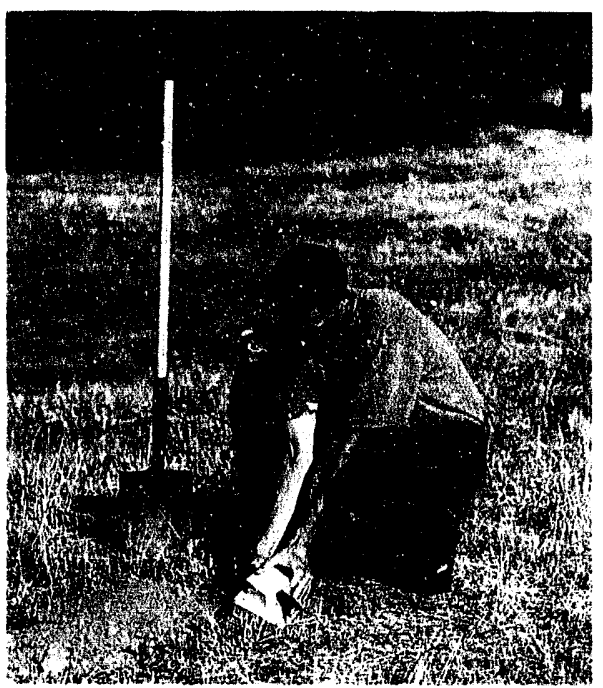

We have developed several unattended ground sensor systems, including one to protect remote archaeological sites on military bases or national park lands. Here, senior electronics technologist Robert Guyton demonstrates the installation of a HIPROTECT sensor.

\section{Summary}

We provide the U.S. government with advanced technologies and scientific expertise to prevent, respond to, and eliminate security threats at all levels, domestic as well as foreign. Our highest priority is to support the nation's nuclear tw: 'nroliferation policy. We also have smaller programs in chemical and biological nonproliferation. Our support of U.S. arms-control activities in cooperation with states of the FSU is continuing. In addition, many of the technologies developed for nonproliferation and arms-control applications are finding important commercial applications.

\section{For further information contact Robert T. Andrews or George G. Staehle (510) $422-5006$.}




\section{1se Systems}

\section{A rapidly changing world is setting new priorities for LLNL's Weapons Program.}

iography at the flash $x$-ray 00 is a major experimental udying the hydrodynamic apon primaries.

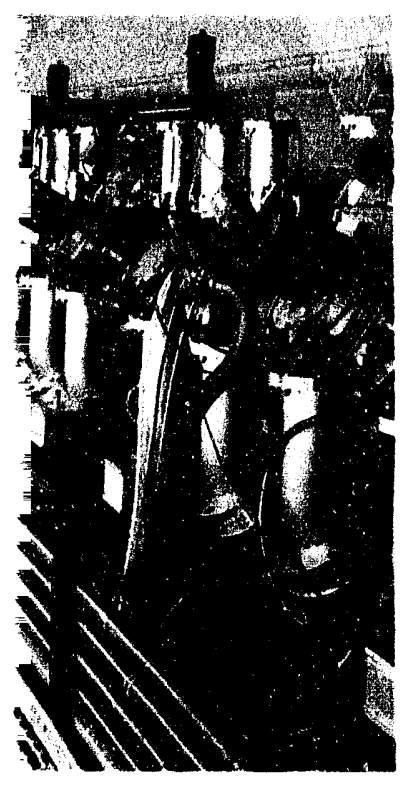

UR mission is changing from that of research, development, and testing of weapons to one of stewardship of a much smaller stockpile and of support of U.S. efforts against proliferation. Dismantlement of the nuclear arsenals of the U.S. and the FSU is an urgent priority. We are also applying technologies and expertise developed in our defense work to strengthen America's competitive position in the world marketplace.

\section{Ensuring Stockpile Safety, Security, and Reliability}

Historically, confidence in the nuclear stockpile has been based on expert judgment derived from a combination of computer simulations, nonnuclear tests, underground nuclear tests, and stockpile surveillance programs. Now that legislation and administration policy have halted nuclear testing, we must strengthen our remaining tools in order to fulfill our stockpile stewardship responsibilities.

The President has directed that we establish the capability to maintain confidence in U.S. weapons as they age

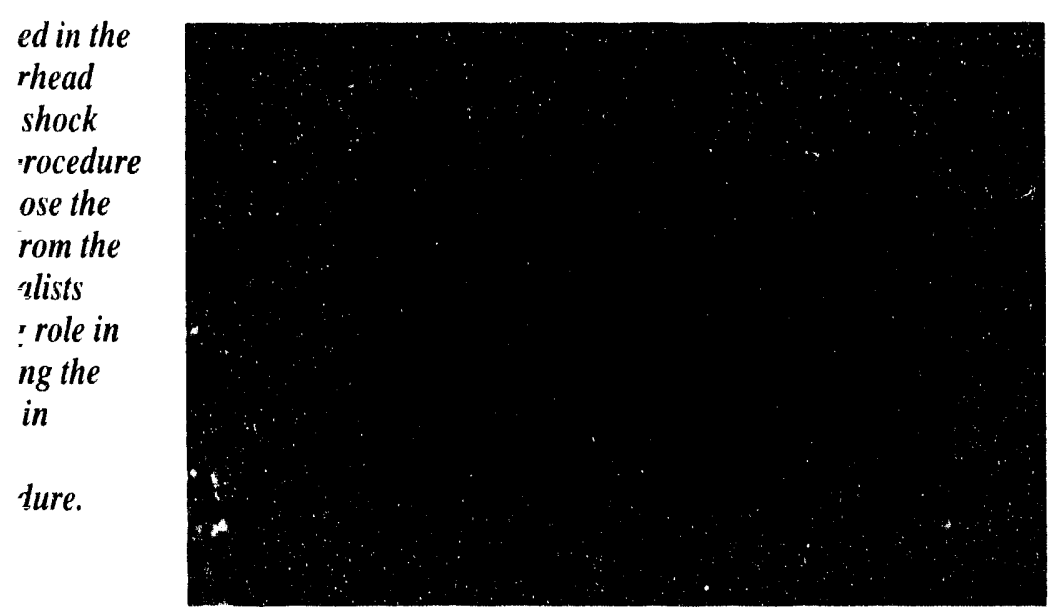

beyond their intended lifetimes and that we do so without nuclear testing. Key elements of this task include new computational capabilities, enhanced and new experimental capabilities, and expanded analysis of the stockpile. Such a stewardship program will enable us to fulfill our stockpile responsibilities and preserve the expertise needed to carry out this new mission.

Some data previously acquired through nurlear testing can be obtained from more advanced facilities. To this end, we are planning significant enhancements of our hydrodynamic and inertial-confinement fusion (ICF) facilities and our computer simulation capabilities. Integrating these activities will provide our only means of addressing the continuing issues of weapon performance and safety.

- Hydrodynamic Experiments. The major nonnuclear experimental technique for studying primaries is high-explosive hydrodynamic implosions. In these experiments, appropriate nonnuclear materials are used in place of nuclear materials. We plan to upgrade our current flash x-ray facility at Site 300 to provide full environmental containment of the detonations and their products. We are planning an even more powerful flash $x$-ray machine, accessible to both the Lawrence Livermore and Los Alamos laboratories, that can penetrate more deeply into the high material densities produced in an implosion. This machine will allow multispacial views of an experiment and will enable us to make a CAT-scan-like movie of an implosion. Finally, we plan to conduct at the Nevada Test Site whatever experiments with fissile material that are allowed under terms of a comprehensive test ban treaty. 
- Laser-Driven Fusion Studies. Weaponphysics experiments with ICF have already influenced our nuclear design codes and other weapons-related research. The National Ignition Facility, designed to produce fully ignited fusion burn in the laboratory, will allow us to access the high-energy density regimes in which thermonuclear secondaries operate (see also the Lasers article on p. 30).

- Computational Modeling. Current computing power falls far short of that needed to model many of the complex phenomena in a nuclear weapon. Massively parallel computers, and the associated software promise huge improvements in physics detail and processing speed. By using them in conjunction with a vigorous program in weapon physics and our new visualization techniques (see the Computers and Computing article on p. 81), we will realize dramatic advances in threedimensional calculations of weapon safety and performance with massively parallel computing.

- Expanded Analysis of the Stockpile. We are assembling comprehensive, computerized archives of all types of past weapons testing, design, and engineering experience. Active reanalysis of past test data with modern computational capabilities will be key to maintaining our capabilities. Together with improved methods of stockpile surveillance, we will be in a much improved position to fulfill our stockpile stewardship responsibilities.

\section{Analyzing the Safety of Nuclear Weapons}

We have developed a method to evaluate safety features that might be incorporated into stockpile weapons. This method uses cost-benefit analysis to compare the costs of implementing safety improvements with the costs and probabilities of possible accidents. We include values that cannot be expressed in terms of dollars but are significant to the decision-making process, such as impacts on health, land use, and public acceptance of nuclear weapons should an accident occur. We have developed a decision tool called WESVA (Weapon Safety Value Assessment) and have used it to assess a variety of enhanced-safety warhead designs, comparing the value of each safety feature against the cost of implementation and the possible reduction in military utility
We also support the Defense Nuclear Agency in assessing safety issues involving possible warheads for the Minuteman III ICBM.

\section{Warhead Dismantlement}

With the end of the Cold War, the U.S. and Russia are preparing to dismantle thousands of nuclear warheads. All these weapons must be dismantled by a limited

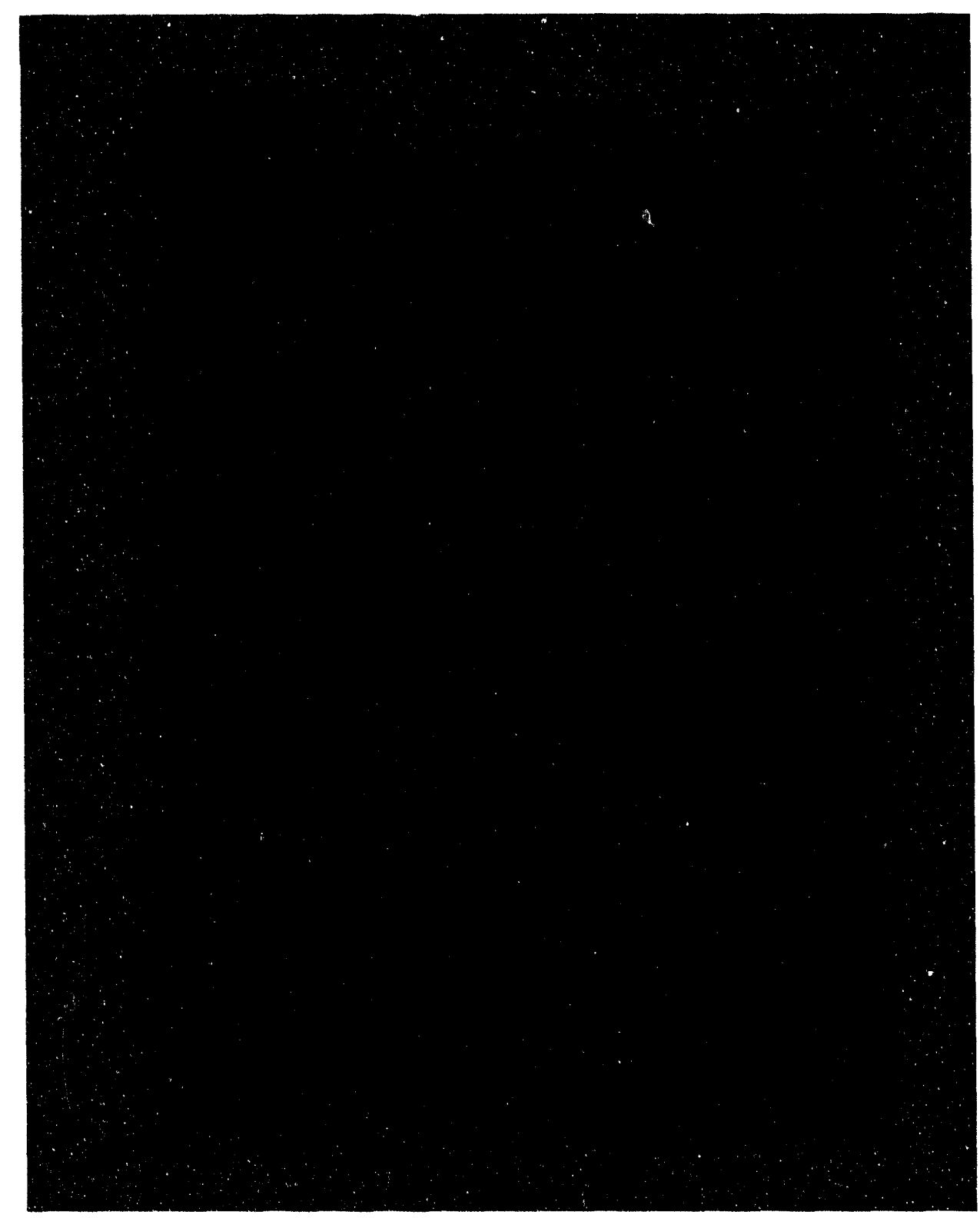


Computer-generated snapshot of atmospheric motion at an altitude of $10 \mathrm{~km}$. Coding techniques developed for simulating the performance of nuclear weapons have proved directly applicable to atmospheric circulation models. This calculation was done with a general-circulation model that is part of the LLNL Earth Systems Modeling Project. number of highly trained specialists. In the U.S., only one facility is currently available for this purpose-the Pantex Plant near Amarillo, Texas. At the current maximum rate of 2000 warheads dismantled per year, it will take many years to do the job.

Successful dismantlement requires close attention to technical detail. The process must be safe and environmentally acceptable, producing minimal wasie and minimal exposure of personnel to hazards. We are fielding multidisciplinary teams to review procedures to ensure that they meet current environmental, safety, and health (ES\&H) standards and provide for an efficient dismantlement process. In conjunction with this review activity, we are developing advanced technologies and methods to make the dismantlement process faster, safer, and able to respond to specific dismantlement incidents.

One such incident illustrates the need for Laboratory participation in the dismantlement process. The W48 warhead, which provided a nuclear capability for 155-mm artillery, was assembled with an adhesive bond between the high explosive and the pit. To separate the high explosive from the pit during dismantlement, a thermal shock procedure was used in which the high explosive was broken

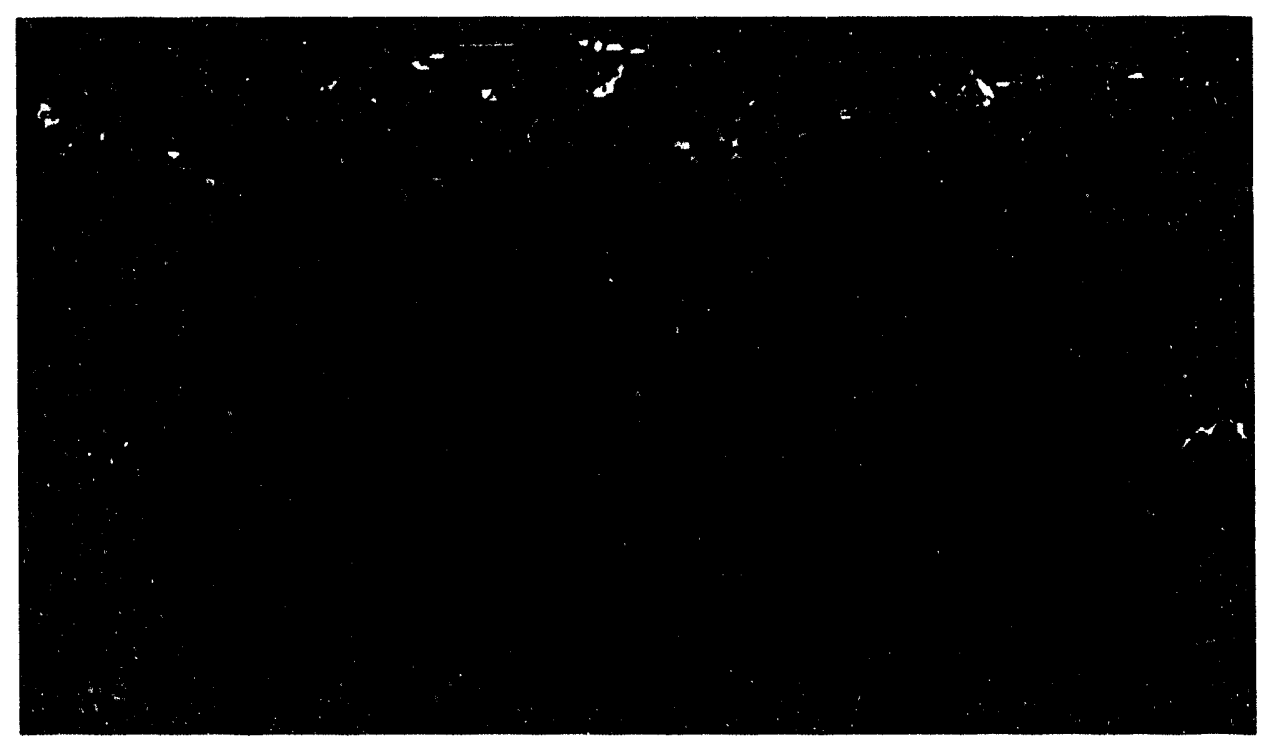

away by first soaking it in liquid nitrogen and then in hot water. After many warheads had been dismantled without incident, a crack developed in one pit, producing minor local contamination. LLNL specialists responded quickly to this incident by minimizing the hazards of the situation. Subsequently, they safely completed the dismantlement of the warhead. The cracked pit was then shipped to LLNL, where we determined the causes of the cracking and devised an improved dismantlement procedure that will prevent future such incidents.

The technical issues posed by the safe and secure dismantlement of FSU weapons and the disposition of their materials are even more challenging. Many of the methods we are developing for U.S. weapons could, in principle, be directly transferred to the Russians.

\section{Defense Conversion and Civilian Projects}

The same human talents and technical resources that undergird the Laboratory's Weapons Program have proved themselves in many other large-scale science and technology programs, such as inertial confinement fusion, magnetic fusion, environmental research, and fossil-fuel technologies. Pressing national needs offer opportunities to apply these strengths to a variety of new programs, both in civilian and national security applications. - Research Partnerships with U.S. Industry. Weapons Program personnel are active in several $R \& D$ partnerships with U.S. industry. In one project, we ‘ re adapting LLNL-developed software to model the forging and extrusion of complex three-dimensional parts. In another, we are working with industry to apply our computational and experimental expertise in electromagnetics to a variety of applications-gyrotrons that could be used to heat the plasma in magnetic fusion reactors, codes that can calculate radar 
cross sections of aircraft and electromagnetic interference in microcircuits, mis. wave tubes for satellite communications, and plasma torch reactors to treat mixed waste in the DOE nuclear weapons complex. In the medical sector, we are pursuing neural-net technology to improve patientmonitoring instrumentation. We are also applying our radiation flow codes to analyze the flow of optical photons in flesh in order to develop a new class of noninvasive medical instruments (see also the Engineering article, p. 62).

- Earth Systems Modeling. We are applying our code-development expertise in LLNL's Earth Systems Modeling Project. Accurate simulation of nuclear explosive performance relies on large codes that embody many physics models operating together. We have found that our coding methods are directly applicable to atmospheric circulation models. The figure at left shows a typical computer-generated snapshot of atmospheric motion that was generated as part of this effort.

- Collaboration with the Russians. In an attempt to deal with ecological issues in the Southern Urals region of Russia, we are collaborating with scientists from the Russian weapons research institute at Chelyabinsk-70 to assess the region's environmental priorities.

\section{Applying R\&D to Conventional Defense}

Reliance on nuclear weapons is giving way to new military capabilities based on smart and accurate nonnuclear weapons. To support this shift, we are studying new missions for advanced defense technologies.

- Sensors. The advent of quieter submarines challenges U.S. detection and tracking capabilities. We are developing high-power, low-frequency acoustic source devices for on-board tracking and miniaturized hydrophones for multipletransducer underwater detection arrays in shallow coastal waters. We are also developing instruments that can remotely detect buried land mines. During the Persian Gulf War, we demonstrated, at the Army's Yuma Proving Grounds, an airborne, infrared device that detects buried mines in the desert. To facilitate further research, we have established a minefield test facility at the Nevada Test Site.

- Energetic Materials. Insensitive conventional munitions enhance the survivability of launch platforms and reduce hazards in accidents. We are synthesizing and formulating new explosives that are relatively inexpensive and promise improved performance. We are also developing extrusion-cast and paste explosives for new precision and multistage munitions (see also the Chemistry and Materials Science article, p. 74).

- New Munitions. We are developing several new designs for shaped-charge penetrating munitions, multistage demolition munitions, fiber-composite penetrators, kinetic-energy penetrators, and explosively formed projectiles. Among these is the Penetration Augmented

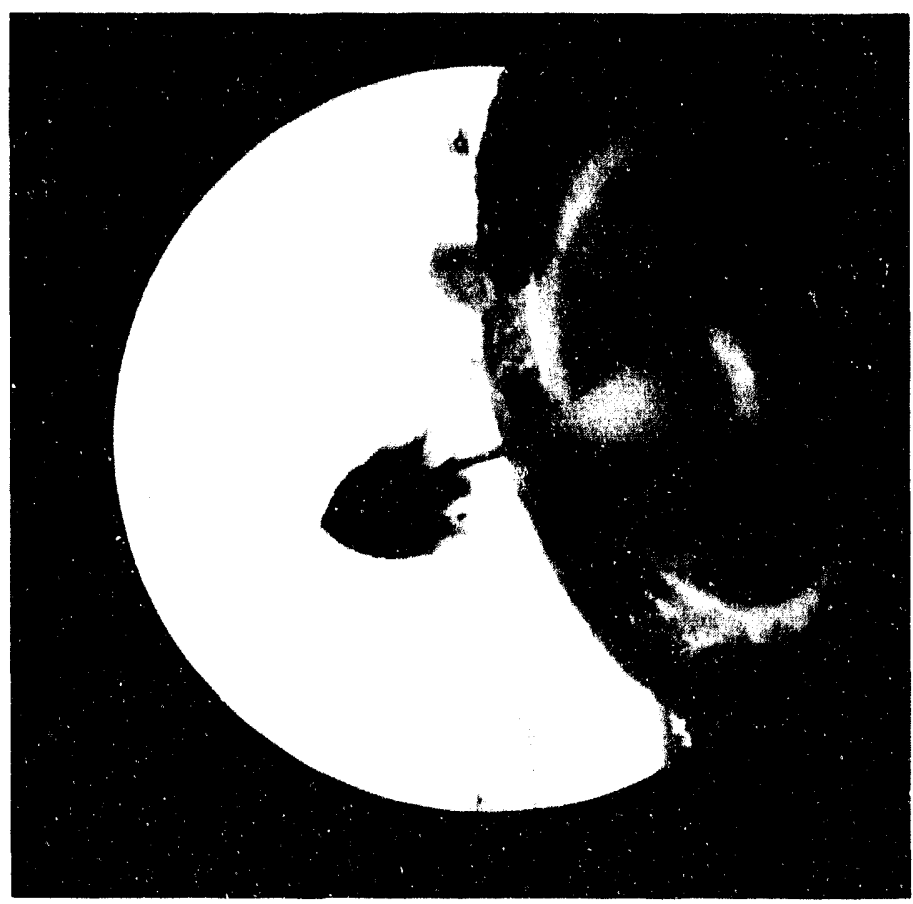

Munition, a multistage munition designed to attack reinforced targets such as bridge piers. Developed under joint Department of Defense (DOD) and Army funding, this munition was recently transferred to U.S. industry for engineering development. - Armor Materials. U.S. mobile forces need lightweight, space- and mass-efficient armor. We are extending our understanding of the physical process of armor penetration in order to design lightweight armor systems for military vehicles (from lightweight personal carriers to tanks). - New Hydrocodes. To support new warhead technologies and the analysis of lethality and survivability, we have developed a new generation of hydrodynamics codes. CALE, our twodimensional, arbitrary Lagrangian-Eulerian code, has been distributed to DOD and industry warhead designers. We have almost completed a three-dimensional version of this code.

\section{Counterproliferation Efforts}

A growing concern among industrial countries is that terrorists could covertly
Laser-illuminated photograph of an explosively formed shaped-charge jet traveling from right to left $50 \mu \mathrm{s}$ after firing. The dark cloud at the front of the jet is low-density ejecta that has blown off as the result of hydrodynamic instabilities but has not degraded the effectiveness of the jet. 
place a nuclear weapon, either crudely designed or stolen, in a populous city. The high-explosive bomb detonated at the World Trade Center in February 1993 caused tremendous damage and destruction; had the bomb been a nuclear device, it would have been an unprecedented disaster. Scientists from across the Laboratory have launched a high-priority effort to address how to disable such a nuclear weapon (see also the Nonproliferation, Arms Control, and International Security article, p. 26).

We have been challenged to develop a field-deployable system that can destroy a nuclear device before it assembles itself into a supercritical mass. The fissile portion of the weapon must be disabled before nuclear yield is produced, a process that takes only a fraction of a second. Under a comprehensive test ban, the ability to conduct treaty-compliant experiments, like the hydronuclear experiments mentioned on p. 18 , would be extremely valuable to confirm the effectiveness of such a system.

\section{Reconfiguring the Weapons Complex}

The nation's nuclear weapons production complex was built to support a production rate that led to a stockpile of tens of thousands of weapons, far larger than the future stockpile. Under the direction of the DOE, we are helping to develop a modernized complex that will be much smaller and less expensive to operate, will comply with future ES\&H standards, and will serve the nation's needs in the first half of the 21 st century. A considerable amount of consolidation is already taking place.

- Lead Laboratories. Recognizing the need to retain the highly specialized knowledge about nuclear weapons

Robotics and
automation are
proving extremely
valuable in weapons
assembly and
dismantlement; they
greatly reduce the
amount of waste
produced and the
amount of radiation
to which workers are
exposed.

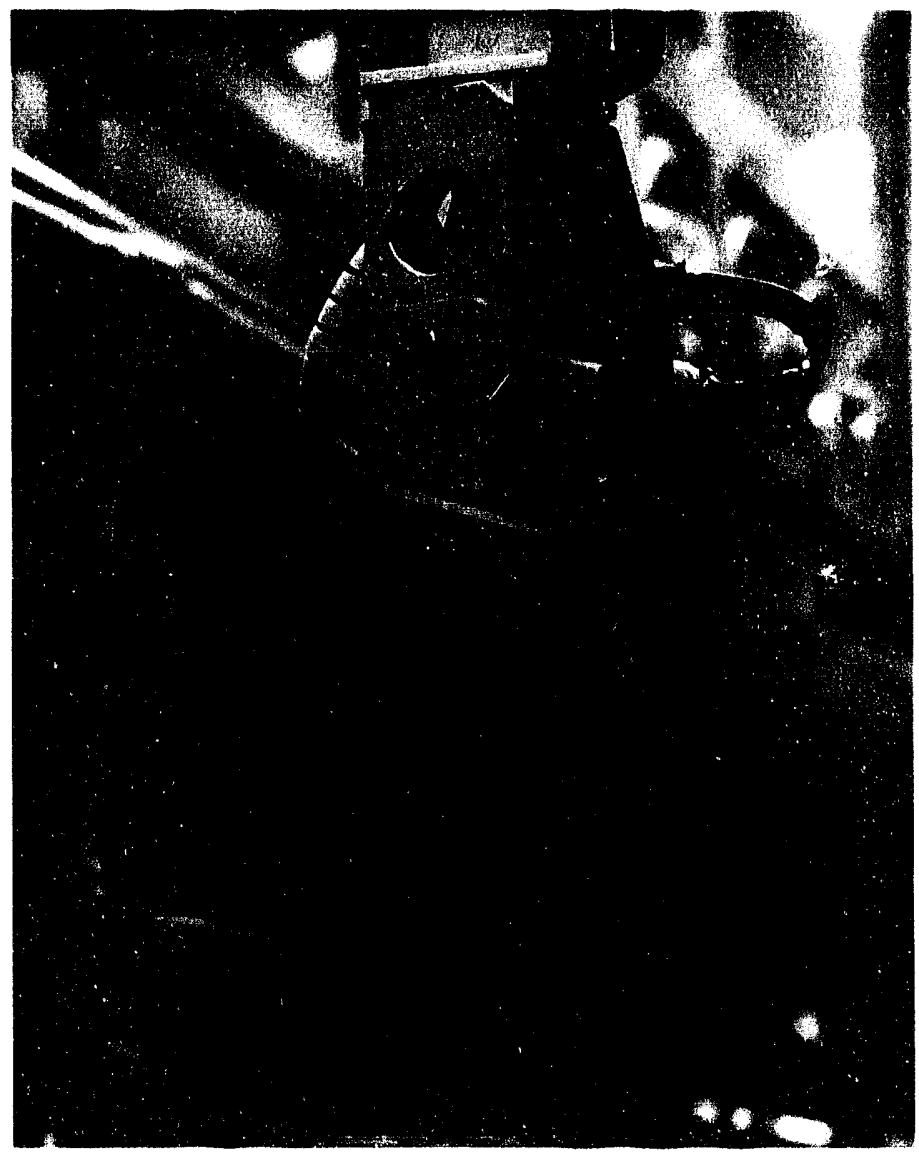

technology, the DOE has recently issued a Lead Laboratory Protocol that assigns specific responsibilities to each of the weapons laboratories, production plants, and other elements of the complex. Los Alamos will oversee technologies related to the chemical processing and storage of plutonium and uranium as well as to the assembly of lithium, tritium, and nuclear components. Responsibility for nonnuclear components will fall to Sandia, which will also serve as a center of excellence for robotics. Lawrence Livermore will coordinate technologies for fabricating uranium and plutonium parts and for producing high explosives. Livermore and Los Alamos will also support each other's lead laboratory activities. This division of responsibilities has already reduced duplication and improved operating efficiency.

- Process Improvement. We are making significant improvements in the processes for fabricating uranium and plutonium parts. For example, we have developed a plutonium casting process that replaces the machining of important plutonium components. This new process dramatically reduces the amount of plutonium scrap and mixed and hazardous waste; it also reduces the amount of radiation to which workers are exposed.

We are studying the use of cold-hearth techniques to melt certain uranium alloys more efficiently. The current process used at the Y-12 Plant (Oak Ridge, Tennessee) requires three steps and generates large amounts of scrap and waste. However, the cold-hearth process, which uses an electron beam to melt the alloys, is much more compact and can accept a broad range of scrap as feed stock. We have already completed a proof-of-principle experiment for this process.

Uranium shrinks when it solidifies from the molten state, and its use in precision casting is therefore problematic. Highly 
advanced computer models that predict complex casting behavior can help compensate for this problem. We have designed a foundry, now in the final stages of assembly, to be used in conjunction with our computer models to define an improved casting process.

- Dismantling Pits. We have developed a remote process to convert plutonium from retired pits into ingots. This process produces no waste and protects workers from exposure to radiation. The pits, which are in a sealed chamber, are first exposed to hydrogen gas, which turns the plutonium into its powder hydride. The hydride is then moved to another chamber where a heater drives out the hydrogen and melts the plutonium. The plutonium is then poured into a mold.

- Disposing of High Explosives. Large quantities of high explosives from disassembled nuclear weapons must be disposed of in a timely and economical manner. We are treating high explosives as an asset to be recycled whenever possible. We have developed a method to strip the high explosives of their polymer binders and additives so that they can be returned to DOD and industry for reuse.

The Pantex Plant currently uses open burning to dispose of high explosives. In anticipation of an eventual ban on burning (for environmental reasons), we are examining alternatives, such as extraction of constituents with molien salt and oxidation with supercritical water. We are also studying ways of recycling explosive materials, cutting up and reducing the size of parts with water jets, and other technologies to minimize waste. In addition, we are looking at bioremediation and other methods of treating organic waste to deal with materials that cannot be treated with thermal processes.

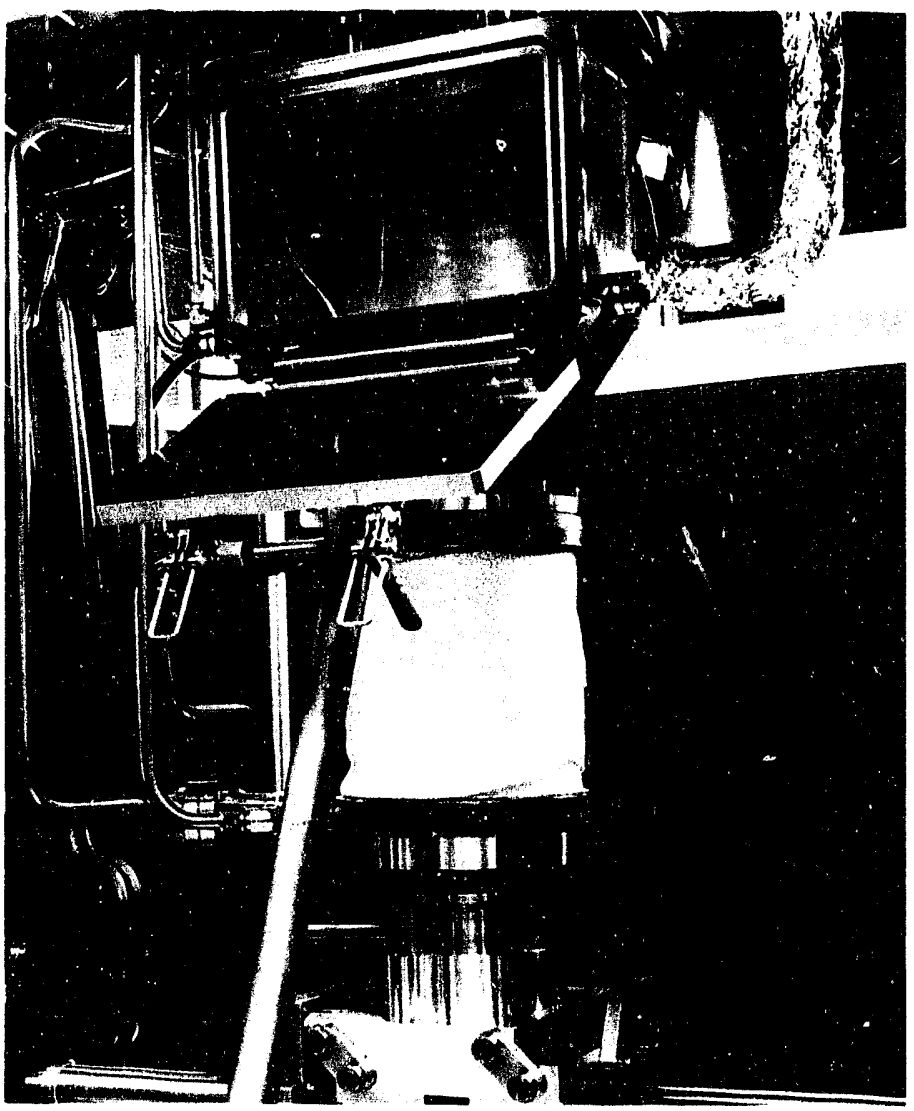

The Hydride/ Dehydride/Casting (HYDEC) Reactor. This reactor is central to a remote process for converting plutonium from the pits of retired weapons into ingots for storage.

\section{Summary}

A rapidly changing world is setting new priorities for the Laboratory's Weapons Program. With nuclear testing halted, we are developing other ways of ensuring the safety, security, and reliability of the nation's remaining nuclear stockpile. Among these are laboratory experiments and advanced computational techniques. In addition, the safe dismantlement of the nuclear arsenals of the U.S. and the FSU is an urgent priority. Also pressing is the specter of proliferating weapons of mass destruction, and we are working to develop technical approaches to this international threat.
Our defense-conversion activities are aimed at strengthening the nation's competitive position in the world marketplace. To maintain our nation's vital edge in conventional weapons, we are refocusing the talents and technical resources developed in our nuclear weapons work. Finally, to reduce operating costs and to ensure compliance with increasingly stringent environmental regulations, we are working with other members of the DOE's nuclear weapons production complex to consolidate and streamline production and $R \& D$ activities.

\section{For further information contact George H. Miller (510) 423-6806 or Paul S. Brown (510) 423-6814.}




\title{
2ar Iesting \& Experimental Science
}

\author{
The expertise developed over decades of underground nuclear testing is finding application in \\ exciting new projects.
}

\begin{abstract}
the Galena Event (June nderground nuclear test :NL. The large crane is iuclear device and the ster, which have been $i$ other and moved inside the before being lowered typical of modern tests, the ed dozens of experiments nstruments; signals were r optical-fiber networks to tining recording equipment. unique expertise. The challenge we now face is to carry out our nuclear weapon responsibilities in the absence of nuclear testing. These responsibilities include:

(1) stockpile stewardship, in particular conducting experiments and modeling to extend our knowledge of weapon physics; (2) developing technologies to help prevent and counter nuclear proliferation; and (3) developing technologies with both defense and civilian benefits, specifically microelectronics and optoelectronics.
\end{abstract}

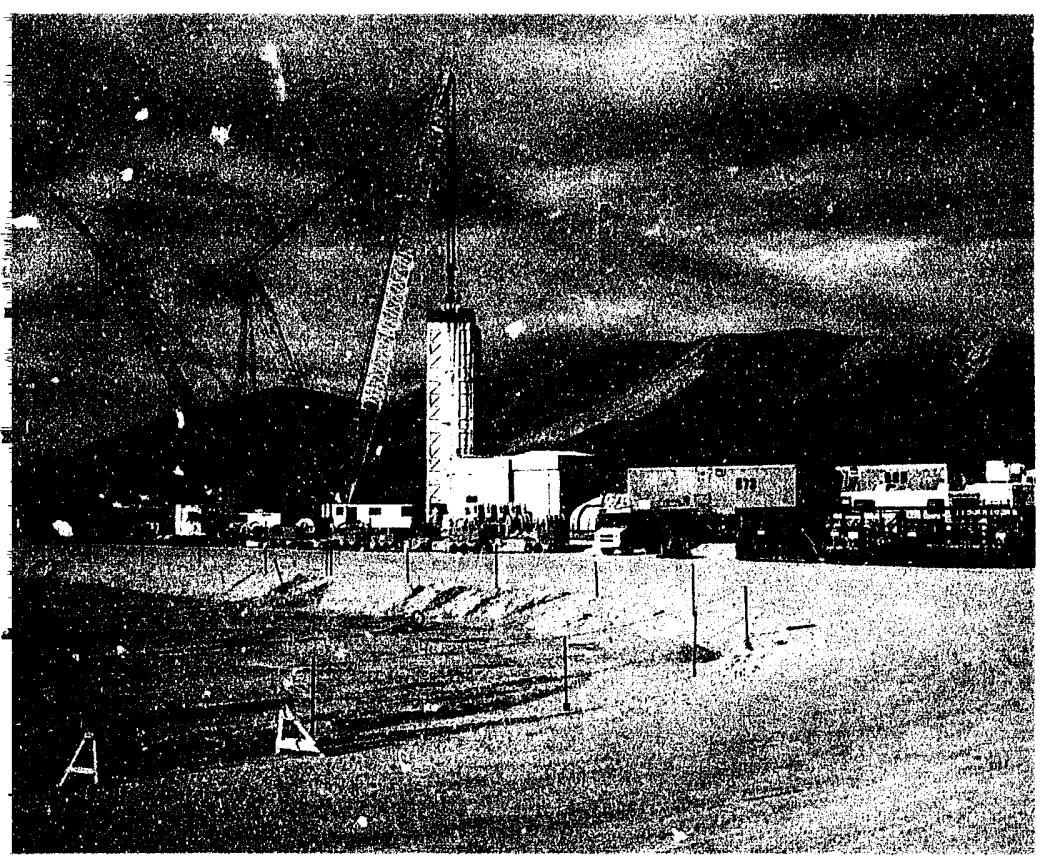

\section{Traditional Nuclear Weapons Activities} period for the Laboratory's work in nuclear testing and experimental science. Most significant was the imposition of a ninemonth moratorium on nuclear testing at the start of the year, extended in July 1993 by 15 months. This period also saw a shift in focus to new activities that exploit our

Even before the current nuclear test moratorium, declining budgets and policy decisions imposed constraints on the Laboratory's underground nuclear test program. As a result, we have had to maximize the quality and quantity of diagnostic data obtained from each test.

This challenge has produced several initiatives in electro-optical imaging and measurement technologies. For example, we have developed new, high-bandwidth electro-optical links with high enough resolution to reveal fine-scale experimental details in routine performance data. These details have been predicted by computational models but have not been seen in expariments until now. We have also devised imaging techniques that capture new details in a rapidly imploding nuclear device. These phenomena are measured by new high-resolution, solidstate imaging cameras that feature faster framing and readout. To improve and expand the databases we use to ensure that an underground test is contained, we fielded new, relatively inexpensive instruments that measure temperature, pressure, and shock patterns in the vicinity of an underground explosion. These and other achievements form the basis for our entry into new technology arenas.

\section{Laboratory Weapon-Physics Experiments}

In the absence of nuclear testing, the role of laboratory experiments in support of the Weapons Program will grow dramatically. In addition to 
hydrodynamic testing - the principal nonnuclear experimental technique for studying primaries (see p. 18)-our current efforts focus on (1) the use of the Nova laser for radiation-driven experiments on compitssible turbulence, (2) the characterization of various pulsed-power heating geometries for use in radiationdriven experiments, and (3) studies with a new ultrashort-pulse laser and very fast plasma diagnostics.

\section{Simulations of Laser-Plasma Coupling}

An understanding of the laser heating of matter is essential for any application of lasers, be it weapon physics, fusion energy, or materials processing. In anticipation of lasers more powerful than Nova, we are examining laser-plasma coupling at the high-intensity limit for pulses (on the order of $10^{21} \mathrm{~W} / \mathrm{cm}^{2}$ ). Recent computer simulations indicate that at such intensities, absorption of laser light by the target is dominated by transfer of the momentum of the reflected portion of the laser beam to a layer of ions vaporized from the target's surface. The main laser beam then accelerates this layer of superheated ions into the target at energies on the order of a million electron volts.

Our simulations of this process have revealed some extremely interesting effects. When the accelerated ions strike the target, they interact with about $10 \mu \mathrm{m}$ of target material in about $1 \mathrm{ps}$, heating very uniformly a high-density plasma to kilovolt temperatures. Heat-flux effects are relatively insignificant in such a large volume, so the plasma remains hot for several tens of picoseconds. This phenomenon should make it much easier to measure the properties of the dense plasma. If our simulation results are correct, the use of high-intensity, ultrashort-pulse laser light to produce ion heating of solid targets may be an effective means of generating high-density plasmas with a high energy density.

\section{Ultrashort-Pulse Laser}

In the absence of nuclear testing, we must find other ways to create the pressure and temperature regimes relevant to weapon physics. Lasers provide one way of creating the high-temperature, highenergy-density conditions we need to study.

The goal of our Ultrashort-Pulse Laser Project is to develop a small, chirp-pulseamplified titanium:sapphire laser with a pulse length of $100 \mathrm{fs}-\mathrm{a}$ thousand times shorter than the Nova laser pulse length. The ultrashort laser pulse will be focused on solid targets to rapidly create highdensity plasmas and heat them to kilovolt temperatures before they can hydrodynamically decompress. Combined with ultrafast diagnostics, this ability to produce such plasmas in the laboratory will make it possible for the first time to study the dynamics of plasmas at very high energy densities. These data will be of great

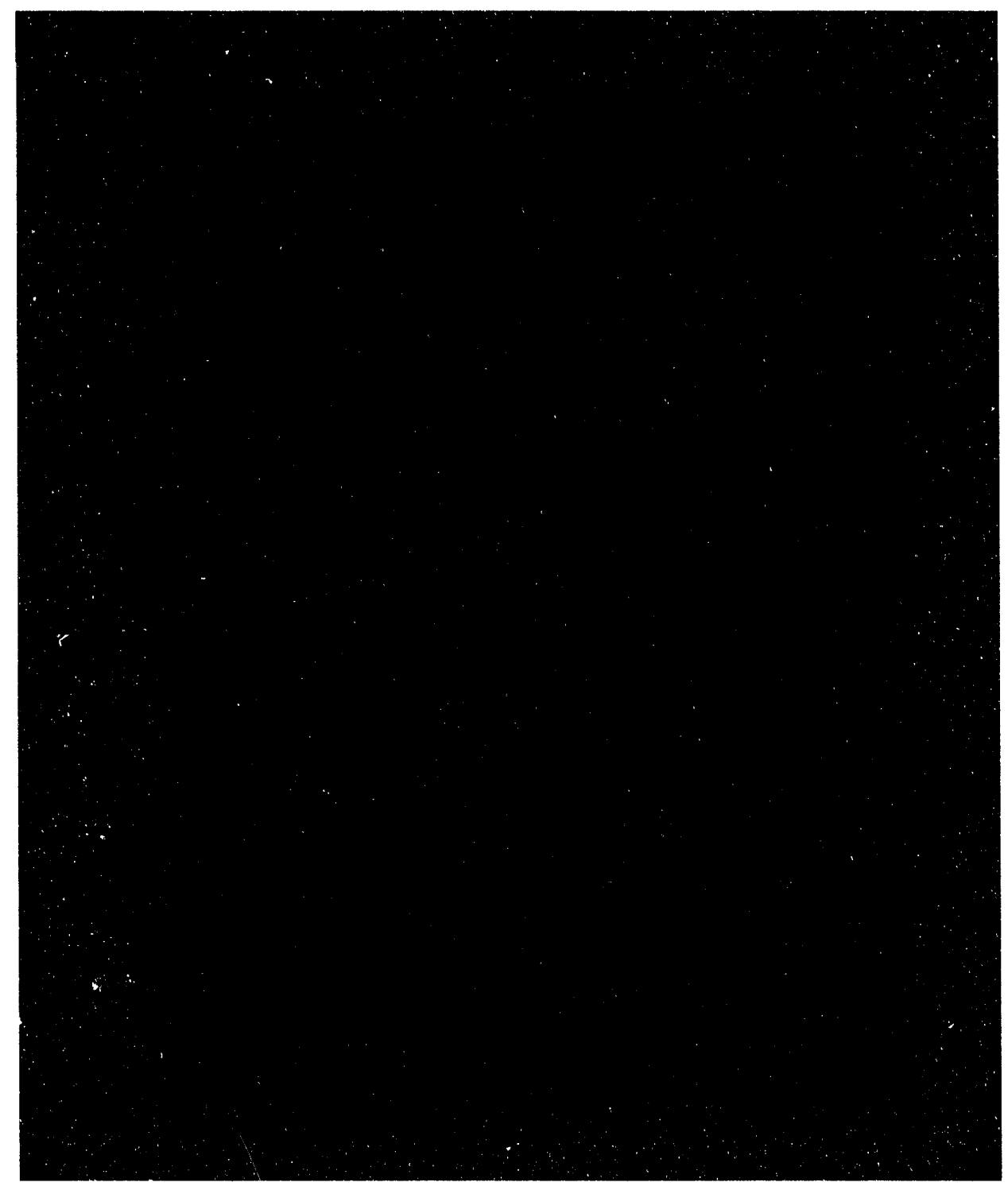


interest to both the Weapons Program and the broader scientific community.

During the past year, we increased the output of the ultrashort-pulse laser by adding a flashlamp-pumped, dye-converted, commercial amplifier. With this amplifier, we generated $0.250-\mathrm{J}, 100$-fs pulses at a repetition rate of 5 to $10 \mathrm{~Hz}$. We used an off-axis parabolic mirror to focus the beam, producing a diffraction-limited spot with a power density of $6.6 \times 10^{18} \mathrm{~W} / \mathrm{cm}^{2}$. To our knowledge, this is the highest focused power yet achieved by any laser.

We have performed our first preliminary experiments with this system, illuminating a target with a $10^{18}-\mathrm{W} / \mathrm{cm}^{2}$ spot to produce a high-temperature, solid-density plasma that emits $x$ rays. At these high intensities, small "wings" or prepulses in the laser beam can generate, at the surface of a target, a low-density plasma that absorbs the energy of the main pulse and either prevents or reduces target heating. We developed a new lens design that fully corrects this problem by reducing prepulses and wings in compressed laser pulses to insignificant levels.

\section{Subpicosecond Streak Camera}

We are also developing a subpicosecond $\mathrm{x}$-ray streak camera. Used in conjunction with the ultrashort-pulse laser, this superfast camera will enable us to measure the properties of plasmas at very high energy densities. We have eliminated transit-time dispersion effects as a limiting factor in this camera and, as a result, have achieved a time resolution of $900 \mathrm{fs}\left(1 \mathrm{fs}=10^{-15} \mathrm{~s}\right)$, the fastest ever with an $\mathrm{x}$-ray camera. We are currently designing a new focusing structure that will enhance sensitivity and should give an even shorter time resolution of 20 to $300 \mathrm{fs}$.

\section{Efforts in Nonproliferation and Counterproliferation}

The proliferation of nuclear weapons is a growing security concern, both nationally and globally. A dramatic reduction in the time and resources needed to achieve nuclear status has moved the threat of proliferation to the top of the U.S. security agenda. As described in the article beginning on $\mathrm{p} .12$, the Laboratory is

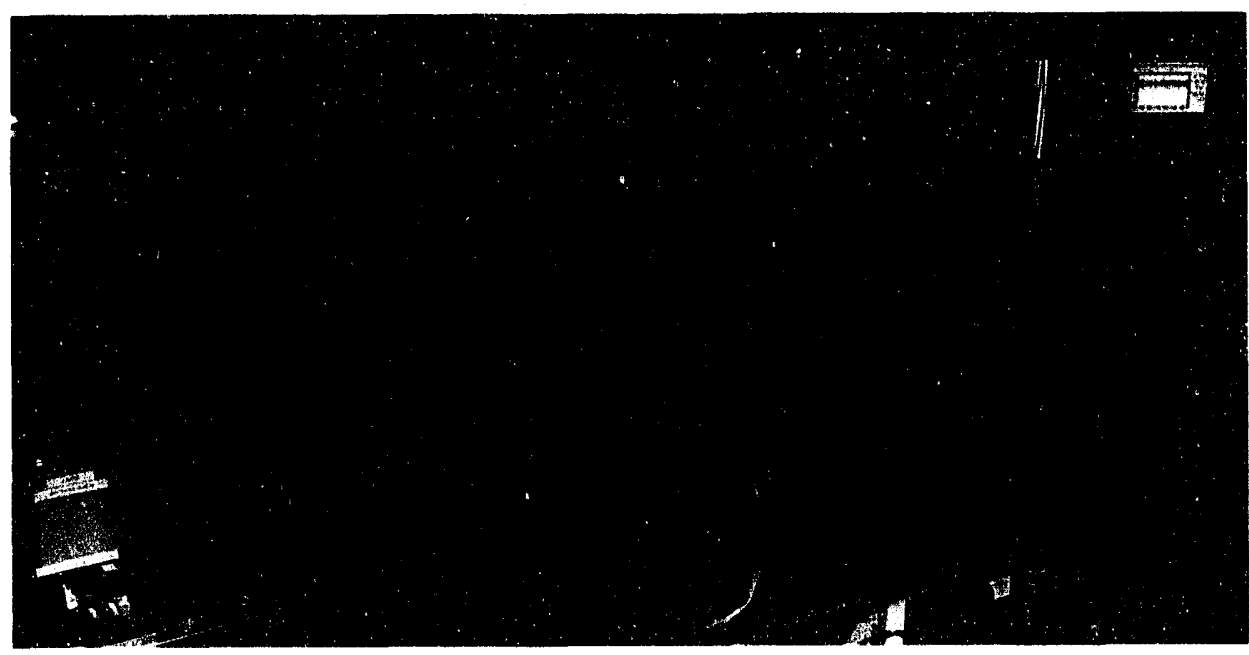

The ultrashort-pulse laser is a small laser with an extremely short pulse length (100 fs; $1 \mathrm{fs}=10^{-15} \mathrm{~s}$ ). When focused on a solid target, the beams from this iaser generate a highdensity plasma heated to kilovolt temperaiures. Measurements of these plasmas will be of interest to the Weapons Program and the broader scientific community. working to define a cohesive approach to this international problem. We are adapting technologies developed for nuclear testing to the detection of nuclear activities and to security responses to the suspected acquisition of nuclear weapons.

\section{Searching for Hidden Nuclear Weapons}

The U.S. remains vulnerable to clandestinely delivered nuclear weapons. The Laboratory's Nuclear Emergency Search Team (NEST) is trained and equipped to respond promptly to a credible threat. In order to carry out its mission, NEST requires an array of diagnostic instruments that are sensitive, specific for nuclear materials, and portable.

A hidden nuclear device reveals itself in the radiation emitted by its nuclear materials. The type and intensity of the radiation limit the effectiveness of search procedures. Recent advances in gamma-ray detection and imaging technology offer significant and cost-effective advances in rensitivity and rejection of false alarms.

- ie result will be faster searches and more cise characterization of nuclear devices. This class of technologies, developed primarily at LLNL, can be quickly optimized, prototyped, and demonstrated for NEST missions.

One of these prototypes is a fieldportable, high-resolution, germaniumbased gamma-ray detector developed by LLNL during the past year for detecting and tracking nuclear materials. Germaniumbased, detectors must be kept very cold to maximize resolution. Most such instruments use a bulky liquid nitrogen cooling system, which is hardly portable. However, our detector features a miniature, vibrationless refrigeration system, which eliminates the need for liquid nitrogen and makes the detector truly portable. The spectral data are analyzed by a computer code that automatically identifies salient features to reveal isotopic abundances. 
We are working to develop other new detectors with resolution enhanced by improved signal processing and the use of semiconductor materials other than germanium. In addition, we are extending gamma-ray imaging techniques developed for arms-control and gamma-ray astronomy missions to NEST applications. The imaging capability provided by these improvements will reduce background uncertainties and false alarms. Our goal is to enhance detection sensitivity by at least an order of magnitude. We expect this new family of detectors to make possible a basic shift in NEST search tactics from reliance on walk-around coverage to wide-area searches using vehicles.

\section{Detecting Clandestine Nuclear Tests}

We are continuing to develop new technologies that will help to quickly and reliably detect an unannounced nuclear explosion, infer the design of the nuclear device, and identify the nation that conducted the test. This "attribution process" requires the collection and synthesis of data from all available sources: seismic and satellite instruments, visual blast effects, and radiochemical and isotopic analysis. We have adapted sophisticated radiochemical and isotopic methods developed for nuclear testing to support the analysis of post-explosion debris.

During 1993, we tested the sensitivity and utility of our techniques by reanalyzing debris taken from a U.S. underground nuclear test during routine drillback. By studying spectral signatures not normally analyzed, we were able to extract information about structural materials in and near the device. Using similar techniques, we plan to analyze short-lived radionuclide species from another test to identify the "fingerprints" of different device designs.

Isotopic analysis will also enable us to identify the origins of materials in an unexploded nuclear device. For example, the precise isotopic composition of plutonium depends on both how it was made and when it was cast. Radiochemical separation plus spectral analysis can reveal whether a sample came from irradiated reactor fuel or from stockpile weapons, either U.S. or foreign. We are assembling a database of expected differences in isotopic ratios that result from differences in the material-processing streams. We have already demonstrated our ability to detect minute quantities of uranium and plutonium isotopes with a precision adequate to this mission. We have also calculated isotope production in several families of nuclear devices to determine whether they provide sufficient data for a skilled nuclear chemist to identify design features and extract other information.

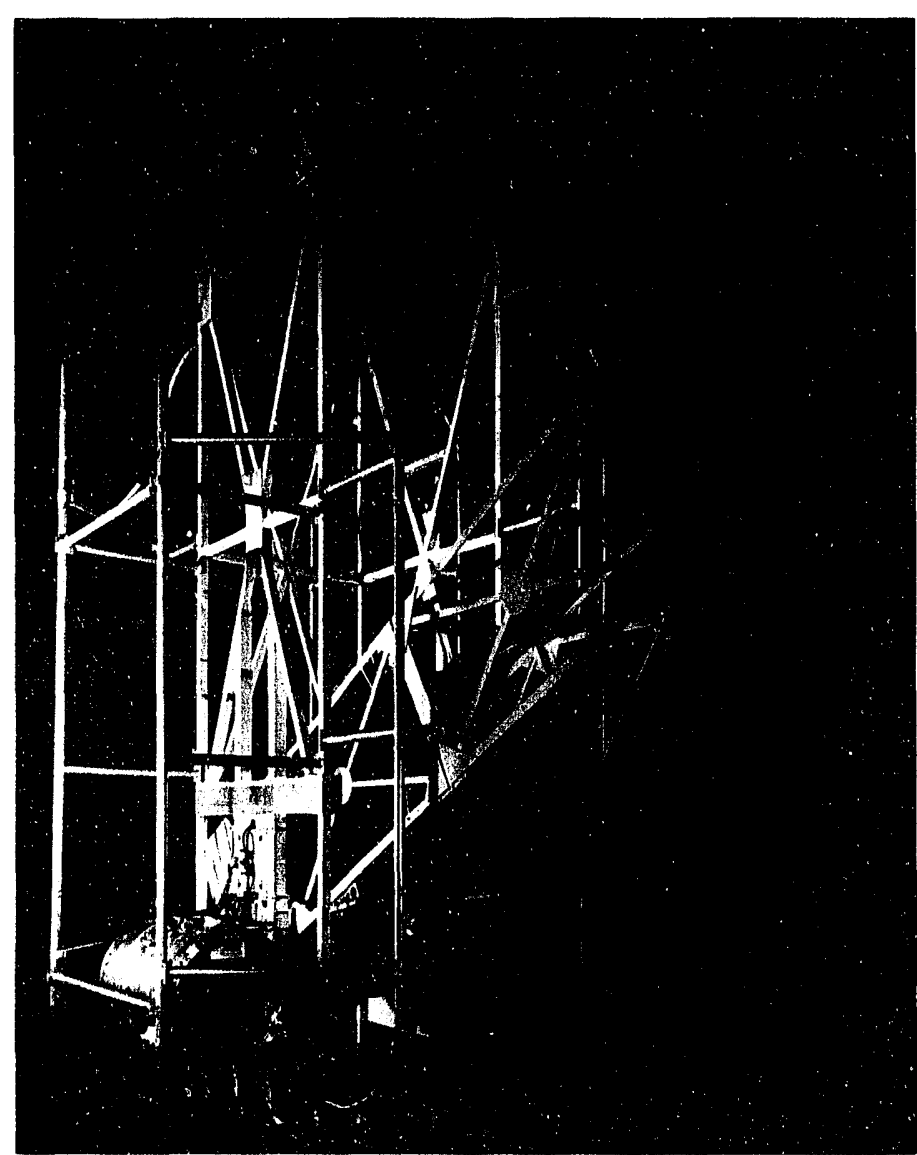

\section{New Infrared Imaging System}

One important technology for detecting nuclear proliferation activities is spacebased thermal imagery (essentially, spacebased thermometers). We are building a Temperature and Imaging System Infrared (TAISIR) that features simultaneous, high-resolution atmospheric spectroscopy, moderate-resolution multicolor thermal imagery, and super resolution of diffractionlimited telescope images (see also p. 14). TAISIR expands the state of the art in temperature and spatial resolucion of thermal imagery. With TAISIR, we may be able to measure from space the thermal emissions of suspect sites. It may be possible to identify facilities engaged in weapons-related activities on the basis of their thermal signatures.

This Temperature and Imaging System Infrared (TAISIR) will provide high. resolution images from space. TAISIR detects and images thermal emissions from sites on Earth with unprecedented temperature and spatial resolution; thus it will be an extremely valuable tool for U.S. efforts in nonproliferation and counterproliferation. 


\section{Dual-Benefit Technologies}

During the past four decades, the Laboratory has developed many sophisticated technologies to meet the demands of the nuclear test program. Some of these, such as high-speed imaging devices and high-bandwidth optical data links (developed to collect data from the exploding underground device) have very promising commercial applications. We are working to adapt such dual-benefit technologies to address national needs, including high-speed data transmission, an understanding of global climate change, and the cleanup of groundwater contamination.

\section{Components for Optical-Fiber Networks}

Optical-fiber technologies are playing a rapidly growing role in the nation's communications networks, both public and private. In addition to their huge bandwidth capacity, which enables them to transmit large volumes of information at high speeds, they provide greater data integrity and security than conventional electronic transmission. However, two problems in particular limit the efficiency of current fiber-optics communications. First, because a single optical-fiber channel can carry many wavelengths of light simultaneously (hence its great bandwidth), it is necessary to have some means of keeping the different wavelength channels separate. Second, because the light pulses in an optical fiber disperse over time, a pulse must be periodically regenerated to restore its integrity.

We have developed a unique channel dropping filter (CDF) to address the first problem. A CDF is a wavelength-selective element that removes the light of a single wavelength from a multiwavelength optical data stream. Wavelength channels that are not "dropped" proceed through the device with minimal attenuation. Previously proposed CDFs exhibit a strong polarization dependence. This polarization dependence renders these devices useless for most communications applications since currently deployed optical fiber does not preserve the polarization of the light signal (and polarization-preserving systems are very expensive). We have invented a novel $\mathrm{CDF}$ with no polarization dependence; the details of this technique are proprietary and are being patented. Our prototype device consists of a fixed-wavelength $\mathrm{CDF}$ integrated with a gallium-arsenide (GaAs) pin diode photodetector. As this project progresses, we will demonstrate a tunable, polarization-insensitive $\mathrm{CDF}$ integrated with our new semiconductor optical amplifier.

The traditional method of compensating for loss in light-based communications systems, the second problem noted above, is to install repeaters along a fiber to regenerate the light pulse. This is a cumbersome procedure that involves first photon-electron conversion, then electrical amplification, retiming, and pulse-shaping, and finally electron-photon conversion. Because the technology is expensive, it can limit the feasible transmission distance, the allowable number of receivers, or both. One approach to solving this problem is the use of semiconductor laser amplifiers. Until now, this technology has been plagued by several shortcomings of its own. However, we have s.....'sped proprietary techniques that provide a simple and inexpensive remedy for these defects and that can operate at several different wavelengths.

During the past fiscal year, we have collaborated with Laboratory engineers to build the skills needed to grow, package, and produce finished $\mathrm{InGaAs} / \mathrm{GaAs} / \mathrm{AlGaAs}$ semiconductor laser amplifiers. This work includes development of a self-aligning process to produce waveguid , a thickoxide liftoff process to generate ridge structures in the semiconductor material, and antireflection-coating hardware and fabrication procedures.

\section{High-Speed Photography}

The history of photography has been driven, in part, by a quest for ever higher resolution and greater speed. The extraordinary demands of underground nuclear testing added a need for extremely rapid transmission and storage of captured images. Modern electronic cameras are based on integrated imaging chips. The resolution of such chips is expressed in terms of the density of their basic picture element, or pixel.

Building on our nuclear-testing knowledge, we have developed a fast video camera with a resolution of $512 \times 512$ pixels, an improvement by a factor of 100 over older cameras. This new camera can capture 400 digitized frames per second with an intensity range of ten shades of gray. To transmit such large quantities of data rapidly, we had to develop new highspeed digitizers and electro-optical data links that support very high bandwidths.

Coupled to an image-intensifier tube, as in its underground-testing application, the camera systom is ideally suited to high-speed photography at low light levels. A microchannel-plate image intensifier with a switching time of a few nanoseconds produces freeze-action images of extremely short-lived events.

This camera has a variety of potential applications. Besides making it possible to capture high-quality images from fastmoving platforms (such as aircraft or satellites), it can image infrared radiation. One application of the latter is to detect buried structures and objects, such as land mines, which produce thermal effects.

\section{Remote Chemical Analysis}

Our expertise in high-speed diagnostics and ultrashort-pulse laser technology is finding application in remote sensing. We are working on techniques to improve the sensitivity of remote chemical sensors. Current chemical spectroscopy methods measure the concentration of a chemical species by recording how the species 
absorbs laser light of two different frequencies. The light is tuned so that one beam is on and the other beam is off the resonant frequency of the chemical of interest. The concentration of the species is revealed by the relative absorption of the two frequencies. Although this is a very powerful technique, current field systems are ineffective when net absorption drops below about $1 \%$.

We believe that by taking into account the inherent noise that currently limits the sensitivity of this technique, we can improve its sensitivity by 100 to 1000 times. Because sensitivity depends on the ratio of two measurements separated in time, much of the noise arises from pulse-to-pulse variations in the intensity of the laser light and from atmospheric perturbations. By making both measurements simultaneously with a single laser beam, we can eliminate these noise sources. We are currently making laboratory measurements to verify the performance of such systems and to determine the optimum laser operating parameters for a field-portable instrument.

\section{Assessing Global Climate Change}

Radiochemical analysis is an essential tool for determining the performance of an underground nuclear test. Our experience in this area is directly applicable to studies of global climate change. Radioactive isotopes produced long ago in materials on Earth's surface can reveal a great deal about the history of global climate. During the past year, we have been studying the chronology of climate change by examining glacial deposits in the Sierra Nevada, on Whidbey Island in the state of Washington, and in debris flows in the Grand Canyon.

One set of studies focuses on analyzing radionuclides that were born in the stratosphere by the action of cosmic rays and then transported to Earth's surface by mixing and settling processes. Our godl is to learn more about how such processes in the atmosphere are correlated with both human-induced and natural variations in climate.

Radioisotopes are produced in the stratosphere when cosmogenic neutrons strike the nucleus of an airborne chemical element and cause it to fission or spall. Trace isotopes generated in this way, such as beryllium-10 or chlorine- 36 , are scavenged by natural aerosols in the atmosphere and are eventually deposited in ice cores and marine sediments.

During the past year, we analyzed icecore samples obtained from Greenland and Antarctica for the presence of beryllium-10, aluminum-26, and chlorine-36. Beryllium isotopes found in a Taylor Dome core from Antarctica reflected the ten-year solar cycle. We plan to compare data from a Greenland core with the Taylor Dome data to establish a record of solar activity. We believe that the ratio of beryllium- 10 to chlorine- 36 in such cores can be used to date old ice layers. Since such layers also contain materials from past geologic events such as volcanic eruptions, these events can be correlated with isotopically established dates to provide information about their effect on global climate.

Other investigators are studying radioisotopes produced by cosmic rays acting on the surfaces of rocks. By measuring the ratio of the various isotopes present in surface material, we can learn something about how the material has been exposed to glaciation and other natural erosive processes over geologic time.

We have measured the ratios of such isotopes produced in situ in rocks obtained from Baffin Island glacial deposits and from debris flows in the Grand Canyon. By correlating our initial estimates of their absolute ages with the results of other dating techniques, we have calibrated our analytical model. The data have also confirmed our model of how isotope production varies as a function of depth in material samples. Continued analysis of the Baffin Island data should help us to understand rapid climate change at the end of the last glaciation some 10,000 years ago, including mechanisms of transition from a glacial to a warmer climate.

\section{Summary}

Driven by the need to maximize the quantity and quality of data obtained from nuclear iests, we have developed a suite of new diagnostic capabilities-highbandwidth electro-optical links with unprecedented resolution, imaging techniques that capture new details in a rapidly imploding device, high-resolution, solid-state imaging cameras with faster framing and readout, and many others. These and other achievements form the basis for our entry into an expanding spectrum of new technology arenas, including nonproliferation and counterproliferation, optical-fiber telecommunications, remote imaging, and global climate change. Our technical skills and talents will be challenged as we meet our stockpile stewardship responsibilities without nuclear testing and as we find innovative applications for our unique expertise in the civilian sector.

For further information contact Richard J. Fortner (510) 423-9597 or Wilson E. Cooper (510) 422-0974. 
Our work at the forefront of laser science and technology is highlighted this year by technical achievements that support the goals of the proposed National Ignition Facility, by successes in uranium enrichment technology, and by many emerging research and commercial applications for lasers.

ition Facility (NIF) will :t-generation, 1- to 2-MJ iroposed site for this 'a laser building.
$\mathrm{T}$

HI: Laboratory is one of the world's preeminent centers for laser science, engineering, and technology. We are applying this expertise to meet national needs in the diverse areas of energy, the environment, the economy, and defense. We are extending our collaborations with industry and other institutions to identify laser technologies that can be developed and transferred to the private sector.

\section{Inertial Confinement Fusion}

The Inertial Confinement Fusion (ICF) Program at the Laboratory, founded in 1972 , includes research on virtually every aspect of inertial-confinement fusion science and technology. In a fusion reaction, the nuclei of two lightweight atoms collide to form a heavier atom,

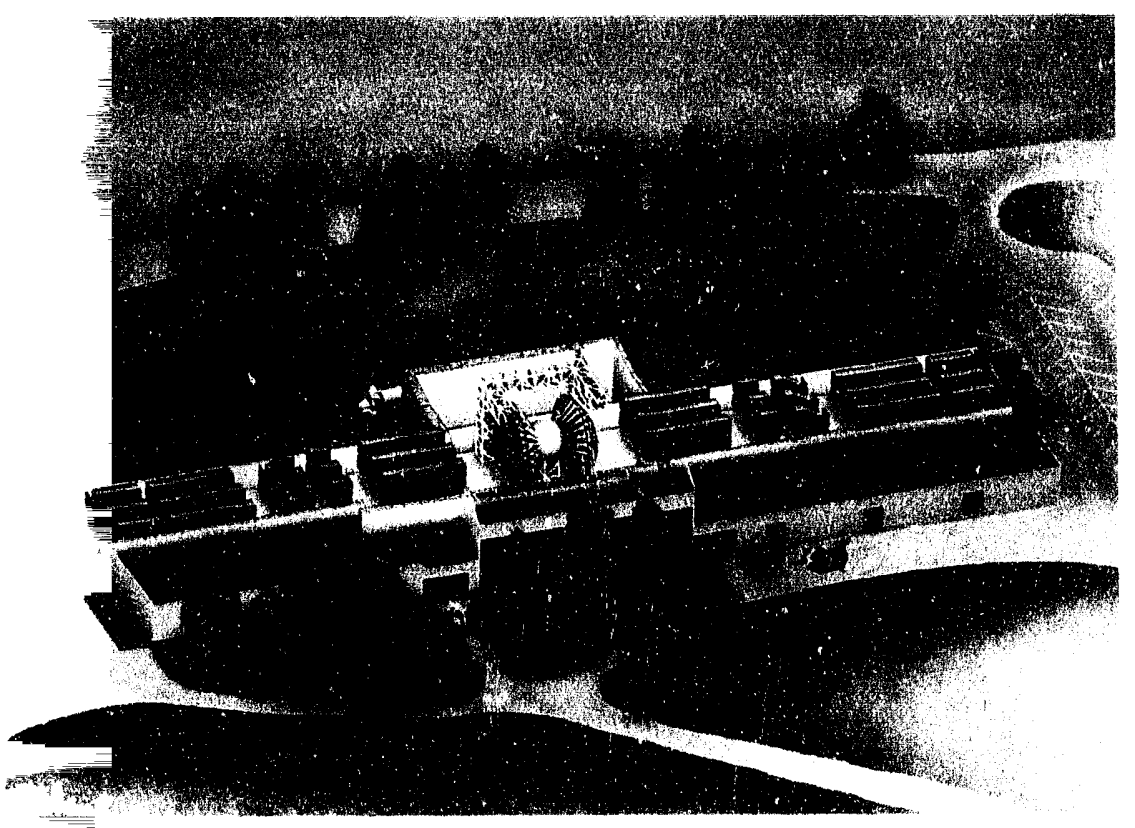

releasing immense energy. Given equal amounts of fuel mass, the energy from fusion is about a million times greater than that released from a chemical reaction, such as the burning of fossil fuels. Our ICF approach uses intense laser light focused onto a target containing deuteriumtritium fuel. The fuel is compressed and heated to "star-like" fusion conditions of tens of millions of degrees.

We say that we have achieved energy gain when more fusion energy is released than the energy required to initiate the fusion reaction. Our continuing goal is to produce thermonuclear fusion gain in the laboratory with significant energy yields for defense and civilian applications.

For defense purposes, we continue to conduct many experiments with the Nova laser as a way to study the basic atomic physics, radiation, equation-of-state, and other processes that are important in understanding thermonuclear weapons. We are extending our ability to simulate the effects of nuclear weapons on hardware that must function in a nuclear environment and are exploring the basic principles involved in advanced nonnuclear weapons concepts.

In civilian applications, inertial fusion energy could eventually provide an environmentally attractive, inherently safe, and virtually inexhaustible source of energy. As our understanding of laser science and technology grows, we are finding many new ways to apply our tools and theoretical results. Our applications range from the imaging of biological specimens to theoretical insight into nuclear synthesis within stars. 


\section{The National Ignition Facility}

Because we study how ICF technologies can address the country's defense and civilian needs, many of our activities are directed by national policy. ${ }^{1-3}$ The DOE's ICF Advisory Committee (ICFAC) is commissioned to review progress in the national ICF Program. Their recent review led the Secretary of Energy on January 15, 1993, to approve a conceptual design study for the National Ignition Facility (NIF). As currently envisioned, the NIF will consist of the next-generation, 1- to 2-MJ glass laser, with the goal of demonstrating fusion ignition and energy gain in the laboratory. (For comparison, the Nova laser produces $\sim 120 \mathrm{~kJ}$ of laser energy at its infrared wavelength in a 2.5-ns pulse.) After receiving DOE approval of the mission need of the NIF, we began conceptual design activities for the facility; our goal is to complete the NIF Conceptual Design Report by the summer of 1994. Our proposed option is to site the glass-laser NIF inside the Nova laser building at LLNL.

The ICFAC also revalidated the "blueprint" for the national ICF Program that was laid out by the National Academy of Sciences in their 1990 program review. ${ }^{1}$ This review judged that the NIF goal could indeed be achieved within a decade and recommended that this initiative be the top priority of the national ICF Program. In response, we have focused our activities in target physics and laser science to support the ignition and gain goals of the NIF.

The Nova Technical Contract defines twelve goals related to ignition physics. ${ }^{1}$ In the area of target physics, we are continuing to make progress in:

- Laser-plasma coupling; incorporating experimental data into theoretical models. - Hohlraum energetics; experimentally demonstrating efficient laser-driven hohlraums (a hohlraum is the cylindrical geometry surrounding the actual target and is ideal for converting laser energy into $x$ rays).
- Hohlraum symmetry; developing techniques to measure and analyze symmetry of the radiation inside the hohlraum canister.

In joint investigations with the Los Alamos National Laboratory, we have nearly completed the NIF target designs. These designs are now sufficiently robust to deal with requirements already specified.

In 1993, we completed the broad-based Precision Nova effort. This work improves the experimental capability of the Nova facility to meet and diagnose the energy balance, power balance, and pointing accuracy of the laser beams needed to achieve target conditions similar to ignition implosions. The improvements associated with Precision Nova have enabled us to demonstrate markedly higher target-fuel densities, an important step in achieving ignition.

We established the Beamlet Demonstration Project two years ago to develop and prove the technology needed in the next generation of glass-laser drivers, such as the proposed NIF. The Beamlet laser is now being assembled at LLNL. In 1993, we demonstrated many advanced components of the Beamlet laser. The Beamlet milestone of $5 \mathrm{~kJ}$ of $0.35-\mu \mathrm{m}$ laser light in a 3-ns pulse is set for the 1994 fiscal year.

In one promising area of inertial-fusion energy research, 2,3 we are exploring a new scenario with small fusion test reactors that use targets the same size as those for the NIF. This scenario could drastically reduce costs and shorten the time required to develop fusion energy as a potential commercial process.

\section{ICF Technology Spinoffs}

ICF technologies continually generate new capabilities and knowledge in areas such as x-ray physics, computational physics, and diagnostic techniques. This year, for example, we received an R\&D 100 Award for developing a single-shot

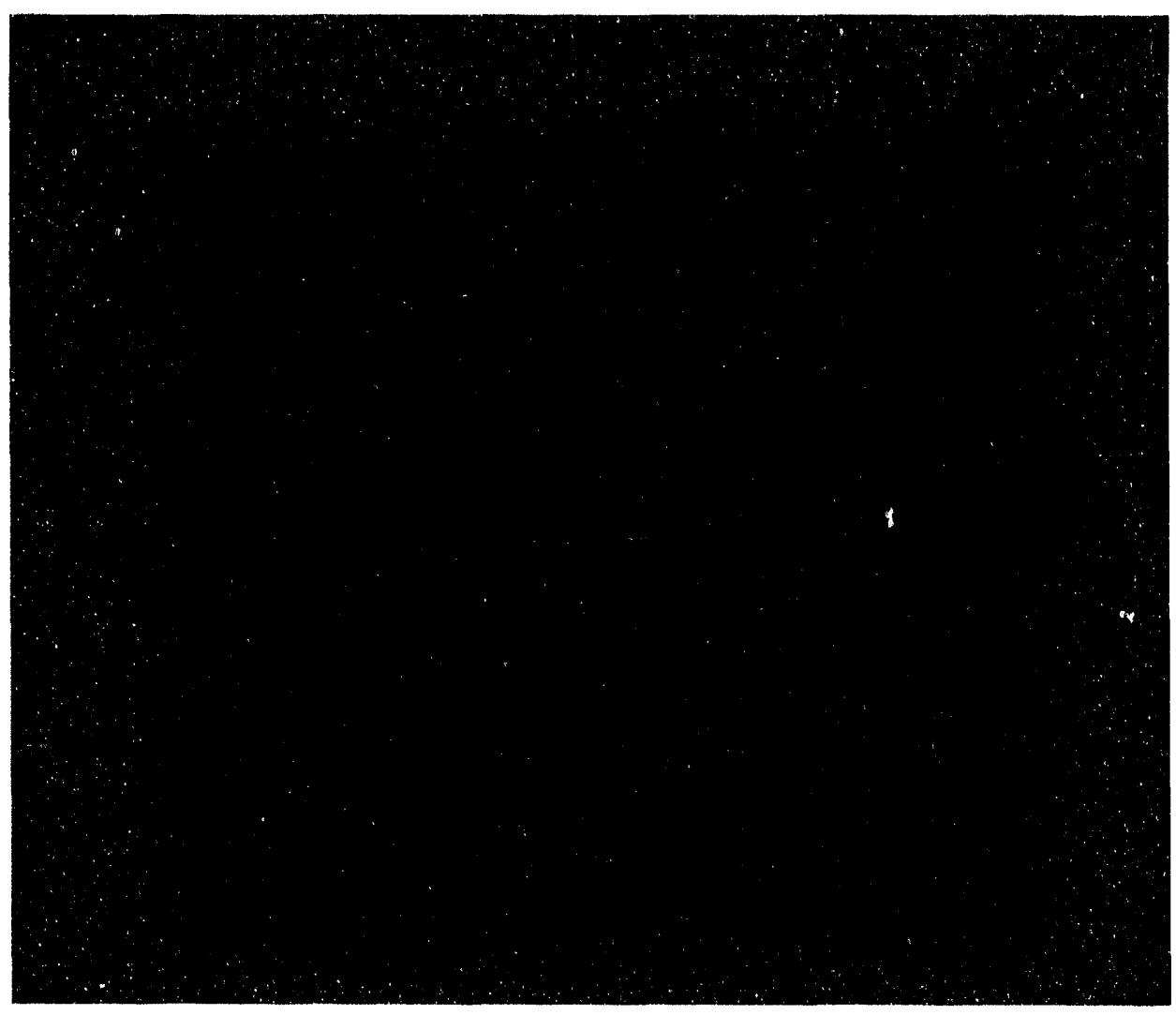


transient digitizer. This inexpensive replacement for oscilloscopes records electrical signals as brief as 300 trillionths of a second - eight times faster than comparable systems - and has applications in high-speed physics, telecommunications, radar systems, and many other areas.

Our expertise has given rise to many multidisciplinary ICF programs for the development and application of laser technologies, such as laboratory $x$-ray lasers and advanced $\mathrm{x}$-ray optics. Laboratory $x$-ray lasers are being used to image biological specimens (see the Biology and Biotechnology article beginning on p. 56). In proof-of-principal experiments, we produced the first-ever, three-dimensional, $\mathrm{x}$-ray holographic images of biological specimens.

We are also collaborating with industry and other DOE facilities to launch a national program in soft-x-ray projection lithography using the advanced $x$-ray optics developed in our ICF work. This process is ideally suited to the manufacture of the next generation of microchips with more than a billion "transistors." Commercially developed soft-x-ray projection lithography could help the U.S. regain preeminence in microelectronics lithography, a $\$ 100$ billion-per-year industry.

Another important achievement in x-ray optics has been the development of a new type of chromatically corrected diffractive lens. Such a lens could have applications in cataract surgery as well as in optics for military use. (This lens is described in more detail in the Economic Competitiveness article on p. 4.)

\section{Isotope Separation and Advanced Manufacturing}

Our Isotope Separation and Advanced Manufacturing (ISAM) Program has two components: Atomic Vapor Laser Isotope Separation (AVLIS), which is directed primarily toward uranium enrichment, and Advanced Manufacturing, directed toward innovative uses for AVLIS technology.

\section{AVLIS}

The mission of AVLIS is to provide the U.S. with a uranium-enrichment technology that can produce nuclear fuel at a cost lower than that of current technologies--gaseous diffusion and gas centrifuge. This new technology would allow this country to compete successfully

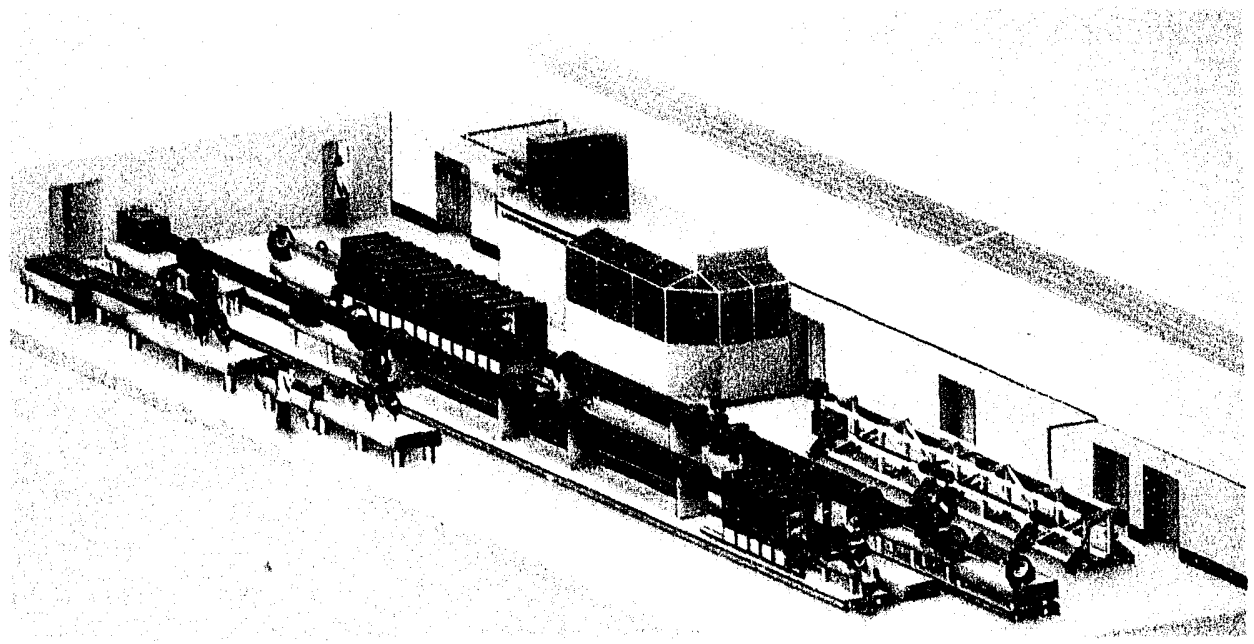

Artist's rendering of the Beamlet laser, now being assembled. The Beamlet project will develop and prove the technology needed in the next generation of glass-laser drivers, such as the proposed NIF.

in the multibillion-dollar-per-year international market for enriched uranium. We have developed and demonstrated the uranium AVLIS process so that it can be rapidly deployed by the private sector. We are completing the documentation of the AVLIS effort, and the Laboratory is in the process of overseeing the transfer of AVLIS to the U.S. Enrichment Corporation (USEC).

AVLIS hardware divides naturally into separator and lase: subsystems. In the separator, an intense electron beam vaporizes uranium metal in a vacuum chamber. In the laser system, fixedfrequency copper-vapor lasers pump tunable dye lasers. Precisely tuned dye lasers selectively excite and ionize uranium-235 atoms in the vapor stream, leaving the inert uranium-238 atoms untouched. The photo-ions of uranium-235 are drawn to an electrically biased collector, producing the enriched product stream. The remaining vapor flows on through, producing the depleted tails stream. Both product and tails are continuously removed from the separator pod as flowing liquid uranium metal. The end result has been aptly described as "doing precision photophysics inside a foundry." - Separator Enrichment Demonstrations. In 1992 and 1993, we completed the most important set of experiments in the AVLIS Program's history. The 15-month series of integrated enrichment demonstrations concluded with a spectacularly successful run conducted in the Uranium

Demonstration System (UDS) in December 1992. In these enrichment demonstrations, a full-scale separator pod was combined for the first time with a laser system capable of illuminating all the vapor passing through it. All run objectives were met or exceeded.

The UDS was operated for 112 hours, exceeding the planned run of 100 hours. More than a metric ton of uranium was processed. More than $8000 \mathrm{~W}$ of power from the copper lasers pumped the dye laser chains, which operated successfully 
at twice their design specification. Dye laser fluence per pulse exceeded plant values. The result of these hardware successes was the production of over $150 \mathrm{~kg}$ of uranium enriched to an assay greater than $2 \%$, adequate to serve as nuclear reactor fuel. Enrichment performance closely approximating that projected for an AVLIS production plant was achieved. - Laser Demonstrations. Between 1985 and 1993, the copper lasers in the Laser Demonstration Facility (LDF) ran 24 hours per day, 7 days per week, accumulating 2.5 million unit hours of operation. The laser amplifiers (the most stressed part of the system) demonstrated a 1200-hour mean time between failure and greater than $95 \%$ availability, both very high values for a high-power laser system. In 1992, two new chains of plant-scale amplifiers were deployed in the LDF. These lasers are designed for twice the output power of the original LDF lasers, approximately $1500 \mathrm{~W}$ per three-amplifier chain. After resolving typical startup problems, the two chains met a high-power demonstration milestnne in August 1992, operating without failure or servicing for more than 1400 hours and generating over $2500 \mathrm{~W}$ (the demonstration target) for 1100 hours and over $3000 \mathrm{~W}$ for 300 hours.

An ongoing effort is to eliminate the chlorofluorocarbons (CFCs) that are currently used to cool electronic components in the copper laser system. Extensive changes must be made to the high-voltage power supplies and pulsepower electronics to move from a design using CFCs to one using solid-state switching and water-air cooling. We designed and built a CFC-free oscillator capable of producing over $40 \mathrm{~W}$ of power (compared to $20 \mathrm{~W}$ from the previous design); in June 1993, we completed a 200-hour high-power demonstration of this new oscillator.

During the last year, the AVLIS tunable dye lasers set new records for system and single-chain power. We are replacing the discrete optical components used to deliver copper laser light to the dye lasers with new optical-fiber delivery systems. The opticalfiber systems are safer, more reliable, and less expensive to build and maintain. In separate developments, we greatly improved two diagnostic laser systems. The cryogenically cooled titanium:sapphire laser, used for uranium vapor diagnostics, was upgraded from a two-rod to a three-rod system, resulting in a power output of $56 \mathrm{~W}$. The laser absorption monitors used for closed-loop vapor rate control were switched from continuous-wave dye lasers to tunable, external cavity diode lasers, reducing costs and increasing reliability.

The need to "thread" laser beams through a row of separator pods places stringent requirements on the beams' spatial stability and wavefront quality. Last year saw great improvement in the AVLIS optical control systems. New closed-loop alignment controls suppress beam motions and maintain beam position on 152-mmdiameter optics to better than a millimeter over very large propagation distances. New closed-loop, controlled, deformable mirrors reduce wavefront aberrations substantially. An advanced wavefront-correction system

\section{A new-generation copper laser amplifier head in final assembly. This 500-W head fits in the same external package as the 250-W head it replaces.}

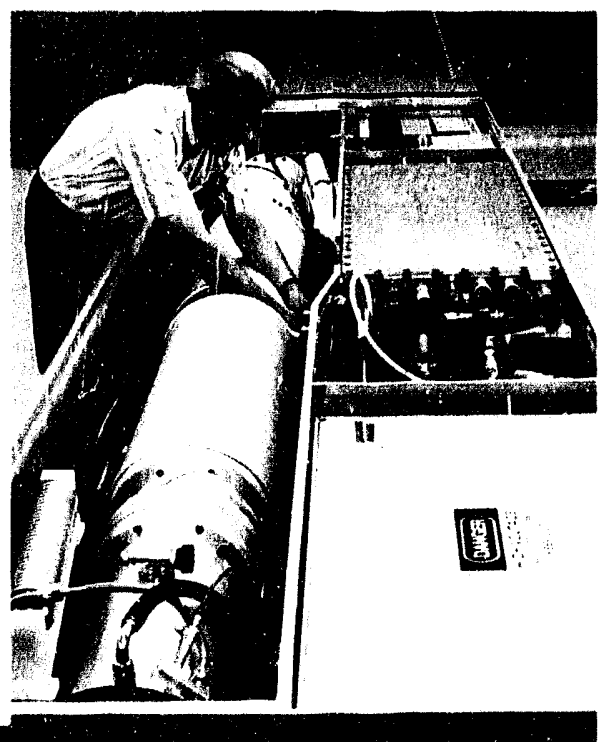

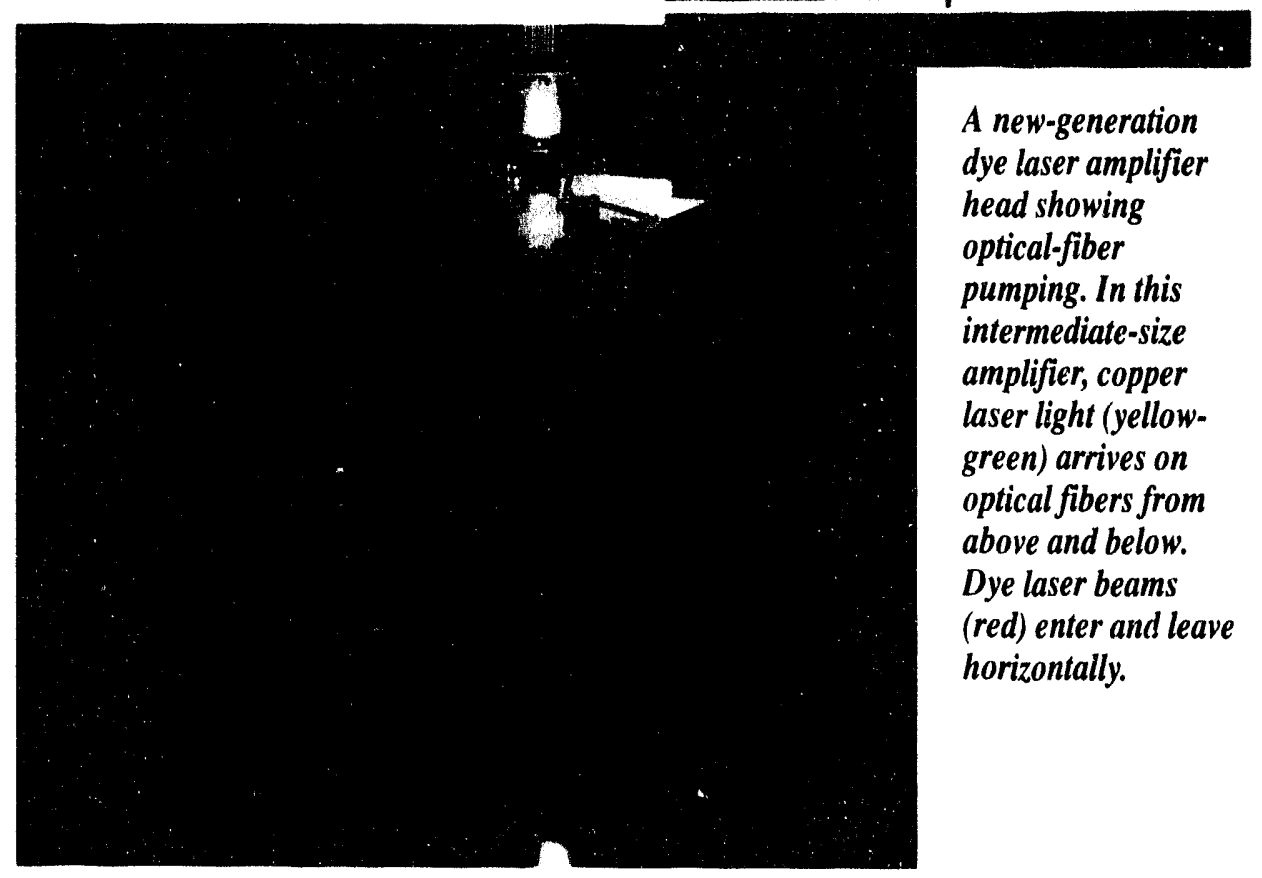


further reduces deformable mirror costs while providing improved spatial resolution and online self-calibration.

- Integrated Life-Test Demonstration. During the integrated life-test demonstration, critical pod subsystems and many added diagnostics worked for 112 hours. This long-duration operation was greatly facilitated by closed-loop control of the vaporization rate (electrongun system) and the separator (emperature (pod heater system). We activated a newgeneration separator pod design, incorporating lessons learned in the UDS demonstrations, in a series of test runs extending through the spring of 1993.

Design improvements include an indirectly heated emitter in the electron beam gun, improved electron-beam transport that gives better protection to the guns, simplified and corrosion-resistant casters for product and tails removal, and simplified liquid containment and thermal control enclosures. The result is a more reliable pod that contains fewer parts, costs less, and is easier to refurbish. In May 1993 , we operated a side-throw pod to process record quantities of uranium.

\section{Advanced Manufacturing}

The Advanced Manufacturing component of our program embraces several disciplines in which world-class technology developed at LLNL is applied to other problems. The most prominent of these efforts is in laser materials processing.

The output of our
new diode-pumped,
$Q$-switched solid-
state laser oscillator
can be frequency-
doubled to $100 \mathrm{~W}$ of
average power-a
world record. This
output is generated
at a wavelength of
$0.532 \mu \mathrm{m}$ (note the
green laser beam
in the bottom
photograph) from
a thin slab of
potassium
triphosphate (KTP).
The top photograph
is a closeup of the
dual-crystal,
thermally
compensated,
lithium niobate
$Q$ switch.
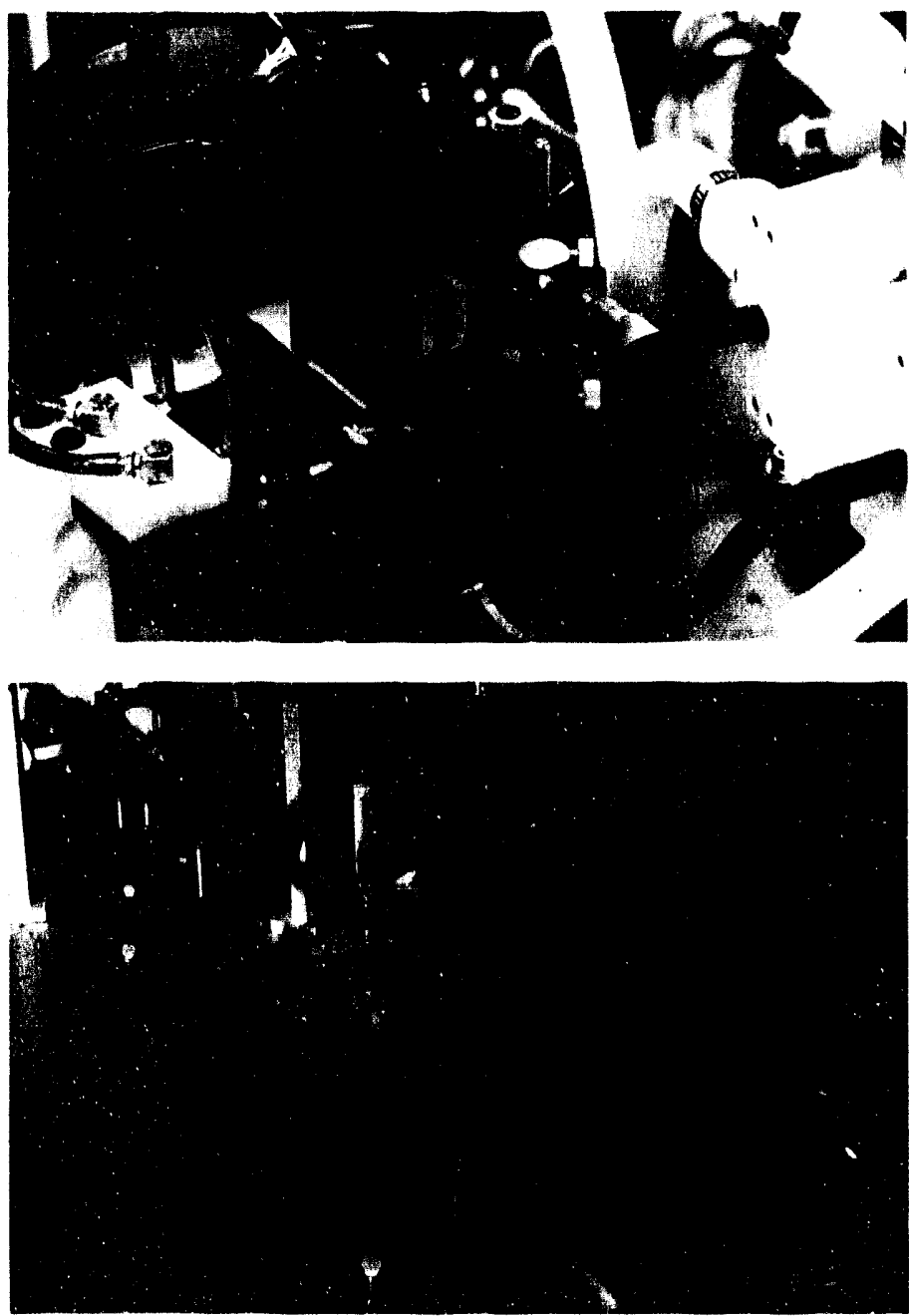

We are applying the beams from our copper lasers, dye lasers, and diode-pumped solidstate lasers to manufacturing processes, such as hole drilling, welding, cutting. surface treatment, and high-energy synthesis. We are showing, time and again, that these lasers are better than existing techniques in both precision and speed.

In 1993, we substantially improved the beam quality of the copper lasers used in laser materials processing. The improved beams give us unique capabilities in precision hole drilling, allowing us to fabricate holes as small as $20 \mu \mathrm{m}$ in diameter with depth-to-width ratios as high as 50:1 and very small (micrometer scale) heat-affected zones. This kind of result makes laser drilling a speedier alternative to electrode-discharge machining.

In a separate activity, we are applying a derivative technology for industrial use. Our extensive experience in the vaporization, corrosion-resistant containment, and chemical processing of actinides is being tapped in the DOE's reconfiguration of the weapons complex. For example, we are helping to develop electron-beam, cold-hearth melting and casting systems to recycle alloyed uranium and reduce the waste stream. These and other environmental restoration and waste management efforts are discussed in the Environmental Research and Technology Development article beginning on p. 38 .

\section{Advanced Applications}

We are developing lasers for a wide range of energy, military, and commercial uses and have technology-transfer projects with several major U.S. companies. In 1993, we made important developments in three principal areas:

- Solid-state laser and electro-optic technology.

- Imaging and signal processing.

- Charged-particle-beam and accelerator technology. 
State-of-the-art lasers have applications ranging from remote sensing and medical diagnostics to manufacturing flat-panel displays or electronic circuits with submicrometer-size features. New lasers can also be used for mine detection in the open ocean, satellite communications and imaging, theater missile defense, and materials processing. Our goal is to develop semiconductor lasers and solid-state lasers of unparalleled performance for each of these applications. To further these developments, we maintain active areas of research in semiconductor laser crystal growth, processing, and packaging; insulator laser crystal growth and packaging; nonlinear materials characterization; phase conjugation; laser systems integration; micro-optics; and remote sensing.

We have initiated joint research projects with 16 Russian institutes. Our Advanced Laser Technology Program has engaged these institutes in a broad range of research projects in solid-state laser technology and remote sensing. This is the largest joint U.S.-Russian program, in terms of numbers of institutes and level of support, sponsored by any organization within the DOD or DOE.

Our Imaging and Detection Program is a multiproject effort addressing a wide range of activities. This effort encompasses advanced imaging concepts, remote sensing, signal processing and detection, and novel airborne platforms for conducting experiments. Our largest imaging and detection project is in radar ocean imaging, funded at approximately $\$ 10$ million per year by the Office of the Secretary of Defense. We are developing advanced radar and signal-processing systems for remote sensing of the sea surface. In particular, we are working to develop the systems and technologies needed to detect surface manifestations of undersea phenomena using both real and synthetic aperture radars.
Other imaging and detection projects include the design and demonstration of a novel tandem-balloon system for conducting remote sensing experiments from high-altitude balloons, development of unmanned air vehicles for various remote-sensing and scientific experiments at high altitudes, and research into signal processing, data fusion, wideband radars, and image-reconstruction techniques.

In addition, we are participating in the laser guide star project, which has received much publicity lately. The laser guide star effort combines lasers, adaptive optics (deformable mirrors), and sophisticated computer controls to help correct for atmospheric turbulence and overcome the blurring in images from ground-based astronomical telescopes. By propagating a dye laser beam at $589 \mathrm{~nm}$ (sodium yellow) into the night sky, an artificial sodium "star" is produced some $96 \mathrm{~km}$ above Earth's surface. When experiments are conducted (in the middle of the night), the vertical laser beam, with a power of more than a kilowatt, is visible from all parts of the Livermore Valley.

We have also continued our research on high-power, short-pulse, free-electron lasers and relativistic klystrons driven by linear induction accelerators. These devices are potential power sources for future linear colliders, which would be several kilometers in length.

High conversion efficiency of electron beam energy to microwave energy can be achieved in two-beam accelerators using reacceleration of the bunched drive beam. To study the two-beam designs, we have assembled an experiment in which the modulated beam's energy is boosted as it passes through several induction accelerator cells. In 1993, we increased the drive beam energy to $5 \mathrm{MeV}$ and tested a new version of the modulator. We achieved microwave power levels of $200 \mathrm{MW}$ in a single output section in these experiments. This result is within a factor of two of the ultimate goal. Such results can lead to a three- to fivefold reduction in the length of the linear accelerator.

\section{Summary}

Over the last two decades, the scope of our laser research has grown immensely. The small, low-power laser systems of our early days have given way to laser systems of record-breaking size and power. Now we are focusing our activities within the target physics and laser science programs to support the ignition and gain goals of the proposed glass-laser National Ignition Facility. In our laser isotope separation work, we completed the most important set of experiments in the history of the AVLIS Program in 1993, which culminated in a spectacularly successful run that met or exceeded all our objectives. We are also developing lasers and laserrelated technologies for a variety of energy, commercial, and defense uses. On the horizon are transfers of important technologies for waste treatment, $x$-ray lithography, cornmunications and security, optical imaging, and remote sensing, among others.

\footnotetext{
References

1. National Research Council, Second Review' of the Deparment of Energy's Inertial Confinement Fusion Program, Final Report (National Academy Press, Washington, D.C., 1990).

2. Fusion Policy Advisory Committee, Review' of the U.S. Fusion Program, Final Report (U.S. Department of Energy, Washington, D.C., 1991).

3. U.S. Department of Energy, Natiomal Energy Strategy (U.S. Department of Energy, Washington, D.C., 1991). Ist ed
}

For further information contact E. Michael Campbell or Donald L. Correll (510) 423-9051. 


\section{We are working to gain a basic understanding of the interrelated forces that govern the environment, th determine and mitigate detrimental effects of human activities on the environment, to develop and apply technologies to correct adverse environmental consequences of past practices, and to modify current practices so they are environmentally benign.}

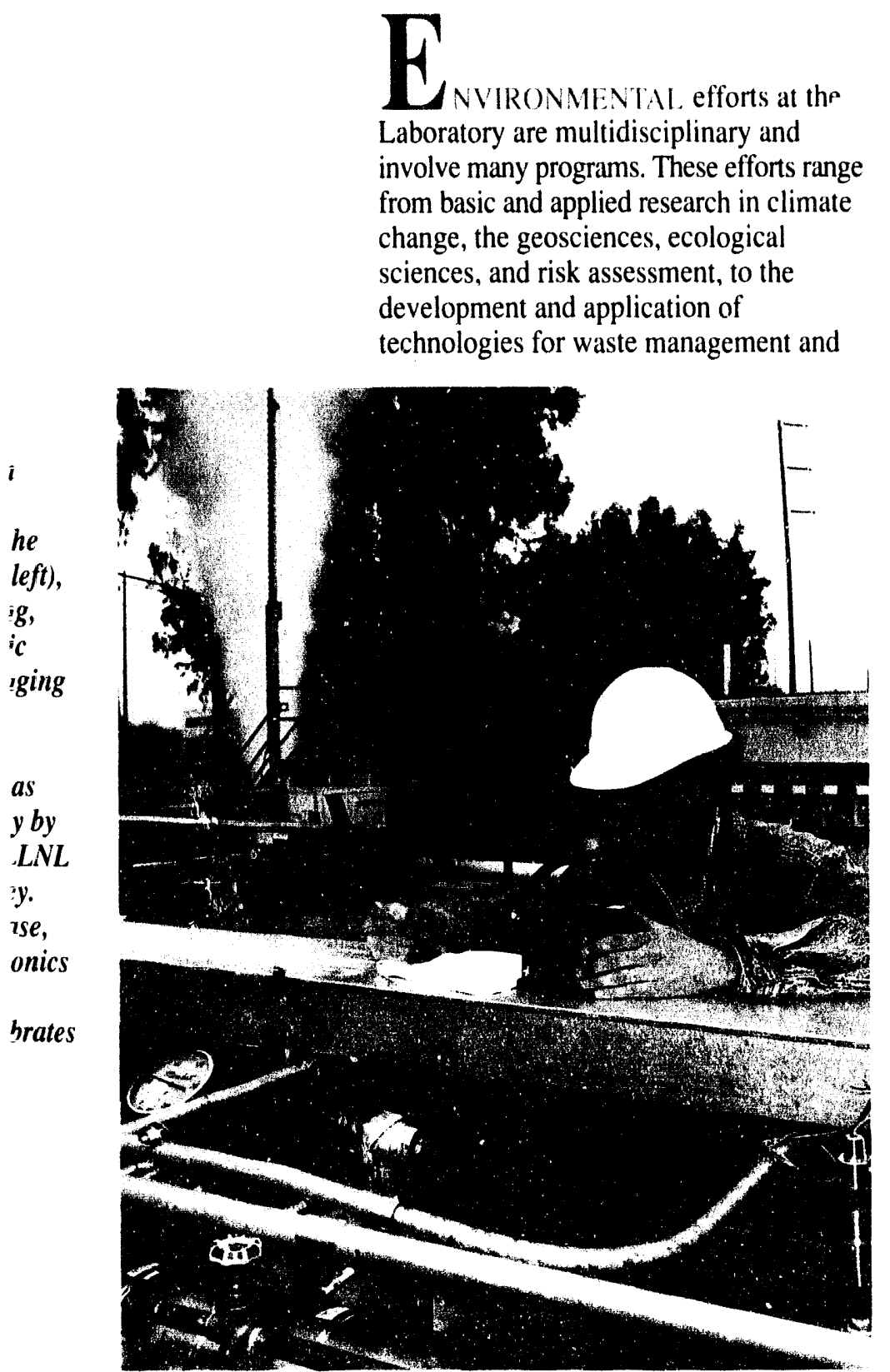

minimization, pollution prevention, and environmental monitoring, characterization, and restoration, to the application of technologies for site cleanup and regulatory compliance. Today, there are numerous laws and regulations that govern Laboratory activities, and we make every effort to comply with both the letter and the spirit of these regulations. As we address the broad spectrum of environmental topics, we must bridge between ongoing institutional support operations and the technology development activities.

Environmental research at LLNL has its origins in the nuclear weapons program. Many of our environmental programs began as small, unrelated efforts during the Laboratory's early days. For example, meteorological monitoring and atmospheric modeling capabilities were originally developed as part of the atmospheric nuclear testing program. Studies of the transport of radionuclides in the environment and their effects on marine and terrestrial biota were initiated to determine the long-term effects of weapons activities. Many of the techniques developed for radionuclides were extended to the detection and study of other chemicals in the environment. Over the years, we have taken an increasingly active role in all environmental aspects of our various research and development projects.

Many of the erivironmental problems we now face are not the result of intentional 
damage but rather the result of common practice based on the (incomplete) knowledge of the day. As we have learned more about the environment, we have found that many of our activities were environmentally harmful. In the 1980 s, onsite monitoring of groundwater and soils revealed chemical contamination resulting, in many cases, from the site's use in the 1940s as a Naval Air Station. A major cleanup effort was undertaken, and programs were initiated to develop innovative, rapid, and cost-effective techniques for environmental restoration.

To ensure that current LLNL activities do not adversely affect the environment, we extensively monitor air and water effluents. In addition, we have developed methods for stabilizing waste materials so that they can be disposed of at suitable off-site treatment facilities. This work has spun-off into a number of active programs to develop other, more cost-effective and environmentally acceptable treatment schemes to completely break down waste components into nonhazardous byproducts.

In the two articles that follow, we describe recent accomplishments in our various environmental programs. We have continuing programs to understand the fundamental physical processes and mechanisms that govern the environment and to determine the effects that Laboratory activities in particular, and human activities in general, have on the environment. With this knowledge, we develop cost-effective technologies for preventing pollution, for characterizing the site, and for monitoring the progress of environmental cleanup operations. We then demonstrate the effectiveness of these technologies and processes and apply them where appropriate. Many of the technologies we have developed are applicable not only at the Laboratory but also at other sites nation- and worldwide.

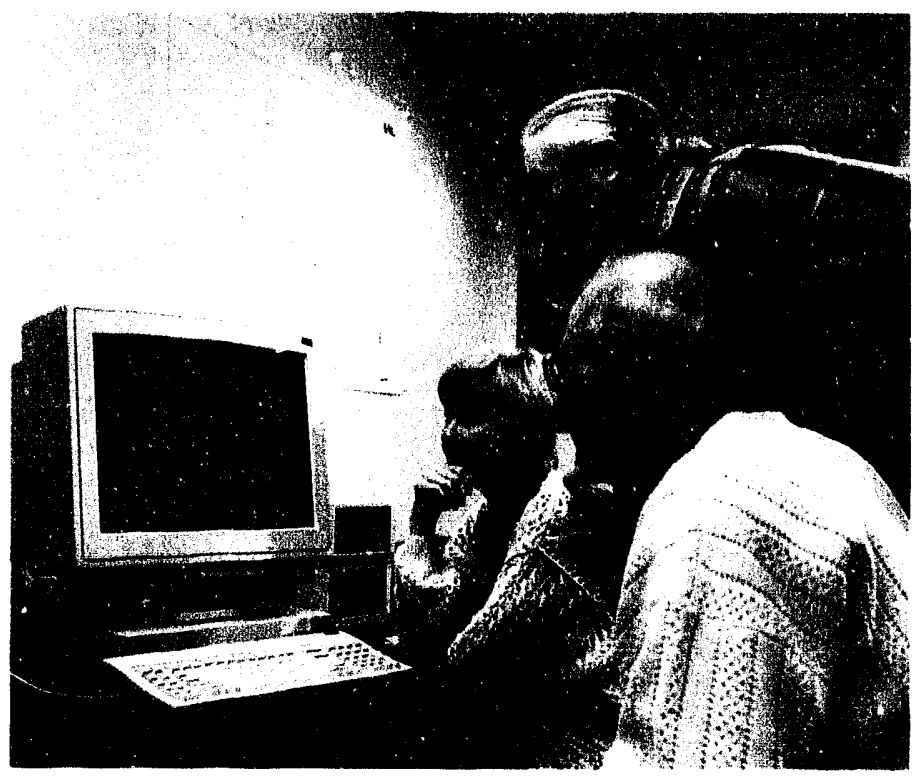

We have developed computer codes for modeling subsurface contamination to identify remediation technologies that maximize contaminant removal and minimize cleanup costs.

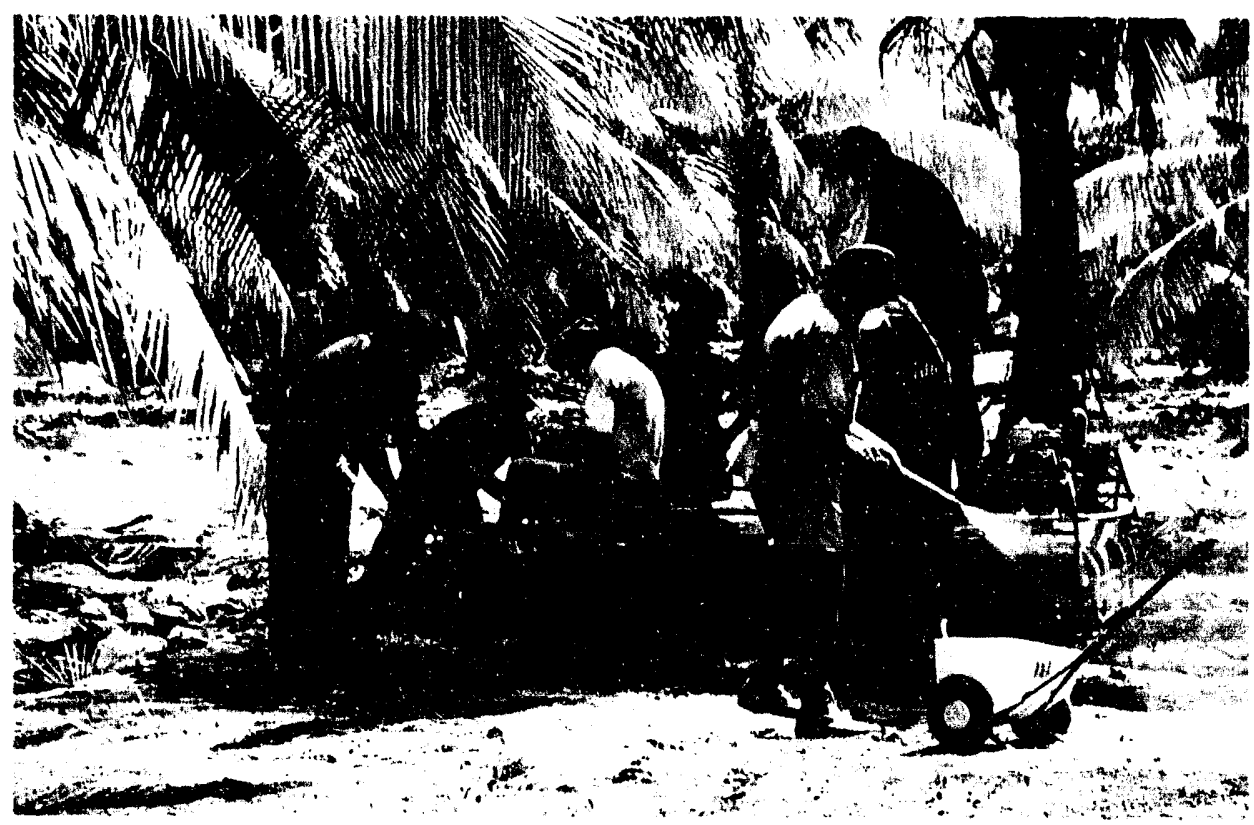

U.S. atmospheric nuclear testing conducted in the 1940s and 1950s in the South Pacific left islands contaminated with radioactive fallout. Starting in the late 1960s, we began field studies to estimate radiological doses to the islanders resettling the islands. This information enabled us to assess radiological conditions at the affected atolls, to determine ways of reducing the contamination in the soil and the uptake of radionuclides into food crops, and to evaluate possible cleanup options. 


\title{
comental Kesearch choology Development
}

\begin{abstract}
We conduct basic research to understand the forces affecting the environment, develop technologies for environmental restoration and waste management, and search for new environmentally benign processes that will use nonhazardous materials and produce nontoxic byproducts.
\end{abstract}

\section{i ARAC plot of the se of sulfur trioxide at al Corp. (Richmond, v 26, 1993. ARAC modeled resulting plume of sulfuric used by emergency Is to advise field monitoring imate possible health effects. the plume calculated for $n$ data. (Photograph sy Times.)}

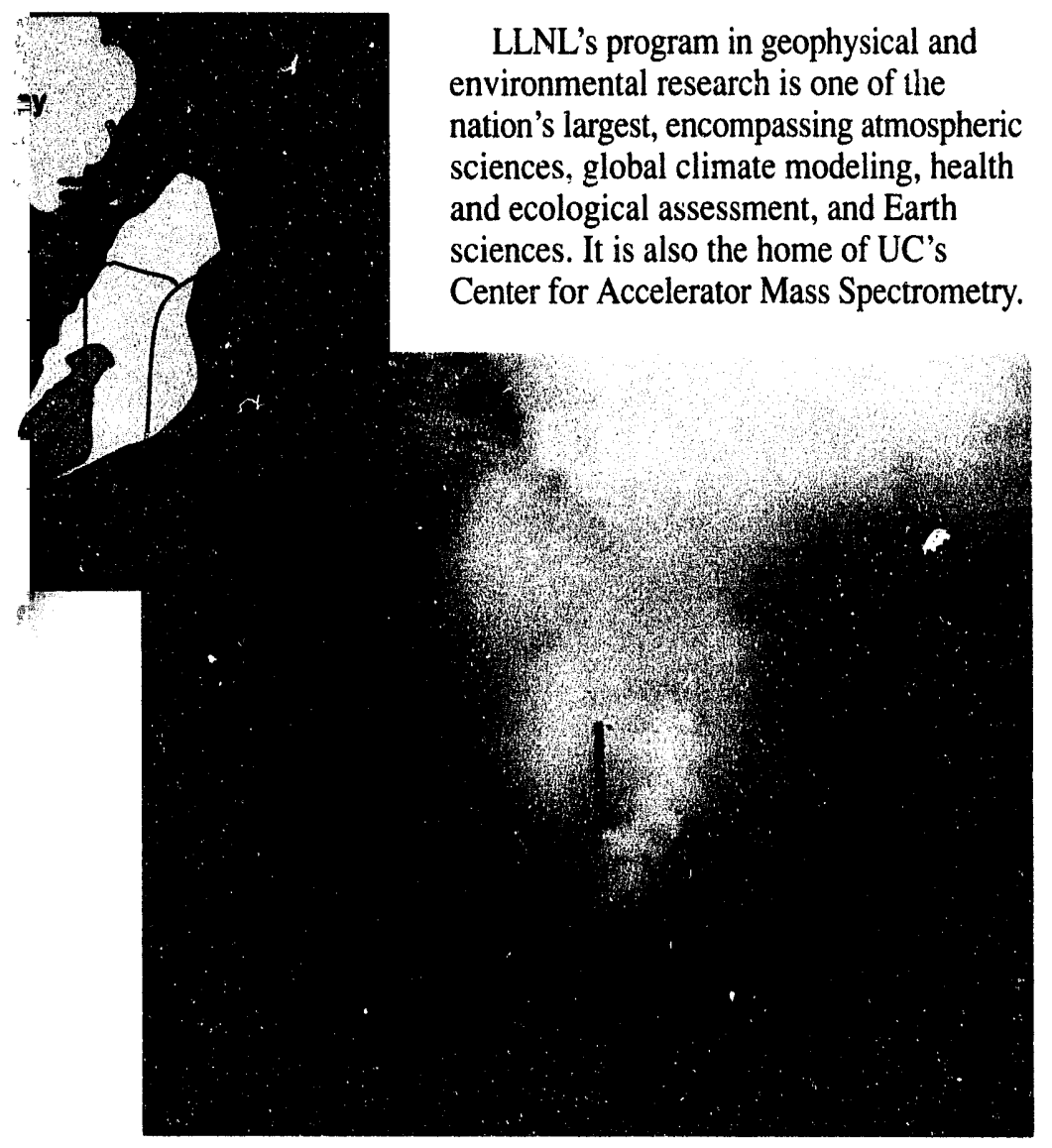
brings together an array of programs, from basic research in environmental phenomena and processes to the development of technologies for environmental restoration and waste management.

\section{Geophysical and Environmental Research}

\section{Atmospheric Studies}

Working on local to regional scales, LLNL is a large-scale enterprise that

we develop models to predict the transport, dispersion, and removal of emissions in the atmosphere and use these models to study such complex atmospheric phenomena as cloud formation and dissipation, turbulent mixing, and wind flow over complex terrain. Our research converges in the Atmospheric Release Advisory Capability (ARAC) center, which we operate for the DOE Emergency Response Program. ARAC provides real-time, roundthe-clock, model-derived assessments of the health and environmental consequences of atmospheric releases of radionuclides and other hazardous materials.

- ARAC Response to $\mathrm{SO}_{3}$ Release. A recent example of ARAC's capabilities arose from an accidental release, on July 26 , 1993 , of sulfur trioxide gas $\left(\mathrm{SO}_{3}\right)$ during the unloading of a railroad tank car at General Chemical Corp., in Richmond, California. The $\mathrm{SO}_{3}$ quickly reacted with water in the air to form a cloud of sulfuric acid $\left(\mathrm{H}_{2} \mathrm{SO}_{4}\right)$. The release began at 7:15 a.m., and the company notified emergency officials at 7:45 a.m. The ARAC team gathered information about the release site and the properties of $\mathrm{SO}_{3}$ and at 8:40 a.m. offered the Bay Area Air Quality Management District help in modeling the release. At 9:20 a.m., the district requested a calculation based on the assumption that the entire 13,000 gallons of $\mathrm{SO}_{3}$ were released within 90 minutes. Current meteorological data, gathered automatically from ARAC stations and the district, indicated moderate winds $(6-12 \mathrm{mph})$ blowing steadily from the south-southwest 
and conditions favoring conversion of the $\mathrm{SO}_{3}$ to $\mathrm{H}_{2} \mathrm{SO}_{4}$.

ARAC completed a worst-case calculation at 10:45 a.m., which indicated that the plume of sulfuric acid would travel across Richmond and over several towns to the northeast. (The actual cloud was observed in approximately the same location.) A plot of the calculated results was faxed to the district and to the state's Office of Emergency Services and Department of Health Services, where it was used to advise field monitoring crews, to assess the significance of the problem and determine the extent of evacuations (if any), and to estimate possible health effects. At 1:40 p.m., the Office of Emergency Services requested new calculations based on the release of half the tank volume over 3.75 hours. By 3:00 p.m., ARAC transmitted the new results, which were similar to the initial plots but, with half the amount released over twice the time, showed that the affected area was smaller. - Global Climate Modeling. Beyond the regional scale, we develop, test, and apply global climate models to improve our understanding of climate change. Our ultimate goal is to develop an Earth system model that represents the full set of coupled physical, chemical, and biological processes that govern the behavior of the climate system. To this end, we study the chemistry of trace species and aerosols at very high altitudes and build computational models of the chemistry and physics of interactions from the microscale to the global scale. We research the physics of clouds and their radiative properties and climate variability and conduct studies of heat, momentum, and water balances.

Current global atmospheric and climate models show important disagreements in their predictions. To assess the reliability of the models' predictions and improve the models so that similar results are predicted from the same input data, we must systematically study the models' errors and trace the causes of the errors. Our Program for Climate Model Diagnosis and Inter-omparison is therefore studying the effects of model resolution, the treatment of clouds and their interaction with radiation, and the models' simulation of the global budgets of heat, moisture, and momentum. This program, in cooperation with the United Nations, is leading the Atmospheric Model Intercomparison Project, the largest internationally coor $r:$ ated test of atmospheric mode!s (30 models in all) ever undertaken.

\section{Health and Ecological Assessment}

The Laboratory has a long-running effort to develop methods for measuring and estimating the exposure of biota (flora and fauna) to radioactive and nonradioactive substances in the environment and the biological effects of those exposures. We evaluate pollutant transport and uptake between air, soil, water, and biota to estimate doses to exposed populations, assess the risks of the exposures, and evaluate potential remedial measures. We have formed a Risk Sciences Center to use these techniques to help rank and assess the results of national regulations and remediation activities and to work with UC researchers in these efforts.

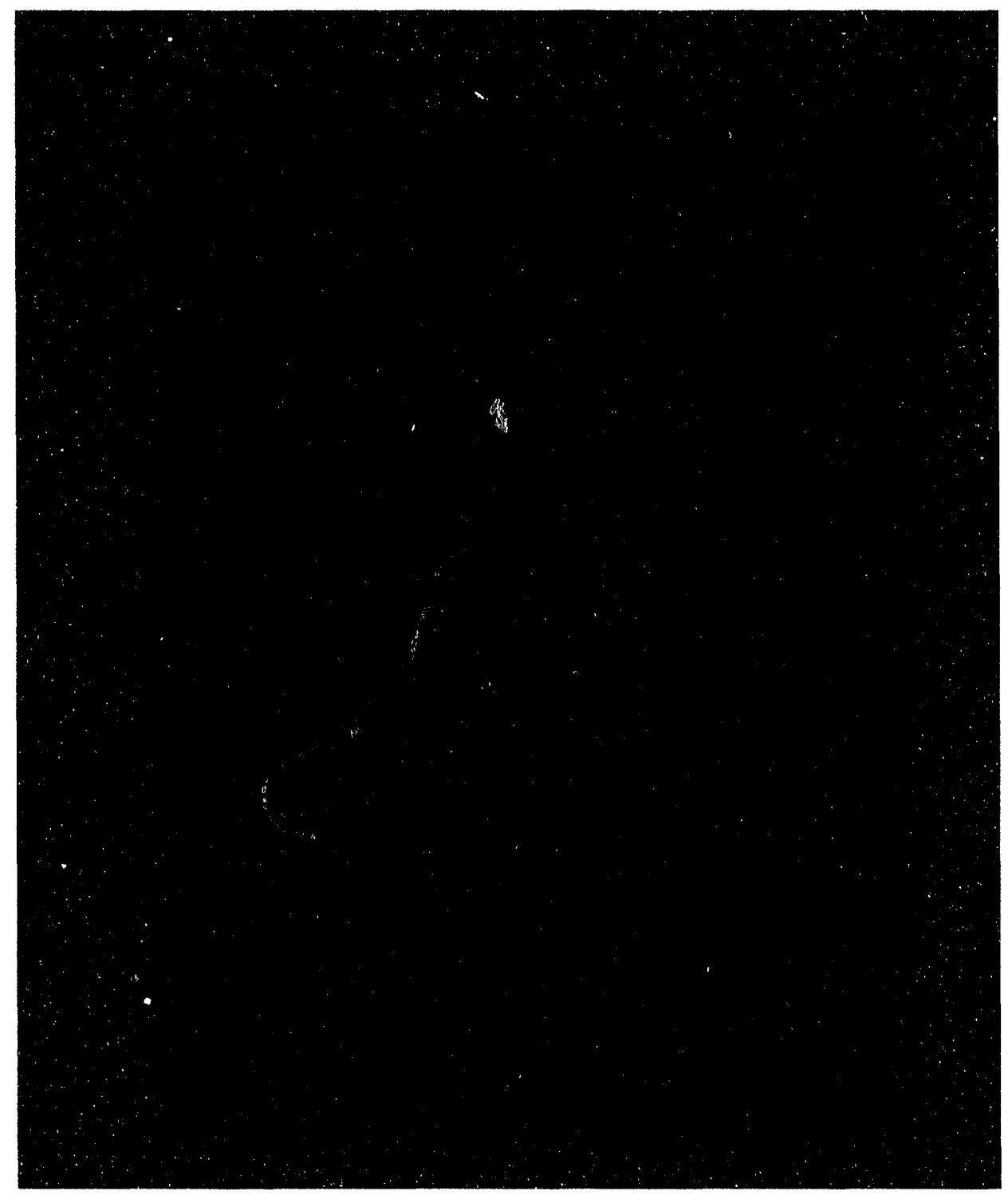




\begin{abstract}
- Revised Estimates of Hiroshima Neutron Doses. We recently completed a reevaluation of the neutron doses received by Hiroshima atomic-bomb survivors. These people, along with the Nagasaki survivors, are used to estimate the risk of radiation-induced cancer in humans and are therefore used as the basis of federal radiation-protection standards. Errors in the bomb-survivor data, either for effects or doses, would cause considerable uncertainty for all radiation protection standards. At the Center for Accelerator Mass Spectrometry (CAMS), we analyzed many new samples of materials that were exposed to the Hiroshima radiation, measuring the concentration of neutron activation products to estimate the total neutron dose. We extended the measurement range to more than $1.7 \mathrm{~km}$ from the blast epicenter.

Our results show that at distances
\end{abstract} beyond $1 \mathrm{~km}$ (distances most relevant for radiation-risk evaluation), the neutron dose may have been two to ten times higher than earlier thought. Our data suggest that neutrons actually contributed $40-80 \%$ of the radiation-induced cancer risk to the Hiroshima survivors, much more than the 15-20\% predicted by most accepted risk models (with gamma radiation comprising the remaining risk). If this finding is supported by other (future) work, the radiation-induced cancer risk estimated from survivors may decrease twofold, and the shift in relative importance of neutron and gamma radiation will significantly affect interpretations of the Hiroshima dose-response data.

\section{Earth Sciences}

Our work in Earth sciences ranges from applying seismology to nonproliferation issues, to assessing earthquake hazards, to developing underground imaging technologies, to studying the physical, chemical, and transport properties of geological materials at high temperatures and pressures. We are also combining experimentation and modeling to study geothermal fields, the formation of petroleum, and the geochemistry, hydrology, thermal-mechanical response, and radionuclide transport in the environment. Radionuclide transport is pertinent to our studies of the waste packages at the candidate high-level nuclear waste repository at Yucca Mountain, Nevada. Our research is enriched by the Center for Geosciences of the LLNL branch of the Institute for Geophysics and Planetary Physics, which promotes collaborative research between Laboratory and UC scientists.

\section{Center for Accelerator Mass Spectrometry}

In the past year, CAMS reached full operational status for eight cosmogenic or anthropogenic isotopes, becoming the world's most versatile and productive AMS facility. We can now routinely measure eight low-abundance isotopes (1 part in $10^{12}-10^{15}$ ), including tritium and carbon-14. We can switch from measuring one isotope to another daily (or more often if needed), a capability not readily available elsewhere. In 1993, CAMS ran approximately 10,000 samples for a wide range of research projects. Three patents have been granted and several filed, promising future commercial application.

We are testing automated operation of the AMS, reducing the need for human operators. Samples would be measured under the control of a data-acquisition system with decision-making capabilities to optimize accuracy as the samples vary. The routine use of such a system would double productivity. This gain is important because new classes of research problems in biology, geoscience, and nonproliferation require either the high throughput or the rapid measurement turnaround that only CAMS can provide; this automation will also greatly reduce the cost of analyzing samples.

\section{Applied Environmental Technologies}

Ideas for new environmental technologies come from many sources. Many arise out of basic research in environmental science; others are created by combining and modifying existing technologies for a new application. The role of the Laboratory's applied technology programs is to turn these concepts into working devices or processes and to demonstrate their effectiveness.

\section{Waste Minimization Technologies}

Waste minimization is the development of new or improved processes that reduce the amount of waste that is generated and must be disposed of (see also the Restoration, Protection, and Waste Management article on p. 44). Robotics is proving extremely effective in minimizing waste from manufacturing processes. Robots can perform many tasks more efficiently than humans, making fewer wasteful mistakes and using fewer expendable supplies. Robotic systems are also ideal for handling radioactive and hazardous materials; they can perform many manufacturing and waste handling operations (such as scrap sorting), reducing the danger of radiation exposure and injury to human workers.

We are developing technologies to minimize the environmental impact of nuclear weapon dismantlement. In particular, we are demonstrating LLNL robotic systems for nuclear weapon disassembly and for pyrochemical operations involving plutonium and uranium. This past year, we:

- Worked with our IBM counterparts to adapt an IBM production robot to handle radioactive materials. Robotic disassembly of a mock nuclear device and processing of the recovered mock nuclear materials were demonstrated.

- Developed an advanced pyrochemical furnace for automated processing and purifying of plutonium and uranium, 
increasing throughput and lowering waste and worker radiation exposure.

- Developed and demonstrated a chemical reactor that removes plutonium from retired nuclear weapon components while producing almost no liquid or solid wastes, a key accomplishment in light of the thousands of U.S. nuclear weapons awaiting dismantlement.

\section{Waste Treatment and Disposal Technologies}

Maintaining a clean environment demands new techniques for treating and disposing of hazardous waste. We have developed several alternatives to incineration, each optimized for a particular class of waste:

- Molten Salt Destruction. Working with Rockwell International (Los Angeles, California), we are developing a molten salt method to trap and destroy organic materials through pyrolysis and oxidation. Shredded organic waste (gloves, wipes, expended solvents, etc.) is fed into a bath of molten sodium carbonate salt. A combination of heat and controlled oxygen flow converts the waste into carbon dioxide gas and water vapor. Toxic heavy metals remain behind in the molten salt, and a recycle system periodically removes the trapped metals and returns the salt to the system for reuse. This process is very promising for the quantities of medical waste now being incinerated as well as for industrial and military wastes. This year, we demonstrated this technology with toxic and high-explosive wastes.

- Mediated Electrochemical Oxidation. For highly toxic organics, we developed mediated electrochemical oxidation. In this aqueous, room-temperature process, silver and cobalt ions are generated in an electrochemical cell; these ions are extremely effective at decomposing organic compounds. Organic waste is converted into carbon dioxide gas and water vapor that, after treatment, can be safely vented to the atmosphere. In 1993, we demonstrated very high destruction factors with nominally $>99.99 \%$ destruction of several common organic materials. This process is well suited for treating wastewater and for removing toxic organics from contaminated equipment.

- Photolytic Destruction. Photolytic destruction combines ultraviolet (UV) light and hydrogen peroxide $\left(\mathrm{H}_{2} \mathrm{O}_{2}\right)$ to destroy trace organic compounds present in wastewater streams. The resulting clean effluent streams can be released without further treatment. We have been working with Purus, Inc. (San Jose, California) to develop high-efficiency, short-wavelength UV lamps that greatly reduce electric power demand, improving the process economics. - Measurement and Characterization. Many technologies are under development for characterizing waste streams, including "smart" systems for recognizing and sorting waste, tomographic techniques for noninvasive measurements of waste drum contents, and advanced radiation detector systems for verifying

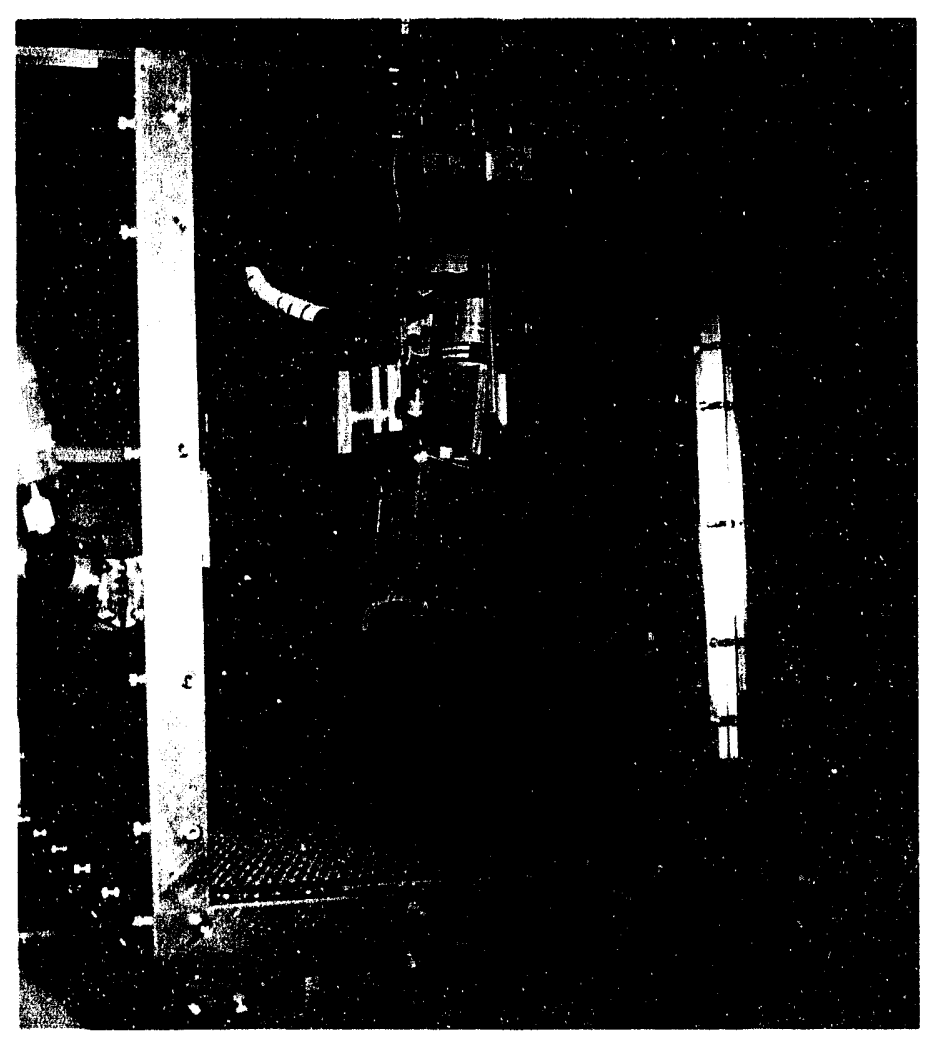

plutonium and uranium concentrations in wastes.

- Waste Treatment. During this past year, we performed significant technical demonstrations in waste treatment. For example, working with scientists from the Institute for Catalysis (Novosibirsk, Russia), we tested at LLNL a catalytic nitrogen oxide $\left(\mathrm{NO}_{\mathrm{x}}\right)$ converter using a novel ceramic catalyst that operates more efficiently and at lower temperatures than conventional converters. This technology could yield large savings to industries needing $\mathrm{NO}_{\mathrm{x}}$ emission controls. In another project, we are working with scientists at the Institute for High Current Electronics (Tomsk, Russia) to develop high-efficiency UV lamps for wastewater cleanup that are twice as efficient as commercially available lamps, which should greatly reduce treatment costs.

For future waste disposal, we are developing sintered ceramic waste encapsulation as an alternative to cement, which is currently used in the DOE

\author{
We have developed \\ robotic systems for \\ manufacturing \\ operations and waste \\ handling operations \\ (such as scrap \\ sorting). Robotics \\ reduce the danger of \\ radiation exposure \\ and injury to human \\ workers.
}


complex. Ceramics under development include oxides, oxide-sulfides, and reactionbonded phosphates, formed into $1-\mathrm{cm}$-sized pellets. These advanced waste forms are designed to encapsulate the waste in the ceramic, preventing toxic and radioactive compounds from leaching into the environment for very long periods of time.

\section{Remediation and Restoration Technologies}

Current techniques for environmental cleanup are often expensive and slow. We are developing new techniques for cleanup and monitoring that are more effective, faster, and less costly than previous methods.

- Microbial Filter. Bioremediation takes advantage of natural bacteria already in the ground to digest and dispose of toxic materials. We have constructed in the laboratory a subsurface barrier of microbes to prevent the spread of ground contamination. The bacteria have been injected in a line of wells around a spill site; as contaminants encounter this microbial filter, they are metabolized and, in the process, decomposed by the bacteria. Downstream sampling has confirmed that the microbial filter does indeed halt the contaminants' spread.

- Dynamic Underground Stripping. Developed jointly by scientists from UC Berkeley and LLNL, this technique combines steam and electrical currents to heat contaminated soils and force contaminants out of the ground. Collection wells channel the contaminants to the surface, where they are treated and disposed of. An underground imaging method called electrical resistance tomography is used to monitor and control the process. In 1993, we used dynamic underground stripping to clean up a spill of tens of thousands of liters of gasoline that had leaked many years ago from underground tanks. In this demonstration experiment, some 30,000 liters of gasoline were removed

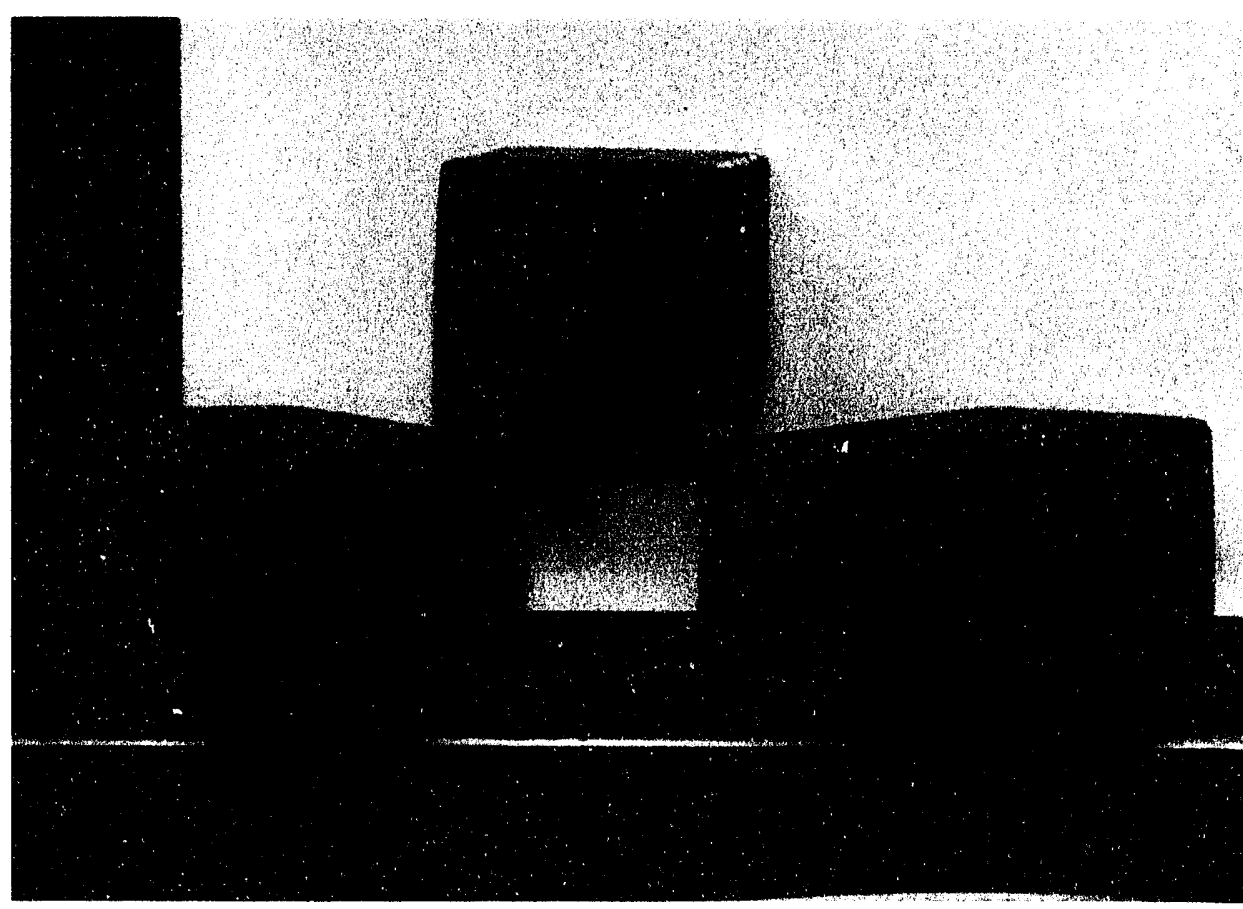

Working with scientists from the Institute for Cataiysis in Novosibirsk, Russia, we tested at $L L N L$ a catalytic nitrogen oxide $\left(N O_{x}\right)$ converter that operates more efficiently and at lower temperatures than conventional converters.

from $600,000 \mathrm{~m}^{3}$ of soil at depths ranging from 20 to $45 \mathrm{~m}$. This cleanup took a few months instead of the decades estimated for traditional processes. We are exploring the use of this technique to clean up chlorinated solvents, like trichloroethylene (TCE) and perchloroethane (PCE). This technique may also be suitable for cleaning up contaminated soil at military bases and industrial sites.

- Fiber-Optic Sensors. We are developing new techniques for measuring underground contaminants. Today, groundwater samples must be drawn from a well, transported to an analytical laboratory, and measured with complex and expensive instruments. Our new approach uses an optical fiber that is driven into the ground with a device called a penetrometer; the aboveground end of the fiber is then connected to a briefcase-sized instrument that quickly measures and displays the presence (or absence) of contaminants in the subsurface water. Also in 1993, we combined fiber optics with molecular spectroscopy to monitor underground contaminants; the fiber sensors, inserted into wells, provide a continuous measurement of underground contamination and are cheaper and more effective than conventional sampling techniques.

\section{Mixed Waste Management Facility}

A major environmental issue is the handling, transport, treatment, and disposal of mixed wastes (wastes containing both radioactive and toxic substances). The DOE complex has no operational treatment or permanent disposal capability for these wastes. To meet this need, we are designing a pilot facility to demonstrate integrated, end-to-end treatment of mixed waste. The facility will process samples of LLNL mixed wastes and will operate under conditions as close as possible to those of a production plant. In addition to demonstrating the destruction of organic mixed wastes, we will also develop and demonstrate systems and processes for waste fuel preparation, material transport, 
aqueous treatment, off-gas treatment, and ceramic final forms. Technologies developed both at LLNL and elsewhere will be tested and evaluated. An existing building at the LLNL site has been assigned for this facility.

\section{Technology Integration}

Often, we must combine various technologies and integrate our efforts with those outside the Laboratory to address specific needs at LLNL, other DOE sites, military bases, state and federal agencies, and private industry.

- Commercialization of Environmental Technologies. We are commercializing many of our innovative environmental technologies through partnerships with private companies, especially small businesses. In 1993, we successfully transferred to private industry a fiberoptic sensor and an electron-beam waste-destruction process.

- Risk Assessments. It is widely recognized that the cleanup of contaminated sites needs to take place on a risk-prioritized basis. However, this process is hampered by a lack of credible risk-assessment methodologies. We are developing verifiable risk-assessment methodologies and are applying them to contaminated DOE sites and to mixed-waste treatment technologies. The first two mixed-waste treatment processes, which we are assessing for the DOE Mixed Waste Integrated Program, are the plasma hearth and joule melter processes. In 1993, we completed a Preliminary Hazards Analysis of the plasma hearth process.

- Decision-Support Systems. We are developing on-line decision-support systems that can be used at a single monitoring station by decision-makers responsible for the restoration of contaminated sites. These integrated online systems include modules for relational databases, statistical analyses, flow and transport models, well-location

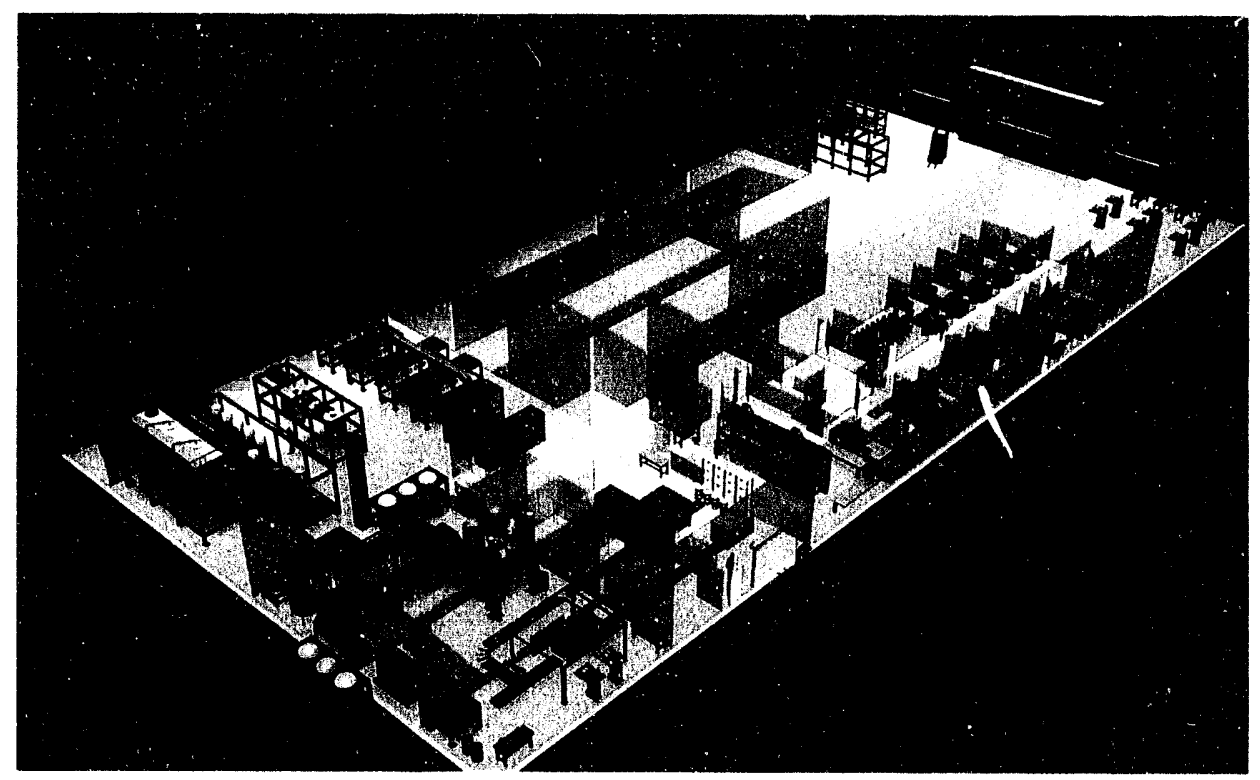

We are designing a pilot facility to demonstrate integrated end-to-end treatment of mixed waste. In 1993, we received official approval from the DOE to proceed with the project.

models, risk-assessment models, and three-dimensional graphics.

\section{- Partnership for Environmental} Technology Education (PETE). This program was developed to link the technical resources of the national laboratories and the private sector with regional community colleges to improve the teaching of environmental science and technology. PETE is a permanent partnership among government, industry, and academia; current government participants include the DOE national laboratories, the Nevada Test Site, and regional EPA, NASA, and DOD facilities. Initially limited to the five western states, the program is now being extended nationwide. Currently, 29 of the 107 California community colleges are actively participating in PETE and offer environmental/hazardous materials technician certificate and degree programs.

\section{Summary}

Preserving the environment is a major challenge facing the U.S. Continuing studies into the dynamic, interrelated forces affecting the global environment are essential to predict accurately the effects of human activities. Correcting the adverse environmental consequences of past activities will require expertise and ingenuity from institutions like LLNL to develop and demonstrate new technologies. Similar attention needs to be given to altering processes and procedures to prevent further environmental damage.

We are developing and demonstrating a wide range of new technologies for waste minimization and management and for environmental restoration and monitoring. Many of these technologies are making their way into the commercial sector as we collaborate with U.S. industries. Our goal is not only to contribute to the nationwide effort to clean up the environment but also to develop better ways to manufacture products. In this way, environmental technology will become an economic asset, making the U.S. environmentally clean and economically competitive.

\section{For further information contact} Harold C. Graboske (510) 422-7264 or Ann C. Heywood (510) 422-8203. 


\title{
ronmental Kestoration, Protection,

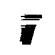 aste Management
}

\author{
LLNL is faced with the challenge of cleaning up contamination from past activities while \\ ensuring that current projects and practices do not adversely affect the environment.
}

OR more than 50 years, the LLNL site has been the locale of activities that result in waste byproducts, first as a Naval Air Station during World War II and then, for the last 40-some years, as the site of intensive $R \& D$ activities. During the earlier decades, there was little awareness, either at the site or in the world at large, of the environmental and potential health impacts of many of those activities and their byproducts. As a consequence, part of the Laboratory's resources must now be devoted to cleaning up the contamination from past activities and eliminating or

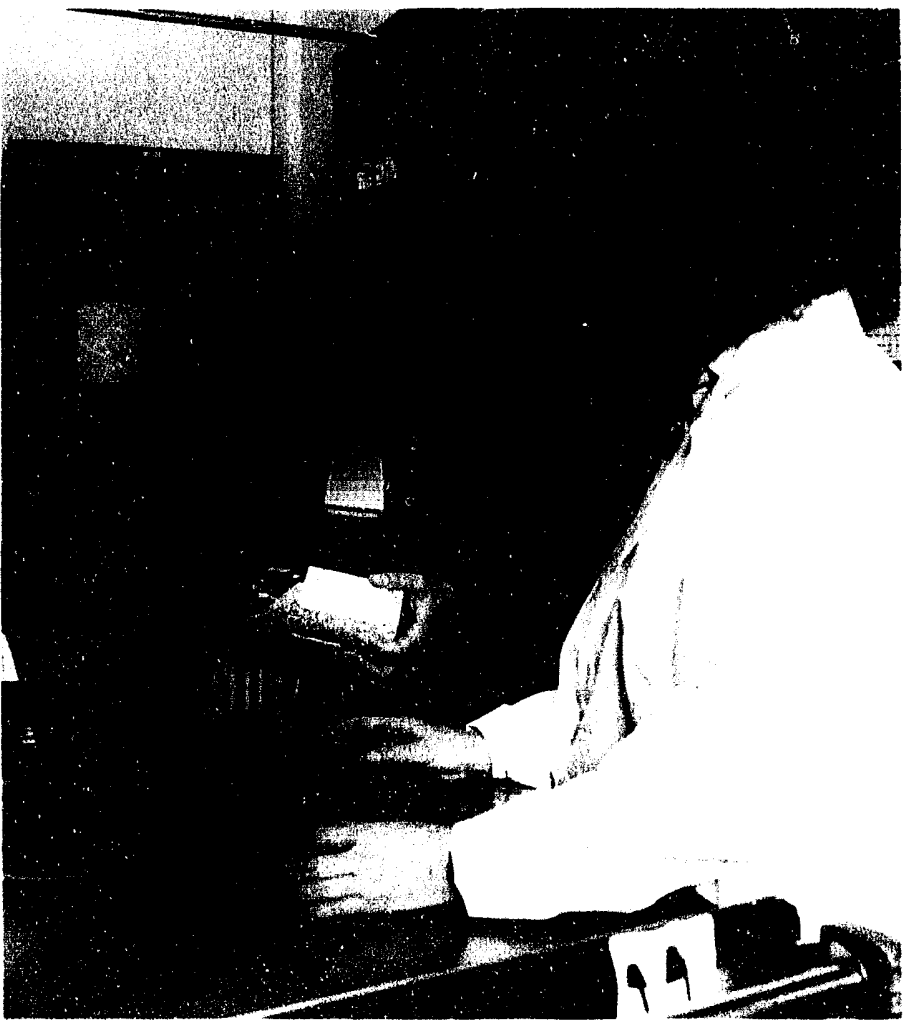

minimizing the unwanted effects of current activities. (These efforts are also applicable to activities outside LLNL, particularly in other government and industrial institutions where R\&D and production activities use processes and materials similar to those used at the Laboratory.) Specifically, we are:

- Developing day-to-day practices and technologies that minimize the amount of waste generated.

- Designing and applying cost-effective technologies for site restoration and remediation.

- Conducting local and regional environmental monitoring for both the Livermore site and Site 300.

- Designing and applying cost-effective means of managing hazardous and radioactive waste.

\section{Waste Minimization}

One way to reduce the amount of waste that must be treated and disposed of is not to generate the waste in the first place. To this end, we evaluate laboratory activities, both highly technical and routine, to determine if alternative procedures or chemicals can be used that will reduce the amount of waste generated. We also provide technical assistance, information exchange networks, new product testing, policy analysis, and reports detailing the progress of waste minimization planning and accomplishments to help the Laboratory reach its waste minimization goals. Many waste minimization 
technologies have been successfully implemented throughout the Laboratory.

\section{Tracking Chemicals}

Almost all activities at LLNL use chemicals of one kind or another, and many of them are reactive or toxic. It is essential that we maintain an up-to-date inventory of the chemicals in use or in storage at the Laboratory. This information is essential for emergency response (such as in the event of an earthquake or accident), both for the safety of the emergency response personnel and for proper treatment of the chemicals involved. The information is also needed to meet regulatory reporting requirements and to efficiently manage LLNL's chemical inventory.

We are implementing a computerized chemical tracking and Material Safety Data Sheet systern called ChemTrack. This system, which uses a barcode scanner to enter and read chemical inventory information, is uniquely designed to provide portability, local control over chemical inventories, and flexibility. ChemTrack will provide real-time chemical inventory data for emergency response and for preparing chemical inventory reports for regulatory agencies. It will expand our ability to identify and exchange excess chemicals, thus reducing the need to procure and store additional chemicals and minimizing the generation and disposal of hazardous waste.

\section{Alternative Solvents}

In response to regulatory and DOE directives to minimize the use of and exposure to hazardous solvents, we have evaluated approximately 50 "environmentally compliant" solvents. We are assessing the performance of these solvents in numerous applications (such as cleaning oil and grease, lapping compounds, resins, inks, and composite printed wire boards) throughout the Laboratory. An integral element of this Alternative Solvents Project is evaluating quantitative methods of determining cleanliness at a microscopic level using Fourier-transform reflective infrared spectroscopy and optical image analysis. We have also developed a unique association with private industry groups to provide them access to the sophisticated instrumentation required to evaluate cleanliness. We recently launched a collaborative effort with TRW Inc., to evaluate cleaning standards for loaded printed circuit boards for aerospace applications. Several other aerospace companies have also expressed interest in collaborating on this project.

\section{Restoration and Remediation}

A major task of restoration at LLNL is the cleanup of contaminated groundwater. (Gasoline and volatile organic compounds from past activities at the Laboratory site, some dating from the 1940s when the site was used as a Naval Air Station, have seeped into the soil and contaminated groundwater.) We have investigated various cleanup methods and have built and operated a number of facilities for extracting and treating contaminated groundwater. One method combines ultraviolet light and hydrogen peroxide

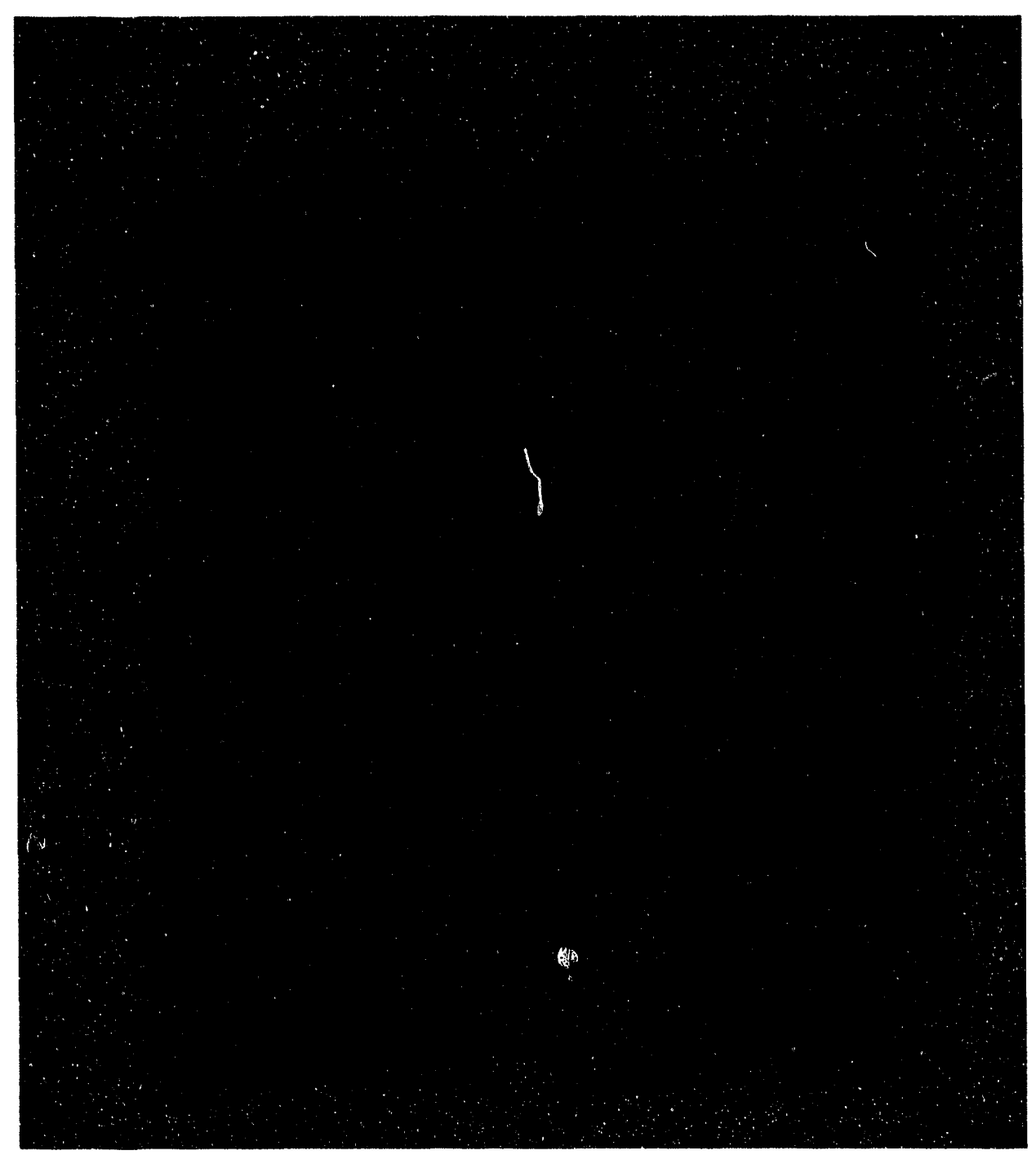


to destroy volatile organic compounds in the water. We have used this method to treat more than 272 million liters of groundwater from under the Laboratory site since 1989 and have successfully halted the migration of the contaminants off-site.

Another cleanup method, called dynamic underground stripping, uses electricity and injected steam to heat the soil and release the contaminants so they can be extracted. In 1993, we applied this new technique to an area where, in the 1970s, gasoline had leaked into the ground. We treated some 4 million liters of contaminated groundwater, extracting 28,000 liters of gasoline. A third of the fuel was condensed for recycling; the rest ran two V-8 engines that provided the vacuum to extract the gasoline vapor. This demonstration experiment took a few months to remove the gasoline instead of the decades required using conventional technologies.

\section{Smart Pump and Treat}

Conventional pump-and-treat cleanup methods are slow and ineffective, primarily because of unrealistic expectations that contaminants, trapped underground for decades, can be removed quickly and inexpensively. We are working to optimize pump-and-treat techniques to significantly improve speed and efficiency. This "smart" pump-and-treat approach requires:

- A detailed understanding of the groundwater flow and the distribution, transport, and fate of the contaminants. - A strategy to control the contamination plume's spread and to remove the source of contaminants.

- Efficient placement and phasing in of the extraction wells.

- Use of enough monitoring wells to carefully track cleanup progress.

- Active management of the extraction well field.

This last feature is particularly important. In most pump-and-treat remediations, some contaminants remain in stagnant areas, which extends the cleanup time. The "smart" method involves identifying these stagnant areas and placing wells within them, selectively pumping at different locations and periodically reviewing the

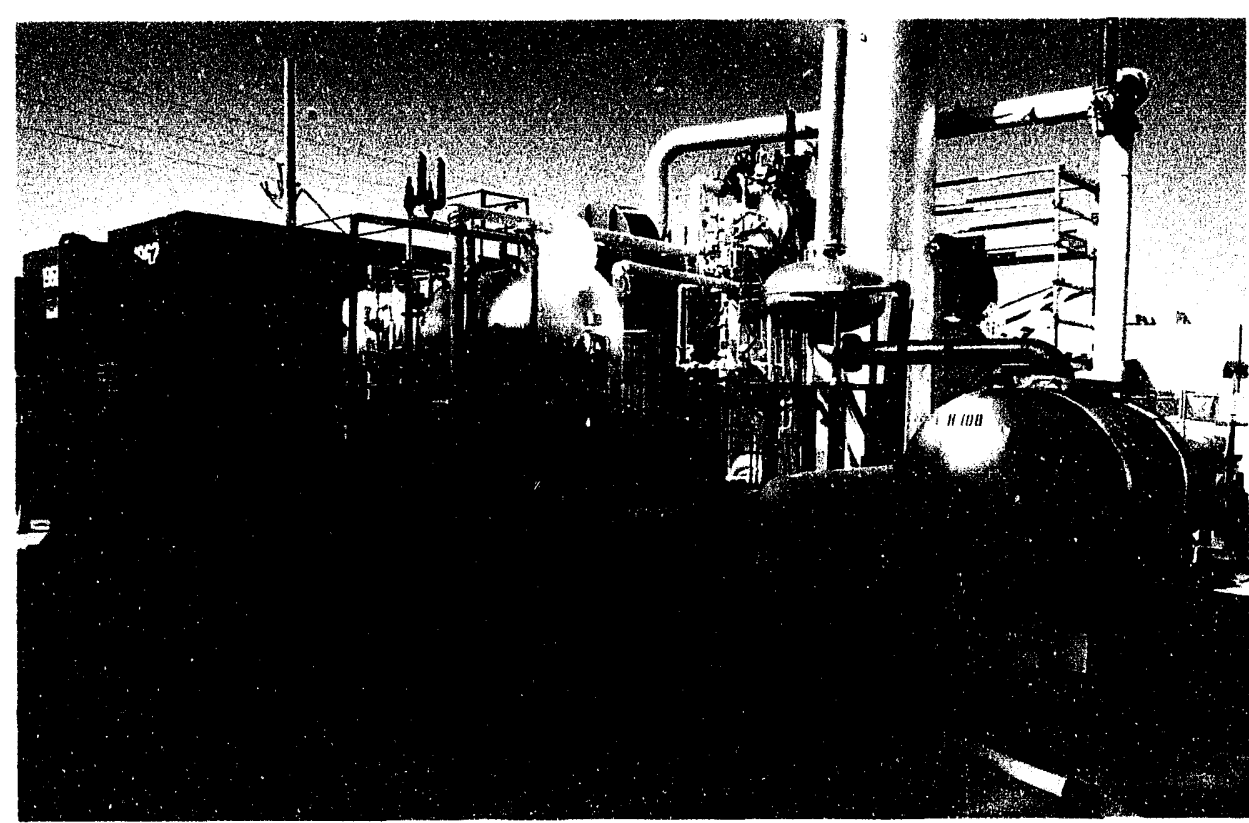

A recent addition to our on-site restoration effort is Treatment Facility $F$, which hosted demonstration experiments of dynamic underground stripping.

results, and changing pumping locations and/or rates according to findings.

We have begun using artificial neural networks (ANNs) to further increase the extractive efficiency of smart pump and treat. Once trained by being presented with thousands of examples drawn from actual runs of conventional flow-andtransport models, ANNs take only seconds to predict a result. (Conventional flowand-transport models take several minutes to hours to generate a result.) The speed of the ANNs lets us explore millions of alternatives to identify the optimum setup. For example, we ran a computer-aided design exercise using real LLNL well locations and estimated remediation costs. We randomly selected 27 extraction wells and three injection wells from a total grid of 199, determined each well's maximum pump rate on the basis of the hydrogeological characteristics of its location, and then varied the possible pumping rates. An ANN search through the possible operating combinations found that the simulated optimum number of extraction wells needed was 8 (not 27), thus lowering the estimated remediation costs over 50 years from $\$ 300$ million to less than $\$ 50$ million.

\section{Subsurface Imaging}

To optimize the cleanup of contaminated groundwater, we must define, in three dimensions, the spatial distribution of sediment types and subsurface geologic features. Working with Resolution Resources, Inc. (Palmdale, California) and Rutter and Wilbanks Corp. (Midland, Texas), we used new high-resolution, three-dimensional, seismic-reflection methods to conduct a shallow survey (<100 m) at LLNL's detailed study area (an area highly characterized by two dozen closely spaced boreholes). These new methods were validated as we used them to identify buried stream channels, delineate contaminant pathways, and map the channels spreading out from the study area. In addition, we were able to gather 
information on the three-dimensional spatial distribution of contaminant migration pathways not available from two-dimensional seismic or borehole data, allowing us to reduce the number of wells needed for the groundwater cleanup.

\section{Modeling Extraction Well Placement}

We have also developed an interactive software package called PLANET (a Pump Layout and Evaluation Tool) that enables the user to rapidly evaluate many pump-andtreat scenarios. PLANET collects, stores, retrieves, and images both field and model data and provides a graphical interface that is simple, intuitive, and map-oriented. Used together with flow- and transport-modeling software, PLANET makes it possible to "watch" contaminant distributions over time and to "test" remediation alternatives, all without dealing with such technical details as model interaction, parameterization, and data management. PLANET allows a user to easily add, delete, adjust, or relocate wells and to change pumping rates to make flow-field adjustments. PLANET can display simultaneously several overlays, including a feature site map, model grids, well locations and status, and contaminant plume and flow field visualizations. In response to numerous industry and government requests, we will commercialize this software.

\section{Vadose Zone Investigations}

Most of our remediation activities involve characterizing or cleaning up the vadose zone-a subsurface interval of soil or rock lying above the groundwater. The contaminants of chief interest to us are volatile organic compounds. Migration of water and contaminants within the vadose zone involves complex processes that are not completely understood. To understand these processes and to predict contaminant movement, we use quantitative models. We have developed a new three-dimensional finite-difference code, called NUFT, that quantitatively solves the balance equations for water, air, contaminants, and energy. NUFT simulates fluid transport through the ground surface, the vadose zone, the capillary fringe, the water table, and the saturated zone. NUFT even has an option for evaluating nonisothermal remediation techniques, such as methods that involve vadose-zone heating (as in dynamic underground stripping). We have begun a program of quantitative modeling, field studies, and laboratory measurements to validate NUFT.

\section{Monitoring and Analysis}

In order to clean up existing contamination and to eliminate or minimize new contamination resulting from current Laboratory activities, we need accurate measurement and monitoring techniques. LLNL maintains a surveillance network that can detect any significant release of contaminants from the site. As part of this ongoing surveillance, we analyzed more than 50,000 samples last year and demonstrated that the impact of LLNL's current activities on local health and safety is far below all regulatory limits.

\section{Analytical Methods}

Tritium is an isotope of hydrogen that is central to significant research activities at LLNL (for example, tritium is a component of the fuel within the targets used in our laser fusion work). Therefore, we monitor the immediate environment with extreme sensitivity to detect any tritium. We recently developed a novel mass-spectrometric method for measuring tritium in environmental materials. The technique exploits the fact that tritium atoms decay to helium- 3 atoms by emitting beta particles. The sample is frozen under vacuum, and all helium is removed. After a measured time, the samples are refrozen, and the helium- 3 that has built up from tritium decay is collected. We measure the helium-3 with mass spectrometry; from that measurement and the elapsed time between the two freezings, we calculate the original amount of tritium in the sample. This technique is thousands of times more sensitive than conventional methods, allowing tritium to be monitored at extremely low concentrations.

Measuring environmental concentrations of radioactive elements requires that we deal with natural background radiation. We are applying a new signal-processing technique that significantly increases the sensitivity and selectivity of the detector counter, providing discrimination with unprecedented sensitivity between the lowenergy emissions of tritium and carbon-14 (a naturally occurring radioisotope used in dating materials) and the high-energy background.

\section{Sewer Monitoring System}

The Laboratory's continuous sewer monitoring system monitors flow, $\mathrm{pH}$, metals, and radioactivity as sewage is discharged to the City of Livermore collection system. LLNL developed the flow-through technology that allows continuous, on-line analysis. Readings of metals and radiation are monitored every 5 minutes. Metals are analyzed by $\mathrm{x}$-ray fluorescence spectroscopy. Radioactivity is monitored by ? liquid-nitrogen-cooled, germanium solid-state detector. Gammaemitting radioisotopes are detected by the identification of specific radionuclides, and transuranics are detected by the identification of $x$-ray emissions from daughter radionuclides. If any of these materials are detected above allowable limits, the sewage is diverted into on-site holding tanks, where it is treated; flow to the sanitary sewer is resumed only after ensuring that all discharges are within the allowable limits. During 1993, LLNL's wastewater controls prevented any releases to the sanitary sewer above our permitted discharge limits.

Also in 1993, we began improving the system's useful life by adopting standard data and user interfaces and architectures that will maximize the speed of analysis 
and data throughput rate. Future upgrades will include data telemetry for remote access to system status.

\section{Hazardous Waste Management}

Even with rigorous waste-minimization efforts in effect, LLNL cannot entirely avoid producing some hazardous waste. Thus, we continually work to develop and improve methods for managing these wastes to assure that the environmental impact of these byproducts is as negligible as possible.

\section{Treating Spent Radioactive Coolants}

During machining on a lathe or other cutting equipment, coolants keep both the workpiece and the cutting tool from overheating. Most such coolants at LLNL are water-based and contain ethanolamines that maintain an emulsion of lubricating oils and water. The emulsion carries away metal turnings from the machining. Spent coolant contains chlorosolvents from cutting, cleaning, and polishing operations, as well as oil from machine bearings. All of these, as well as any radioactive material from the workpiece, are removed when the coolant is processed.

LLNL effluents must meet regulations for sanitary sewer discharge limits and criteria for land-based disposal of hazardous and mixed wastes. We use industrial waste treatment and in situ carbon adsorption to separate the radioactive and hazardous contaminants from the wastewater. First, hydrogen peroxide is added to the wastewater to maximize the oxidation of dissolved metals, which facilitates precipitation, and to minimize solubility of the precipitates; the hydrogen peroxide also cleaves the bonds of more complex organic molecules, which helps to reduce clogging during filtration. Ferric sulfate is then added to loosely aggregate the oxidized metals so that, when precipitated, they will not pass through the filter. The oxidized metals are precipitated with sodium hydroxide. The precipitate is filtered with a rotary drum vacuum filter. Solvents and oils (essentially,

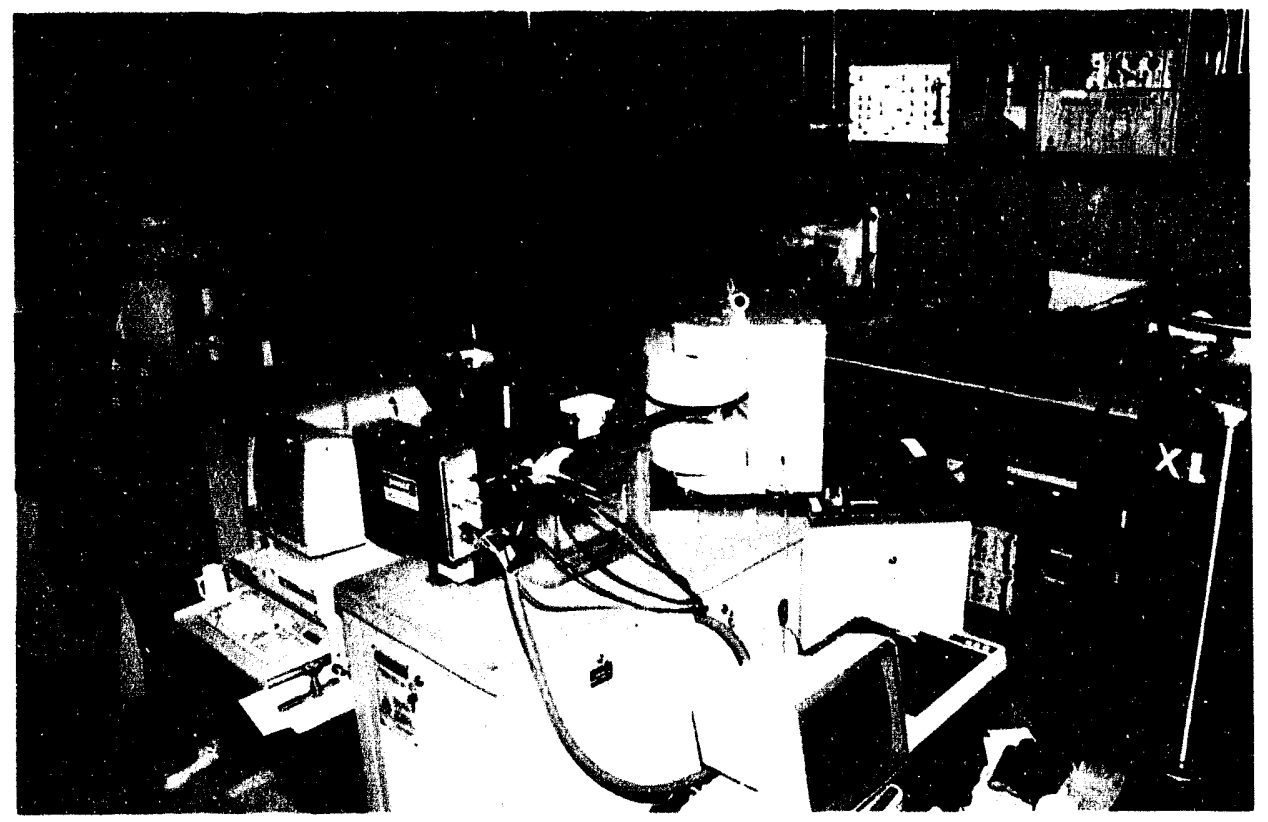

We use helium. 3 mass spectrometry to monitor for tritium. This technique is thousands of times more sensitive than conventional methods, allowing us to measure tritium at extremely low concentrations.

organic molecules) are removed from the wastewater by powdered-activated carbon, which has a large, very porous surface area. The organic molecules are adsorbed within the pores of the activated carbon, and the carbon is filtered out. The treated wastewater is then analyzed; when it meets sanitary sewer limits, it can be discharged. The residue trapped on the filter is stabilized for disposal-that is, treated and packaged so that hazardous constituents cannot leach into the environment.

\section{Stabilizing Filter Residues}

Various processes throughout the Laboratory produce waste byproducts that must be isolated by passing through rotary drum vacuum filters. The filter residue must then be stabilized for disposal. The residue consists primarily of diatomaceous earth (the filter medium) and hazardous and radioactive contaminants. If organics are adsorbed onto carbon, then spent carbon is also a contaminant.

For treatment, we use a modified version of a technique that the EPA has designated a Best Demonstrated Available Technology. This process is a means of providing a stable matrix for land disposal within current EPA regulations. Materials used to solidify or stabilize mixed, hazardous, or radioactive wastes range from plastics to bitumens to Portland cement. We are evaluating silicate-, sulfate-, and oxide-based materials (that is, clays) for optimum stabilization because they produce a minimal increase in total waste volume, are of uniform composition and reasonable cost, and have long-term performance records for use with radioactive wastes.

The primary clays that LLNL uses are natural clays for which the optimum clayto-waste ratios must be determined in the laboratory for each new waste type. The mixing is key to the stabilization process. We use a double planetary mixer that folds the waste material into itself for uniform 
mixing. Properly mixed, the clays can hydrate and adsorb hazardous constituents. The hydrated clays become stronger as they are left standing undisturbed, and they capture metals in their structure, preventing the metals from leaching into the environment.

\section{Decontamination and Waste Treatment Facility \\ LLNL's current waste treatment and} storage facilities are distributed throughout the site. We are upgrading these aging facilities with a more consolidated Decontamination and Waste Treatment Facility capable of handling the Laboratory's "legacy wastes." Design work began in 1993, and construction is scheduled to begin in 1995. There will be separate buildings for receiving, classifying, and processing solid waste as well as for reactive materials processing, radioactive and clean storage, chemical waste storage, and operational support. The wastetreatment building will be the largest and will house the largest number of operations, including treatment of mixed aqueous waste and organic solvents. We plan to automate process control and monitoring systems with some robotic operations.

\section{International Environmental Training}

LLNL is a world leader in technologies for environmental restoration. We have provided training in remediation technologies both in the U.S. and overseas. Our training promotes the transfer of U.S. environmental technology to European markets and facilitates partnerships with European scientists and engineers. In 1989. at the Ettore Majorana Centre for Scientific Culture (Erice, Sicily) we founded the International School of Innovative Technology for Cleaning the Environment.

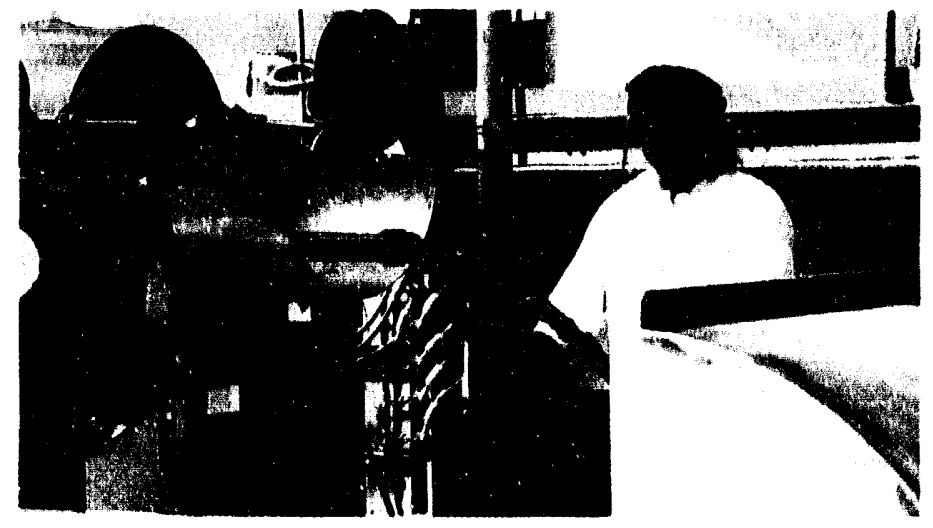

Spent coolant is poured into a tank for chemical precipitation, after which it will be filtered. The filter residue consists of diatomaceous earth with trapped contaminants. In each dish (bottom photograph), a different substance is

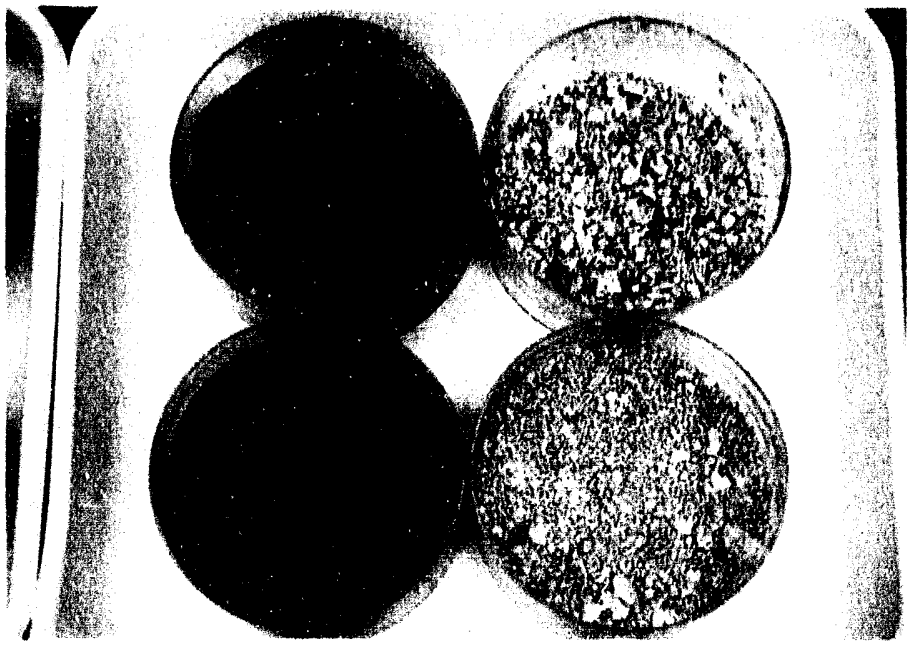
prevalent; clockwise from top left: iron salts (deep orange), organics trapped in carbon (gray), iron (tan), and nickel from treated industrial waste water (dark brown).
We have also organized several international events:

- The International Course on Innovative Cleanup of Contaminated Soils and Groundwater (Erice, Sicily, 1990). - The International Conference on Innovative Technologies for Cleaning the Environment: Air, Water, and Soil (Erice, Sicily, 1992).

- The Eurocourse on Technologies for Environmental Cleanup: Soils and Groundwater, at the Commission of the European Communities Joint Research Centre (Ispra, Italy, 1992).

- The UCLA Extension Engineering and Computer Science Short Course, Soil and Groundwater Remediation (given annually, coordinated by LLNL).
Summary

We are working vigorously to eliminate the environmentally harmful effects of past activities at the LLNL site and to minimize such effects from current activities. We are advancing our capabilities on all fronts, from finding ways to reduce the production of waste and to clean up the site, to devising ever more sensitive methods of detection and measurement. To these ends, we are designing or adapting varieties of hardware, implementing the use of artificial neural networks, and finding more efficient ways to apply our expertise.

\section{For further information contact Ellen Raber (510) 422-3985.}


Researchers at $L L N L$ are working to develop energy sources and energy-use technologies that are environmentally and economically attractive. These technologies are being developed with and transferred to U.S. industry for commercialization. We are also addressing energy issues that are beyond industry's normal planning horizon.

y concepts could help put on the road. At left are

Noring and metallurgist with a prototype of a new At right is physicist with a model of the ig for an electromechanical

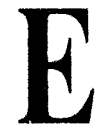

NERGY security is essential to the economic health and national security of the United States. The Laboratory's energy-related work focuses on two dominant U.S. energy needs. First, for electric power generation that does not rely on fossil fuels, we are developing fusion, fission, and renewable energy technologies. Second, we are examining transportation alternatives to the use of Middle East oil, including new approaches for batteries and new technologies to maximize domestic resources. Specifically, we are:

- Developing new or alternative energy technologies to meet near-term energy needs.

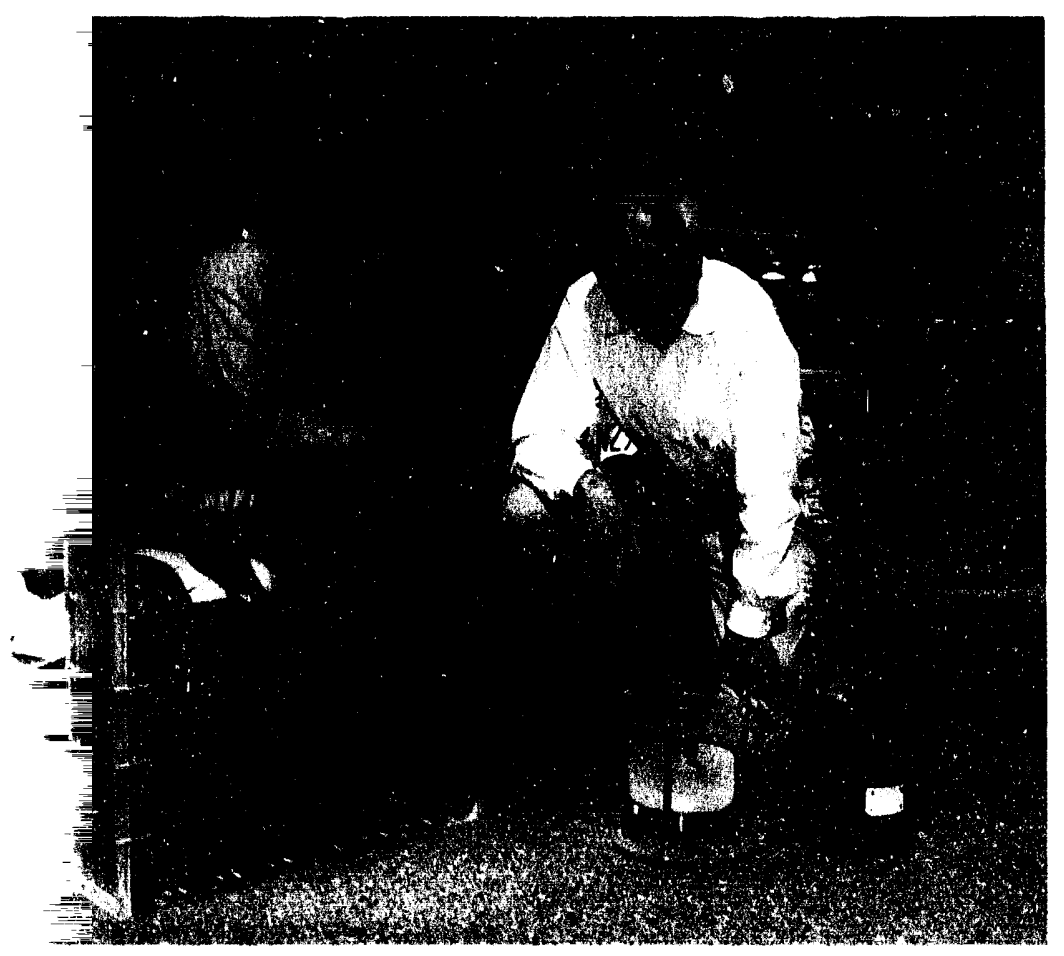

- Improving the environment, health, and safety related to nuclear power plants and other facilities.

- Continuing to develop magnetic fusion as an energy source for the 21 st century.

Our goal is to develop these technologies to provide reliable energy and stimulate economic growth while enhancing the environment. We are working with U.S. industry to demonstrate these technologies and ultimately to introduce them into the marketplace.

\section{Alternative Energy and Fossil Energy}

The economic security of the United States depends, in large part, on a secure and plentiful supply of fuel for transportation and industry. Currently, the nation relies almost exclusively on fossil fuels-coal, natural gas, gasoline, diesel fuel, and other petroleum products.

Although the hardships of the oil shortage of the mid-1970s are fading from memory, researchers at LLNL are pursuing a number of innovative concepts to free the U.S. from its dependence on Middle East oil.

\section{Advanced Battery Concepts}

Electric-powered vehicles have a great environmental advantage over vehicles powered by internal combustion enginesnamely, zero emissions. However, the lead/acid batteries used in the past to power electric vehicles also have several disadvantages, including low power, short range, short battery lifetime, and problems in disposing of the hazardous materials contained in the batteries. We are working on two separate approaches to energy 
storage that will avoid some of these disadvantages and could lead to commercially viable vehicles.

- The Electromechanical Battery. The electromechanical battery is based on the flywheel concept of energy storage. We are drawing upon a range of Laboratory expertise-from composite materials to magnets-to develop a device with high levels of power and energy storage, an extraordinary energy recovery efficiency of $95 \%$ (compared to electrochemical batteries, which typically have an energy recovery efficiency of 60 to $70 \%$ ), and a long lifetime, all without the use of hazardous materials. This battery is the first application of a Halbach magnetic array, a unique arrangement of permanent magnets, to function simultaneously as a generator and a motor and thus to accommodate both continuous recharging and power generation. One challenge in particular has been to develop concepts for simpler magnetic bearings that can suspend the flywheel within its vacuumsealed case. There are many potential applications for this electromechanical battery, from all-electric or hybrid-electric vehicles to load-leveling and powerconditioning for computers, sensitive equipment, and utilities.

- New Zinc/Air Battery. We have successfully tested a new zinc/air battery that converts $1-\mathrm{mm}$ particles of zinc combined with oxygen from the air to produce electricity at greater than $97 \%$ chemical conversion efficiency. Our novel approach solved a fundamental problem of zinc/air batteries by consuming all the zinc, without clogging or changes in electrical properties ovur time. (Other zinc/ air batteries consume only a small fraction of the zinc before clogging.) In 1993, we tested $600-\mathrm{cm}^{2}$ cells for up to 16 hours under simulated vehicle and road conditions. (The $600 \mathrm{~cm}^{2}$ is the area of the cell's air electrode; the greater the area, the more power produced.) We have now engineered and fabricated $1000-\mathrm{cm}^{2}$ bipolar cells for assembly into multicell stacks. Next year, we plan to test a 12-cell stack of zinc/air cells on board an electric bus. This test will establish energy and power characteristics as well as rapid refuelability as part of a hybrid power system with lead/acid batteries. We envision that, in the near term, zinc/air batteries could provide a practical power source for fixed-route vehicles, such as buses, vans, or industrial vehicles. Our final goal is to power general-purpose vehicles with a $400-\mathrm{km}$ range, 10-min refueling, and highway-safe acceleration, using a battery that can either be electrically recharged or refueled.

\section{Hydrogen as an Alternative Fuel}

We are also studying the potential of hydrogen as an alternative fuel. Hydrogen can be produced from a number of domestic sources, including renewable sources, and has many possible applications, including transportation. We have identified technical and economic rationales for accelerating a transition to hydrogen as a transportation fuel.

One of the major technical issues for the use of hydrogen as a transportation fuel is how to store the hydrogen on board a vehicle practically and safely. In 1993, we investigated several original approaches to solving this hydrogenstorage problem, including carbon aerogels, thermo-electrically cooled pressure vessels, and pressure vessels made of high-performance composites. Our analysis shows that a cryogenically cooled pressure vessel has favorable performance characteristics for using hydrogen in light-duty vehicles. Research will continue in developing advanced thermoelectric and other cooling devices for practical use. Measurements of carbon aerogels' characteristics indicate their promise as a high-density hydrogen storage medium. In addition, we are developing new fabrication methods and materials that permit glass microspheres

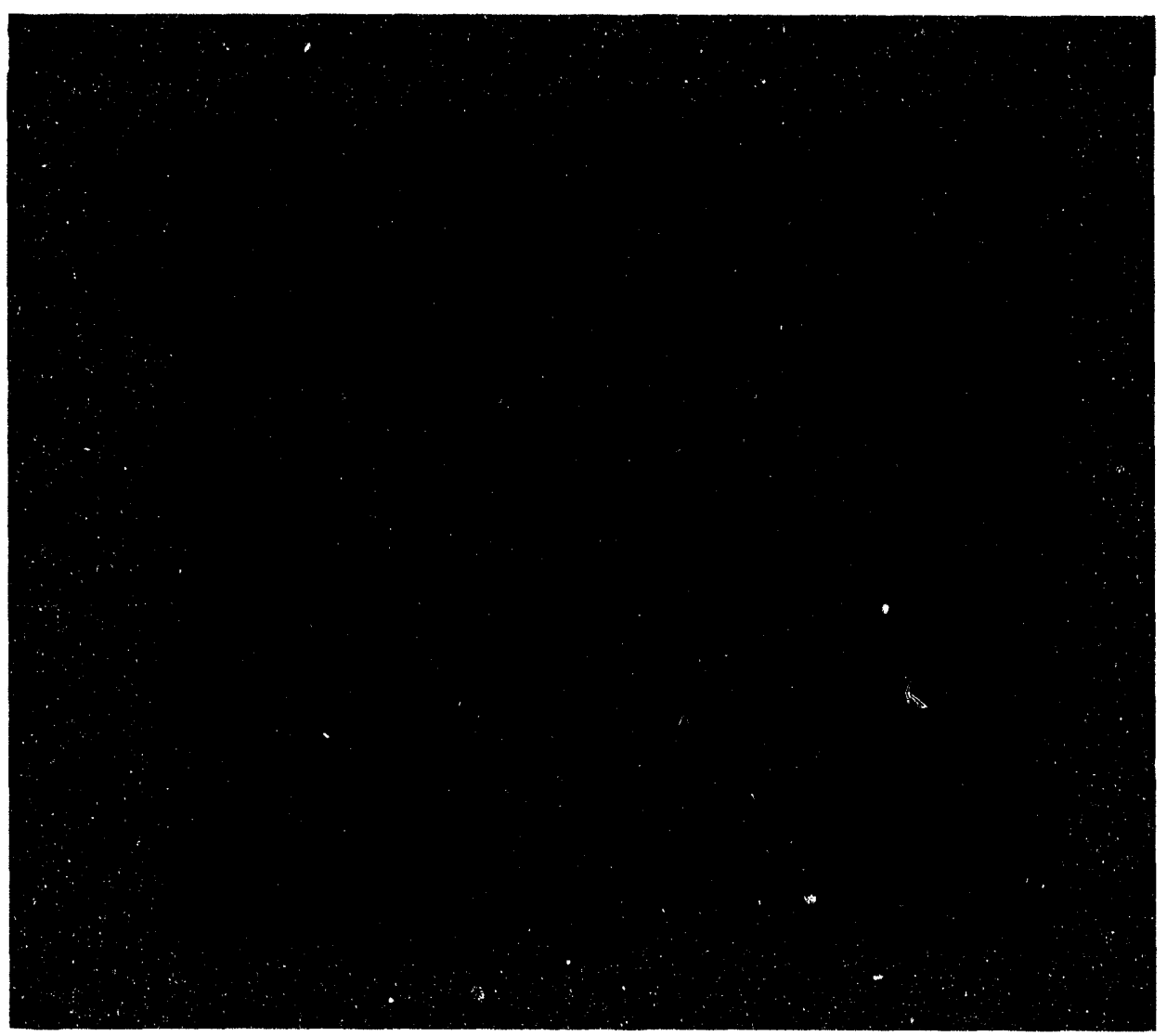


Michael J. Wilt, a Laboratory engineer, works in the field with diagnostics to image steam injected underground for enhanced oil recovery.

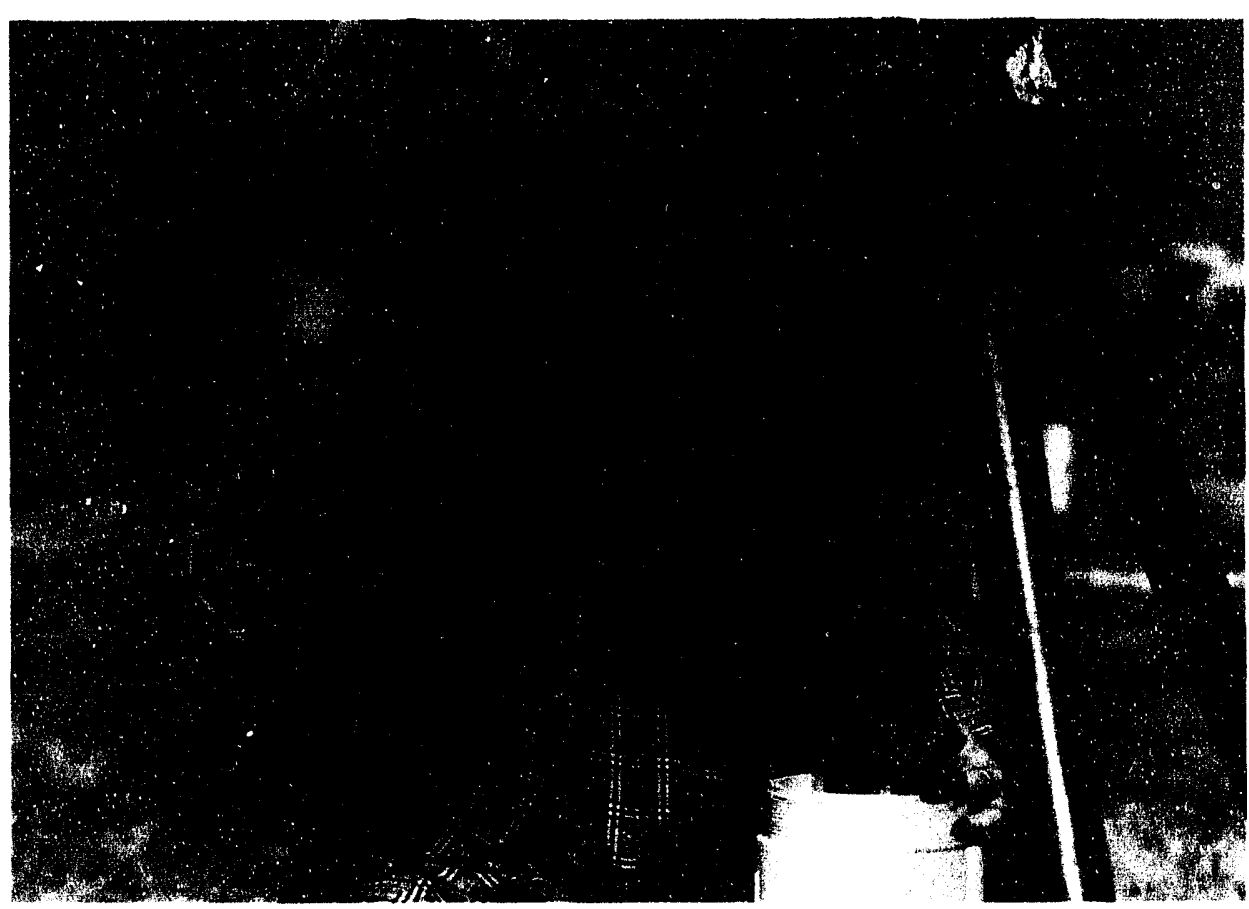

to be a practical method for the bulk transport of hydrogen.

\section{Oil Shale Retorting}

As a step toward tapping the energy resources of the vast oil-shale deposits in the western United States, we have explored advanced oil-shale retorting technologies by operating a 4-ton-per-day retorting facility on site at Livermore. We are testing the hot-recycled-solid process, in which raw shale is mixed with hot spent shale to reach the reaction temperature of $500^{\circ} \mathrm{C}$ within $1 \mathrm{~min}$. Each ton of shale produces about three-quarters of a barrel of oil. We have successfully demonstrated, in short-term tests, that certain types of hot vapor filters can remove all the dust from the oil. In addition, we have significantly increased our understanding of ways to reduce $\mathrm{NO}_{\mathrm{x}}$ emissions in the processing. This work has been partially supported by a CRADA with several U.S. oil companies.

\section{Oil-Field Tomography}

To enhance the recovery of oil, we are working on a tomographic technology 
oversight for compliance for the handling, transportation, and storage of nuclear materials. For example, we are performing criticality calculations to help DOE's two gaseous diffusion uranium enrichment plants operate safely. In addition, we are assisting the DOE's Office of Uranium Enrichment in developing technical inspection and verification processes to ensure that the low-level enriched uranium that the United States has recently purchased from Russia actually comes from highly enriched uranium from dismantled Russian nuclear weapons. Also in 1993, we estimated the radioactivity and the level of contamination from naval reactors that the former Soviet Union dumped into the Kara Sea.

We are working with the Nuclear Regulatory Commission to provide technical consulting to Ukraine for establishing a regulatory framework for the transportation and storage of nuclear materials. With the breakup of the Soviet Union, Ukraine can no longer ship the spent fuel from its operating reactors to Russia. Therefore, it is in the process of developing safety regulations for handling and storing nuclear materials within Ukrainian boundaries.

\section{Yucca Mountain Repository}

We continue to work with the DOE in studies for a potential permanent repository for high-level radioactive waste at the Yucca Mountain site in southern Nevada. (U.S. law mandates a mined geological disposal system for the waste.) We are responsible for establishing the scientific bases for the design of the waste package. Central to this effort is a determination of the surrounding geologic environment that can affect the performance of the waste package. We continue to explore the "extended-dry" concept that we developed-a unique method using the heat released from the radioactive decay of the nuclear waste to keep moisture away from the waste package for tens of thousands of years. This revolutionary concept in disposal strategy and repository design could result in significant cost savings, improved performance, and greater public and scientific acceptance of the potential Yucca Mountain site.

We are also preparing to conduct an above-ground test of a large block of the repository host rock. The block will be heated and stressed at the Yucca Mountain site to simulate the pressures that the rock 1000 feet deep will undergo when it is subjected to heat from the buried nuclear waste. This testing will allow us to study the effects of stress, hydrology, and geochemical changes several years ahead of when we can do such tests underground; it will also enable us to validate the codes and models used in the evaluations of various wasteemplacement scenarios, including the extended-dry storage concept.

\section{Nuclear Facility Security}

We also provide support to the DOE to meet security requirements at LLNL and other DOE energy-related facilities.

Argus is an interconnected computerbased personnel-access system that serves

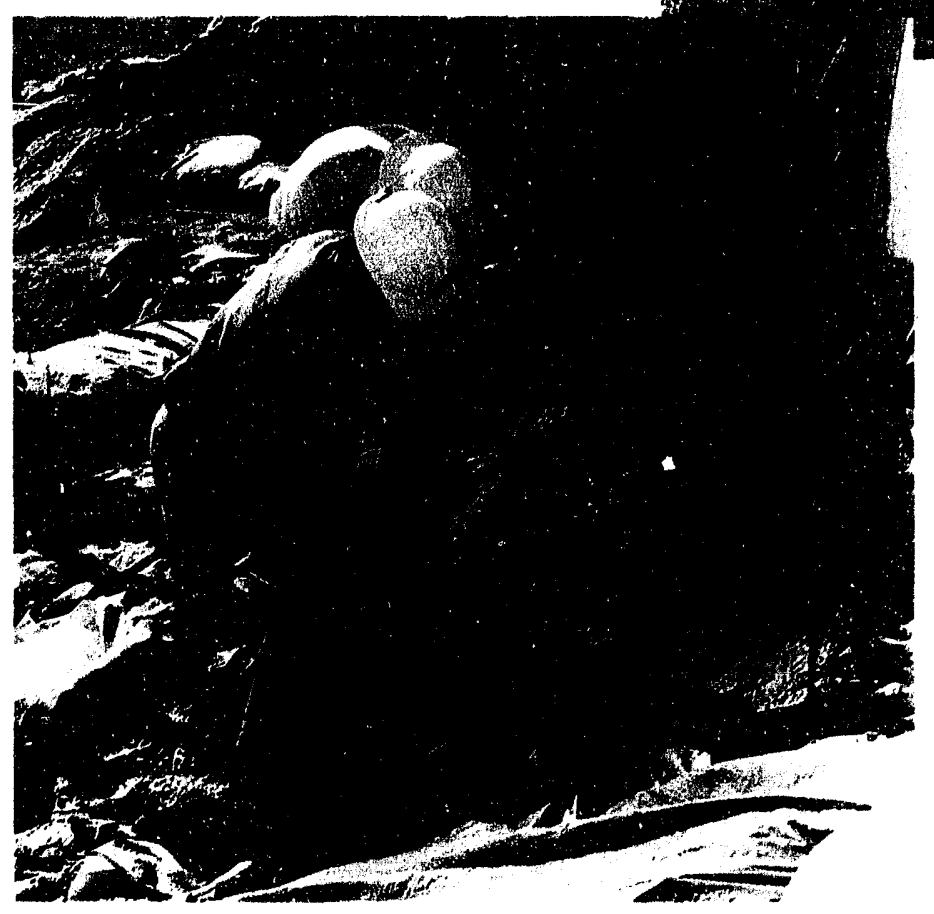

LLNL's Livermore and Site 300 facilities. We have been asked by the DOE to develop an Argus installation for the Pantex Plant in Texas to meet the latest security requirements, and design work is under way. (Pantex is the only facility in the United States where nuclear weapons are assembled or dismantled.) Recently, the DOE selected Argus as the standard automated electronic security technology to be used by the entire DOE complex because of its reliability, adaptability, and high performance.

\section{Magnetic Fusion Energy}

In the 21 st century, magnetic fusion could be the source of large amounts of electricity, without contributing to global warming or acid rain. LLNL continues to play a significant role in national and

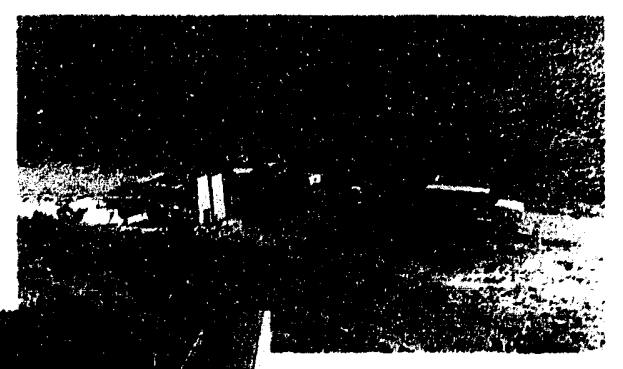

Physicist Wunan Lin, left, and Mark W. Owens, senior engineering associate, examine the cuts made by $a$ prototype saw into the tuff at Yucca Mountain. The cuts will define a large block of rock that will be subjected to tests simulating the effects that rock deep in the mountain will experience when nuclear waste is buried there. 
international collaborations to develop the next generation of tokamak fusion reactors, including both the Tokamak Physics Experiment (TPX) and the International Thermonuclear Experimental Reactor (ITER). The U.S. goal is to have a magnetic fusion Demonstration Power Reactor on line by the year 2025 .

\section{The DIII-D}

In 1993, we expanded our ongoing collaboration with General Atomics on the DIII-D tokamak in San Diego. We now have core staff at both Livermore and San Diego. The DIII-D's goals are in general to advance the tokamak concept and in particular to study the plasma edge (such as the interface between the plasma and the material walls).

A major design concern for current tokamaks is the exhaust of a small amount of power to the plasma edge, which is concentrated in a small area called the diverter. We are leading the effort to develop a new concept for an improved diverter that will spread this heat flow. In 1993, we added a diagnostic capability for measuring heat flow, and we are doing theoretical modeling of the plasma and performing experiments with General Atomics to benchmark the codes we have developed. This work will also guide the design of the TPX and ITER.

Our work with General Atomics on the DIII-D is also supporting advanced tokamak concepts, in particular with measurements of the plasma current profile, especially at the plasma edge. We are using a new diagnostic instrument (based on a phenomenon called the Motional Stark Effect) to study the shape of the plasma, especially near the plasma edge. This work is guiding the development of improved operational modes for tokamaks.

A third aspect of our collaboration involves developing and implementing a way to use high-performance communications networks and distributed computing for conducting tokamak experiments from a distant site. This network would make it possible for researchers to do work at various national research facilities without having to leave their home institutions. For example, LLNL scientists will be able to conduct experiments on the TPX, to be located at Princeton, without leaving Livermore.

\section{The TrX}

The TPX (Tokamak Physics

Experiment) is a national initiative-now in the design stage-to demonstrate, for the first time, continuous tokamak operating modes with both high plasma pressure and enhanced confinement. These advanced modes are based on experimental results from present pulsed devices. The proposed TPX facility will provide essential data that will lead to more compact, economically attractive fusion reactors-including the Demonstration Power Reactor. The TPX
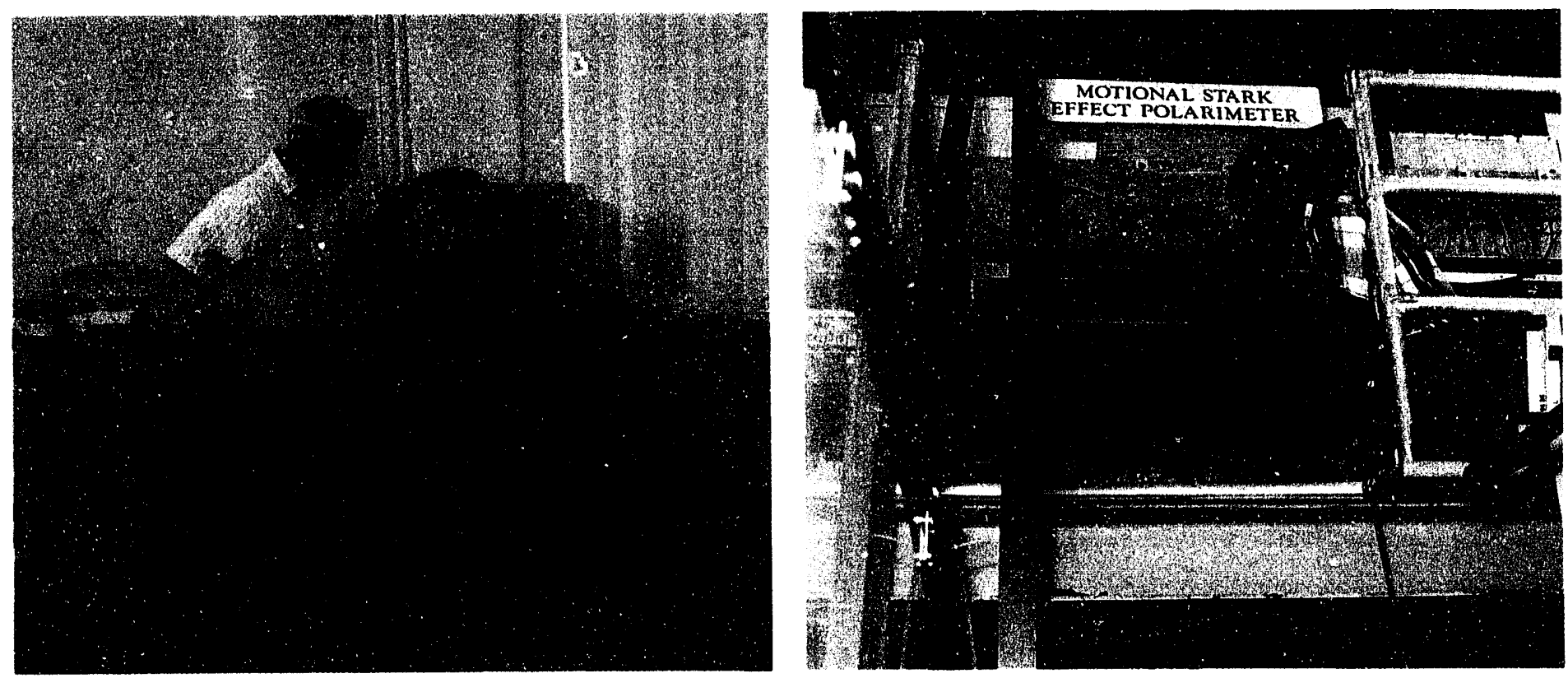

LLNL and General Atomics (San Diego, California) are collaborating on experiments using an interactive communication network. On the left, Laboratory physicists Thomas A. Casper and William H. Meyer, at Livermore, access real-time data from San Diego. On the right, LLNL physicist Bradley W. Rice, in San Diego, adjusts a diagnostic on the tokamak. 
is envisioned as a national facility, to be located at the Princeton Plasma Physics Laboratory. It is being designed by a team of researchers from a number of U.S. fusion institutions (including LLNL), with the Laboratory's Keith Thomassen serving as Program Director. Our primary responsibilities include the superconducting magnet systems (both toroidal field and poloidal field), the structure to hold these together, the cryogenic system for cooling the magnets, and the cryostat.

\section{The ITER}

We have been major participants in the ITER (International Thermonuclear Experimental Reactor)-an international collaboration among the European Community, Japan, Russia, and the United States-since its conceptual design began in 1987. Now, at the start of engineering design activities, we have personnel on both the U.S. ITER Home Team and the Joint Central Team that will design the 1.5-GW facility. We are supporting both the engineering and physics design, have a primary role in the research and development of the superconducting magnets for the ITER, and are performing additional work on the diverter and on systems analysis.

\section{FENIX}

The Laboratory's Fusion Engineering International Experiment (FENIX) facility is the premier test facility in the world for superconductors of the size and type needed for the next generation of tokamaks, such as the TPX and ITER. We have begun testing sample superconductor materials for the ITER from the European Community and Japan. Data gathered from many such tests will be compiled into a database that will allow tokamak designers to calculate the performance of system elements using various possible materials. Whereas previous facilities have tested small pieces of conductors at

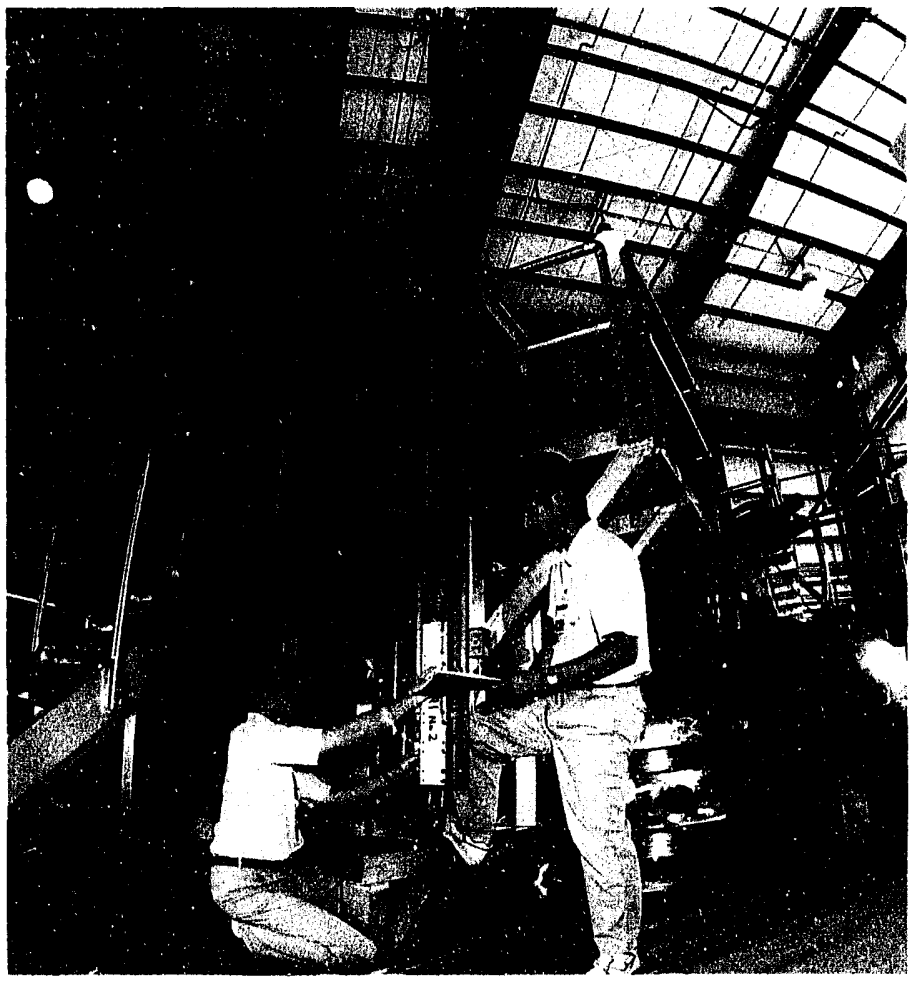

LLNL engineer Stewart Shen (right) and visiting Japanese engineer Fumikazu Hosono inspect a sample of superconductor material for testing in the Fusion Engineering International Experiment (FENIX) facility (photographed with a wide-angle lens).

low levels of currents and fields, FENIX permits the testing of large samples $(5 \mathrm{~m}$ long) under realistic conditions, with magnetic fields up to $14 \mathrm{~T}$ and currents up to $45,000 \mathrm{~A}$.

\section{Numerical Tokamak}

We continue to make strides in developing the theoretical understanding and computer codes needed to interpret and support magnetic fusion research. We are working on the highly complex task of developing a "numerical tokamak"-a physics-based computational model of an entire fusion device-made possible only recently with the advent of more powerful supercomputers. A national consortium (in which we are a major player) has succeeded in developing a suite of codes to simulate the turbulent transport of energy out of the core of the plasma, a critical problem in fusion research. These turbulent transport codes will be a significant part of the prototype "numerical tokamak" code.

\section{Summary}

Our near-term goals include the development of innovative technologies, such as electromechanical batteries, that will have a major impact on the nation's transportation industry, and the development of hydrogen as a practical and economical transportation fuel. We will expand our technology base in fission energy and systems safety, applying it to both nuclear and nonnuclear projects. We will also contribute to the national magnetic fusion energy program on the DIII-D, TPX, and ITER projects, with special focus on improving the tokamak concept.

\section{For further information contact} David E. Baldwin (510) 423-1415. 


\section{y \& Biotechnology}

We are developing some of the tools and strategies required to map the human genetic blueprint, to characterize the genes involved in DNA repair, to estimate health risk following exposure to harmful agents, and to understand the complex interplay of structural and functional mechanisms at the molecular level.

\section{Iaboratory biomedical \\ e Hewlett-Packard ORCA \\ tt to make high-density \\ 56 chromosome 19 \\ sferred 96 at a time onto \\ - filters resting on growth related to energy. Today, as the Biology and Biotechnology Research Program, we provide the scientific foundation for understanding health effects from energy alternatives, their use, and development. Our emphasis is on developing technological solutions for problems}

$\mathrm{T}$ anniversary of a formal biological and environmental research program at LLNL. The Biomedical Program was established in 1963 to study the dose to man from radioactive isotopes in the environment. Over the years, the program evolved in response to changing national needs and new technologies. Although we still study the dose to man, our interests have widened to include other important issues broadly

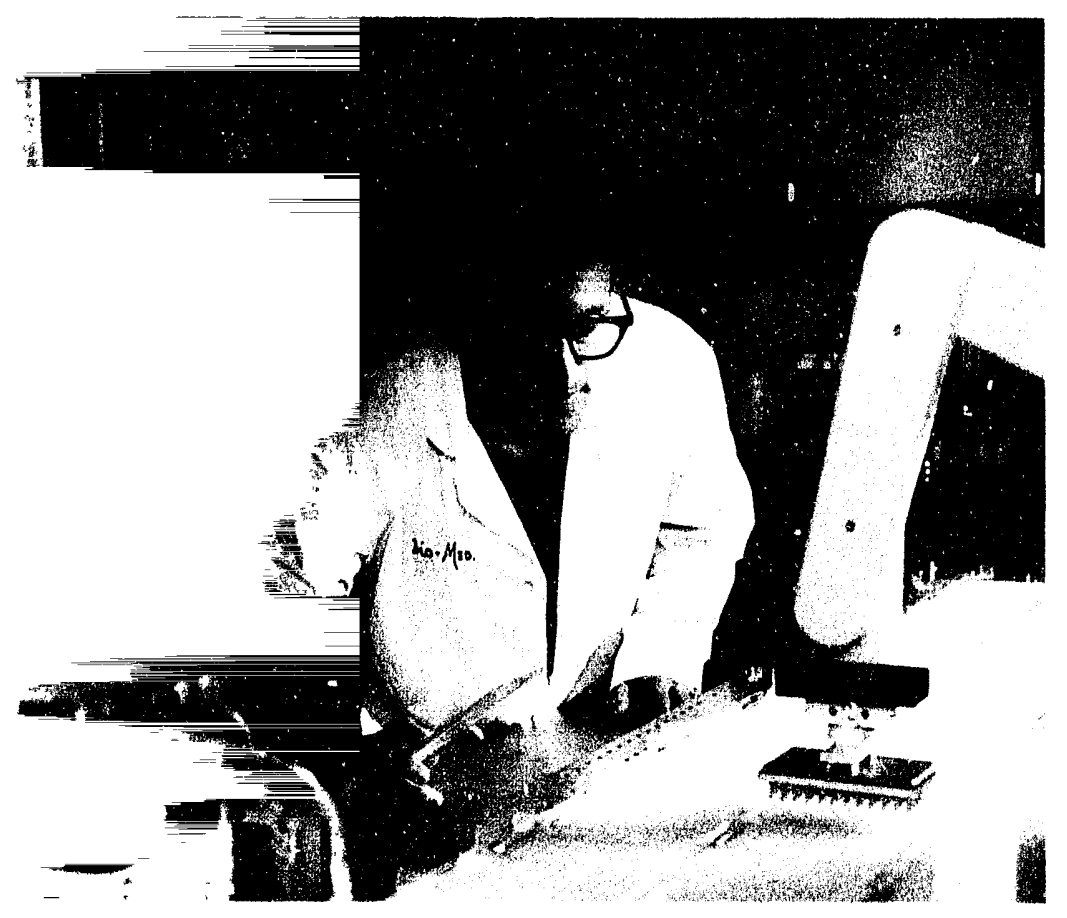

associated with health assessment and fundamental biology, usually at the genetic or molecular level. Our research is directly linked to the long-term goals of the DOE and, in particular, the Office of Health and Environmental Research.

The broad scientific objectives of our ongoing projects are to:

- Unravel the structure of mammalian chromosomes and the genetic code, which serves as the blueprint for the body's proteins and hence its structures and functions.

- Identify and characterize the genes that can repair damage to DNA and understand how these genes prevent or ameliorate damage.

- Develop and apply methods to assess risk to humans from exposure to radiation and chemicals.

- Develop biophysical techniques to understand protein structure and function. - Develop and apply new instruments, procedures, and computer software for biotechnology research and technology transfer.

We are a multidisciplinary, teamoriented program. As such, we are adept at coupling the strengths of our biochemists, biologists, and geneticists with resources available to us from other Laboratory organizations, such as computation, physics, and engineering. In the past year, we increased our interactions with the academic community by creating the Institute of Genetics and Genomics for graduate and postgraduate study and by strengthening our relationship with minority colleges and universities. Through our memoranda of understanding with Morehouse College of Medicine and 
Northern Arizona University, we hope to encourage greater participation of minority students in science. In the past year, we also broadened our interactions with the biotechnology industry, several of which culminated in joint working agreements or other means of technology transfer.

\section{Molecular Genetics and Genomics}

Through much of our program's history, we have sought to understand the structure of mammalian chromosomes and chromatin, which form the major portion of the material inside a cell's nucleus and package the DNA. This interest is manifest in many different kinds of approaches. For example, we have developed imaging techniques, such as the use of fluorescent dyes, whole chromosome paints, and atomic-force and scanning tunneling microscopy. Our highspeed flow analysis instruments can differentiate among chromosomes in terms of their specific DNA content. We have developed ways to identify and isolate genes that encode information about DNA repair.

We are one of three DOE Human Genome Centers (the other two are at Lawrence Berkeley Laboratory and Los Alamos National Laboratory) appointed by the Secretary of Energy. The word "genome" refers to the total genetic material, the DNA, in the chromosomes of a single cell. In general terms, the genome can be thought of as our complete biological inheritance that has evolved over several billion years. In more quantitative terms, it consists of the unique string of some three billion subunits of DNA, called base pairs, inside the nucleus of each cell in an individual.

Our genome research has been centered on constructing a high-resolution physical map of human chromosome 19. This year, we have at least $90 \%$ of that chromosome covered in cosmids, which are small cloned fragments of DNA. Of the more than
12,000 cosmids we have analyzed or "fingerprinted," at least $50 \%$ are now oriented relative to one another to form about 800 contiguous groups. These contiguous, overlapping cosmids are called "contigs." We have also oriented at least half of our cosmids to the genetic map, which shows the relative position of known genes or genetic variations along chromosome 19.

We are beginning to shift some of our emphasis to DNA sequencing and the study of highly repetitive DNA structures. A sequence map is the highest-resolution genome map because it shows the precise sequence of individual base pairs along the DNA.

The Human Genome Project is an international endeavor to decipher the genetic code of humans. In this context, our broad goals are to develop some of the biological products and physical tools required for genome work. Our unique contributions include ways to measure the length of DNA strands, gene-mapping software, new DNA-sequencing instrumentation, robotics and flow systems, and chromosome libraries,

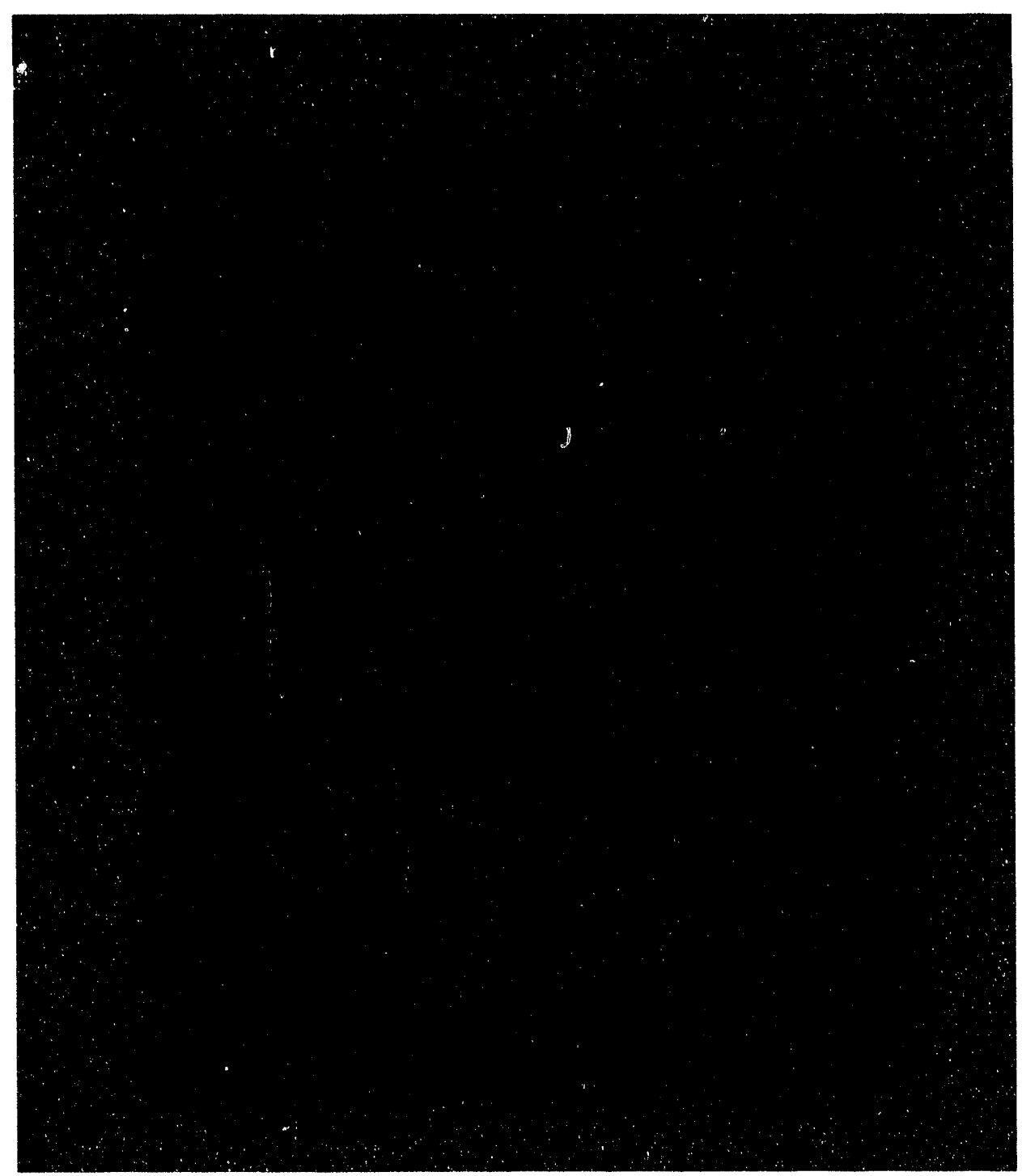


The instrument shown next to molecular biologist Jane Lamerdin performs DNA sequencing, the chemical reactions involved in reading the genetic code. This machine can prepare the sequences of 72 different stretches of DNA in a 15-hour period.

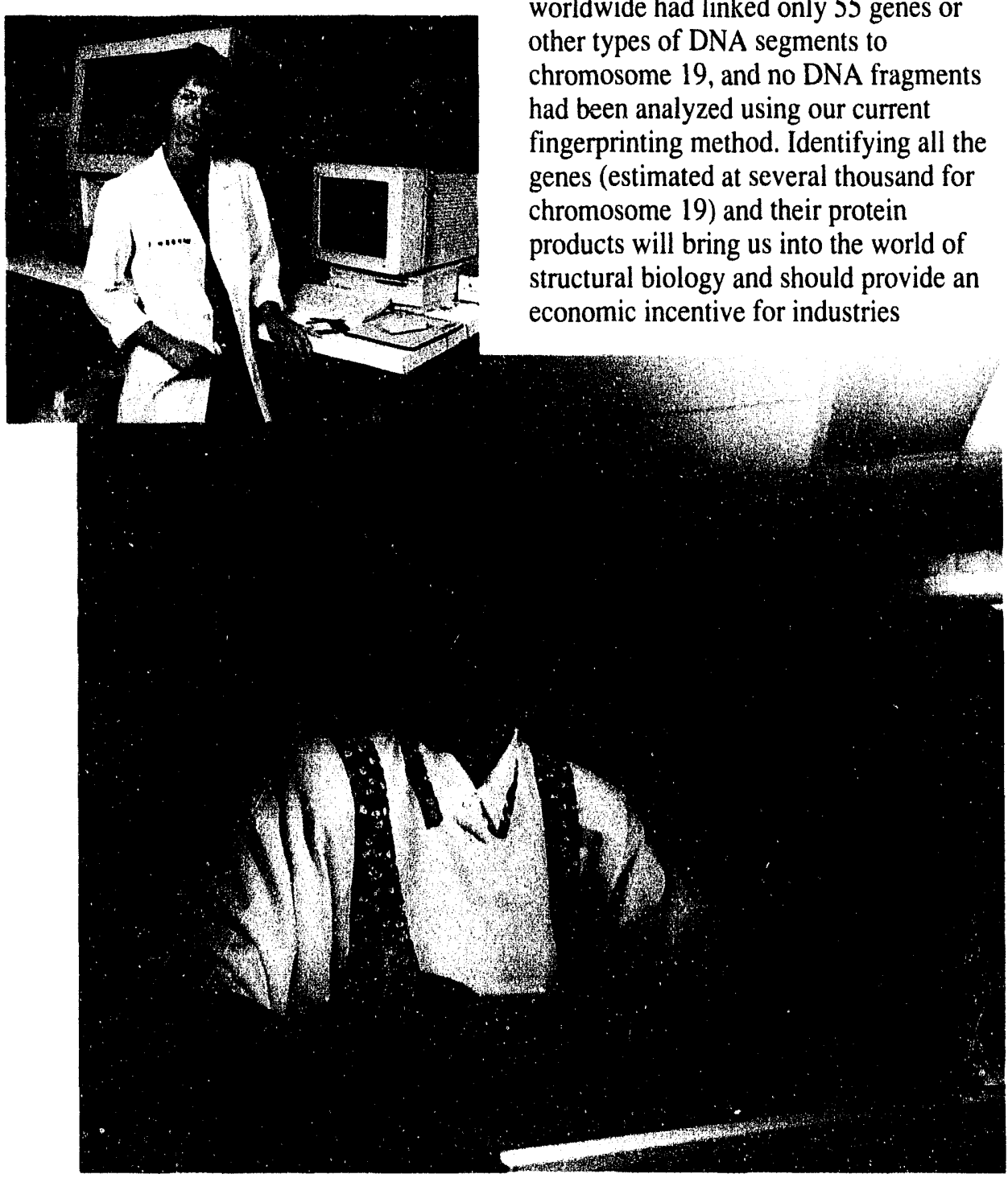

The LLNL Human Genome center has created a collection of recombinant DNA clones that contain pieces of the genetic material (DNA) from human chromosome 19. These clones are arrayed as small dots of DNA on a nylon filter at a density of 3456 dots per 15 in $^{2}$. The high-density filters are sent to collaborating investigators throughout the world to assist our staff in locating new genes. Here biomedical scientist Anca Georgescu is examining a collection of the filters to determine which DNA clones might contain a gene of interest.

LLNL researchers have now located more than 160 genes or genetic markers on chromosome 19, including the structural defect associated with the muscle disease myotonic dystrophy. When our mapping efforts began in 1987, researchers worldwide had linked only 55 genes or other types of DNA segments to had been analyzed using our current fingerprinting method. Identifying all the chromosome 19) and their protein products will bring us into the world of structural biology and should provide an economic incentive for industries

collections of genetically identical clones that can be used for further study. 
multistep process removes damaged or inappropriate pieces of DNA —often a precisely determined length of DNA containing the damage - and replaces them with intact ones.

We have isolated, cloned, and mapped several human repair genes associated with the nucleotide excision repair pathway and involved in the repair of DNA damage after exposure to ultraviolet light or mutagens in cooked food. We have shown that a defect in one of these repair genes, $E R C C 2$, is responsible for the repair deficiency in one of the groups of patients with the recessive genetic disorder xeroderma pigmentosum (XP group D). This year, we began exploring ways to purify sufficient quantities (milligrams) of the protein products of these and other repair genes so that we can understand their functions. For example, we are using the human repair gene $X R C C l$ to purify the encoded protein from bacterial and mammalian cells so that we can determine its precise role in repairing DNA strand breaks. Our long-term goals are to link defective repair proteins to human DNA repair disorders that predispose to cancer, and to produce transgeric mice-that is, mice that are deficient in their ability to repair DNA. Such mice can serve as models for the human repair disorders and for studying the role of repair genes in the origin of mutations, aging, and other processes.

\section{Human Risk Assessment}

A primary goal of most toxicological research around the world is to estimate human health risk. But before we can estimate risk accurately, we need to develop techniques that assess the biologically relevant exposure to toxic agents, carcinogens, and mutagens. Our Biological Dosimetry Group does just that. We look at classical end points, such as large structural aberrations in chromosomes, and new end points, such as those that allow us to identify persistent chromosome changes or to estimate very low doses of a potentially harmful agent.

In recent years, we have developed the glycophorin-A (GPA) bioassay for measuring directly in humans the levels of mutation expressed in red blood cells. The assay can be done quickly and inexpensively after obtaining a blood sample so that individual variations and exposures can be estimated. Our new chromosome painting techniques, which involve fluorescent dyes attached to DNA, can identify persistent translocations (rearrangements between chromosomes) long after exposure to radiation. We have used chromosome painting to measure aneuploidy (abnormal numbers of whole chromosomes or parts of chromosomes) in human sperm, and we are refining ways to measure heritable mutations.

We are bringing together these methods and others in coordinated epidemiological studies to quantify radiation and chemical exposure in several populations, including smokers, pesticide workers, and cleanup workers from the nuclear power plant accident at Chernobyl. We are attempting to link the data from these studies to

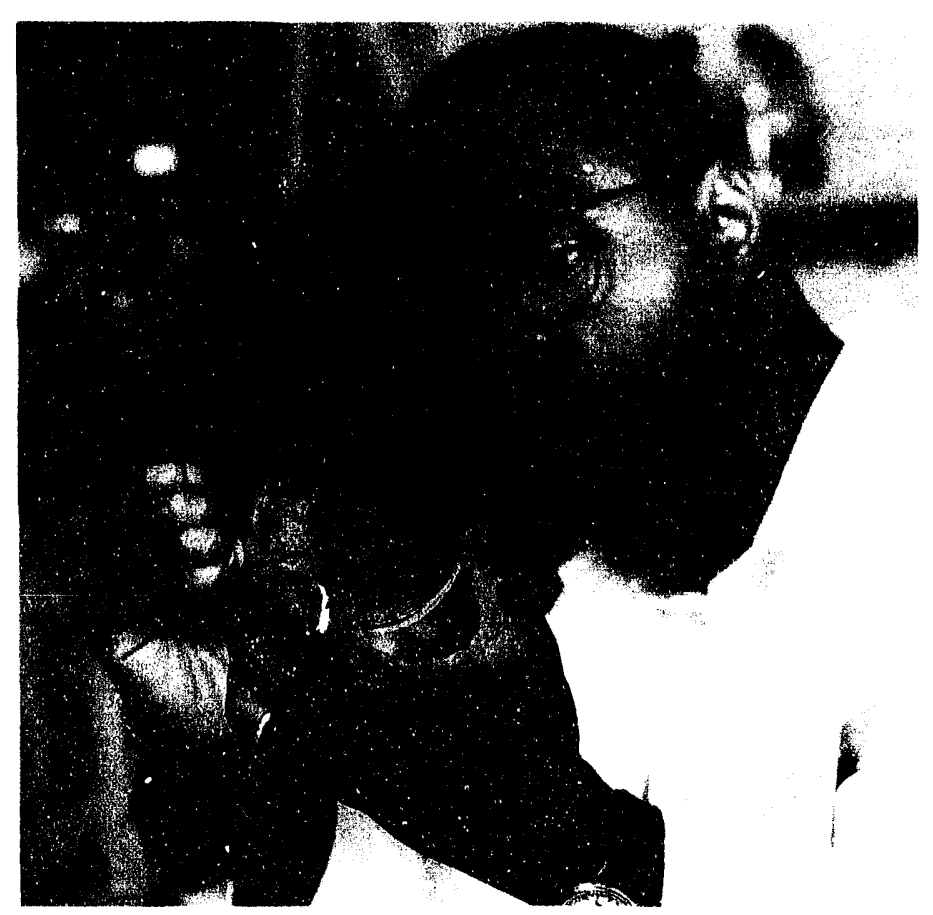

Our recent atomic force microscopy (AFM) image showing the structure of human sperm chromatin. The donut-shaped structures, called toroids, consist of some 40,000 base pairs of DNA and only occur in sperm. The toroids in intact sperm are lined up into layers, something like donuts on a cookie sheet. This is the first time the toroid has been seen in any cell.

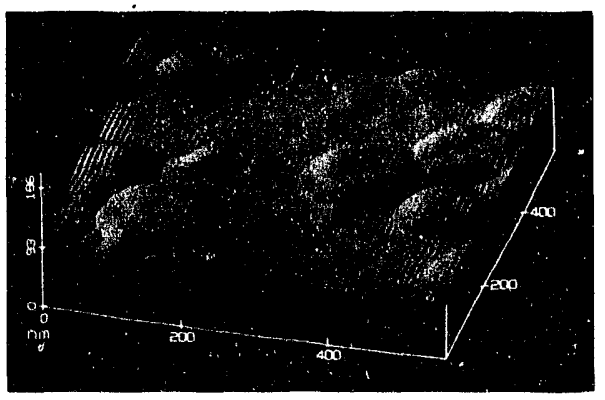

Biomedical scientist Jeffrey Garnes isolates bacteria containing recombinant DNA clones from selected agar plates. Artificial chromosomes in the bacteria contain human DNA fragments ranging in size from 150 to 200 kilobases. $L L N L$ is constructing a total genomic DNA library to be used as a resource for characterizing human genes or DNA sequences. 
Images of rat sperm nuclei taken with a pulsed $x$-ray laser microscope. (top) The two darker, elongated structures are unstained nuclei. The natural contrast is provided by the DNA and protein packed tightly inside. (bottom) We obtain much higher contrast when the nuclei are stained with antibodies to one of the two proteins that pack DNA inside the sperm head.
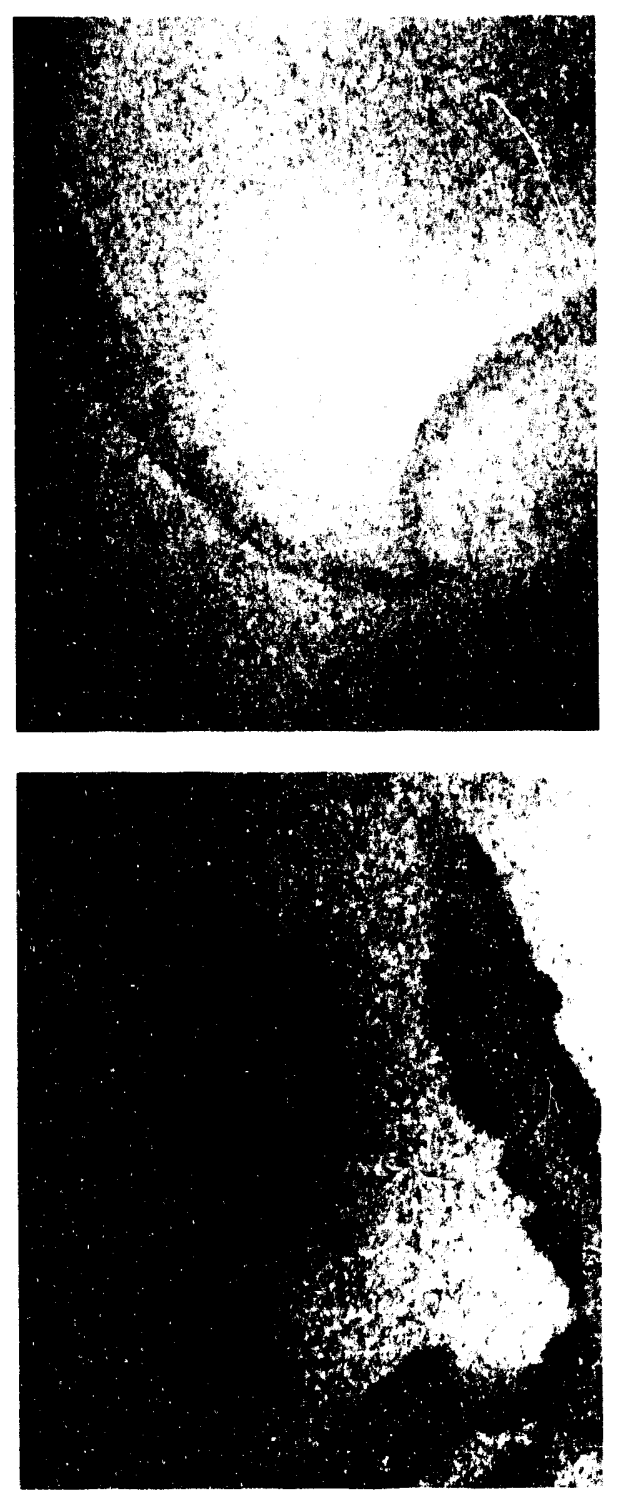

health consequences, such as cancer, birth defects, and spontaneous abortion. In 1992, we received support from the National Cancer Institute to assess the mutational and cytogenetic effects in people exposed to radiation from Chernobyl. This project represents a major collaboration with Russian and Ukrainian scientists and lets us make use of our unique expertise in applying multiple "biomarkers" and end points for assessing genetic damage in humans. In 1993, we received hundreds of blood samples from workers exposed at Chernobyl. We began measuring mutational changes in the blood cells and established a database for tracking and comparing these data in time.

During preliminary studies to establish dose-response relations for our various estimators of biological dose, we identified individuals with a high level of genetic damage but without known exposure or risk factors (for example, nonsmokers with lung cancer). It is possible that these people may be members of families that are genetically predisposed to cancer. We now envision a new field of research, called molecular epidemiology, to study genes that may be responsible for predisposition to cancer and identify individuals with unique risks.

In the area of molecular toxicology, our efforts have shifted from the effects of energy-related chemicals to mutagens formed during the cooking of food and the consequences for human cancer. We are now able to predict low-dose effects from chemical exposure using the Laboratory's accelerator mass spectrometer (AMS; also see p. 40). With this ultrasensitive instrument, we have measured extremely low levels of carbon-14-labeled adducts (simple molecules chemically linked to DNA) in mice that have eaten food mutagens. We are expanding our AMS studies to quantify low-level exposures to benzene and other chemicals. The new AMS technology has created considerable interest in monitoring low-level exposures (one part per billion or less) in environmental samples as well as in humans.

\section{Structural Biology}

Our current efforts in structural biology are relatively small and focus on the organization of chromatin (the collective term for DNA and its associated proteins) in sperm and the function of proteins associated with DNA repair genes. In the DNA repair work, we are emphasizing those aspects of protein chemistry that allow us to determine the structure and function of specific protein products encoded by repair genes. Sperm chromatin packaging is important because errors in this process can have profound effects on fertility or potentially heritable, adverse genetic consequences. In our sperm chromatin studies, we are using protein sequencing, Raman and nuclear magnetic resonance spectroscopy, and other biochemical techniques to determine how two proteins (protamines) bind to DNA, temporarily inactivate essentially all the genes, and package the sperm. We are also using the Laboratory's imaging facilities, such as the atomic-force and scanning tunneling microscope and the $\mathrm{x}$-ray laser, to study how chromatin fibers are packed inside the sperm nucleus and to develop new ways to image DNA and DNA-protein complexes.

This year, for the first time ever, we used a pulsed $\mathrm{x}$-ray laser to take images of a biological structure. To generate these images of the nuclei of rat sperm, we used two arms of the Nova laser. The advantage of obtaining our images via a pulsed $\mathrm{x}$-ray laser is that far less time is required to generate the image. Unlike other techniques, such as scanning an $\mathrm{x}$-ray beam across a structure, the pulse time is 
so brief that no damage to the biological structure occurs from the $x$ rays themselves; thus we obtain an image of the specimen that is unchanged by the imaging technique.

Our 1993 atomic force microscopy (AFM) studies of various types of sperm are revealing the structure of sperm chromatin in startling detail. AFM is a new type of scanned probe with threedimensional, atomic-level resolving power. It can be operated quickly in both air and liquid environments. Our high-resolution images show that sperm chromatin has a toroidal subunit containing approximately 40,000 base pairs of coiled DNA. These toroid structures appear only in sperm cells and have never been seen before.

\section{Technology Development}

The development of new technologies has always accompanied our basic and applied efforts in biomedical research. With the increased emphasis on technology transfer today, new biotechnologies are assuming even greater importance. We have now completed the development of a prototype high-speed flow cytometer and sorter and transferred to industry the information and materials necessary for its commercialization. In the genome area, we have designed and constructed a new, high-density, 384-well microtiter dish, which is also being transferred to industry. This dish allows us to store and process DNA or DNA clones at four times the unit density ( 384 versus 96 samples in the same area), thus reducing the storagecapacity needs and simplifying sample handling. We also constructed a new robotics tool to accommodate the dish.

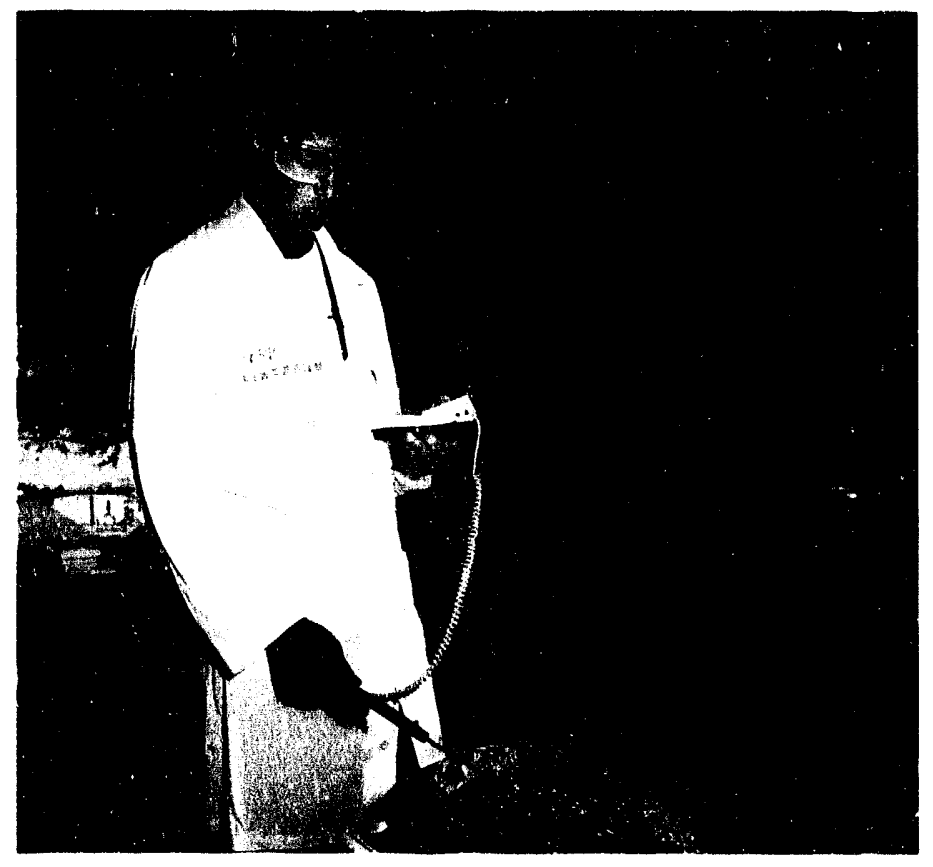

As part of our study on diet and cancer, we are investigating the formation and composition of carcinogens in cooked meat and their contribution to the incidence of human cancer. Meat cooked on a heated surface or over flames until very well done has considerably more carcinogens than meat cooked to medium under the same conditions. Summer student Ahmik Jones is shown here preparing hamburgers.
In an initiative just getting under way, we are developing a prototype instrument for high-speed, high-throughput electrophoresis, which is a method for separating DNA fragments according to size (molecular weight). This instrument should increase rates at least tenfold for required DNA separations, such as those in DNA sequencing. As in the past, our efforts related to instrumentation make use of the computational and engineering expertise at LLNL and also rely heavily on industrial collaboration.

For more information contact Anthony V. Carrano (510) 422-5698. 


\section{A great strength of $L L N L$ is our well-developed ability to turn scientific ideas and experiments into working devices.}

E systems in support of Laboratory programs and develops manufacturing capability in support of the DOE production complex; work with private

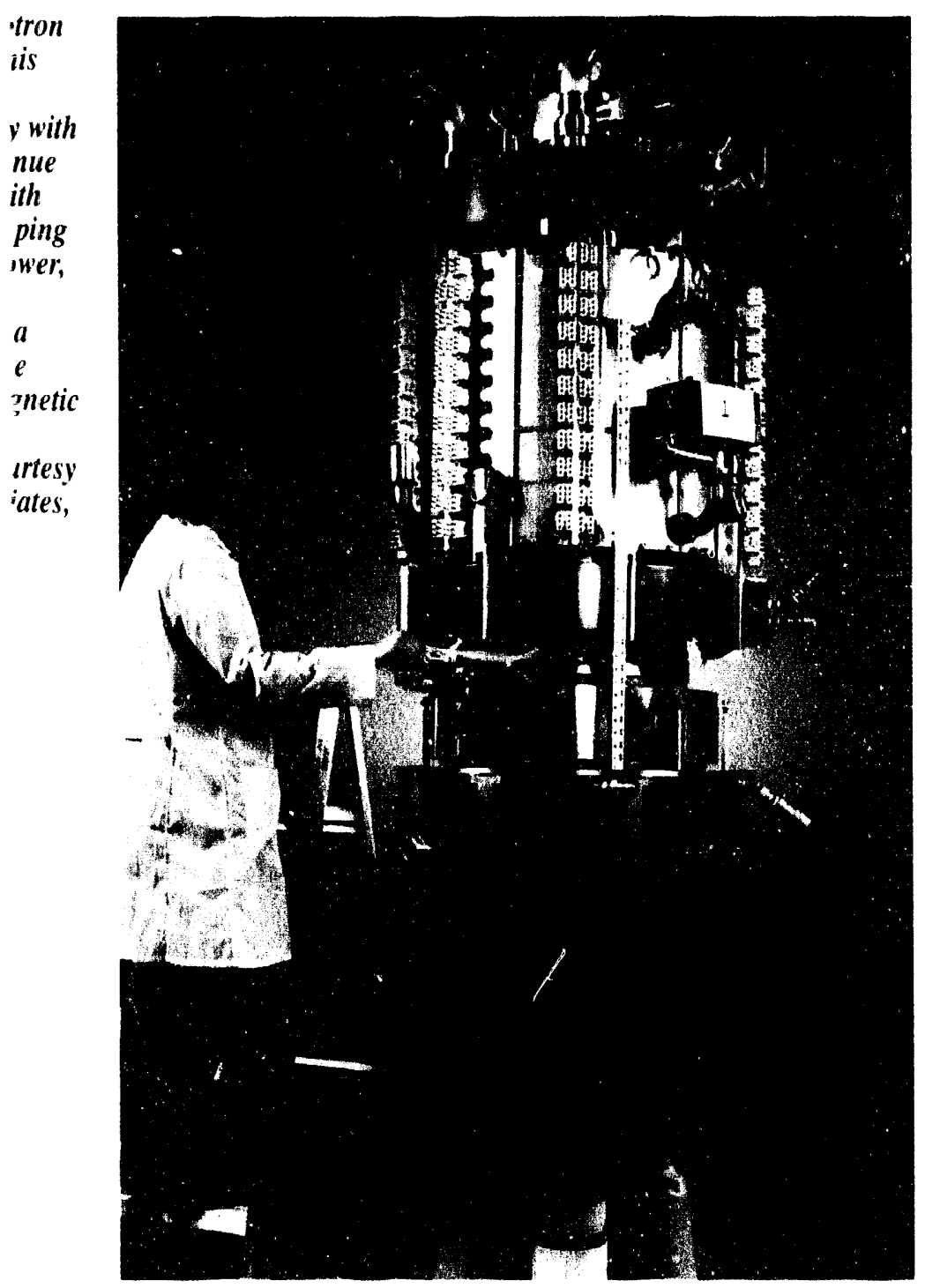

industry has been integral to these roles. Our engineers, technicians, and craftspeople conceive, design, fabricate, test, and install experimental equipment, working on advanced technologies that can help assure our country's economic future. Skilled in cross-disciplinary work on challenging projects, engineering personnel support programs throughout the Laboratory.

Even as we apply existing technology to current projects, Laboratory programs continue to develop in new directions, and engineering is responsible for developing the enabling technologies for these future needs. This work is synergistic-our cutting-edge technologies suggest new directions to the programs at the same time that new programmatic goals suggest fruitful areas for research and development to engineering.

Engineering's technology base at LLNL is organized into nine integrated activities:

- Computational electronics and electromagnetics.

- Computational mechanics.

- Diagnostics and microelectronics.

- Fabrication technology.

- Materials science and engineering.

- Power-conversion technologies.

- Nondestructive evaluation.

- Remote sensing, in aging, and signal engineering.

- Emerging technologies.

Over the years, we have developed a broad spectrum of special facilities, natural outgrowths of our work with unique materials and ultrahigh-precision machining. These include facilities for materials fabrication, nondestructive 
evaluation, materials development, and measurement and endurance testing. We also maintain a microtechnology laboratory, a high-pressure laboratory, and the Large Optics Diamond Turning Machine (LODTM), which sets world standards for accuracy in precision machining.

\section{Computational Electronics and Electromagnetics}

Computational electronics and electromagnetics involves the development of theoretical and computational models of electronic and electromagnetic phenomena and software tools based on these models, as well as the application of these tools to programmatic and industrial problems.

We currently have projects in electronics modeling software and applications, timedomain acoustics modeling, threedimensional electromagnetic modeling on massively parallel computers, and groundpenetrating impulse radar to evaluate imaging techniques for bridge and roadway structures. We also have a Cooperative Research and Development Agreement (CRADA) with the microwave tube industry involving high-power microwave sources for magnetic fusion, a vacuum electron device for communications, and transmission-line components for a tokamak experiment.

\section{Computational Mechanics}

The thrust of computational mechanics is research into heat transfer and mechanics (solid, structural, and fluid) as an experimental basis for state-of-the-art, broadly applicable computer codes. Our DYNA, NIKE, and TOPAZ codes, for example, have teamed us with industry and extended our code capability to such specific industrial interests as casting, metal forming, and automobile crash dynamics. ' We also continue to develop new codes and refine existing ones. Codes under development include a viscous flow code, HYDRA; an animation code, GRIZ; and an explicit, finite-element modeling code, PING, for linear structural acoustics. We are transforming our DYNA solid and structural mechanics code into ParaDyn for massively parallel computers, which will extend our computational capabilities in this area a thousandfold (from gigaflop to teraflop power). In other projects, we have investigated boiling mechanisms that lead to burnout in microchannel-cooled devices and, working with LLNL Earth sciences researchers, developed a method for evaluating the response of manmade structures to large earthquakes.

\section{Diagnostics and Microelectronics}

Our efforts in diagnostics and microelectronics are focused on developing optoelectronics for high-speed communications, electronic devices for radiation detectors and displays, and microstructure devices for such applications as chemical sensing, biotechnology microinstrumentation, and microsurgical tools. Projects for 1993 included a semiconductor chip for opticalwavelength-division multiplexed communications (see also the NTES article, p. 24); a lithium-niobate electro-optic

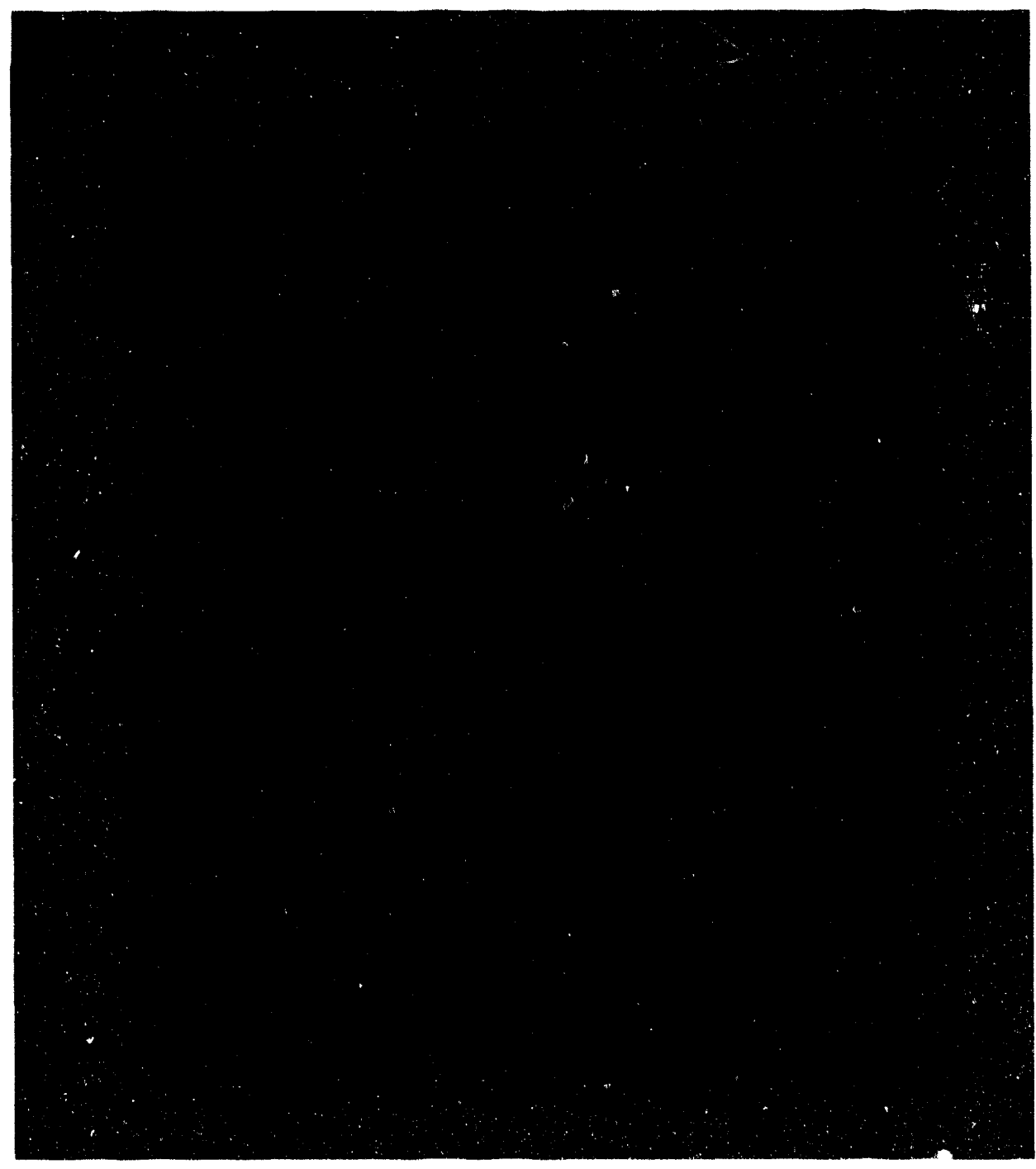


modulator for use as a high-speed communications interface to superconducting digital circuits operating at cryogenic temperatures; chemical microreactors for the polymerase chain reaction (PCR) used to replicate DNA in genomic research and diagnostics; and a micromachined actuator for use in intervention therapies for brain aneurysms. We also manage the LLNL Microtechnology Center, a state-of-theart fabrication facility for microdevices in three semiconductor material systems: (1) silicon and silicon compounds for microelectronics and micromachining applications, (2) semiconductors (such as $\mathrm{GaAs}$ ) for optoelectronic applications, and (3) lithium niobate for electro-optic applications. This facility has the equipment and infrastructure needed for lithography, etching, diffusion, and thinfilm depositions via chemical-vapor deposition and vacuum techniques. It also has dry laboratories for surface

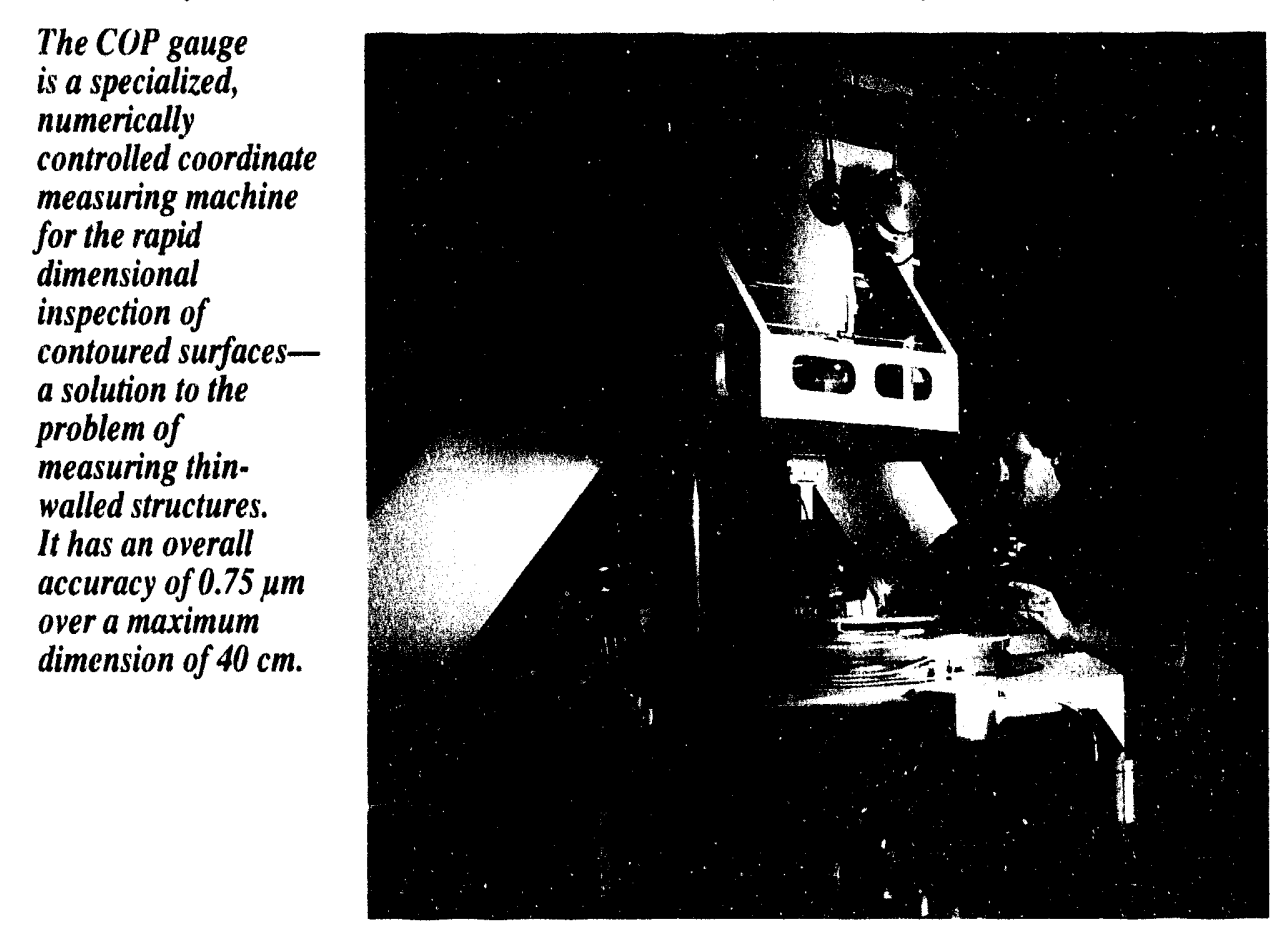

inspections, packaging, and electrical and optical device testing.

\section{Fabrication Technology}

We are endeavoring to establish a base of manufacturing technology-not necessarily resident at LLNL - that will meet the needs of future programs. For this, we are developing an understanding of fundamental fabrication processes and are constructing widely applicable, generalpurpose models of these processes. We also interact with colleagues at other research institutions, industry, and academia to advance our collective understanding of fabrication processes. Projects for 1993 included high-speed manufacturing of precision flat components, developing a diamond composite for optical-surface grinding applications, and investigating microplasticity and damage initiation in silica. We have also completed development of a precision coordinate

measuring machine called the Certification of Process (COP) gauge.

\section{Materials Science and Engineering}

In materials science and engineering. we concentrate on composites (polymer and metal matrix), superplasticity, and process modeling. Composites projects deal with the commercialization and application of new materials and with issues like reduced processing costs, ultrareliability, process monitoring and control, product quality, and mass production. In 1993, we collaborated with the aerospace and automotive industries on developing laminated metal composites and a new family of high-temperature, lightweight materials for aerospace applications. We also developed an economical method for infiltration processing that is particularly applicable to the fabrication of boron-carbide-aluminum cermets. In our work on superplastic forming, we are addressing such manufacturing issues as enhanced design freedom, net-shape processing, minimizing scrap, fabricating complex shapes, and reducing the overall cost of materials, machining, and material usage. Our ability to simulate such manufacturing processes as metal forming, casting, heat treating, and welding will help to reduce manufacturing costs, enhance safety, minimize waste, and make the casting and formation of toxic and radioactive materials more feasible. We have several ongoing LLNL-industry projects in modeling the casting process and the behavior of aluminum casting alloys and in developing predictive models of heat-treatment distortion.

\section{Power-Conversion Technologies}

In 1993, our pulsed-power and microwave-technology projects explored a wide spectrum of areas ranging from the use of pulsed power for environmental applications to the development of unique 
components and systems. The latter area included measuring electron emission characteristics, developing compact solidstate modulators, and studying high-power, electron-beam-induced switching in diamond. Projects exploring environmental applications of pulsed power included applying plasma torch technology to hazardous waste destruction, testing environmentally safe refrigerants, and pulsed-plasma processing of effluent pollutants and hazardous chemicals. We also applied statistical electromagnetic theory to mode-stirred chamber measurements. This application is an alternative, low-cost method of testing the effects of electromagnetic energy, such as microwaves, on avionic boxes in commercial aircraft.

\section{Nondestructive Evaluation}

We use nondestructive evaluation (NDE) to inspect finished parts and complex objects for flaws and fabrication defects and to determine their physical and chemical characteristics without damaging or destroying the object being examined. We also design control sensors, monitor processing and in-service damage, and provide valuable tools for environmental monitoring and for the characterization and reduction of waste. In 1993, we concentrated on x-ray and gamma-ray, ultrasonic, and infrared imaging methods. Since each method analyzes objects by different physical means, each produces different information that can be used separately to analyze an object or combined to obtain the most complete characterization. Work this year included real-time radiography of a Titan IV missile and NDE inspection of the Boeing 737 using dual-band infrared imaging. A number of projects involved computed tomography, including development of a tomographic scanner for inspecting the contents of waste drums and examining diesel-engine components.
The scanner was also used to examine a dinosaur egg found in northern China.

\section{Remote Sensing, Imaging, and Signal Engineering}

In 1993, projects in remote sensing, imaging, and signal engineering included high-resolution telescope imagery, radar remote sensing, and advanced medical imaging. We have also refined a number of our software systems to provide portability among the many computer systems in use at LLNL. Portability is essential if we are to readily transfer the results of our research and development projects-such as object clarification for identifying breast cancer-to the application areas. VIEW and VISION are our signal- and image-processing systems, and VISION also performs pattern recognition. The two are being widely used throughout the Laboratory and have been distributed to many universities, industry, and government sites.

\section{Emerging Technologies}

In 1993, to help establish technology areas with national and commercial impact, we applied modeling techniques

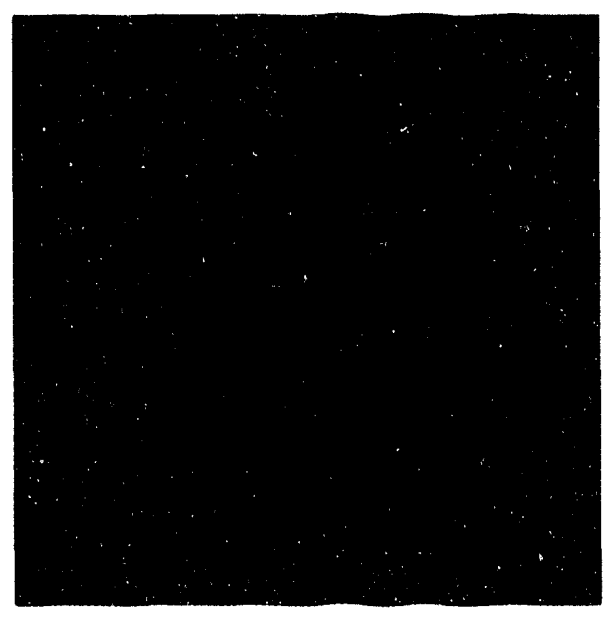

to transportation problems and applied our expertise in robotics microassembly and machine vision to manufacturing problems. In transportation, for example, we used DYNA3D to model and analyze vehicle-crash impacts with the goal of designing a software tool that highway engineers at the Federal Highway Administration and California Department of Transportation can use tc achieve good quantitative results at the workstation level. We also modeled thermal fluid dynamics to make climate control in electric vehicles more energyefficient.

To assemble smali devices automatically with submicrometer accuracy, we began automating the fiberpigtailing and photonics-device assembly process, using machine vision and robotics techniques to design a flexible work cell for the high-precision alignment and attachment of fibers and photonics devices. This should reduce the assembly time from 8 hours to 10 minutes, resulting in a significant cost saving. In addition, we embarked on CRADAs with the photonics and textile industries to improve the efficiency of their manufacturing processes through automated assembly and inspection.

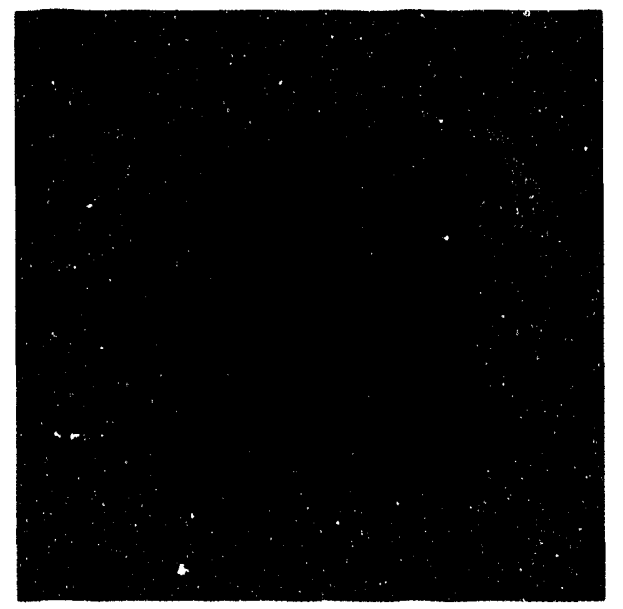

Three-dimensional image rendered from CT scan data of the surface of a sauropod (dinosaur) egg from northern China. The cutaway view, with the outer shell removed, shows the egg's internal details. 


\section{Highlight Projects for 1993}

We can highlight only a few of our engineering projects. These projects bridge the gap between idea and product, giving form and function to what might otherwise exist only in imagination.

\section{Bridge-Inspection Radar}

We are developing and evaluating components and system concepts for applying ground-penetrating radar to inspect bridge decks and other large concrete structures. When integrated with imaging technologies, ground-penetrating radar can locate and characterize construction flaws and wear- or ageinduced damiage without the need for destructive or costly techniques like coring. To demonstrate the enhanced performance of ground-penetrating radar using advanced hardware and software, we have designed, developed, and characterized ultrawideband antennas and pulse generators and used them in an experimental test bed to generate data for image processing. We have also tested off-the-shelf antennas and pulse generators to provide benchmarks against which to evaluate our designs.
Computational Integrated Photonics

Computational integrated photonics is that area of computational physics that studies the propagation of light in optical fibers and in integrated optical circuits. We are working to develop computational tools to analyze the performance of the advanced photonic and optoelectronic integrated devices that will form the basis of future high-speed, high-bandwidth information-processing systems.

We met all our research goals for 1993, and developed several new important capabilities. We used negative conductivity and anomalous dispersion to simulate higher-order mode lasing in optical traveling-wave amplifiers. We developed a coupled-mode theory that allows us to narrow parameter choices and identify key device-optimizing parameters for a variety of optoelectronic devices. We also developed new computational tools to model both flat and curved gratings for possible application to high-bandwidth optical modulators.

Besides developing modeling software, we also supported several optoelectronics experimental projects. To form optical waveguides on wafe $i$

\section{Computational tools help us to analyze the performance of advanced photonic and optoelectronic devices. In this BEEMER computer simulation of the operation of an all- optical switch, light enters from the left and is combined into a waveguide. If the combined intensity is great enough, the switch will turn on.}

substrates, we investigated use of the process of annealed proton exchange, a process in which an exposed region of lithium niobate substrate exchanges lithium atoms for protons from a bath of molten organic acid, and is then baked in an oven. The baking produces a change in the optical properties in the exposed substrate, and is one of several promising approaches to manufacturing optical waveguides. In another hardware project, we helped develop a novel photodetector called a vertical impedance-matched photodiode, which is substantially smaller and faster than conventional detectors.

\section{Cure Monitoring of Composites}

Quality control in composite materials, especially during the cure cycle, is essential if these materials are to be commercially acceptable. We are using Raman spectroscopy and a fiber-optic technique to monitor the cure reaction of resins and composites remotely and in situ both during and after manufacturing. We hope such monitoring will make it possible to reduce the number of finished parts that are rejected.

In 1993, we applied the Raman analysis technique to uncured and fully cured cyanate ester, a one-component resin with a higher temperature capability than epoxy resin. This was the first time the chemical reaction rate and temperature of a resin had ever been measured simultaneously with a single probe. We also extended the Raman technique to polymer-matrix, fiberreinforced composite materials. By using a laser light source at $64.7 \mathrm{~nm}$, we were able to obtain good characterization of glass fiber/epoxy composites, proving the Raman technique is applicable to automated manufacturing processes and is suitable as a smart sensor for polymer matrix composites.

\section{Laminated Metal Composites}

We have been investigating the influence of processing and structural variables on the mechanical properties of multilayer 
laminated metal composites made of two constituent materials, one ductile but tough and the other brittle but strong. The idea behind lamination is to form a composite that exploits the good properties of both materials. In 1993, our main thrust was to study the fracture toughness of a laminant made of aluminum and of an aluminumbased, SiC-particulate-reinforced metalmatrix-composite (MMC), as a function of the volume fraction of the metal and matrix components, under both heat-treated and untreated conditions. Results showed that heat treatment increased the composite's yield strength and tensile strength, decreased its tensile ductility and interlayer bond strength, and had no noticeable effect on laminate toughness. There was, however, an increase in both fracture and tensile strength when the volume percent of the $\mathrm{MMC}$ or the $\mathrm{SiC}$ reinforcing agent was increased; this increase was limited only by the ability to make the material.

\section{Fiber-Optic Transceiver}

We are characterizing the performance of high-speed photodetectors and electrooptic modulators at cryogenic temperatures (down to $4.2 \mathrm{~K}$ ) to determine the viability of interfacing superconducting electronics with fiber-optic transmitters and receivers. Our efforts are driven by the need for a high-speed electro-optic modulator that can be used as a high-speed communications interface to superconducting digital circuits that operate at cryogenic temperatures. These circuits provide processing speeds that far exceed those of conventional electronics, answering the need for increased performance from advanced signal-processing systems and for applications such as supercomputing and high-speed switching.

Experimental results in 1993 demonstrated that, at cryogenic temperatures, the performance of $\mathrm{GaAs}$ photodetectors and lithium-niobate electrooptic modulators was marginally degraded at most and could even be improved. Results also showed that the packaging of

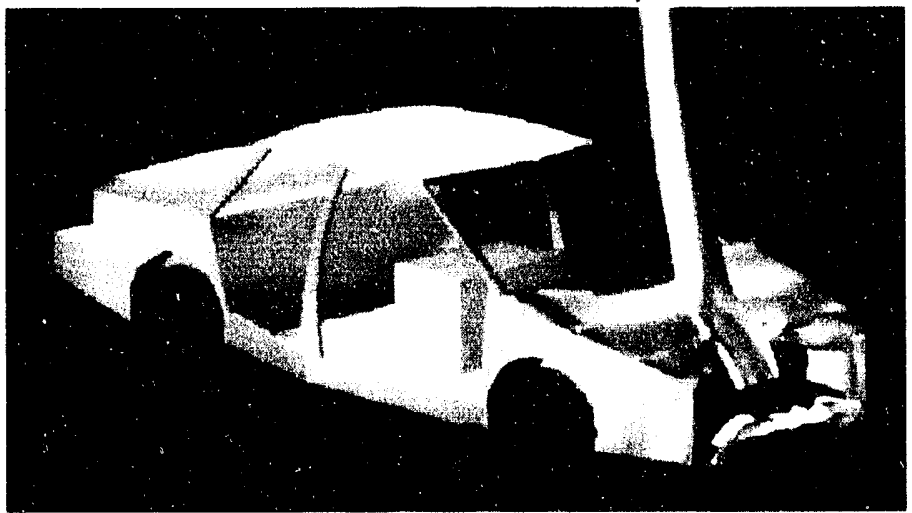

DYNA3D model of a domestic sedan hitting a light pole. We have run similar simulations of cars hitting rigid walls and bullnose barriers as part of our work for the TAHRS project.

optoelectronic devices, including opticalfiber pigtails, is robust enough for cryogenic temperature transitions so long as care is taken when cooling them down.

\section{TAHRS Project}

Our Tire, Accident, Handling, and Roadway Safety (TAHRS) project is developing software tools to model vehicle/ barrier crashes and post-crash events as part of the VISTA (Vehicle Impact Simulation Technology Advancement) program. The goal is to develop an easy-to-use tool for analyzing vehicle handling and crash impact and to determine ways to improve the design of highway barriers and minimize the risk to occupants and the hazards of the vehicle's post-crash motion (e.g., to prevent the vehicle from rebounding into the traffic lane).

We have developed rigid-body algorithms to be used with our DYNA and NIKE codes, which will be combined with other technologies worldwide to create a user-friendly highway design tool for national highway engineers. In 1993, we used these codes for experimental and numerical studies of crush behavior on extrusion sections of aluminum spaceframes to improve both material behavior (strength with energy absorption) and numerical modeling technology so that we can scale up our simulations to a full-vehicle, finiteelement model. These studies provided valuable information about the way aluminum buckles in a crash and helped us determine the minimum mesh size for full-vehicle modeling. We also videotaped a full-scale barrier impact test at Site 300, using a 1978 Ford Fairmont instrumented with strain gauges and accelerometers, and are comparing the results with DYNA simulations.

\section{Conclusions}

By continually expanding Engineering's technical base, we provide vital support to existing and emerging Laboratory programs. In addition, our cutting-edge technologies point the way to new program opportunities. As the needs change, our engineers will be ready to provide innovative, high-quality, rapid solutions to the difficult technical problems posed by defense needs and the new national goals that are evolving in our rapidly changing world. And, as the gap between government and industry narrows, we can form the bridge between ideas and reality, while forming partnerships with U.S. industry to assure competitiveness in the global marketplace.

\footnotetext{
Reference

1. The September-October 1993 issue of Energy and Technology Review (UCRL-52000-93-9/10) describes the use of DYNA3D to assess vehicle crashworthiness, the application of NIKE in an integrated study of the effect of earthquakes on large structures, and the development of CAST2D, an outgrowth of TOPAZ, to model casting and metal forming.
}

For further information contact Roger W. Werne (510) 422-8351. 


\section{Research into various areas of physics provides the foundation on which many of the Laboratory's programs are built. The scope of our physics investigations ranges from the subatomic to the extragalactic as we strive to understand the world around us.}
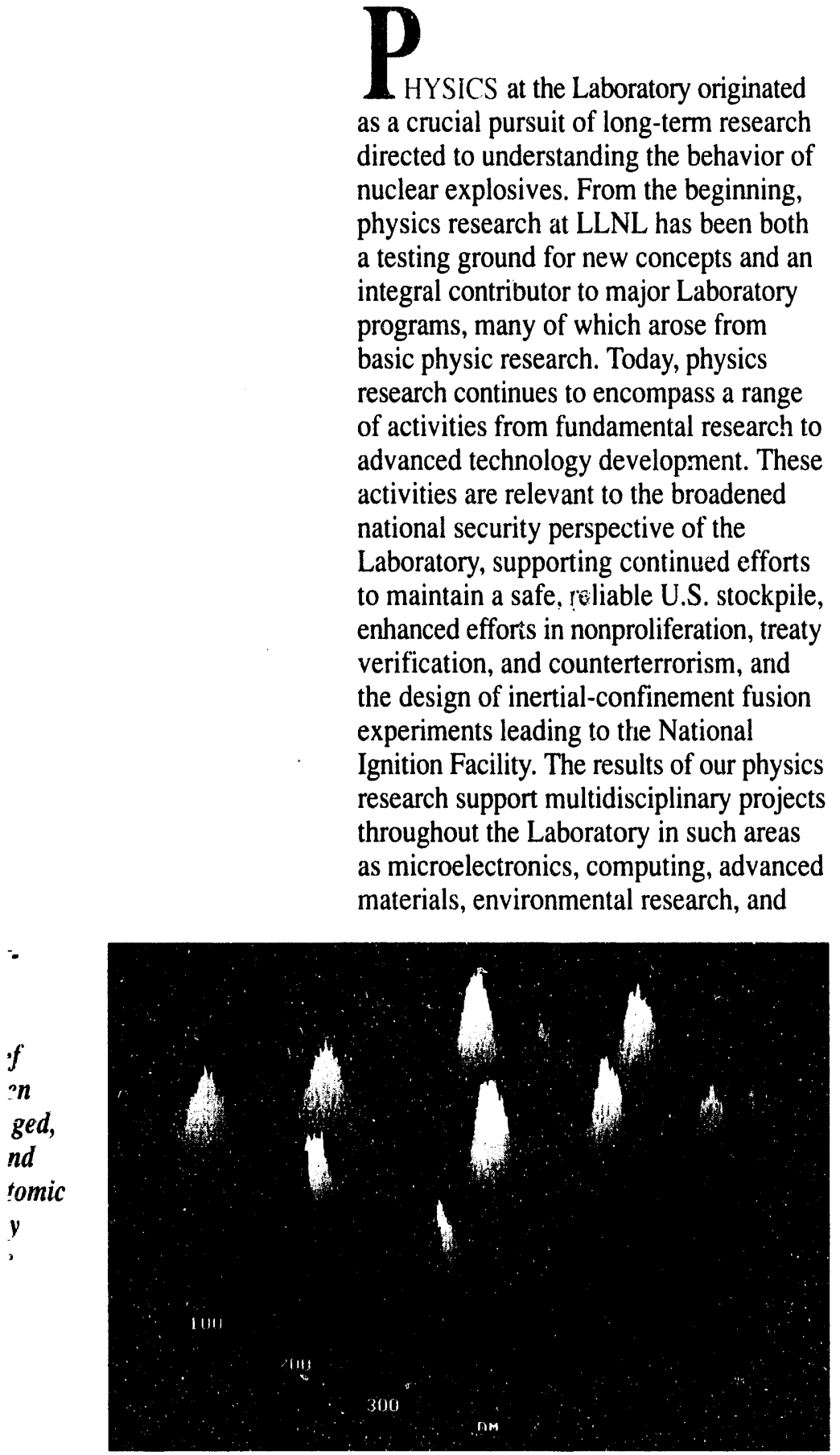

astronomy. In 1993, we made important advances in high-energy particle research, experiments with condensed matter, designing novel materials by computer, and ground-based astronomy.

\section{Highly Charged Ions}

LLNL's electron beam ion trap (EBIT) is a unique experimental device for producing and trapping ions in extremely high charge states. EBIT is the primary facility in the U.S. for precision study of the highly charged ions present in the hot plasmas that are of interest to researchers in fusion, lasers, nuclear weapons, and astrophysics. The first EBIT began operating in 1986 and produced a series of hitherto impossible spectroscopic and cross-section measurements that received worldwide attention.

By increasing the electron beam energy of the original EBIT from $25 \mathrm{keV}$ to $200 \mathrm{keV}$, we recently built the SuperEBIT, which allows us to produce and trap uranium that is stripped of all electrons (i.e., uranium ions with a +92 charge). For any element up to and including $\mathrm{U}^{92+}$, we can also strip ions to one or a few electrons. Since the few remaining electrons in such highly charged ions move at nearly the speed of light, we can test theories of relativity and quantum electrodynamics in conditions of extremely high electric fields.

This year, we made the first measurements of collisions between very highly charged, very slow ions and surfaces. The incoming ions carry so much Coulomb energy that the collision with the surface results in a Coulomb explosionthe transformation of molecules into 
clusters of charged atomic particles driven apart by their Coulomb repulsion. We have observed secondary electrons, secondary ions, and $\mathrm{x}$ rays from such Coulomb explosions, and using an atomic force microscope we have obtained images of surface damage by a single ion.

We have nearly completed the construction of a magnetic trap to collect the highly charged ions from the SuperEBIT. We will load large numbers of ions into the trap and cool them until they freeze into a crystal of pure ions, creating a type of crystal that has never before been studied. We will also load a small number of ions or even a single ion into the trap to make precise measurements of its mass. We are improving the sensitivity of our system so that we can detect and weigh individual ions and thus study nuclear decay processes. We have been developing a high-resolution, high-sensitivity mass spectrometry system to measure fundamental atomic constants on fully stripped heavy ions, which standard spectroscopic techniques cannot do. For example, we want to precisely measure the increase in weight that a fully stripped ion undergoes because of its increased potential energy, and (the ultimate test of quantum electrodynamics in superhigh fields) to precisely weigh the energy fraction in bare uranium arising from quantum electrodynamics.

\section{Condensed Matter}

We have a large experimental program for synthesizing new materials unique to their purpose, such as for high-temperature superconductivity and microelectronics. We have also begun to design materials by computer. Using supercomputers (particularly massively parallel processors) and innovative algorithms, and working solely with the identities of the constituent atoms and the laws of quantum mechanics, we are designing novel materials with properties optimized for their purposes. In 1993, we applied our modeling methods to several problems with important results.

\section{Metallic Hydrogen}

Metallic and near-metallic hydrogen are believed to have several interesting properties. They are thought to make up the interiors of the giant planets Jupiter and Saturn and to be the source of these planets' enormous magnetic fields. Metallic hydrogen has been predicted to be a very- high-temperature superconductor, possibly even at room temperature. This year, we made the first measurements ever of the electrical conductivity of hydrogen at densities approaching its metallization density (approximately nine times the density of liquid $\mathrm{H}_{2}$ ). Our experiments will lead to better physical models and 
will further our basic understanding of the properties of condensed matter.

\section{Polymeric Nitrogen}

If polymeric nitrogen could exist in stable form, it wculd have potential applications as a superexplosive or an environmentally benign and signatureless monopropellant. We have predicted the existence of a threefold coordinated polymeric form of nitrogen that would have a stored energy density per unit volume three times that of HMX (the "standard" explosive for weapons use). It would also experience significant barriers inhibiting the energy-releasing transformation to $\mathrm{N}_{2}$-gas reaction products. That is, it would be more powerful yet much safer than HMX. New calculations in 1993 greatly enhance the prospects for the existence of polymeric nitrogen. They show unequivocally that this hard, transparent insulator (i.e., electrically nonconducting) material should indeed be mechanically stable at atmospheric pressure in bulk form.

\section{Microplasticity of Silica}

Commercial application of ceramic materials is limited by the cost of fabricating precise surfaces. To probe these fabrication processes, we have simulated the response of fused silica (glass) during surface indentation and crack propagi tion to learn how silica deforms on the nanoscale. However, since the interatomic force model and, in particular, the interaction with water limit the accuracy of such simulations, we have performed $a b$ initio total-energy calculations of the polymorphs of silica. The results agree well with the observed phase diagram for silica and provide a database from which we can improve our empirical interatomic force models.

\section{Molybdenum Silicides}

We have gained a microscopic understanding of the chemical bonding in the binary molybdenum-silicon system, a system that has important technological applications to multilayer $\mathrm{x}$-ray mirrors, metal-semiconductor interconnects, and high-temperature structural materials. In particular, we have demonstrated a hierarchy in the relative strength of Mo-Mo, $\mathrm{Mo}-\mathrm{Si}$, and $\mathrm{Si}-\mathrm{Si}$ bonds that underlies many physical properties of these materials and can be traced to electronic structure. We are using these results to improve models of the interatomic force laws, which will make possible more realistic atomistic simulations of the growth of Mo-Si multilayers.

\section{Particle Physics}

Our expertise in nuclear experiments has led to significant involvements in various projects in particle physics.

\section{The B Factory}

We are collaborating with the Lawrence Berkeley Laboratory and the Stanford Linear Accelerator Center (SLAC) in the design and construction of the B Factory, to be built at SLAC. This facility will accelerate electrons and positrons around two storage rings, each $2.2 \mathrm{~km}$ in circumference, and then crash them together, creating b-quarks. The goal is to learn why maiter gained predominance over anti-matter at the time of the Big Bang. Basic physics argues that, shortly after the Big Bang, matter (protons and electrons) and anti-matter (anti-protons and positrons) should have been created in equal quantities and thus later annihilated, leaving only photons. A clue to this mystery was discovered 30 years ago in a series of experiments at Brookhaven National Laboratory that revealed a decay mode, previously presumed to be forbidden, of a particular subatomic particle. With the B Factory, we will be able to study this "symmetry violation" in the b-quark system.

- The PEP-II Accelerator. The PEP-II collider is a highly innovative accelerator project, both because the electron and positron beams will have different energies ( $9 \mathrm{GeV}$ and $3.1 \mathrm{GeV}$, respectively) and because very large currents will be stored (up to 3 A per beam). The large currents imply enormous gas loads in the vacuum beam pipe due to atomic desorption by the intense synchrotron radiation. In 1993, we provided results on a new distributed-ion pump, developed and demonstrated at LLNL, which were critical to the successful DOE review that led to the project being awarded to the three-laboratory consortium. For this project, we have major responsibilities in the design and construction of the vacuum system, wiggler magnets, and high-power beam dumps for emittance control of the beams, the vacuum straight sections, the interaction region where the electrons and

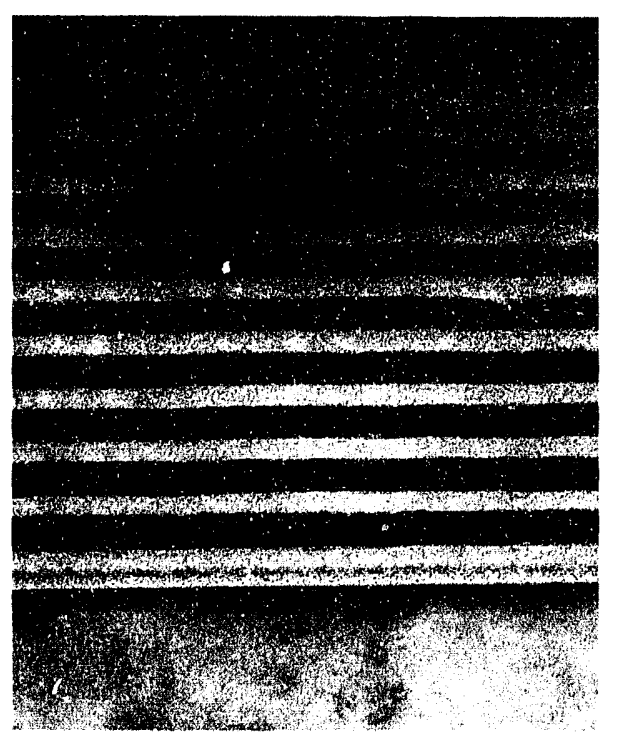
High-resolution electron micrograph of a molybdenum-silicon (Mo-Si) multilayer grown by the Advanced Microtechnologies Program. This $L L N L$ experimental effort motivated the theoretical effort. Mo-Si multilayers are used in multilayer $x$-ray mirrors, metal-semiconductor interconnects, and high-temperature structural materials. We are gaining a microscopic understanding of the chemical bonding in this system, which will improve the realism of our atomistic simulations of the growth of Mo-Si multilayers. 
positrons will be brought into collision, and power conversion.

- The BaBar Detector. The BaBar detector will be installed and operated at the interaction region of the PEP-II collider. $\mathrm{BaBar}$ will detect the decay products of the B-meson containing the b-quark and its anti-particle. By precise measurement of the time evolution of the B-mesons, the physics of the sought-for symmetry violation can be obtained. We have completed the advanced design for the solenoidal magnet and the steel flux return for this detector. We have also developed lightweight detectors, called resistive plate chambers, that will be used to detect muons and hadrons (subatomic particles). Expertise in scintillating crystal calorimetry, gained in work for the Superconducting Super Collider (since canceled), is being applied to the $\mathrm{BaBar}$ detector; the device will contain an array of 15,000 cesium iodide

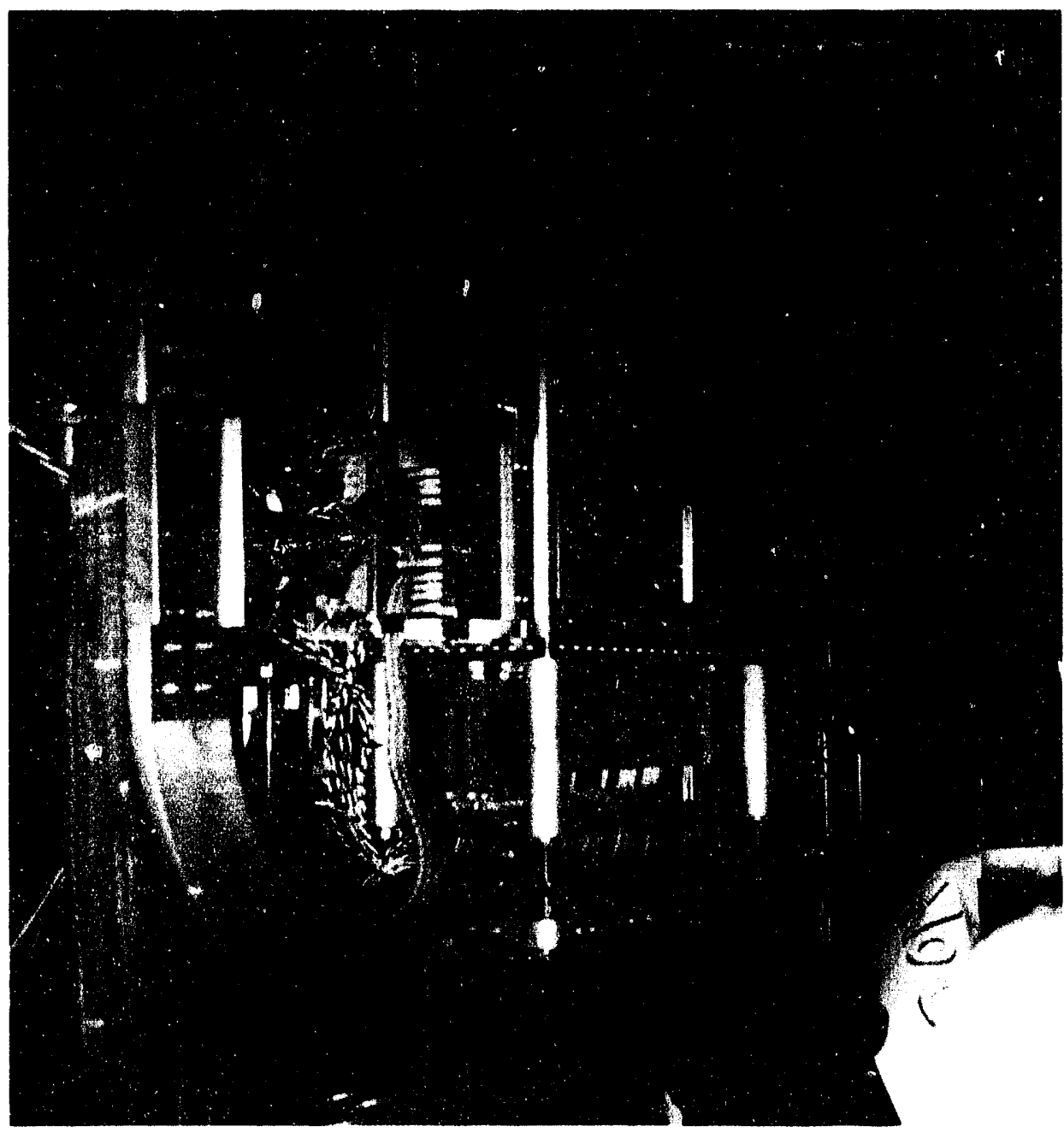

The high-multiplicity drift chamber is one of three new detector systems we designed and fabricated for the Alternating Gradient Synchrotron (AGS) at Brookhaven National Laboratory. Data from the first gold-beam experiment reveal that our detectors exceeded expectations for particle identification and resolution. Indeed, as the term "high multiplicity" suggests, this chamber simultaneously detects five times more particles than any other similar detector.

crystals to detect electrons and photons. In addition, we have developed and applied fast Monte Carlo codes to model the physics that will be performed at the B Factory and to optimize the detector design.

\section{The Alternating Gradient Synchrotron}

We are one of several institutions working with the Brookhaven National Laboratory on the Alternating Gradient Synchrotron (AGS). The AGS can deliver beams of gold nuclei at an energy of $11.7 \mathrm{GeV}$ per nucleon (2.3 TeV total kinetic energy). When these relativistic gold beams collide with a stationary gold nucleus, nuclear matter is drastically compressed. This extremely hot, dense matter produces copious amounts of particles, requiring innovative detection techniques to identify and measure them. We have fabricated and installed three new detectors for the gold-beam experiment:

(1) a tracking chamber to identify particles that pass through the primary magnetic spectrometer, (2) a 100-element array to measure proton and ion emissions at large angles to sensitively probe the early stage of the collisions, and (3) a projectile scope to provide an event-by-event reaction plane to study aspects of collision dynamics that are sensitive to the equation of state.

The knowledge gained from these AGS experiments will be applied to the Relativistic Heavy Ion Collider (under construction at Brookhaven), which offers the only opportunity to create and study the quark-gluon plasma (QGP), a state of matter that existed only microseconds after the Big Bang. Two large detector facilities, PHENIX and STAR, are being designed to observe the QGP; we have finished designing the two primary magnet systems for PHENIX and will soon begin fabricating them.

\section{Evaluated Nuclear Data Libraries}

Over years of defense work, we have assembled a national repository of experimental and evaluated basic nuclear data, the Evaluated Nuclear Data Libraries. We must be able to process the data in this 
repository into applications-oriented files so that we can readily determine the effects of changes in basic, microscopic nuclear data on macroscopic properties of complex computer simulations. We are developing a system for achieving consistency in processing these evaluated nuclear data files to make possible comparisons among applications (such as determining the properties of various first-wall containment designs in future fusiun reactors). For medical applications (e.g., to accurately calculate the medical dose delivered to a tumor by commonly used radiotherapy beams), we are extending the evaluated libraries from 20 to $250 \mathrm{MeV}$ for protons and neutrons incident on biologically important elements. We are also developing a three-dimensional Monte Carlo computer simulation code that uses actual medical images, such as computedlomography scans of the human body. To validate our evaluated libraries and applications files, we maintain an extensive set of computational benchmarks for comparison to experiments.

\section{Earth-Based Space Exploration}

There are dozens of major Earth-based astronomical observatories that can benefit from the kinds of corrections that computers and lasers can combine to supply. Our Laser Guide Star has demonstrated that these capabilities are real. Our MACHO project is demonstrating that a groundbased observatory, with the help of computer control and analysis systems, can achieve sufficient sensitivity to distinguish between two sources of fluctuation in the light from starsfluctuations originating in the star and those resulting from the gravitational effects of massive, unseen astronomical objects.

\section{Laser Guide Star}

Atmospheric turbulence severely degrades the resolution of ground-based telescopes. In principle, a technology called adaptive optics can remove most of the blurring by measuring the iurbulence hundreds of times a second and making corrections through a deformable mirror

We are extending
our Evaluated
Nuclear Data
Libraries for protons
and neutrons
incident on
biologically
important elements
and developing a
three-dimensional
simulation code that
uses actual medical
images (such as
computed-
tomography scans)
of the human body.
The scan shown
here, of a rat leg
bone, is typical of the
complex images that
our code will handle.

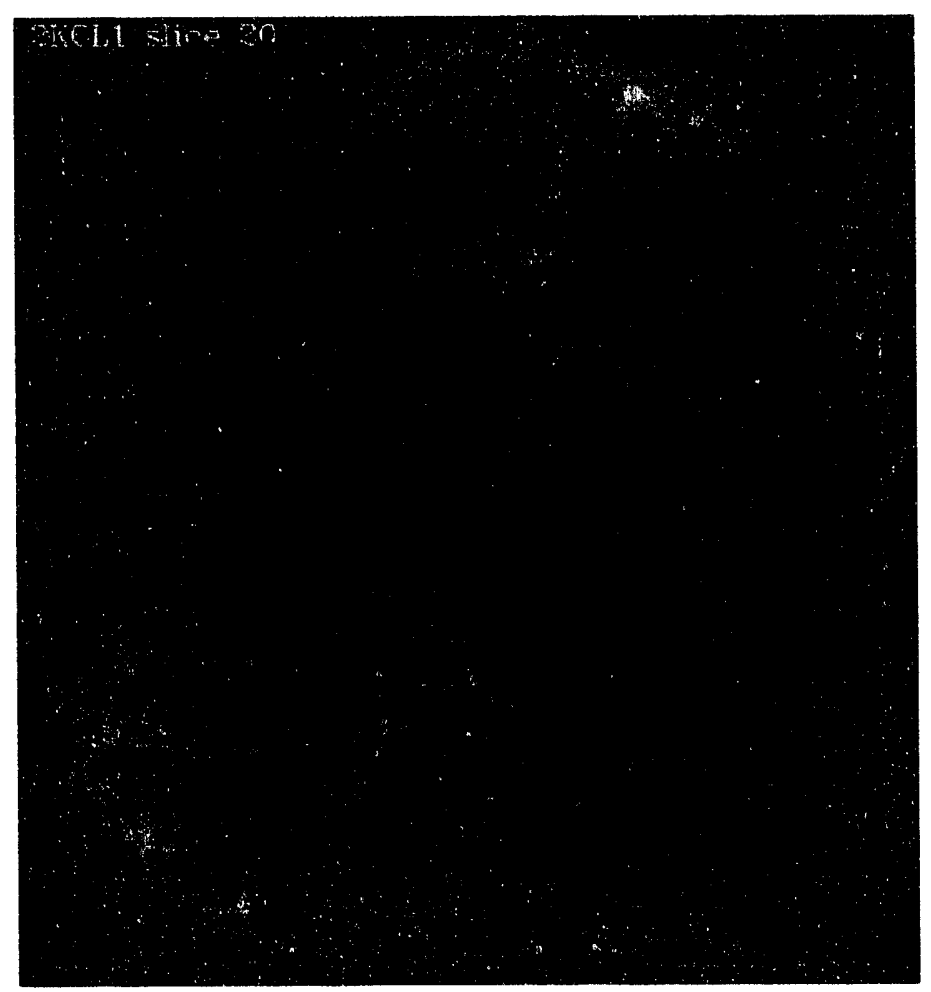

behind the telescope's main mirror. However, too few stars are bright enough at many observing wavelengths to be natural references for measuring turbulence, so we need an artificial reference source.

To create a guide star, we tune the LLNL atomic vapor laser isotope separation (AVLIS) lasers to $589 \mathrm{~nm}$, the resonance frequency of atmospheric sodium atoms, and transport the light by underground pipe to the laser guide star's optical site, where it is directed into the atmosphere. We then measure the characteristics of the resulting emission of the atmospheric sodium layer at an altitude of $95-105 \mathrm{~km}$. We measure spot size, brightness, and stability of the emission as a function of laser power from 7 to $1100 \mathrm{~W}$. Brightness is particularly important, as it determines the accuracy with which atmospheric turbulence can be measured. The measured brightness at $1100 \mathrm{~W}$ agrees with our computational models for the atomic physics of the atmospheric sodium layer.

This year, to demonstrate that the sodium-layer laser guide star is adequate for an adaptive-optics reference, we used a high-speed sensor to compare the wavefront measured using the laser guide star with that measured using a natural star. The two spectra were similar, giving us confidence that sodium-layer laser guide stars are indeed feasible for adaptive-optics systems at large (3- to 4-m) ground-based telescopes using modest laser power $(10-20 \mathrm{~W})$.

\section{The MACHO Project}

Measurements of the observed motions of stars and gas in the Milky Way suggest that the total mass of the galaxy is 10 to 100 times greater than the estimated total visible mass. Thus, most of the matter in our galaxy (and other galaxies as well) must take the form of invisible components we call dark matter. The nature of this dark matter is unclear. Some astrophysicists speculate that it could consist of hypothetical elementary particles such as axions, massive neutrinos, or weakly 
interactive massive particles (WIMPs), while others speculate that it could be made up of brown dwarf stars or planets like Jupiter, neutron stars, or black-hole remnants of primordial stars, which are called MACHOs (massive compact halo objects). We are testing the latter hypothesis.

In 1986, it was proposed that MACHOs would produce a gravitational microlensing signature: when a MACHO moves close to the line of sight between Earth and a background star outside our galaxy, the MACHO's gravitational field acts as an amplifying lens. As the MACHO moves across the field of view, the star appears to brighten and then return to its original intensity. Because all objects in our galaxy are in motion, a highly characteristic pulse occurs in the brightness of the star and provides the MACHO signature.

We have chosen the stars of the Large and Small Magellanic Clouds, two nearby galaxies, as optimum background sources for amplifying MACHO events. Our search should yield millions of convincing events; if we see no events, we can eliminate MACHOs as candidates for dark matter.

For this search, we must make an unprecedented number of photometric measurements on millions of stars. We have modified the $1.27-\mathrm{m}$ reflecting telescope (the Great Melbourne Telescope) near Canberra, Australia (the Magellanic Clouds are visible only from the Southern Hemisphere), designing corrector lenses so that the telescope mirror's parabolic reflector can take in the exceptionally wide field of view required. Our cameras, the two largest charge-coupled-device (CCD) cameras in the astronomy world, are now in routine use on the telescope. We constructed the electronics and software for controlling these cameras and for handling the image data that they produce at a prodigious rate (approximately 32 million pixels every $6 \mathrm{~min}$ ). In 1993, this project received an $\mathrm{R} \& \mathrm{D} 100$ award from $R \& D$ Magazine (see the Awards article, p. 98).

When we complete our survey, we will have analyzed nearly 10 billion photometric measures. By late 1993, we had monitored 3.3 million stars for a year, observing each star hundreds of times in that period. Although we have analyzed only $15 \%$ of our first year's data, we have isolated one remarkable event: over a 34-day period in early 1993, a star appeared to increase to 6.86 times its normal brightness and then returned to normal. Many features of this event were consistent with gravitational microlensing. However, this brightening could be due to some previously unknown intrinsic source of variation, so we must detect other candidate events before we can confidently make far-reaching conclusions.

\section{Space-Based Exploration}

Two advanced technology projects, the Clementine and the Miniature Seeker Technology Integration (MSTI) programs, draw components from our research theatre missile defense. The Clementines, I and II, are spacecraft, whereas the MSTI is a low-orbit satellite. For both vehicles, we have designed essentially the same camera but have modified it to suit the purposes of each mission.

Clementine I, launched January 25 , 1994, will perform a multispectral mapping of the moon's surface and a close flyby of the near-Earth asteroid Geographos. Clementine II, scheduled for launch in spring 1995, will target two near-Earth asteroids, performing both a flyby and impactor experiments. Clementine II will carry an onboard hyperspectral imaging spectrometer and four impactors, two per asieroid. (These impactors derive from antiballistic missile development.) To determine the composition of the asteroid, the impactor will strike the asteroid, producing a flash that will be recorded by a hyperspectral imaging system to capture the spectral information needed for analysis.

The Clementine spectrometer uses a wedge-shaped filter (called a linear variable filter) located at the focal plane of the imaging camera. Looking through the linear variable filter is like looking through rainbow-colored glasses. For example, if the filter is set to span the entire visible spectrum, the scene will vary from red at one end to blue at the other. To obtain an image of a scene in only one wavelengthsay, in blue - one takes a sequence of side-by-side images while moving the blue region of the filter across the scene. The motion of the spacecraft past the asteroid moves the imager across the scene to generate the sequence of images.

We are developing a different version of this same instrument for an upcoming MSTI-3 satellite experiment, scheduled for launch into low-Earth orbit in the summer of 1994. The MSTI cameras differ from the Clementine cameras chiefly in the choice of spectral filters and image-integration times. The MSTI iterations started life in the Brilliant Pebbles program. Although the cameras for the MSTI- 1 and 2 satellites have insufficient resolution and too much signal noise for tracking dim objects, such as missiles after burnout, they are well suited to weather prediction, environmental monitoring, and gathering data for validating models of cloud dynamics.

\section{Summary}

LLNL scientists conduct physics research ranging from the subatomic to the extragalactic. We design and build devices to investigate the innermost workings of atoms and nuclei. We also design and build cameras to collect extragalactic evidence about the nature of dark matter. We use massively parallel computers and first-principles physics to custom-design materials that do not yet exist. Physic research at the Laboratory advances our scientific understanding of the universe and its building blocks and makes it possible to measure the effects of our activities on the world around us.

\section{For further information contact} Harold C. Graboske (510) 422-7264. 


\title{
istry \& Materials Science
}

\author{
We are synthesizing new materials and devising ways to create unique structures, \\ manipulating objects at atomic or near-atomic levels of resolution, and exploring new \\ processes and technologies with innovative end applications.
}

\section{ect in $C \& M S$, we are ' explosive formulations , more energetic i explosives) and -w high-energy-density $e, C \& M S$ researcher mines under a microscope $\boldsymbol{B}$ (triaminotrinitro- urrent insensitive high sice. The background ows TATB crystals at high}

HEMISTRY and materials science affect almost every aspect of our lives, from the production of cleaner, cheaper energy to national defense and U.S. economic competitiveness. The Chemistry and Materials Science (C\&MS) Department directly supports LLNL programs, performs both basic and applied research and development, and initiates leading-edge science and technology programs that will develop into major programs of the future.

The chemistry and materials science community at large has come to recognize that an understanding of the field is

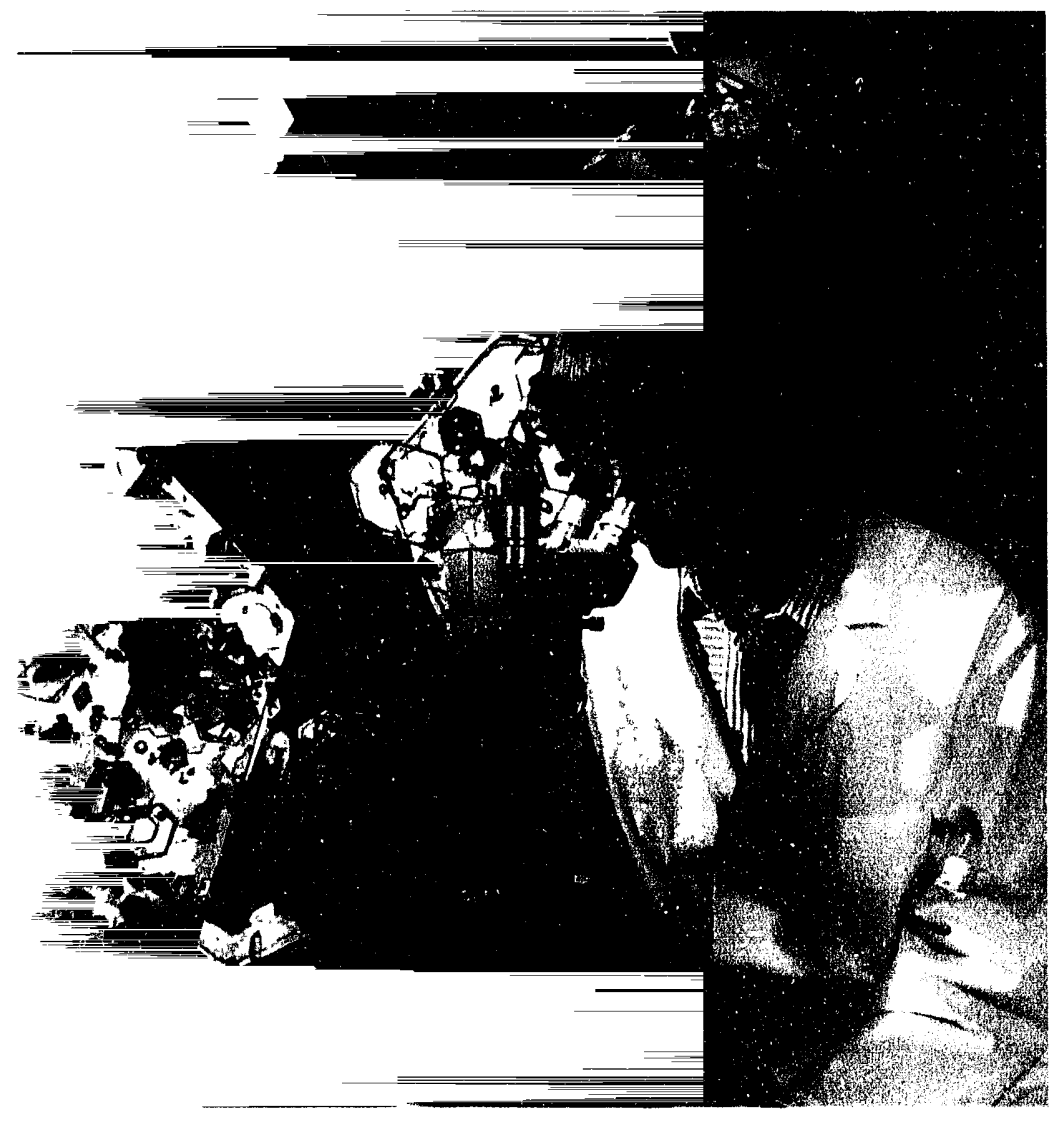

much clearer when viewed from the perspective of the steps by which new materials or processes are developed and then put to use. No longer do we make distinctions along the lines of physical chemistry, organic chemistry, analytical chemistry, etc. Rather, it makes much more sense to view $\mathrm{C} \& \mathrm{MS}$ activities according to the methods we use in our research: (1) synthesis and processing of new materials, (2) characterization of the structure and properties of the materials, and (3) evaluation of material performance for specific applications. In each step, fundamental theory, modeling, and simulation provide essential guidance and feedback. Our main activities in these areas are summarized below. - Materials Synthesis and Processing. We are studying bicrystals, composites, advanced alloys, energetic materials, glasses and laser materials, lightweight porous materials, coatings and surface modifications, nanoengineered materials, catalysts, chemical processing, surface physics and chemistry, aerogels, and welding and joining.

- Characterization and Performance Evaluation. We have core strengths in electron and probe microscopies, photoelectron spectroscopies, photon and neutron scattering, magnetism and transport, femtosecond spectroscopy, nuclear magnetic resonance (NMR) imaging, Mossbauer imaging, mechanical and micro testing, ion-beam characterization, surface analytical techniques, mass spectroscopy, and trace analysis (for forensics).

- Theory, Simulation, and Modeling. Our theoretical efforts involve materials by design, such as alloys, interfaces, 
heterogeneous materials, adhesives, molecular solids, and materials for microelectronics and optoelectronics. They also include molecular dynamics of surface processing, film growth, plasma processing, machining of metals and ceramics, transport phenomena, burn fronts and detonation, and equations of state (mathematical expressions that relate the volume of a material to pressure and temperature).

In the following sections, we highlight a few of our C\&MS projects and discuss some of the most important accomplishments made this year. These projects are multidisciplinary, cutting across the traditional boundaries of the scientific disciplines. Every projectbe it primarily synthesis and processing or characterization and evaluation-relies heavily on fundamental theory, simulation, and modeling to provide guidance and feedback.

\section{High Explosives}

Researchers in our Chemical Sciences Division are responsible for developing and characterizing all the energetic materials (high explosives and propellants) to support DOE and DOD programs at the Laboratory. The objective is to develop new explosive formulations, binary explosives, composite explosives, and new insensitive high explosives as well as to synthesize new high-energy-density molecules. We want to understand the behavior of these materials both theoretically and experimentally and to use environmentally conscious materials. An adjunct program is developing processes to deal with the explosives from dismantled nuclear weapons.

The computer models, synthesis and formulation processes, and characterization techniques we are using with explosives are applicable to other materials as well. For example, we are applying the same codes to model the flow of resin during the fabrication of fiber composite structures. The waste-destruction, recovery, and minimization methods we developed specifically for energetic materials used in nuclear weapons are applicable to a variety of industrial hazardous wastes and processes.

Safety is the primary focus of our synthesis research. Our goal is to synthesize new materials that will contain more energy than TATB (triaminotrinitrobenzene), the current compound of choice for its extreme stability and insensitivity (see the figure at left). In one thrust area, we are studying easily synthesized, moderately energetic materials as building blocks to form new insensitive high explosives. In another, we are synthesizing heterocyclic rings containing nitro and amino groups. We will process these new molecules to create energetic materials that provide an optimal balance of safety and performance.

Theory and modeling complement and guide these efforts. Molecular dynamics methods predict the crystal structure of organic compounds by allowing the crystal to cool out of a melt. Quantummechanical methods estimate the heat of formation. Computational methods we have developed give us a better understanding of energy transfer between vibrational and phonon modes. At first, we modeled the interactions of simple energetic molecules; now we are moving on to more complex species, such as HMX. Our models provide the first detailed theoretical description of

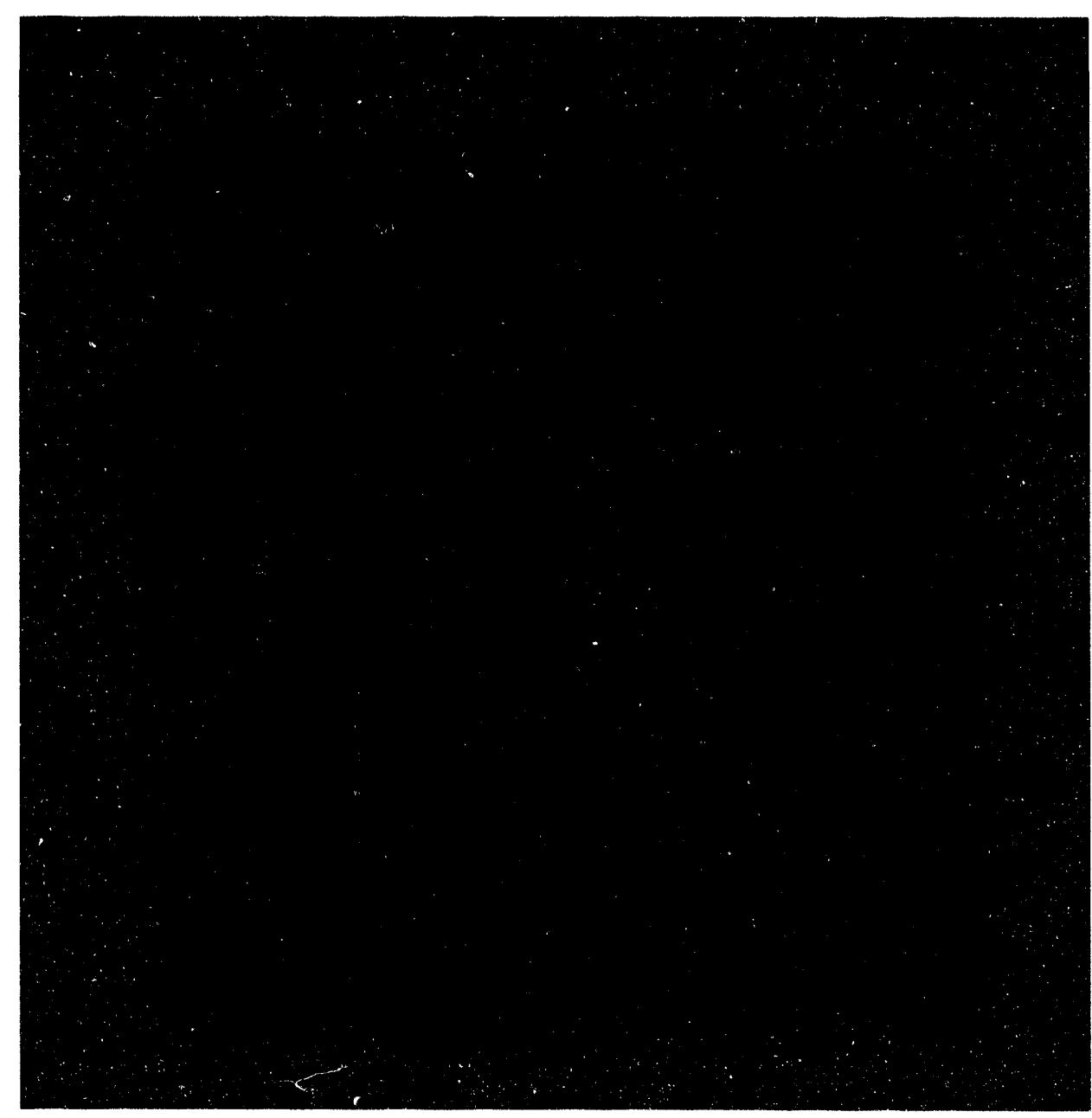


the initial stages of chemical reactions in high explosives.

The equations of state (EOSs) of unreacted explosive and its reaction products are essential for determining the useful work done by detonating solid explosives. Our continued research in this area will allow EOSs to become much more realistic as they are able to calculate measurements over a wide range of pressures, volumes, and energies.

Modeling is complemented by our large experimental and characterization program. We are applying modern laser spectroscopy techniques to study processes at the molecular and atomic level in the interactions of energetic

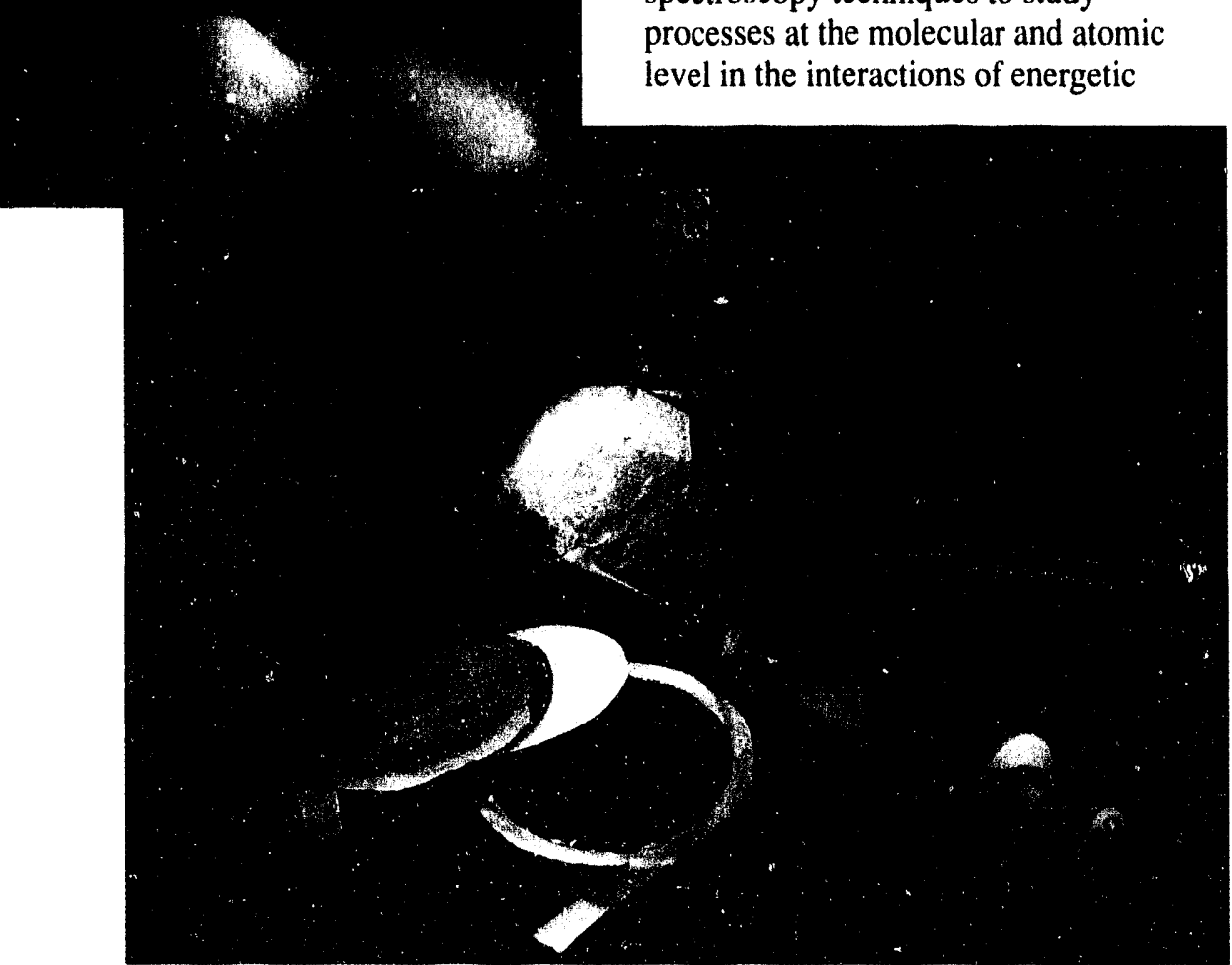

Aerogels are porous materials with an ultrafine pore size, a high surface area, and a matrix of interconnected particles of chains. The nanostructures of aerogels are responsible for their unique optical, thermal, acoustic, mechanical, and electrical properties. We have synthesized various organic and inorganic aerogels (inset photo), tailoring their structures and properties for specific applications. In the aerocapacitor (the components of which are shown in the large photo), the low electrical resistivity of the aerogel network and the large surface area per unit volume of aerogel material are being exploited to create a supercapacitor with high specific energy $(\sim 5 \mathrm{~W} \cdot \mathrm{h} / \mathrm{kg})$ and power $(\sim 10 \mathrm{~kW} / \mathrm{kg})$; such a device can be used for load leveling in electric vehicles. materials. The techniques include highpressure experiments in diamond-anvil cells and femtosecond pump-probe experiments. (A femtosecond is one thousandth of a millionth of a millionth of a second, or $10^{-15} \mathrm{~s}$.) Such experiments give us benchmark data for more sophisticated theoretical interpretations.

For the vast array of munitions being returned to U.S. strcispiles, we are pursuing industrial partners to further explore environmentally sound alternatives to open burning and open detonation, now the most widely used disposal techniques. The newly formed Energetic Materials Center, a joint LLNL-Sandia venture, is increasing our interactions with academia and industrial staff. We anticipate that the Center will support graduate students while they pursue advanced degrees and be the focus of industrial collaboration.

Through a Memorandum of Understanding with the Office of Munitions, we have developed explosives such as LOVEX - a low-cost, massproducible, low-vulnerability explosive. We have also performed initiation studies and are developing underwater explosives for the DOD. Waste processing and minimization for the DOD complex have been a priority with the development of extrusion cast explosives (ECX).

\section{Aerogels}

Aerogels are porous materials that have an ultrafine cell and pore size $(<100 \mathrm{~nm})$, extremely high surface area (400 to $1100 \mathrm{~m}^{2} / \mathrm{g}$ ), and a solid matrix of interconnected colloidal-like particles or fibrous chains with characteristic diameters of $10 \mathrm{~nm}$. This small-scale structure (nanostructure) of aerogels is responsible for their unique optical, thermal, acoustic, mechanical, and electrical properties. For example, aerogels can be prepared as transparent porous solids because their ultrafine cell and pore size minimizes light scattering in the visible spectrum. 
Aerogels are also one of the few monolithic materials in which we can clearly delineate the benefits of cluster assembly and controlling structure at the nanometer scale.

Aerogels fall into two classes, inorganic and organic. Inorganic aerogels are formed from the hydrolysis and condensation of metal alkoxides. We have demonstrated a unique, two-step, sol-gel polymerization of tetramethoxy silane (TMOS), which gives us inorganic silica aerogels with densities ranging from $0.003 \mathrm{~g} / \mathrm{cm}^{3}$ (two to three times the density of air) to $0.600 \mathrm{~g} / \mathrm{cm}^{3}$ (about half the density of water). The properties of our silica aerogels can range from gas-like to solid behavior, depending on their density. Silica aerogels in thin layers have important applications in the potential development of integrated circuits with five- to tenfold improvement in processing speed.

We have also developed new ways to make organic aerogels based on resorcinolformaldehyde, melamine-formaldehyde, and carbon chemistry. We have synthesized organic materials with densities ranging from 0.035 to $0.900 \mathrm{~g} / \mathrm{cm}^{3}$. Organic aerogels have improved thermal and mechanical properties over silica aerogels and are cheaper to process. Carbon aerogels can be synthesized from organic aerogels and have potential use in energy and power storage, with expected order-of-magnitude improvements over current technologies.

The ability to tailor the structure and properties of aerogels at the nanometer scale opens up exciting possibilities. Aerogels are superinsulators with low thermal conductivities of $\sim 0.015 \mathrm{~W} / \mathrm{mK}$ under ambient conditions, about three times lower than conventional chlorofluorocarbon-blown foams. Because aerogels also exhibit low longitudinal sound velocities $(<100 \mathrm{~m} / \mathrm{s})$, they can be used as coatings for impedance-matching ultrasonic transducers to air. Carbon aerogels are particularly important because they are the first electrically conductive aerogels to be made. We are exploiting the low resistivity of the aerogel network and the large surface areas per unit volume in supercapacitors that have both high specific energy $(\sim 5 \mathrm{~W} \cdot \mathrm{h} / \mathrm{kg})$ and power $(\sim 10 \mathrm{~kW} / \mathrm{kg})$ densities. Such devices can be used for load leveling in electric vehicles (see the Energy section, p. 50). Other applications of aerogels include thin-film dielectrics, gas adsorbents, Cerenkov detectors, cosmic-dust collectors, catalysts, and filters.

\section{Scanned Probe Microscopies}

Materials scientists need to be able to examine atomic-scale flaws in crystals, microelectronic engineers must lay out circuit patterns only a few tens of atoms thick, and biologists want to study single molecules of protein or DNA. Until recen.ly, this minute world could only

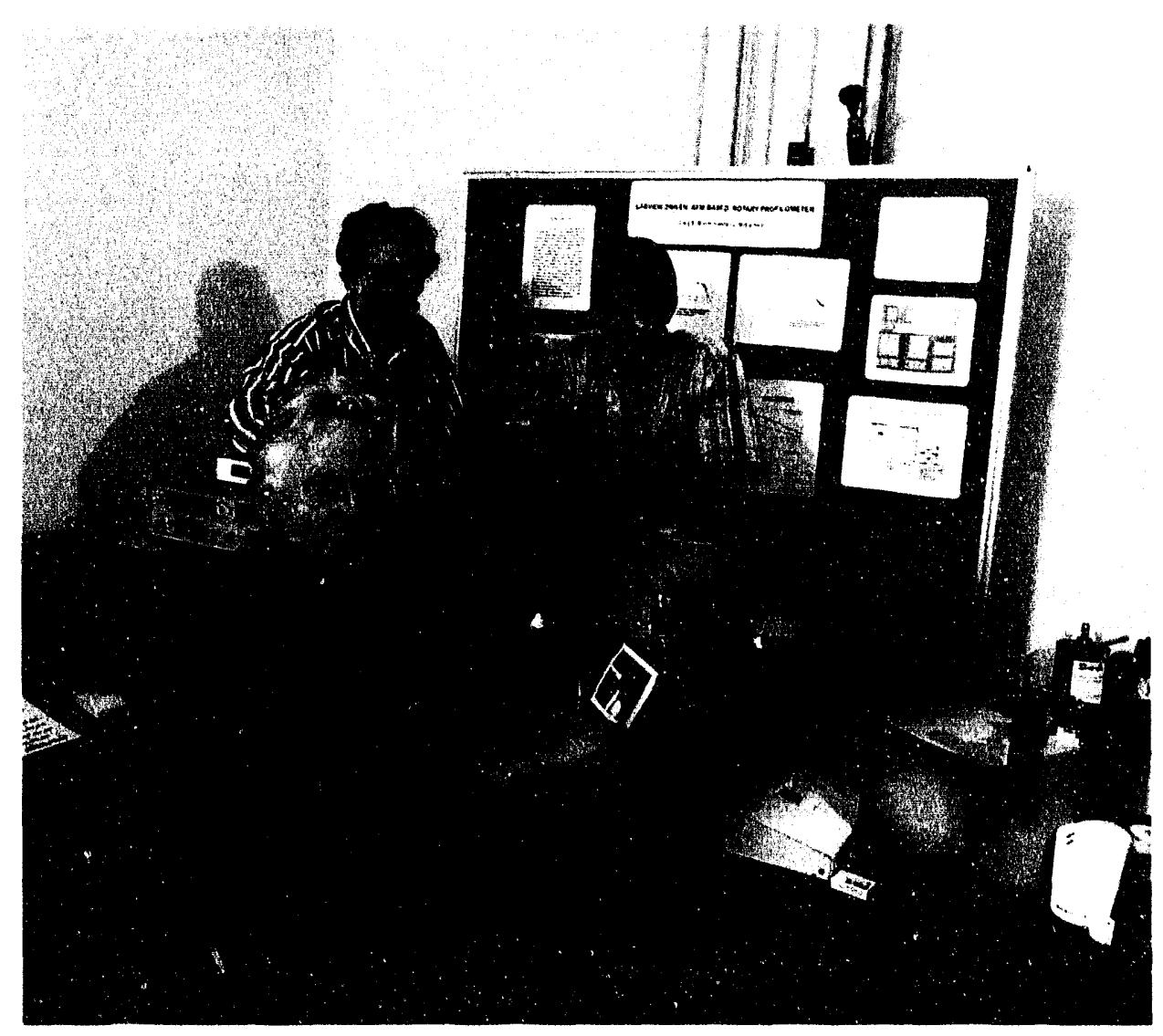

Using the scanning tunneling microscope (STM), we have studied on the atomic scale the nucleation and growth of one material deposited onto another. 
be seen by cumbersome, often destructive methods, such as electron microscopy and $x$-ray diffraction.

A family of new microscopes opens this realm to direct observation. Two instruments, the scanning tunneling microscope (STM) and the atomic force microscope (AFM), have changed the way we think about materials problems and how to solve them. Moreover, the tiny probes-as small as a single atom in diameter-can be used as tools to manipulate materials and to induce chemical reactions on the atomic scale.

The probe in the STM is a tungsten wire sharpened so that the tip consists of only a single atom. The tip is mounted onto piezoelectric crystals that move the probe across the surface of an electrically

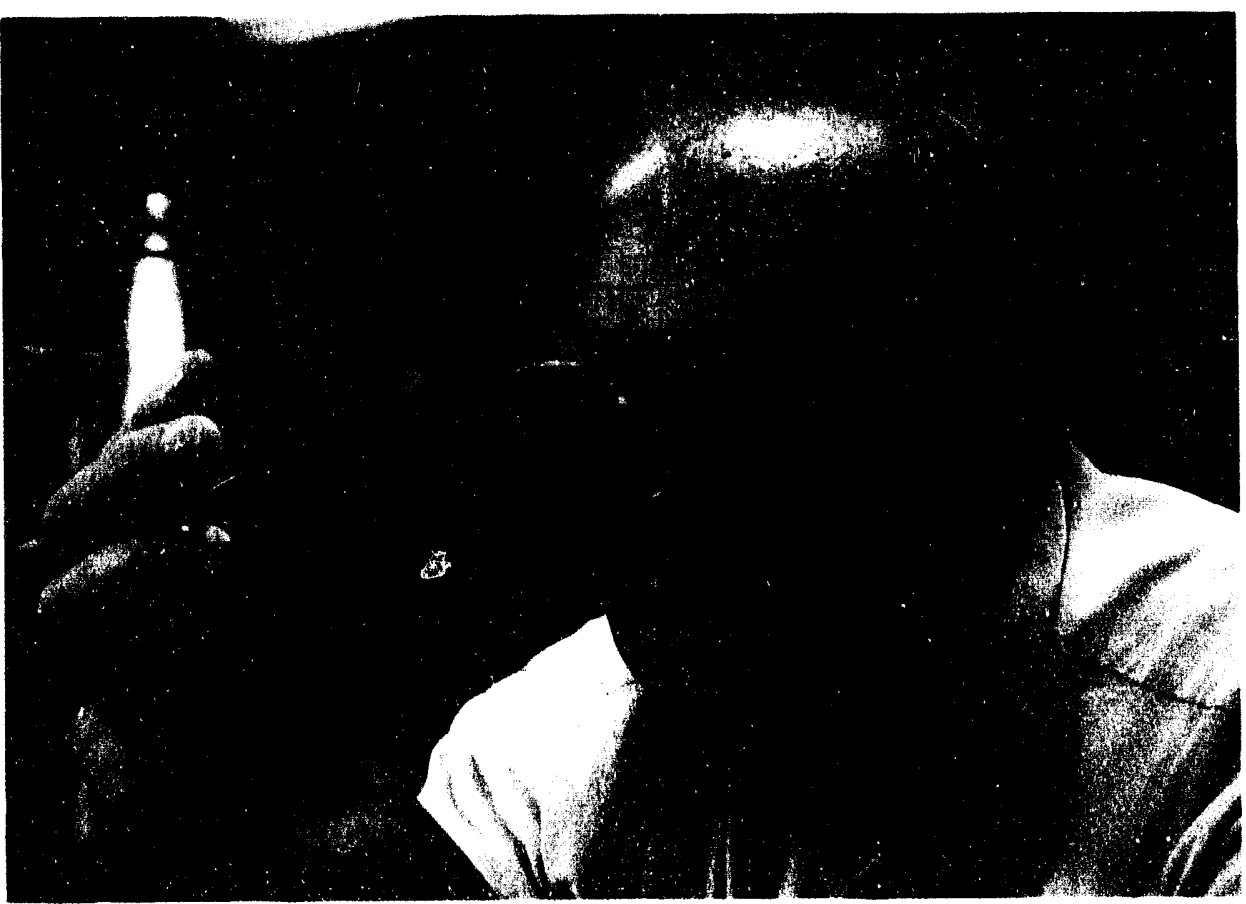

Multilayer materials can be prepared using elements from all parts of the periodic table using various atom-by-atom synthesis techniques (such as molecular beam epitaxy). We have recently developed processes for depositing thick, nanostructured multilayers (up to $500 \mu \mathrm{m}$ thick and 50,000 layers); previously, multilayer materials had been limited to thickness of less than $\sim 0.5$ um. Here, C\&MS researcher Troy Barbee examines one such high-quality, thick multilayer sample. conducting specimen. Individual atoms on the surface are sensed through the tunneling current of electrons across the gap between the tip's last atom and the surface's nearest atom. Because this current is highly sensitive to the width of the gap, electronic feedback controls can sense a height profile of the surface at atomic resolution.

We operate the STM in ultrahigh vacuum to study epitaxy (crystal growth) on the atomic scale and the nucleation and growth of one material deposited onto another. We find that the deposited material forms clusters on the surface in the early stages of deposition. The STM can also be operated in air to determine the epitaxy of organic molecules, an important topic in the emerging science of lubrication and friction.

In studying the site specificity of chemical reactions $\left(\mathrm{O}_{2}\right.$ and $\left.\mathrm{O}_{3}\right)$ reacting with $\mathrm{C}$, we have shown that extremely low reaction rates (down to one atom per day per site) can be accurately determined by STM. We have measured chemical attack at grain boundaries in situ. We have also induced local chemical reactions important in the electronics industry, such as the growth of $\mathrm{SiO}_{2}$ on $\mathrm{Si}$, and the removal of silicon atoms by $\mathrm{XeCl}_{2}$.

Whereas the STM is largely restricted to imaging electrical conductors, the AFM overcomes this limitation. In an AFM, piezoelectric crystals move a minute tip (such as an atomically sharp, hard material like diamond or $\mathrm{Si}_{3} \mathrm{~N}_{4}$ ) mounted onto a cantilever. Deflection of the cantilever, induced by individual surface atoms, is detected by a photocell as the shifting of a laser beam reflected off the cantilever. The signal from the photocell activates the piezoelectric crystal to maintain steady tip displacement. AFM instruments can operate in vacuum, in all optically transparent fluids, and are small enough for many experimental setups. 
We are using the AFM to study how atomic-scale defects can initiate laser damage on the surface of optical components. We have shown that atomicscale defects on graphite (carbon) initiate damage, and that defects in optical multilayers lead to catastrophic failure. We are studying defects during the growth of KDP (potassium dihydrogen phosphate), which is an essential material for frequency conversion in lasers. The deposition and growth of polymeric materials onto a substrate, also of importance for laserfusion target fabrication, has been studied by AFM. Moreover, we are measuring the roundness and roughness of laser-fusion spheres on the atomic scale by spinning a finished fusion sphere mounted on an air bearing under the tip of an AFM.

Among many other projects, we are applying AFM techniques directly at the diamond-turning lathe and comparing the results to molecular models of diamond turning. In the important field of biomaterials, AFM can tell us how lasers interact with the dentin in teeth. This work will help define wavelength, laser intensity, and laser pulse length for laser drilling of teeth in dentistry. Finally, we have developed and submitted for patenting a technique to use the AFM as a "nanotome." Our technique can cut biological and inorganic materials on the nanometer scale, compared to the micrometer scale for traditional microtomes.

\section{Multilayer Materials}

Multilayer materials engineered at the atomic level are dense, ultrafine-grained, high-interface-concentration solids characterized by truly microscopic microstructures and thus by large interfacial area-to-volume ratios. Although multilayer materials are widely known and studied, the most visible of these materials have been semiconductor superlattices synthesized using molecular beam epitaxy. Nevertheless, multilayers can be prepared using elements from all parts of the periodic table and with a variety of techniques for atom-by-atom synthesis.

Until now, a major constraint of nanostructured multilayer materials has been thicknesses, which are limited to less than about $0.5 \mu \mathrm{m}$. We recently developed processes for depositing thick nanostructured multilayer materials. We have now fabricated freestanding, highquality structures up to $500 \mu \mathrm{m}$ thick and containing up to 50,000 individual layers. Our samples are highly uniform and have areas of up to $700 \mathrm{~cm}^{2}$.

Our developments move multilayers out of the realm of thin-film $x$-ray optics and solid-state electronics into bulk structures and other applications. The new structures have the potential for exceptional mechanical performance as a result of their microstructures and atomic distribution. In addition, mechanically active flaws that often limit mechanical performance are controllable so that the full potential of structural control and theoretical properties becomes accessible. We envision a variety of applications ranging from those that require unique strength or hardness to new electronic uses, such as high-performance capacitors and thermoelectrics.

\section{Conclusions}

C\&MS strives to provide the best support possible to all the programs at LLNL. At the same time, we use our interdisciplinary approach of weaving theory, modeling, and simulation with synthesis, processing, and characterization to initiate leading-edge science and technology projects that will develop into major programs for the future.

To ensure that we remain at the leading edge of scientific research, we have a vigorous postdoctoral research program so that we are constantly exposed to new ideas and techniques. Our strong ties to universities the world over are now being extended to industrial partners so that we can better understand the needs of U.S. industry in the coming decade. Our basic and applied research will lead to new products and processes that will enhance U.S. competitiveness in the world marketplace, provide for enhanced energy efficiency in an environmentally conscious world, and contribute to national security.

For further information contact Jeffrey Wadsworth (510) 423-2183. 


\section{puters \& Computing \\ Computations are central to virtually all the work done at the Laboratory. Because our ever growing demands must keep pace with increases in the speed and power of computers, we are crossing the threshold into the world of massively parallel processing.}

OMPUTERS have revolutionized not only the way we gather, store, and retrieve information at the Laboratory but also the way we practice science. Today, a large part of research and development is rooted in a partnership of computer simulation and experimentation; as computer simulation becomes more capable, the need for expensive experiments decreases. Computers have enabled us to extend our design and predictive capabilities and therefore our ability to make breakthrough discoveries in virtually every field of science-from physics, material. ince, and chemistry, to engir logy, biology, and med ear, a new computer architc i'grades of an existing network, several new computer models and research initiatives, and collaborative efforts with businesses in the computer industry had a significant effect on the Laboratory's work in energy, the environment, defense, health, and

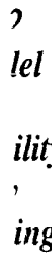

? lel ility ing

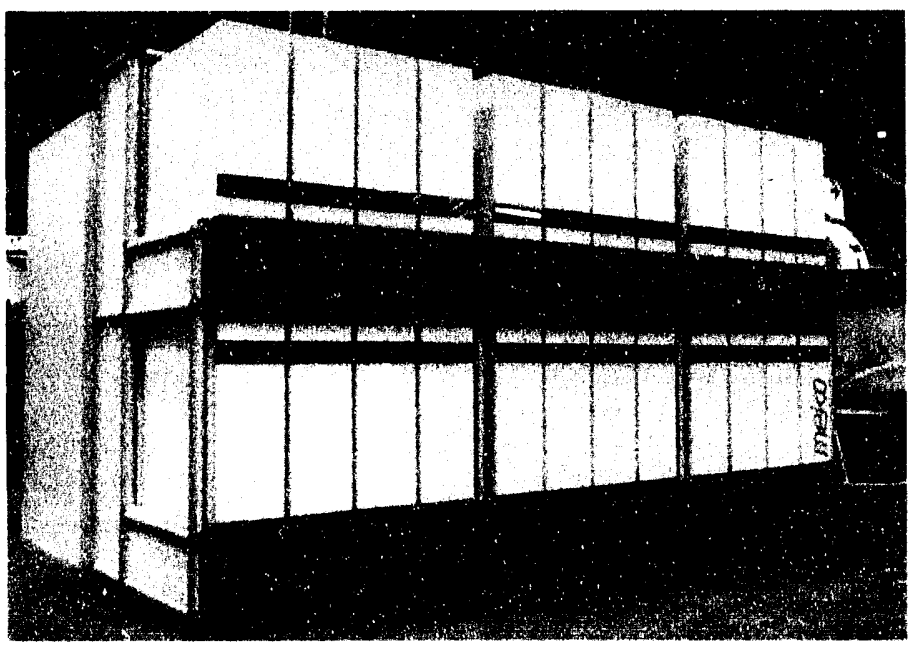

technology transfer. We present here a representative selection of these computerrelated accomplishments.

\section{Massively Parallel Processors for Production Workloads}

Traditionally, the Laboratory has relied on improvements in the performance of the central processing units in supercomputers to increase computer speeds. In recent years, however, improvements in the performance of supercomputers have become harder and harder to achieve. At the same time, the speeds of inexpensive, microprocessor-based computers have increased to the point that they rival those of supercomputers. This has spurred interest in the use of massively parallel processors (MPPs), high-performance supercomputers in which large numbers of processors divide the parts of a problem into fragments so that each processor works on a different fragment at the same time.

Our two supercomputing centers, the Livermore Computer Center and the National Energy Research Supercomputer Center (NERSC), have taken steps to move from a conventional supercomputing environment to a massively parallel environment. At the Livermore Computer Center, which serves both classified and unclassified programs, we will be using the newly acquired Meiko CS-2 MPP (which has 256 processors) and a migration strategy called the Livermore Model (which enables us to partitio: a massively parallel environment so that monoprocessing, multiple processing, and massively parallel processing can be performed simultaneously). The first shipment of 
64 Meiko CS-2 processors arrived at LLNL in December 1993.

Since the individual processing elements of the Meiko CS-2 are more powerful than the original Cray-1 computer, we will use the MPP in a capacity mode-that is, processing large numbers of serial jobsas well as in a capability mode-that is, processing single applications or several parallel applications. In addition, since it must accommodate large physics applications that consist of three to ten separate packages, each with its own data structures and algorithms, the MPP will also have to support multiple programming styles within a single application.

We will use the Meiko CS-2 primarily in a capacity mode with a small number of parallel applications, such as modeling global climate and electromagnetic propagation and simulating nuclear weapon performance. The next step is to migrate key applications that will benefit most from increased capability, such as the Monte Carlo codes, physics models, and global climate models being used in many of our computing initiatives. At NERSC, a DOE study of the need for production-level, massively parallel computing in energy research was completed. The study recommends that we begin the competitive procurement actions necessary to acquire a full-scale MPP by fiscal year 1995; it also advises the development of a production quality MPP capability to replace conventional supercomputing at NERSC. These steps are under way.

Overall, our goal is to achieve a massively parallel environment for the Laboratory's high-performance computing facilities by the end of this decade.

\section{The Numerical Tokamak}

This year, as part of the Numerical Tokamak Project, a national effort to study the possivility of using fusion energy reactors to generate electrical power, we began to use massively parallel computers to simulate the fluid turbulence in tokamak (toroidal, or donut-shaped) plasmas. Our goal is to predict the scaling behavior of plasma transport in tokamaks. We are particularly interested in how piasma turbulence changes with the size of the tokamak and the shape of the electrical plasma current. Earlier numerical models could represent small- or large-scale disturbances separately but could not resolve both types of disturbances simultaneously. This simultaneity of smalland large-scale disturbances is a key feature of strong turbulence that we will be able to address with our new massively parallel numerical models.

\section{Global Climate Modeling}

With uncertainty about the effects of human activities on local and global environments, climate models have an obvious timeliness. Atmospheric models are well along in development at many institutions worldwide, but oceanic models are less advanced. As part of our long-range plan for a comprehensive climate systems modeling capability, we are developing an advanced generation of climate models that will operate in parallel environments. This year, we completed an atmospheric climate model that incorporates hydrodynamics and column physics as well as a modular oceanic model that includes detailed bathymetry and coastline boundaries. Both models use latitude, longitude, and a vertical coordinate as independent variables. They are portable, being able to take advantage of the features peculiar to different computer architectures. We will begin to exploit this portability in the near future.

We are working on coupling these models and others, such as a land surface model and an atmospheric chemistry model, under a single driver on the Meiko CS-2 to predict long-term climate changes. The vector processors and large memory of the Meiko CS-2 MPP will allow us to increase the accuracy of these models and still reduce turnaround time, both of which are necessary to make accurate predictions of the climate over decades.

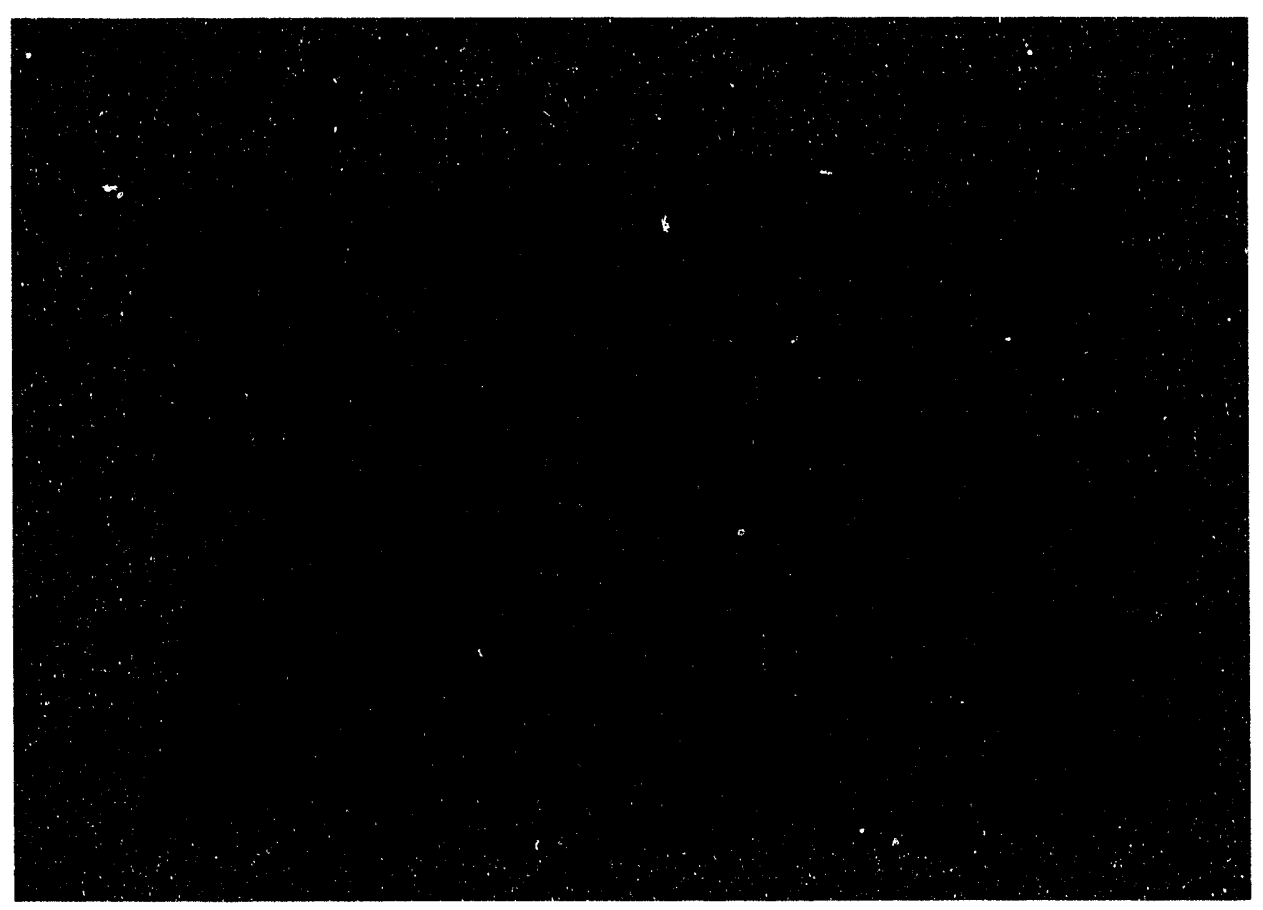




\section{Scientific Visualization}

In recent years, as computers have grown in speed and memory size, they have been applied to ever larger, more complex problems. The tens of gigabytes of data being generated by today's supercomputers on such problems defy the standard methods of analysis-there is simply more information than a researcher or team of researchers can process and analyze in a reasonable amount of time. Scientific visualizationthe conversion of quantitative data into visual representations-has therefore become a most important tool.

Visualization tools are necessary to the understanding of the scalar and vector outputs of global climate simulations. Algorithms (well-defined calculational procedures) convert the masses of raw data (whether collected at sensing stations or generated by computer simulation) into visual formats that the users assign and with which they can interact. We have developed several techniques for

\section{A two-dimensional latitude/longitude domain decomposition used for parallelizing global climate model components.}

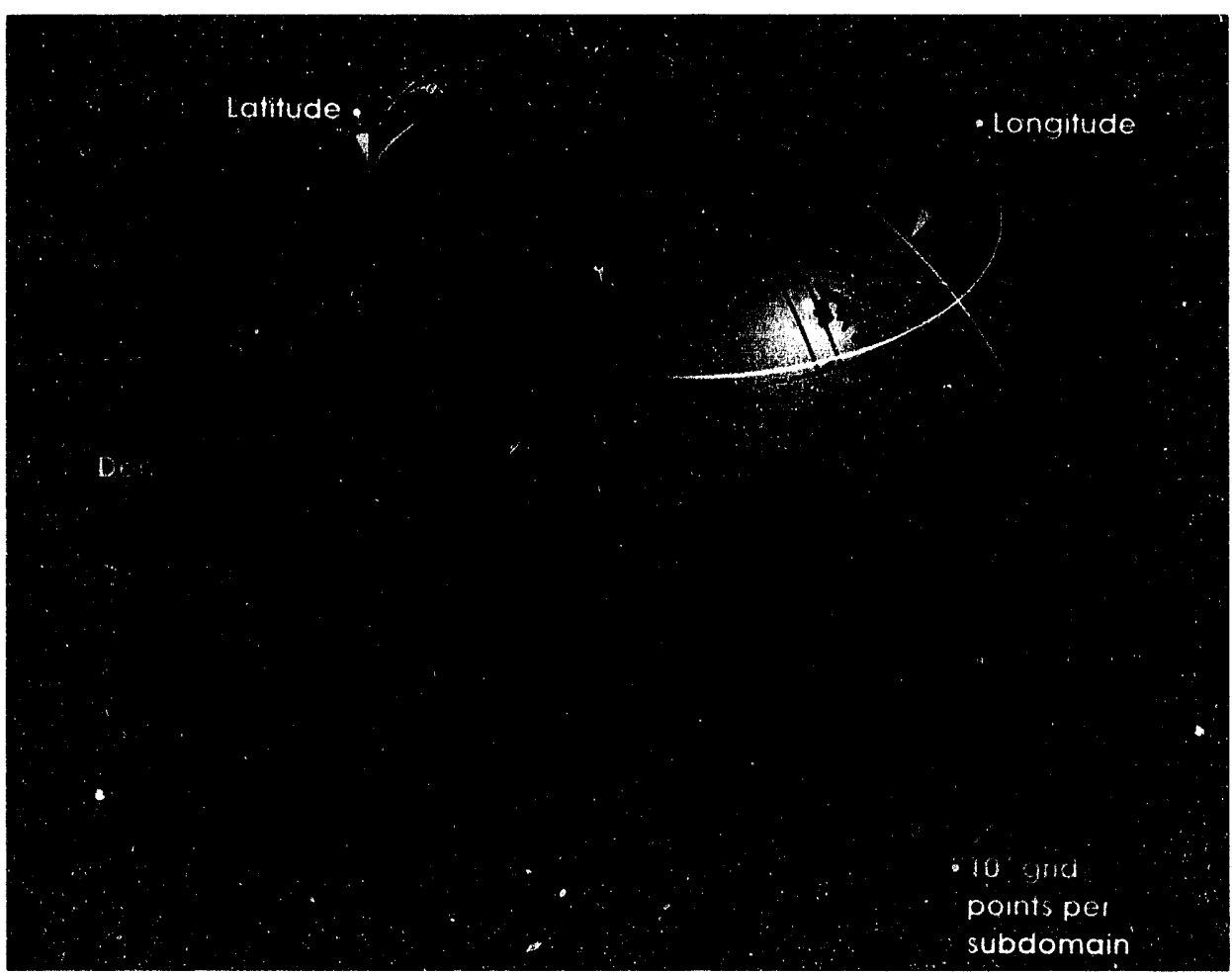

visualizing these climate variables, particularly clouds and wind velocities. All involve algorithms for converting numerical data into optical properties, such as color and opacity. These algorithms represent advances in the state of the art, providing new visual effects, particularly for overall views of large datasets.

This year, we used scientific visualization to produce an award-winning high-definition television (HDTV) animation showing the simulated global cloud motion during ten days in January. The climate simulation was run on a Cray- 2 computer at NERSC. The computational grid was defined by 320 evenly spaced longitudes, 160 unevenly spaced latitudes, and 19 unevenly spaced vertical levels. This grid has nearly a million data points. Among the variables that can be output are temperature, pressure, humidity, wind velocity, short-wave and long-wave radiation, and cloud density.

Although much of our visualization effort has been applied to atmospheric research, it can be applied to virtually any field of scientific investigation that generates or collects three-dimensional data, right down to the simulation of atomic and subatomic events.

\section{Applied Computations}

A good portion of the Laboratory's computational research is devoted to developing numerical algorithms for various scientific and technical applications. For example, we recently developed Parflow, a computer model that simulates the flow of groundwater and contaminants in soil. This computational tool, which will be used to design and evaluate environmental remediation strategies, surpasses existing technology because it can model the full three-dimensional, heterogeneous, subsurface geometries that are needed to study physical phenomena such as the nonuniform dispersion of contaminants. It has been designed for use on all distributed memory systems, ranging 
from workstation clusters to massively parallel computers.

In another project, our computational models were used to develop steel highefficiency particulate air (HEPA) filters. These uniquely designed stainless steel filters will replace common glass-paper filters used by the nuclear industry. A HEPA filter made of steel can handle the high temperatures in a nuclear environment, and its reuse enables us to reduce the amount of material entering waste streams. We are also developing a filtration modeling system that will allow us to explore new air-cleaning concepts and to interpret test data from existing air-cleaning systems. The filtration modeling system will also reduce the number of physical prototypes needed to optimize air-cleaning systems. Thus, through computer modeling, we are replacing qualitative uncertainty with quantitative precision in filter development.

\section{Using Computers in the Design of Anti-Cancer Drugs}

In December 1993, we signed a threeyear, \$6 million CRADA with BioNumerik Pharmaceuticals (San Antonio, Texas) and IBM's RISC System 6000 Division (Austin, Texas) to write new computer programs that will help speed the development of anti-cancer and cardiovascular drugs. The goal of this project is to develop "pharmaceutical discovery software" and simulation technologies that can be used to advance research on drugs currently being developed and to help design new ones. According to BioNumerik, the computer simulations will help researchers characterize and identify the molecular interactions of proteins or DNA that have been altered by cancer. Using this information, the company will be able to develop "selective" anti-cancer drugsthose that kill cancer cells but spare normal cells. The drugs will be applied to the most common and lethal cancers (solid tumors of the lung, breast, colon, prostate, and pancreas that do not respond to current chemotherapy) and should result in better treatments and fewer side effects for cancer patients.

The pharmaceutical software will be written in Sisal, a Laboratory-developed language that is particularly suited to parallel programming and will run on an advanced RISC-based parallel computing architecture being developed by IBM. However, because of the inherent portability of the Sisal language (it runs on Cray supercomputers, the Convex II, IBM RISC/6000 machines, Silicon Graphics and Sparc workstations, and Encore Multimax machines), the software will also be able to be run on different makes of computers and in different computing environments without sacrificing performance.

BioNumerik estimates that when combined with its in-house expertise in chemistry, biology, and pharmacology, the three-party CRADA in software development and high-performance computing could save $\$ 200$ million in development costs per drug and cut years off the time it takes to bring a new drug to market.

\section{The National Storage Laboratory}

In recent years, transferring and storing information has become a major challenge in computing. Because of the volume of demand and the size of datasets and models, users can now wait for hours-or even days - to retrieve their supercomputer data. Although today's storage systems can move 10 to 20 million bits of information per second, they fall far short of accommodating today's computing needs. Because of large applications, supercomputing, massively parallel srocessing, and high-performance workstations, we now need storage systems that can move 100 million to 1 billion bits per second. Last year, LLNL and six companies with interests in highperformanice storage systems joined together in a collaborative research project called the National Storage Laboratory
(NSL) to investigate, demonstrate, and commercialize technologies that can be used for such a system. Their goal was to develop a prototype storage system that could accommodate diverse data types, very large datasets, and very high rates of data transfer. Today, a prototype storage system is up and running at NERSC, and participation in the NSL project has expanded from the seven original members 1 to 26 members ( 20 private companies and 6 national laboratories).

The first software developed for the NSL features network-attached storage, dynamic storage hierarchies, layered access to storage-system services, and extensive storage-system management capabilities. A commercial version of this software, developed late in 1992 by IBM Federal Systems Company, is currently running at NERSC as a demonstration system connected to a Cray-Y/MP-C90 and a
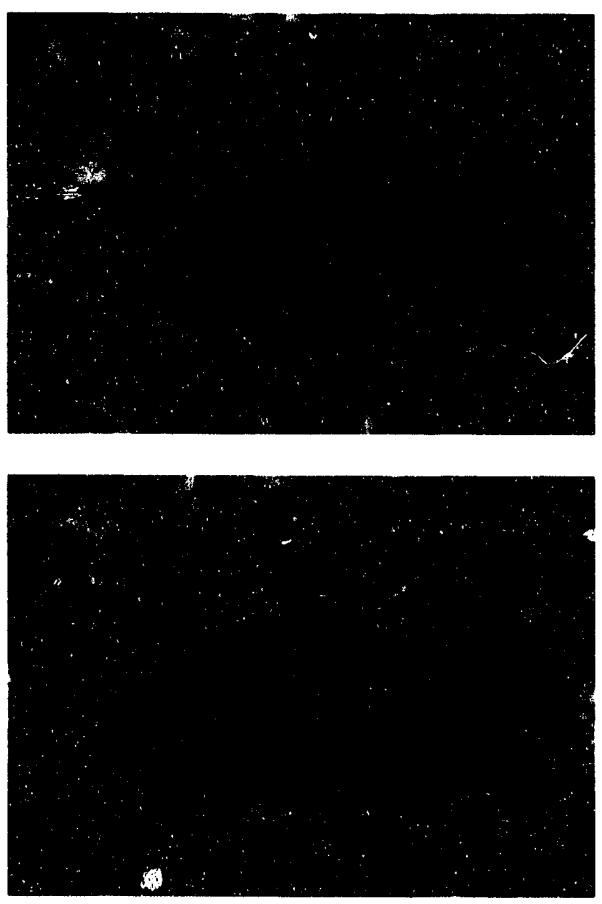

Frames from our award-winning HDTV demonstration film showing contour surfaces of $15 \%$ cloud cover. A transparency texture was added for greater realism. 
The control center of the Energy Sciences Network, a nationwide computer data communications network that connects multiple facilities in energy research 24 hours a day.

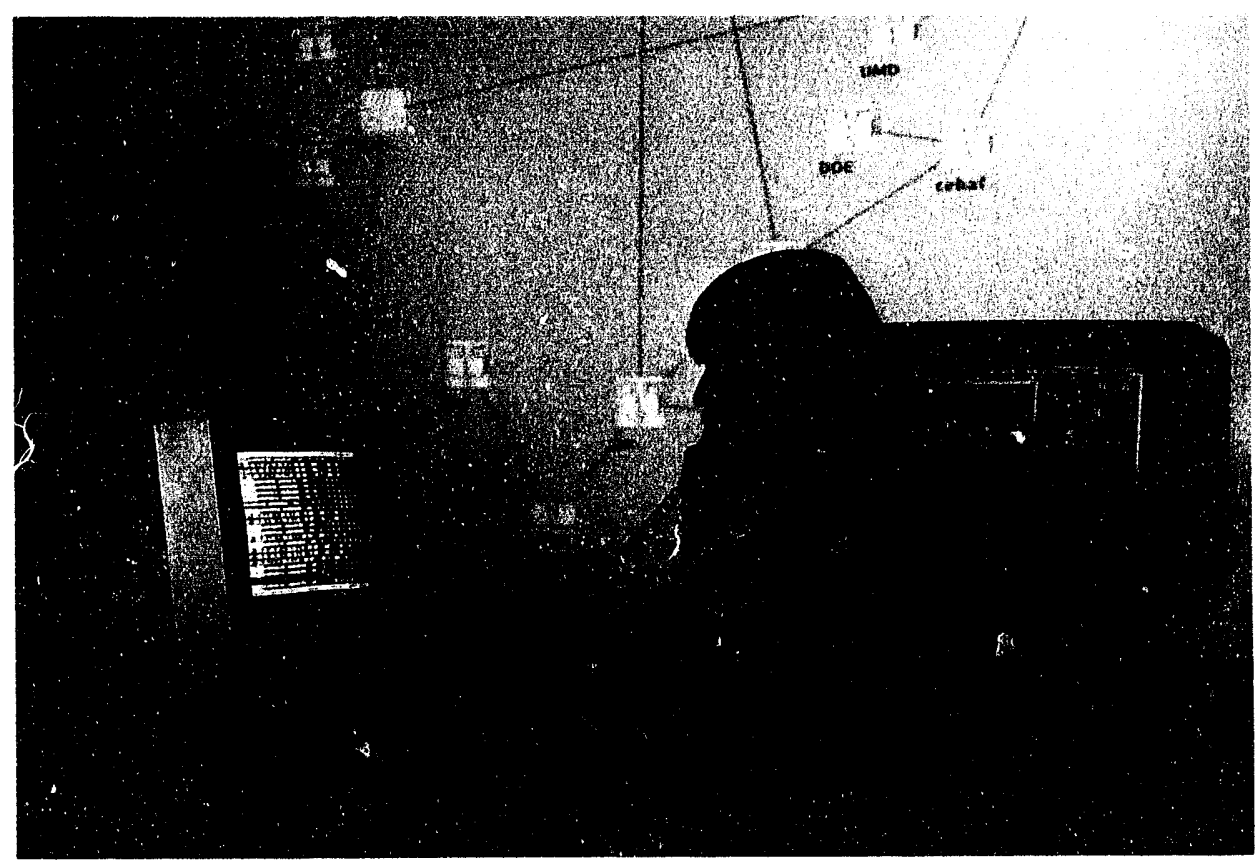

Cray-2 and is expected to be available for use on a wide variety of platforms through future licensing agreements between NSL members and other parties. Networkattached, hierarchical storage is provided by a Zitel solid-state disk, an IBM solid-state disk array with a Maximum Strategy controller, and an Ampex DST 800 automated type cartridge library. A highperformance PsiTech frame buffer and a high-resolution Sony monitor connected to the system's high-speed HIPPI data-transfer network allows animation of images for climate modeling, molecular modeling, and magnetic fusion modeling.

We are currently working on a second NSL software system, called the HighPerformance Storage System (HPSS), that will be able to move large data files between storage devices and massively parallel computers 100 to 500 times faster than existing commercial systems and at least 10 times faster than the NSL's original goal. The focus is on using scalable, parallel storage and retrieval techniques to develop a high-speed data transfer capability for computers with hundreds or thousands of processors.

\section{A Preprocessor for High- Performance Computing}

Work continues on developing a parallel data-distribution preprocessor (PDDP). This is a language model for distributedmemory MPPs. A common problem in distributed-memory machines is nonuniform memory access; memory further away from a processor takes longer to access. PDDP allows users to lay out data on the MPP in a pattern that naturally fits the problem. At run time, PDDP uses the knowledge of where data are to compute locally. This typically results in an application that can run faster, because it uses less of the communications bandwidth and more of the local memory bandwidth.

\section{Energy Sciences Network}

The Energy Sciences Network (ESnet) is a nationwide, computer data communications network that supports multiple-program, open scientific research. Operated 24 hours a day by the networking staff of NERSC, it provides reliable, stateof-the-art networking services to the DOE and to major energy research facilities throughout the country.

ESnet began operational deployment of a T1 (1.5-Mbit/s) circuit-based backbone in late 1989 with 19 major sites. Today, it interconnects more than 25 research laboratories with other networks, providing access for numerous scientific and educational researchers. Routing equipment is located at each site to send data to its ultimate destination. These routers are capable of processing several protocols, including Department of Defense Internet Protocol, DECnet Phase IV, X.25, and Open Systems Interconnection ConnectionLess Network Protocol.

This year, we initiated an upgrade of the $\mathrm{T} 1$ bandwidth from 1.5-Mbit/s to $45 \mathrm{Mbit} / \mathrm{s}$. Over the next three years, the ESnet 
backbone will be designed to operate at data rates up to $622 \mathrm{Mbit} / \mathrm{s}$, a 400 -fold increase over current speeds. The new network will make the transition from leased line operation to one that uses a high-speed switching architecture based on Fast Packet technology, the next step in the evolution of high-speed data transfer. Speed increases to 155 and $622 \mathrm{Mbit} / \mathrm{s}$ are planned for 1994 and 1996, respectively.

\section{A Distributed Database for the Human Genome Project}

The Laboratory's role in the Human Genome Project (see the Biology and Biotechnology section, pp. 56-61, for more information) is to develop efficient biological and computational techniques for chromosome mapping. This year, LLNL computer scientists built a database to hold all the relevant data, designed automated tools for analyzing and reassembling the tens of thousands of DNA fragments needed to map a single chromosome, and developed a graphical "browser" tool to allow rescarchers to navigate the chromosome data as the map is being constructed. Another focus of the project is to make sure that the information obtained from biological experiments is stored in usable, sharable form. This year, we developed an internationally distributed database system for that purpose. Our work has become a comerstone of the entire project, accentuating the importance of software engineering in biomedical research.

\section{Computer Security}

For the past several years, we have focused our computer security efforts on developing tools and methods for automatically detecting intrusions and recognizing malicious codes in our open computing facilities. Some of our software products, such as the Security Profile Inspector, which assesses the security of Unix and VMS systems, are specific to certain platforms. Others, such as the Network Security Monitor, which detects malicious activity on computer networks, are more general. We are continuing to develop, refine, and augment techniques for detecting computer intrusions in standalone and distributed computing environments.

Our incident-handling effort, a DOEbased group called CIAC (Computer Incident Advisory Capability), has assisted in quelling more than 200 security incidents, ranging from personal computer viruses to network intrusions and has helped federal law-enforcement agencies in several incidents involving computer intrusions on networks for unclassified research. We have also designed and implemented an in-school computersecurity program for children in kindergarten through the third grade. The program introduces children to issues in computer security and to the ethics of computer use.

\section{Success for Elertronic Commerce}

Last year, in support of the Department of Defense, we developed a computer network called Electronic Commerce (EC) for paperless processing of businessrelated transactions. The project offers managers new ways to facilitate their workflow without modifying the programming of database machines, networks, or associated workstations. This year, the system was tested at Wright-Patterson Air Force Base as an extension of the Air Force procurement system. As of June 1993, EC was handling well over $40 \%$ of all commodity procurement actions. It showed a reduction in purchase-order processing time from
30.5 days to 11 days and a reduction in the unit cost of goods procured of approximately $10 \%$.

\section{Summary}

Computer simulation augments experimentation in virtually every field of science at the Laboratory. It has enabled us to extend our design and predictive capabilities and to make breakthrough discoveries. In 1993, we advanced significantly into the realm of massively parallel processing, made upgrades of an existing network, acquired several new computer models, and undertook research initiatives and collaborative efforts with businesses in the computer industry. Computations work at LLNL in developing both software and hardware benefits other programs throughout the Laboratory as well as our industrial and academic collaborators.

\section{Note}

1. The seven original members of the NSL project are LLNL, IBM Federal Systems Company (Houston, Texas), Ampex Corporation (Redwood City, California), General Atomics DISCOS Division (San Diego, California), Maximum Strategy (San Jose, California), Network Systems Corporation (Minneapolis, Minnesota), and Zitel Corporation (Milpitas, California).

\section{For further information contact William A. Lokke (510) 422-4170 or Joseph J. Brandt (510) 422-7043.}




\section{ation}

\section{The Laboratory is applying its resources and expertise to enhance the teaching of science, mathematics, and technology both locally and nationwide.}

developed by our scientific staff, were

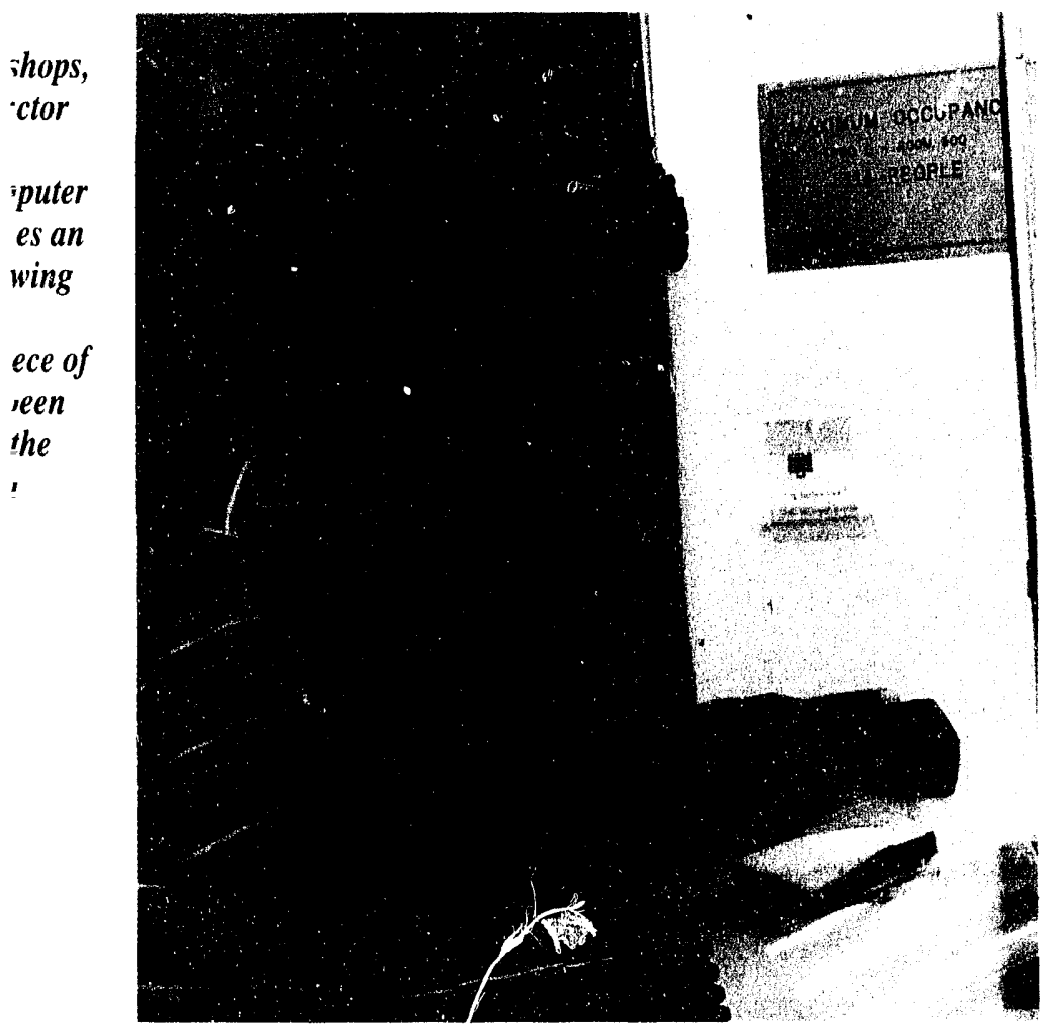

1) CIENCE and technology are increasingly important everyday aspects of society. It is essential, therefore, that teachers, students, and the general public be scientifically and technologically literate. LLNL is a national resource of scientific and technologic expertise and has gained recognition as a valuable educational resource as well. We are working both as an institution and as individual volunteers to promote and enhance the teaching of science, mathematics, and technology.

The Laboratory has been actively involved in science education for decades. Initially, traveling science shows and "prepackaged" science education courses, presented in local schools. Our efforts were soon broadened to include collaborations between teachers and LLNL technical staff to develop materials that would help the teachers improve their understanding and teaching of science. In October 1983, the Science Education Center-the first of its kind at a DOE laboratory - was opened and dedicated to providing teaching tools for science teachers through a variety of workshops. Later, student computer classes were added. These activities were very well received, and demand soon outstripped available resources.

In 1991, the Laboratory's Education Program was formally established to further fulfill the goals of the DOE. Recent efforts have been focused on collaborations with community organizations, industry, and schools and school districts to improve science and math curricula. A number of special interest activities have been established, and innovative tools and curricula for science and math education continue to be developed. In 1993, we offered a wide array of science education activities that reached more than 13,000 students, more than 1500 teachers, and, more than 100 school districts.

\section{Teacher Enhəncement}

Particularly effective are activities that provide hands-on techniques and opportunities for the teaching of science. One of our longest running programs is LESSON (Lawrence Livermore Elementary School Science Study of Nature). In LESSON workshops, teachers with little 
science background learn how to do simple and inexpensive experiments that demonstrate fundamental scientific principles. With such training, the teachers develop a genuine enthusiasm for science, which they are then able to convey to their students. In 1993 alone, four LESSON workshops were provided to 71 teachers. More than 1000 teachers have attended LESSON workshops since its beginning in 1969. These teachers, in turn, have influenced the lives and education of thousands of students.

Project HOPES (Helping Our Partners Enrich Science) strives to develop partnerships between education and science/technology communities. Teachers and scientists work together to develop lessons and curricula. Project HOPES is part of the National Science Foundation and DOE National Teachers Enhancement Program, a networking activity with other DOE laboratories.

Science On Site (S.O.S.) is designed to help teachers and school principals recognize the value of hands-on discovery learning. One-day workshops packed with such activities are given for the entire staff of elementary schools. Teachers also learn to apply cooperative learning strategies in their classrooms.

Additional activities that have proven to be extremely effective include the Summer Research Internship Program, the Global Climate Change curriculum development program, the National Education Supercomputer Program, the Science and Engineering Research Semiester, the Teacher Research Associate Program, and many others.

\section{Curriculum Development}

At the request of school districts and colleges, we have helped to develop and implement "custom-designed" science education programs. Each school, district, or college designs its curriculum plans to meet the needs of its students and to make use of area resources and specialties. Two examples are the Castro Valley School District, which has decided to specialize in biotechnology, and the Sacramento School District, which is concentrating on the environmental sciences. The Partnerships for Environmental Technology Education (PETE) program reaches numerous community colleges in the five western states. (The PETE program is also described on p. 43.) Other schools have received assistance in developing curricula in multimedia and electronic technology.
A number of programs have been specifically designed to assist universities and colleges with high minority enrollments. In one particularly successful endeavor, a Communication Technology degree program was created for Clark Atlanta University in Georgia.

Communication specialists (artists, photographers, writers, etc.) from the Laboratory have labored long hours to give guidance in setting up the program and to work closely with students. In 1993, six LLNL communications specialists

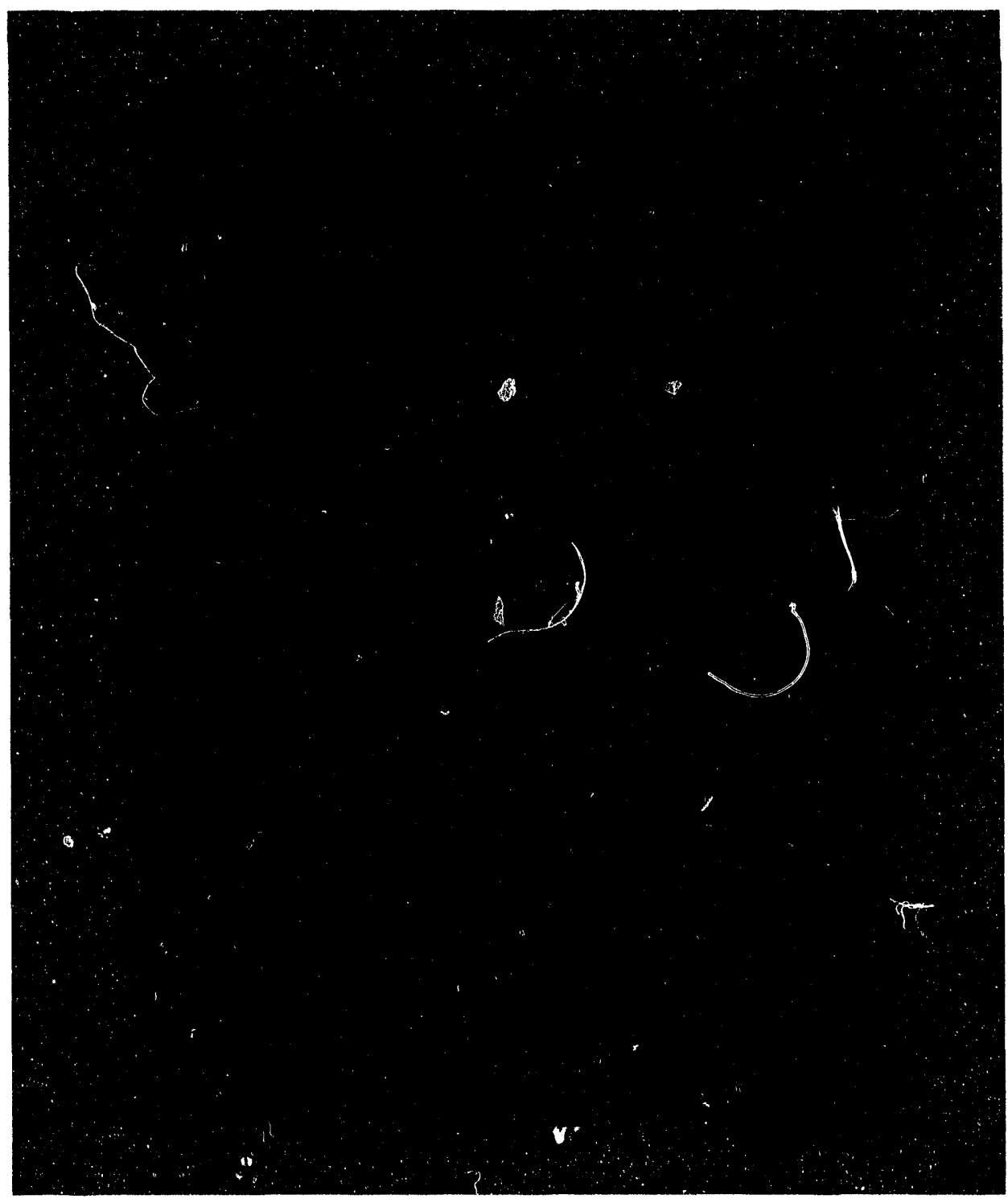


conducted five workshops at the university, reaching 33 students. Since the inception of this program, more than 21 workshops have been held, reaching a total of 65 students.

\section{Regional Collaboration}

We are also collaborating with various high-tech industries and other research institutions to improve science and math education. One example of this collaborative approach is the Bay Area Science and Technology Education Collaboration (BASTEC), which was established in 1989 to help the Oakland Unified School District strengthen its science programs. In addition to LLNL, BASTEC participants include the DOE, Lawrence Berkeley Laboratory, SandiaLivermore, and the Stanford Linear Accelerator Center, together with Samuel Merritt College, the Lawrence Hall of Science, the UC Berkeley Mathematical Engineering Science Achievement (MESA) Program, and the National Organization of Black Chemists and Chemical Engineers. Since BASTEC was founded, we have conducted workshops for over 400 teachers, upgraded several computer labs with loaned equipment, and worked with a team of bilingual instructors (Mandarin Chinese and
Spanish) to develop bilingual LESSON curricula.

\section{A National Educational Resource}

LLNL is an important educational resource for northern Califormia and the nation. In the spring of 1993 , recognizing the effectiveness of DOE-sponsored education programs, Senator J. Bennett Johnston of Louisiana promoted a DOE education conference in Louisiana. We, as a DOE laboratory, participated and, as a result, were asked to work with the Louisiana state school system to enhance science education from kindergarten through college. LLNL has since become a member of the Louisiana Systemic Initiatives Program (LaSIP) to assist the State of Louisiana in reforming its education programs. This summer, five workshops were held for teachers in the Louisiana schools:

- A LESSON workshop was conducted for 20 high-school teachers, in which they learned how to present LESSON's simple and interest-stimulating hands-on science experiments.

- A Multimedia Optimizing and Reinforcing Education (MORE) workshop was presented for 20 more high-school teachers, in which they learned to use

\section{A group of students \\ from a Stockton elementary school works together on an experiment in one of the Laboratory's popular summer programs on global climate change.}

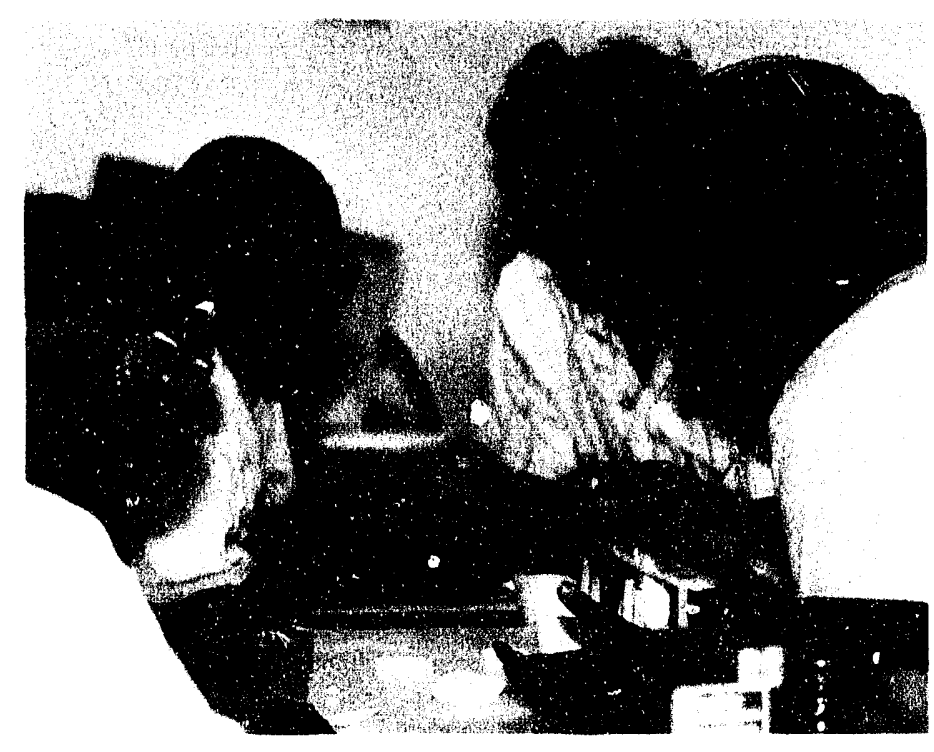

computers and laser-disk equipment to enhance their classroom presentations. - A session of Principals for the Advancement of Leadership in Science (PALS) was conducted at Southern University for 40 school principals and teachers, in which they received help in developing plans for improving science programs in their schools.

- Two Global Climate Change workshops for 40 teachers were conducted at Southern University, in which they learned how to teach a hands-on curriculum on the effects of global climate change on the environment.

We also sponsor a variety of programs to address specific student interests. For example, thro'igh the LLNL Speakers Bureau, local schools and community organizations can request Laboratory scientists as guest speakers on various scientific and technical topics. An annual Science Bowl and a Math Challenge involve more than 1700 high-school students each year.

\section{Innovative Educational Technology}

Just as the Laboratory develops and applies innovative technologies to solve scientific and technical problems, we also devise new ways to use technology to enhance education. The Science Educa.ion Center (SEC) provides a place where students and teachers can learn to use computers and telecommunications technologies to enhance the learning process. Since the SEC was established in 1983, more than 2500 students and 5000 teachers have taken part in classes, including 416 students and 322 teachers this year alone.

Educational technologies such as distance learning, supercomputing, electronic networks, and software for interactive curricula are constantly being upgraded and updated. Collaborations in education with Pacific Bell and other businesses are being developed to increase 
the impetus toward systemic change in our nation's educational institutions.

\section{Training LLNL Scientists as Teachers}

In 1993, working with the San Jose State University School of Science and its Mathematics Department, a customdesigned program to certify LLNL scientists to teach grades $\mathrm{K}-12$ in California public schools was begun. Over a two-year period, these future teachers combine classwork one night a week with practice teaching during one school period each day. The first class of 24 people (with specialties in the physical sciences) will receive teaching credentials in 1994. The second class, beginning in February 1994, will be designed for mathematicians; a third class, slated to start in September 1994, will combine physical and life scientists. The Laboratory people participating in this program will be trained to teach part-time or to change careers; either way, they will bring to the classroom world-class scientific knowledge, good communication skills, and an enthusiasm for science and math as careers.

\section{Expanding Your Horizons}

Expanding Your Horizons (EYH) is a nationwide program that encourages junior-high and high-school girls to develop and maintain an interest in science education and careers. Hundreds of LLNL women participate in the local EYH conferences, describing their careers, presenting hands-on workshops, and helping to produce the conferences. During the past year, four local EYH conferences (co-sponsored by the Laboratory) were attended by more than 1800 young women from surrounding comm .... ies, including the East Bay and the San ioaģuin Valley. More than 140 EYH conferences: are conducted across the nation each year.

\section{Native American Program}

The Laboratory's American Indian Program focuses on issues important to Native Americans. These include increased emphasis on education and on careers in science and engineering. Native American participants in this program gain increased opportunities for employment, both at LLNL and elsewhere, and increased options for career advancement. Also through this program, LLNL participants gain an enhanced awareness of American Indian values and culture.

One of many activities for Native Americans is the one-week workshop provided to college-bound students in the Southwest Indian Polytechnic Institute; each year, 20 students take part in an
LLNL-sponsored supercomputer workshop. Another is the annual Indian Regional Science Bowl competition, sponsored by the Laboratory and held on the Navajo Nation to sharpen students' enthusiasm for knowledge and skills in science.

\section{Supercomputing Program}

The National Education Supercomputer Program provides a unique instructional tool for science and mathematics students and teachers from schools across the U.S. The National Education Supercomputer (NES) is a Cray-X/MP donated to the DOE for the National Education Supercomputer Program by Cray Research, Inc. The machine, housed at and operated by the

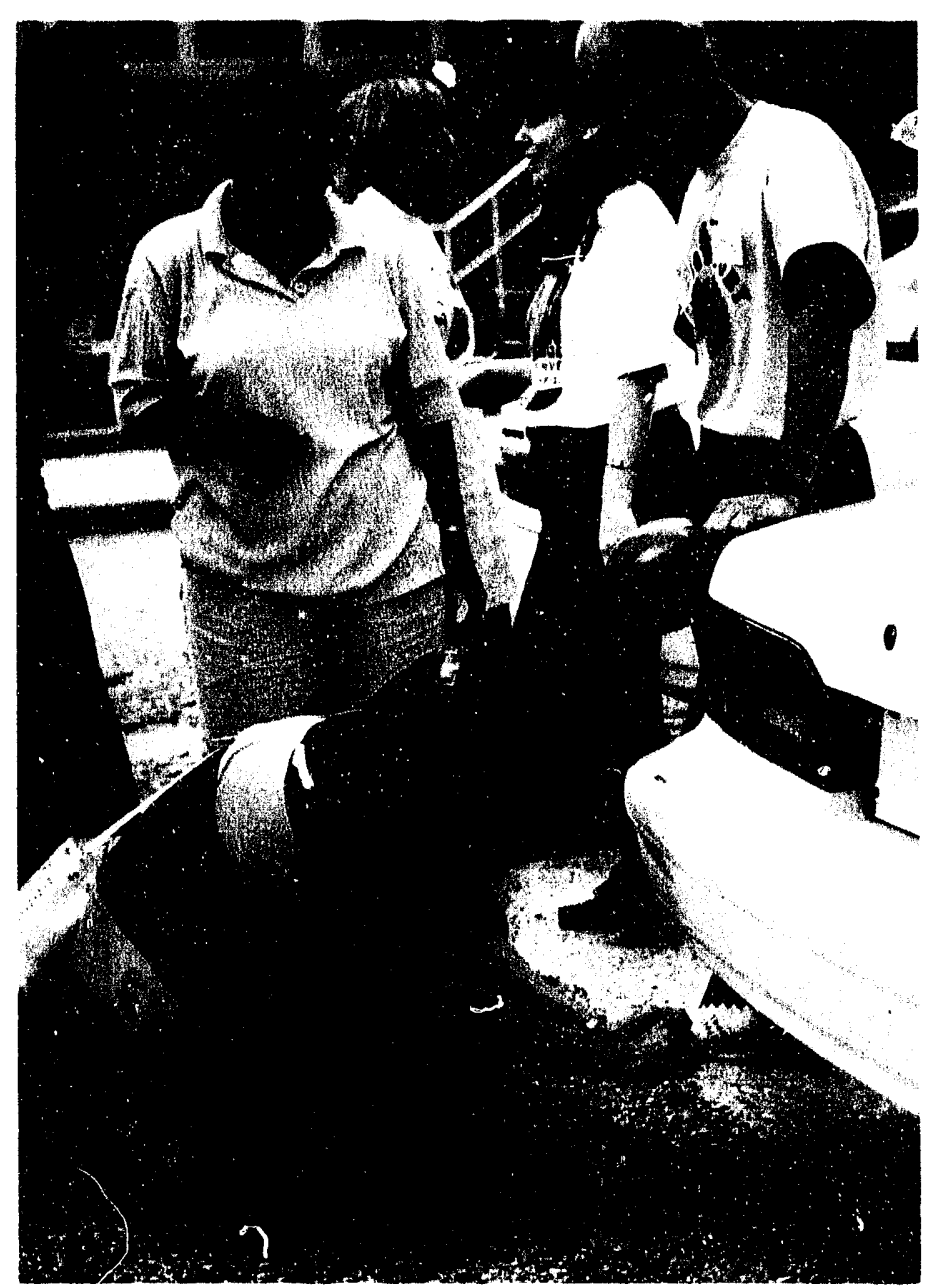

To determine the environmental effects of automobile emissions, teachers taking part in the LaSIP program in Louisiana examine the exhaust coming from a car's tailpipe. LLNL is a participant in LaSIP, the goal of which is to enhance science education in the Louisiana state school system. 
National Energy Research Supercomputer Center (NERSC), is used exclusively for educational purposes.

\section{Supercomputing Workshops for Teachers}

In summer supercomputing workshops at LLNL, teachers work on projects using various applications to learn how to use the NES. They work with LLNL professionals and other workshop participants to develop curricula that make use of the NES and that they can apply in their classrooms. Upon completion of the workshop, the teachers are expected to complete their curriculum development and plan for the introduction of new materials to their students throughout the following year. At the end of the school year, each teacher submits a report detailing their new curriculum, describing how it was used in their schools, and summarizing their students' projects. Also through these summer workshops, we assist in the development and training of "master" teachers who can

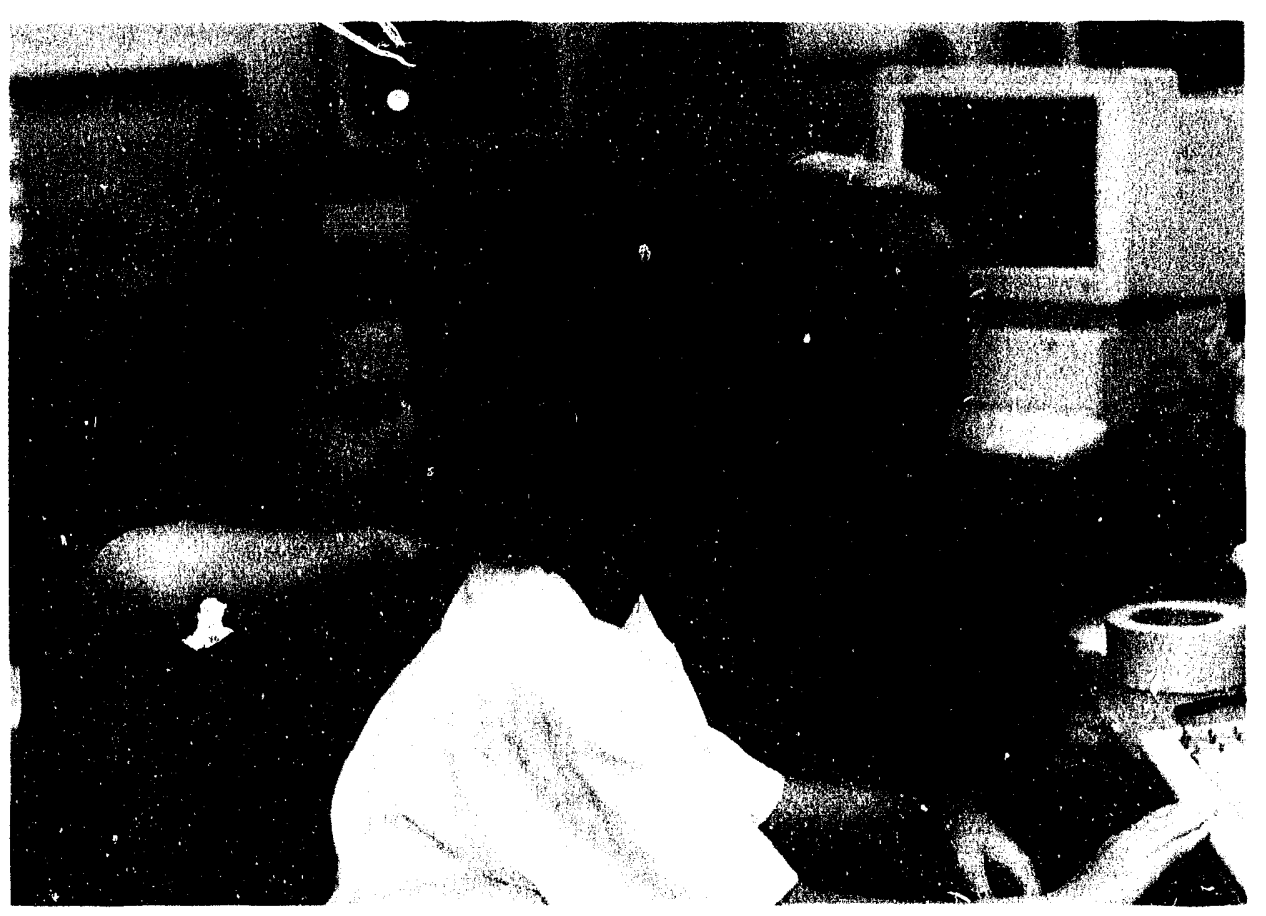

Students Ernie Franic, Meaghan Lamarre, and Patrick Sanders work on a computer project at LLNL's Science Education Center.

conduct similar workshops for teachers in their local areas, enabling more teachers and students to access this national resource.

Long-distance learning opportunities are available through the "new account," which allows computer-literate teachers and students to run the simulations and models on the NES by network or modem access. The simulations run on the NES remotely through the National Education Bulletin Board System.

\section{Superkids Program}

Since 1985, the DOE High-School

Science Student Honors Program in Supercomputing (also known as the "Superkids" program) has brought some of the world's most talented students to LLNL for a two-week, hands-on opportunity to use the NES and other computing resources at NERSC. This program motivates and encourages participating students to continue postsecondary studies in mathematics, science, engineering, and computer science.
Students attend lectures by LLNL scientists and programmers on such stateof-the-art supercomputer applications as aerodynamics, climate, chemistry, physics, fusion energy, engineering, robotics, graphics, and computer modeling. The Laboratory scientists and programmers assist the students as they explore individual interests in computational science in projects of their own choosing. Typical student projects include climate simulation, scientific visualization, massively parallel processing, laser fusion, fractals, molecular modeling, and ray tracing.

\section{Southwest Indian Polytechnic Institute College Bound Program \\ This one-week program is held each year for students from American Indian reservations throughout the U.S. During the "Countdown to Supercomputing" workshop at NERSC, student teams study the use of supercomputing for simulations of the food chain, plant cycles, climate, and population growth.}

\section{College-Level Programs}

Programs are also available for college students at both the undergraduate and the graduate level to conduct research with Laboratory scientists full time during the summer and part time during the school year.

\section{Science and Engineering Research Semester}

The DOE initiated the Science and Engineering Research Semester (SERS) program to encourage undergraduate students, particularly women and minorities, to pursue advanced degrees in science or engineering. This program provides students with the opportunity to participate in research at one of seven DOE laboratories during the academic year. SERS students learn to use state-of-the-art facilities and equipment, and the experience enriches both their scientific background 
and their perspectives for future career decisions.

At LLNL, approximately $80 \%$ of a SERS student's time is devoted the research project. Other "enhancement" activities, including seminars and tours, university visits, a technical presentation/writing workshop, poster and symposium presentations, a supercomputer course, and social activities, comprise the remaining $20 \%$. From the first semester the program was implemented (the fall 1992 semester) through the end of the sprint 1994 semester, LLNL will have hosted a total of 66 SERS students.

\section{Historically Black Colleges and Universities}

We have a number of agreements with historically black colleges and universities to help enhance the ability of these institutions and provide quality education in science and technology. We are developing collaborative research projects with several of these colleges and universities, including Fisk University, Morehouse College, Spleman College, and Southern University. The communication technology program at Clark Atlanta University, described earlier, is another example of our work with these institutions.

\section{Department of Applied Science}

The Department of Applied Science (DAS) is a graduate branch of the UC Davis Engineering Department, located at LLNL. Laboratory researchers serve on the DAS faculty, and students work on their thesis projects at LLNL.

For ten years, the Laboratory, in cooperation with DAS and the Fannie and John Hertz Foundation, has provided a two-week summer institute on topics in applied physics, chemistry, mathematics, and engineering. Students attending the institute spend mornings at lectures on LLNL programs and afternoons working with program researchers on specific projects. At the end of the two weeks, the

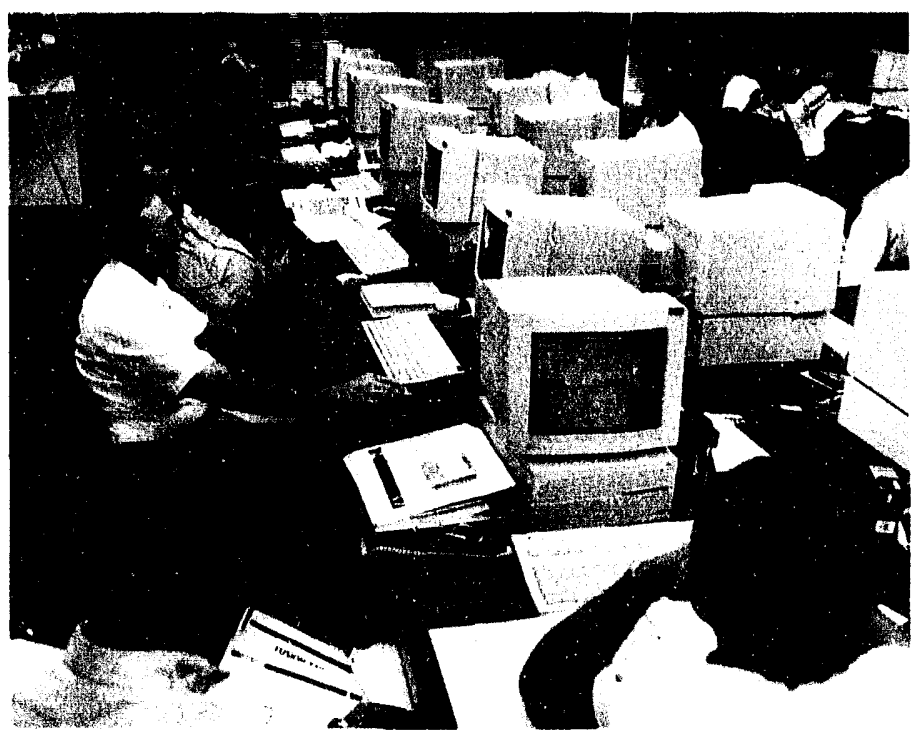

Workshops are held at LLNL each year for teachers to learn to use the National Education Supercomputer.

students present their project results at a poster session. Approximately 500 students from colleges and universities throughout the country have attended this summer institute.

\section{National Physical Science Consortium}

The Laboratory is also a member of the National Physical Science Consortium, a collaboration among more than $50 \mathrm{Ph}$.D.granting universities and a growing number of employers of scientists and mathematicians. The consortium provides multi-year support for minority and women students earning advanced degrees in the physical sciences. In 1993, LLNL sponsored 15 students to do their thesis research at the Laboratory.

\section{National Consortium for Graduate Degrees for Minorities (GEM)}

Since 1976, the Laboratory has been a member of GEM, a national consortium that supports minority students earning graduate degrees in science and engineering. As a GEM participant, LLNL pays the student's tuition, fees, and monthly stipends, and provides them summer employment. GEM has been an effective recruiting tool for the Laboratory, and has led to career employment for about $20 \%$ of the students sponsored by LLNL.

\section{Summary}

LLNL is a national resource of scientific and technological expertise, and our charter is to apply this expertise to national needs. There is a growing recognition that one such national need is to improve the teaching of science and math at all levels in schools across the country. It is imperative that today's students be scientifically literate so they can succeed in a world that is increasingly technological. At LLNL, we are expanding our efforts to help improve the teaching of science, math, and technology. We offer a wide range of workshops and programs for enhancing leachers' abilities to teach science, for helping school districts and colleges custom-design their science curricula, and for providing students of all levels with hands-on opportunities in science research. Over the years, our programs have reached hundreds of school districts, thousands of teachers, and hundreds of thousands of students.

\section{For further information contact Eileen Vergino (510) 424-0567.}




\section{imistrative \& Institutional Services}

hines have a safety box that $v$ interlock chain but does s. We developed this small, $x$-ray monitor to detect ie experimental enclosure ir presence.
XTENSIVE administrative and operational services are required to support the Laboratory's programmatic work. These services and operations are split between the Laboratory's Director's Office and the Plant Operations Directorate. Broad-based functions like the budget, business operations, and human resources are administered in the Director's Office. Operational support for the Laboratory (at its main Livermore site and at Site 300) is provided by organizations for Hazards Control, Plant Engineering, Information Systems, Environmental Protection, Health Services, and Quality Assurance within the Plant Operations Directorate.

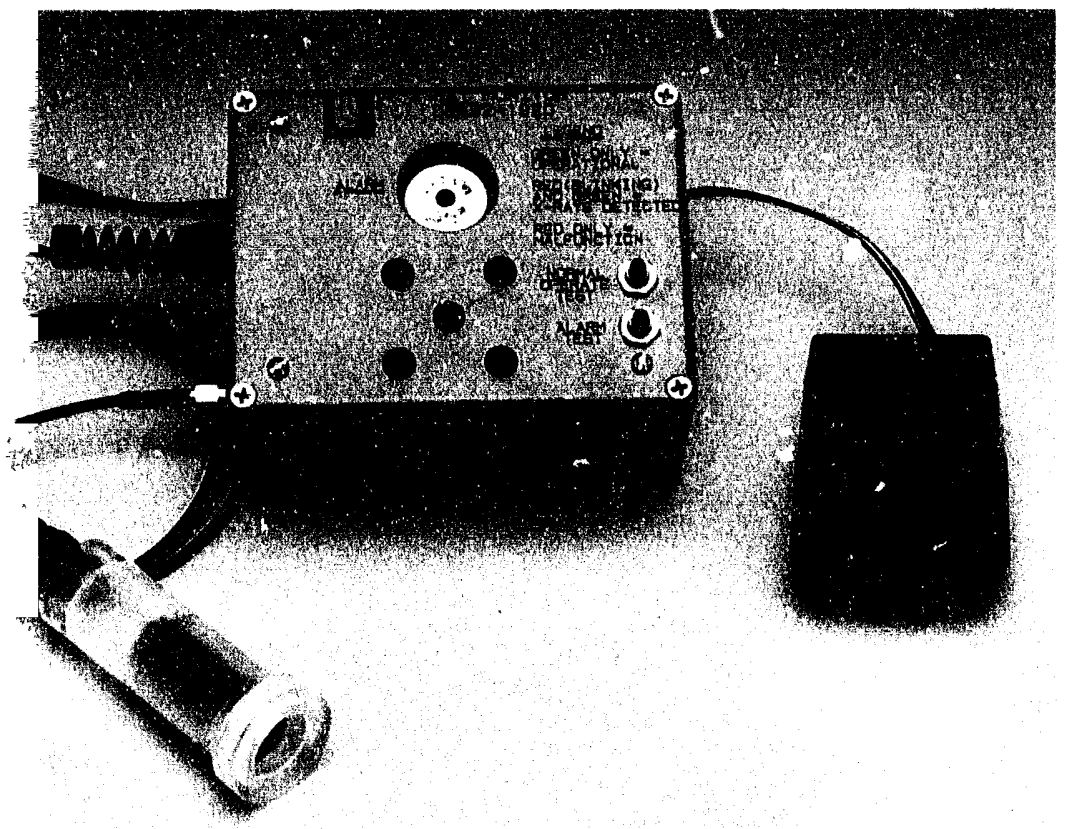

\section{Financial Management}

As of September 1, 1993, the Laboratory's fiscal-year 1993 operating budget was $\$ 972$ million. Funding for general equipment, general plant projects, and line-item equipment were an additional $\$ 74$ million, $\$ 10$ million, and $\$ 67$ million respectively. These funds supported a workforce of approximately 8500 career employees and approximately 2000 contracted support personnel.

Helping the Laboratory manage its financial resources is the role of the Controller. Through the Budget Office and the Finance Department, the Controller assures the integrity and accountability of financial operations and supports Laboratory management by interpreting and analyzing financial and resource requirements. The Budget Office analyzes budget status and trends, provides and analyzes budget-related information, and supports programmatic and operational missions. The Finance Department provides institutional management of financial and accounting functions in accordance with accepiet accounting principles. Over the past several years, the Controller's Office has aggressively implemented improved and automated financial systems and procedures to support LLNL missions and to assure compliance with the UC/DOE contract for managing the Laboratory.

\section{Business Operations}

The Business Operations organization supports Laboratory programs and departments by procuring, supplying, 
and distributing materials and services. A major restructuring was accomplished this year to improve service and costeffectiveness and to modernize the organization's materials management procedures. The team used the continuous quality improvement (CQI) process to solicit input from all levels of Business Operations, Laboratory customers, and the DOE's Oakland field office. The three departments of Business OperationsProcurement, Business Services, and Supply and Distribution-were consolidated into two departmentsContracting and Material Management, and Services and Distribution. This new organization, which took effect October 1, 1993, eliminates some layers of management, improves responsiveness to customer requirements, reduces costs, and uses personnel assets more productively.

\section{Human Resources}

Laboratory personnel are LLNL's greatest resource. The Laboratory recognizes that all people have the potential to contribute something of value, both at work and in society, and we are striving to create an environment that encourages and enables them to reach their maximum potential. In pursuit of this goal, the Laboratory provides classes and seminars for employees that facilitate the recognition and understanding of differences, has developed proactive practices that support the principles of a diverse workforce, and encourages individuals and organizations committed to those principles. The result is a highly talented, diverse, and productive Laboratory workforce.

The demographics of the U.S. and LLNL worktorce continue to shift, and women and minorities are assuming an increasingly important role in keeping the $\mathrm{n}_{\mathrm{i}}$.ion and the Laboratory competitive globally. To address these issues, the Laboratory has initiated several contracts and memoranda of agreement with varicus minority institutions, universities, and organizations establishing relationships for collaborative research, educational assistance, and other mutually beneficial endeavors. Laboratory programs have also been established to increase manager and employee awareness of many of the issues surrounding changes brought about by a diverse workforce and to give them

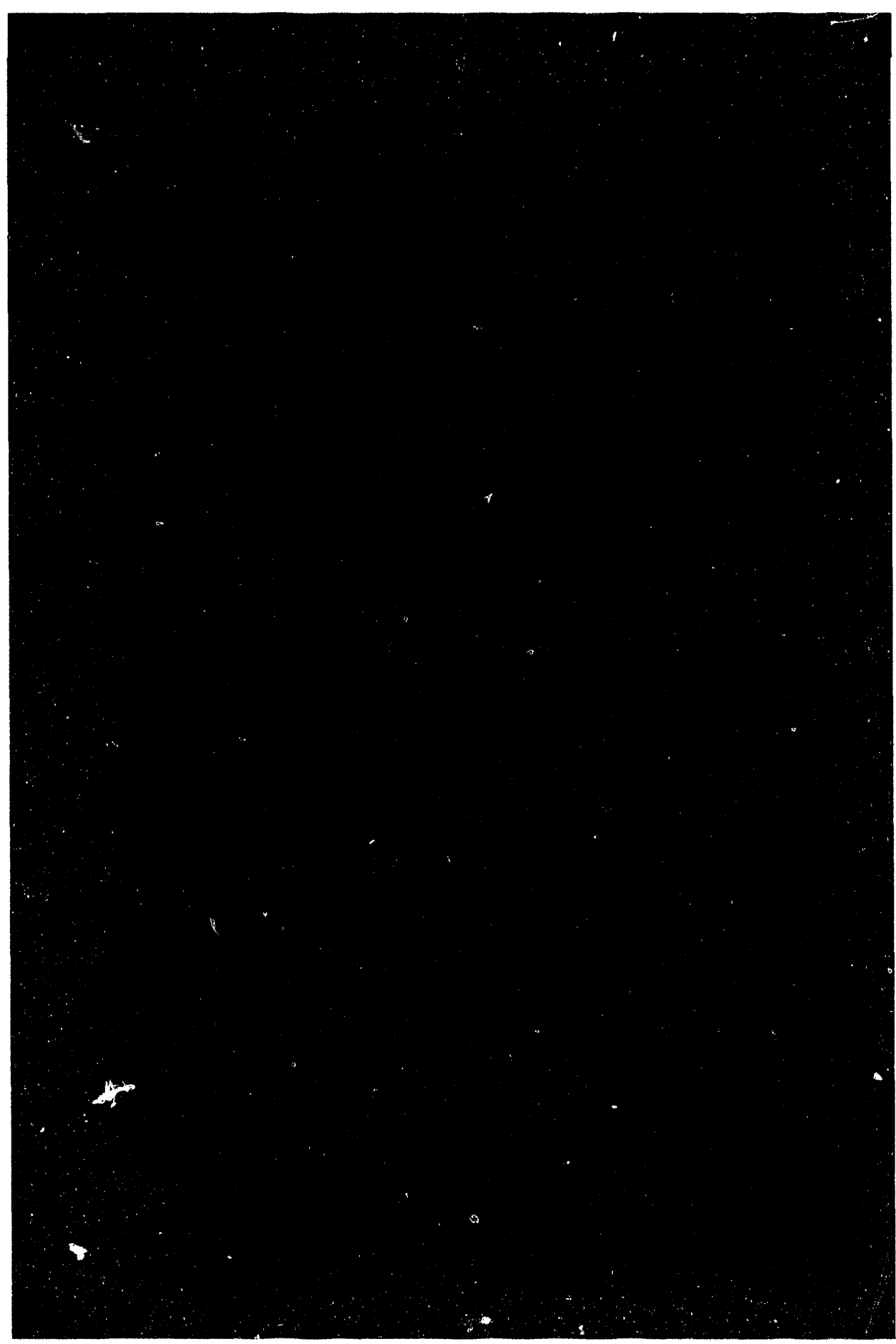


the skills needed to manage diversity effectively.

\section{ES\&H}

Many administrative and plant operations activities involve monitoring and improving the Laboratory's facilities, equipment, and business infrastructure, with particular attention paid to meeting the Laboratory's commitment to ES\&H (environment, safety, and health).

-X-Ray Safety Monitor. The Laboratory has more than $100 x$-ray machines in use in various experimental setups. Most x-ray machines have a safety box that provides a safety interlock chain but does not detect $x$ rays. To correct this safety deficiency, we developed an $x$-ray safety monitor that detects $x$ rays outside the experimental enclosure and warns of their presence. This new monitor is small and suitable for a wide range of experimental setups. It is sensitive enough to measure air- scattered $x$ rays for nearly all settings used on LLNL $x$-ray machines but not so sensitive that it detects radiation at normal background levels. The monitor also provides a warning to shut off the $x$-ray machine should it detect unsafe conditions and the interlock system fail to shut off the machine. The device can also give warning when the $x$-ray beam is present, when changes in experimental configuration are made during setups, or when the enclosure shielding is inadequate to protect nearby personnel from exposure to $x$ rays. No similar $x$-ray safety monitor is available commercially. This new monitor inexpensively replaces the more expensive $x$-ray safety box currently used ( $\$ 500$ vs $\$ 10,000$ ).

- Ergonomics. In 1990, we initiated an Ergonomics Program to address the growing problem of cumulative trauma disorders (repetitive motion injuries), such as carpal tunnel syndrome, and vision-related illnesses caused by the use of video display terminals. Cumulative

More and more jobs,
at LLNL and
elsewhere, involve
many hours in front
of a computer and its
glaring screen, and
incidents of
cunulative trauma
disorders (like carpal
tunnel syndrome)
and vision ailments
are increasing. Our
Ergonomics Program
assists employees
with education and
ergonomic computer
and office
equipment.

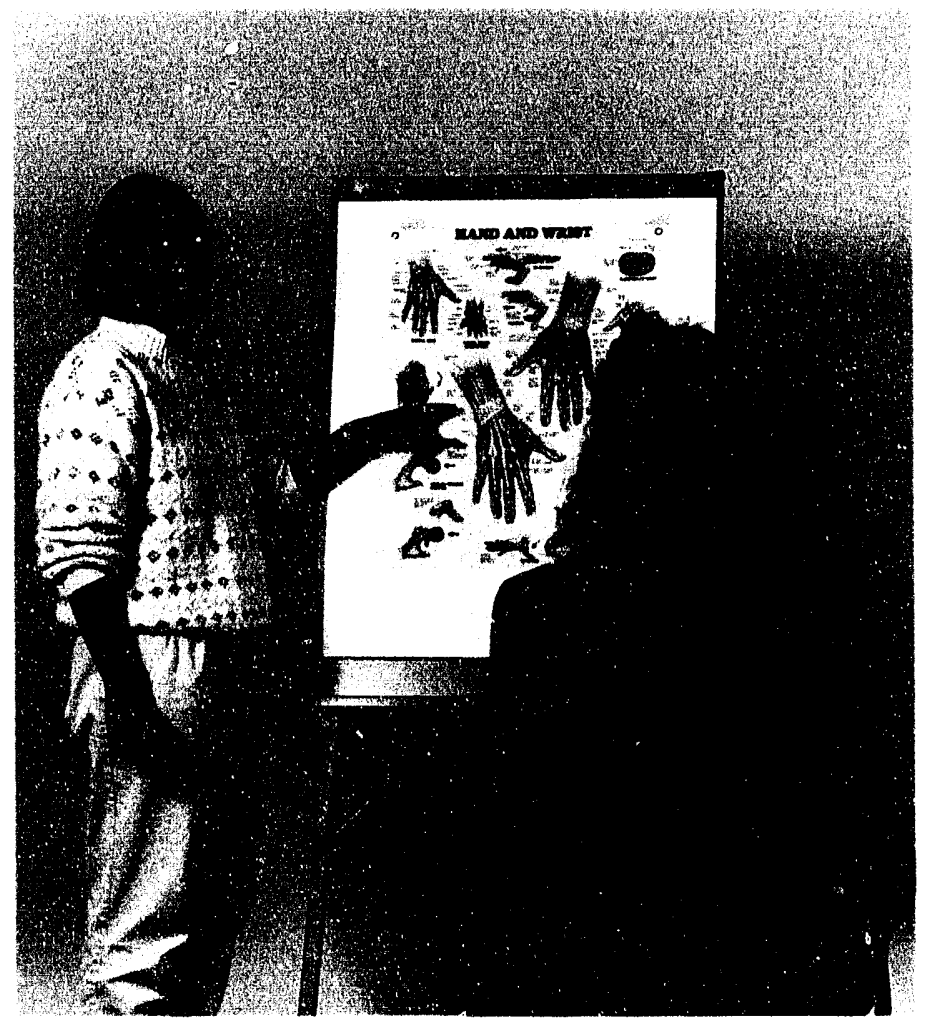

trauma disorders can be caused by extensive use of computers and input devices and by other aspects of the work environment such as poor placement of work things in relation to the worker (for example, positioning a video display terminal in a way that causes the worker to assume an awkward posture), poor lighting, improper seating (for example, the wrong chair or the wrong chair height), and a poorly designed workstation. In some cases, these conditions can be severe enough for an employee to consider a job change.

We have implemented programs in medical management, job redesign, workstation analysis, and vision ergonomics and have provided employees with ergonomic chairs and office equipment. We established an Upper Extremity Clinic that combines active surveillance, accurate diagnostic methods, and conservative therapy to treat cumulative trauma disorders in their early stages. We also loan a variety of pointing devices to mouse and trackball users so they can find alternative devices that are suited to their hand structure and therefore more comfortable to use. We conduct surveys to determine whether users are satisfied with these devices and whether the devices affect worker productivity.

An ergonomics research team evaluates screening tests for carpal tunnel syndrome. If the disorder can be identified at an early stage and treated by adjusting or changing things in the employee's work place, serious and irreversible damage may be avoided. In addition, research is under way to determine if alternative keyboards are effective in minimizing the risk factors associated with these disorders.

- Realistic Model of Air Filtration. We recently developed a computer model of air filtration that simulates particle removal in realistic air filters rather than in the imaginary air filters of previous simplistic models. This new model can predict the 
capture efficiency for different conditions, devices, and operations; it also combines the capture mechanisms of diffusion and inertia as a single process in the simulation. The realism of these simulations improves our understanding of the filtration process and makes it possible to reduce the number of experiments and prototypes needed to develop new filters.

- Support to Pantex. The Laboratory provides ongoing ES\&H support to the weapons dismantlement project taking place at Pantex in Amarillo, Texas. This support includes developing dismantlement procedures for the W79 warhead, evaluating ES\&H aspects of the dismantlement process, and developing a process and workstation for dissolving the high explosive from retired weapon systems. In January 1993, we completed the safety oversight for the handling, packaging, and transport from the Pantex Plant to LLNL of the pit of a W48 warhead (an LLNLdesigned weapon) that cracked unexpectedly during removal of the high explosive.

\section{- Recruitment and Training of}

Firefighters. Fire safety at the Laboratory is a key concern, and a fully equipped fire department is maintained at the Livermore site. A desire by the fire chief to increase the number of minority and women firefighters led to a recruitment effort aimed at those groups. Recruitment efforts found a lack of qualified minority firefighter candidates, so we decided to "grow" our own. We joined other fire departments in the East Bay to create a recruitment video and information packet aimed primarily at women and minorities in local high schools and junior colleges. Recruitment is ongoing, with visits to schools, libraries, career-day presentations, and brochures.

We also started our own program for training firefighters, with costs split between the Emergency Management Division and LLNL's Office of Equal Opportunity. The first three trainees were hired in March 1992; two have since found employment as firefighters, one at LLNL and the other outside the Laboratory, and the third remains a trainee because no positions are currently available. Two new candidates are currently in training. This training is proving very successful. It gives minority and women candidates career opportunities that would otherwise not be available, augments fire protection at the Laboratory, and puts better trained people into the firefighting field.

- Human Reliability Programs. To assure the safety and reliability of individuals in safety- or security-sensitive positions, we have implemented a pre-assignment and random drug-testing program that complies with DOE requirements for people whose jobs give them access to explosives or special nuciear material. Special software for randomly selecting the people to be tested was developed for this program. Recently, DOE Headquarters asked the Laboratory for this software for use in DOE's drug-testing program.

\section{Improved Business Practices}

Increasing emphasis is being placed throughout the Laboratory on projects that improve the way LLNL conducts its business, saving money, time, or both.

- Hardware Downsizing. The

Administrative Information Systems (AIS) Department is in the process of retiring its older computer equipment (mainframes and minicomputers) and replacing them with the new generation of smaller servers. The smaller servers are better suited to today's distributed work environment, are faster and easier to maintain, and are significantly less expensive than the older mainframes. Computing systems based on the new servers offer many advantages. We can adopt emerging U.S. standards instead of proprietary products (as was often the case in the past), making it possible to use components from different vendors. Upgrades can be implemented quickly since the servers are so much smaller (the size of a desktop PC) than the older mainframes (one occupied $2000 \mathrm{ft}^{2}$ ) and computing tasks can be spread among many systems. Since the brand of server is unimportant, we can take advantage of sales and special manufacturer discounts. In addition, the new systems are easy to use (which improves worker productivity) and take fewer people to operate. Software licenses for the new systems are also less expensive. This downsizing process should be completed in 1994, as the last of AIS's large computers are replaced with new systems the size of an individual workstation.

- High-Speed Telecommuting. A growing number of LLNL employees telecommute-using personal computers in their homes to access the Laboratory's open computing facilities over telephone lines. Many telecommuters work a 40-hour week on site and then telecommute on nights or weekends. Responding to telecommuters' concerns that

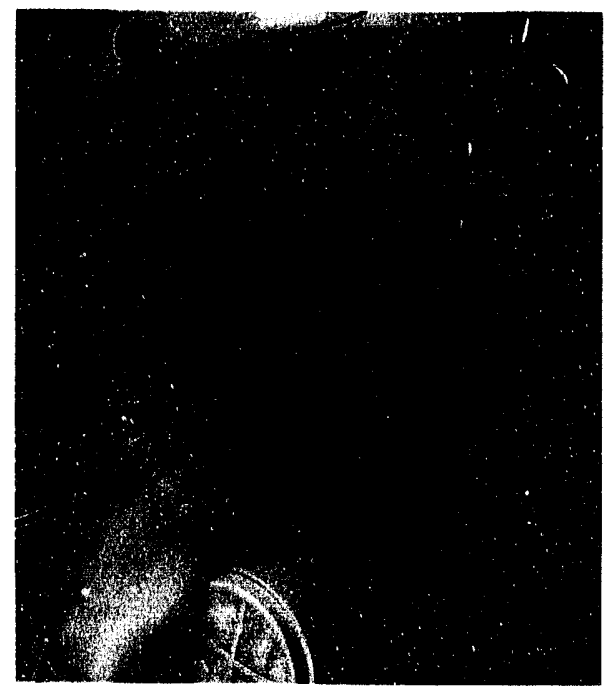

We have joined with other fire departments in the East Bay to recruit and train minority firefighter candidates. This effort gives minority candidates career opportunities that would otherwise not be available and augments fire protection at the Laboratory. 

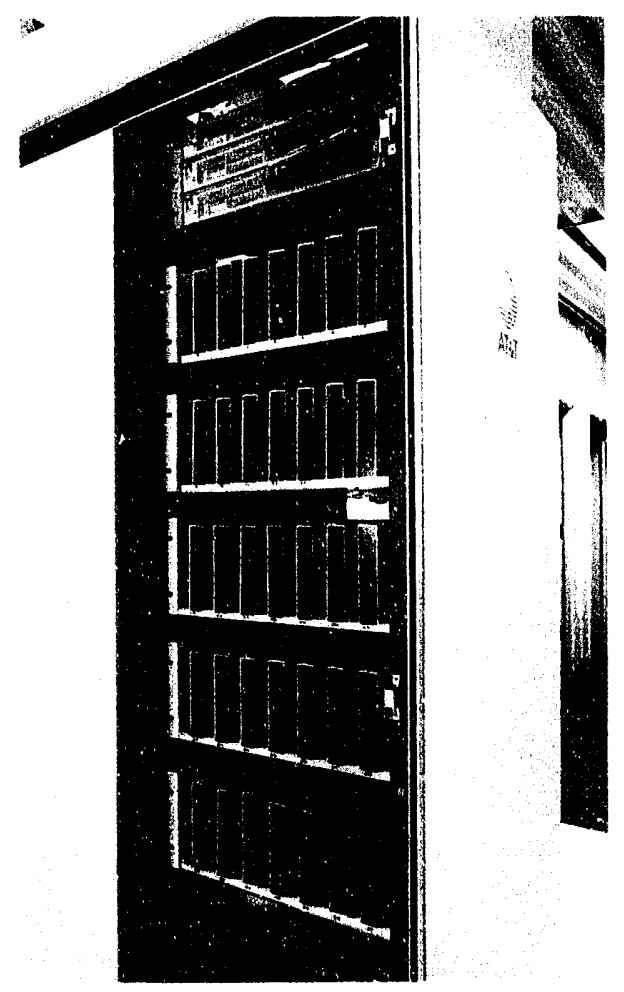

Our high-speed, telecommuting modem pool is the key element in local-area network access. Telecommuting-using home personal computers to access the Laboratory's open computing facilities over telephone lines-is now 13 times faster than before. We developed a way to use the digital telecommunications technologies (Integrated Services Digital Network or ISDN) and Ethernet to increase data transfer and communication speeds. communication from their homes to LLNL was too slow, the Telecommunications Systems Department developed a new way to use the digital telecommunications technologies (Integrated Services Digital Network or ISDN) becoming available in the public sector to increase their speeds. At our urging, Pacific Bell installed an AT\&T 5ESS telephone system at the local telephone office in Livermore. We then began installing equipment that allows telecommuters to take advantage of these new high-speed digital technologies. Once installed, this equipment connects the user to Laboratory local area networks, allowing a full complement of network applications and data transfer rate that is at least 13 times faster than with previous connections.

More than 100 people have requested installations in their homes; some are new requests and others are replacements for old analog systems. We have finished approximately half of these installations already and should compiete the others soon. - Energy Management. The Laboratory's Energy Management Program received four energy efficiency awards from the federal government (two of them from the DOE) in the 1993 fiscal year for work done in 1992. The first federal award was an energy efficiency award for LLNL as a whole; the other was a special award for using alternate fuels in the Laboratory's fleet vehicles. These awards join six previous energy efficiency awards received from the federal government and the Pacific Gas and Electric Company in the past three years. They are confirmation of the success of Laboratory-wide efforts to reduce energy consumption and costs, increase energy-use efficiency, and demonstrate new and emerging energy technologies, renewable energy sources, and alternate fuels.

- New Financial Systems. In April 1993, in order to streamline its business processes, the Finance Department updated its accounts payable, electronic timecard, and electronic cost-transfer systems. The electronic timecard and cost-transfer systems were updated to eliminate paper records and to provide users with direct computer access. The accounts payable update was needed to replace an aged UNISYS system that was failing, jeopardizing the Laboratory's entire financial system. We were also able to merge the two existing systems into one. This update was a cooperative effort between Finance, AIS, and Oracle (the software vendor). The new systems are based on relational database-management technology, and the failure rate has been cut to zero.

- Electronic Directory. The Laboratory's electronic directory is a quick way of getting information to everyone (including nonemployees) at the Livermore site. Part of the E-Mail system, it was created by a multidirectorate group of Laboratory employees after commercial attempts to design such a system failed. By querying the system, users can retrieve information such as names, telephone numbers, mailstop numbers, FAX numbers, E-Mail numbers, account numbers, department affiliations, and building and room numbers and use this information to direct mail to everyone or to selected users (e.g., all FAX users). The directory, which is updated daily, can be used as an electronic telephone book; it also serves as a gateway system between E-Mail, VMS mail, and Quick Mail and can respond to international queries. In a very short time, this directory has proven to be very cost-effective and environmentally beneficial; the cost of the electronics (much of which was already in place) is minimal compared to the cost of buying, handling, distributing, and destroying paper.

- Compliance Management Systems. The Laboratory established the Compliance Management System (CMS) in answer to 
a DOE request to assess LLNL complian with DOE orders. In an effort to meet Laboratory needs, AIS personnel identified an already-developed CMS prototype from the Pinellas Plant and modified it to meet LLNL requirements. Our CMS system greatly reduces the time and costs of the self-assessment process. We were the first DOE facility to send CMS self-assessment data to the central server at DOE Headquarters. In addition, our CMS system is easily portable and is compatible with many types and makes of computers. Thus, it is finding increasing use by others in the DOE community. - Savings through CQI. Secretary of Energy Hazel O'Leary has stated her commitment to the use of modern management practices, including the continuous quality improvement (CQI) process, throughout the DOE complex as a way to.improve productivity and responsiveness to customer needs. Organizations throughout LLNL are actively instituting these processes. For example, the Technical Information Department (which provides the Laboratory with library, editorial, art, composition, photographic, printing, and video services,) has had success implementing CQI to improve service and cut customer costs. In the past year alone, the Technical Information Department saved $\$ 344,000$ for its various publication and information customers and markedly reduced the amount of time to complete jobs (up to 70\%). The Telecommunications Systems Department has also successfully applied CQI to identify ways of improving service. A number of changes, some imperceptible to customers (e.g., changing long-distance carriers, changing the calling card program, identifying and disconnecting unused equipment), have resulted in cost savings of more than $\$ 600,0(0)$ per year with no loss in the quality of service.

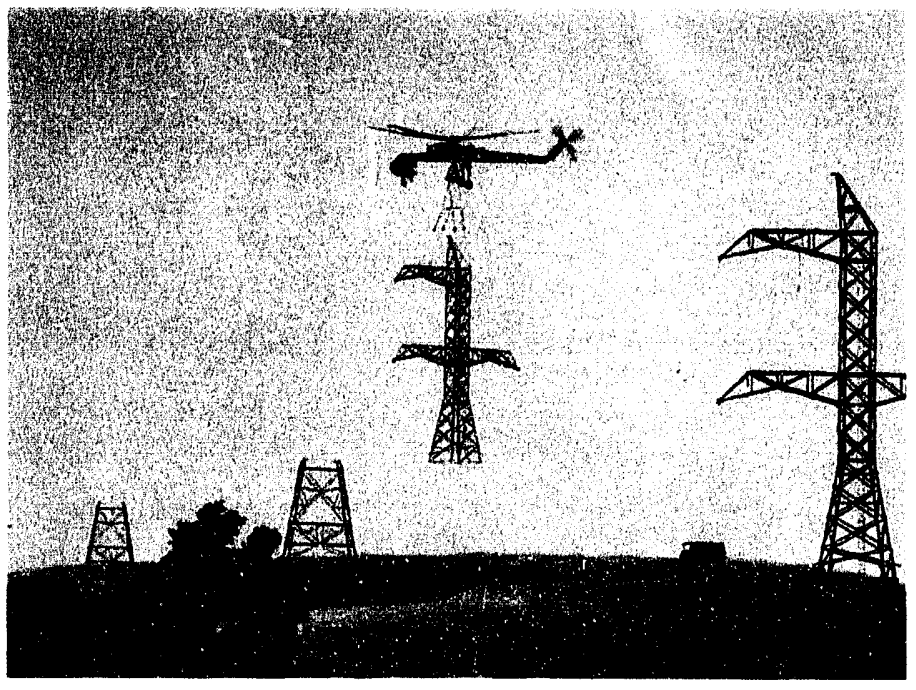

A new agrecment provides $L L N L$ access to additional, lower cost $(\$ 2-\$ 3$ million less per year) electric power. Power will be transmitted from PacifiCorp in Oregon to the Laboratory via the new 500-kV California-Oregon Transmission Project and the $230-\mathrm{kV}$ Tracy Tie-Line transmission facilities.

- California-Oregon Transmission Project. Through a series of multiparty agreements, the Laboratory has obtained access to additional, lower cost $(\$ 2-$ $\$ 3$ million less per year) electric power resources. This power will come initially from PacifiCorp in Oregon and will be transmitted to the Laboratory via the new 500-kV California-Oregon Transmission Project (COTP) and the 230-kV Tracy Tie-Line transmission facilities. A contract among the DOE, Pacific Gas and Electric (PG\&E) Company, and the Western Area Power Administration will provide the Laboratory with access to the CO'TP while allowing it to continue purchasing electrical power from $P G \& E$ as needed. Another agreement among the DOE, Lawrence Berkeley Laboratory, and Stanford Linear Accelerator Center provides for optimal use of all available power sources and an equitable sharing of the cost savings.

\section{Summary}

These institutional accomplishments, although not as visible as those of the major programs, are crucial to the Laboratory's operation. Improvements in costeffectiveness, efficiency, and productivity translate into significant monetary savings (in the millions of dollars), and the money not spent to "run" the Laboratory can be spent instead for R\&D. In addition, an institution like LLNL must deal effectively with such issues as workforce diversity, modern business practices, regulatory compliance, ES\&H, and facility maintenance in order to successfully conduct its scientific and programmatic work. Laboratory Administration and the Plant Operations Directorate are committed to providing the essential services and infrastructure for the Laboratory site and its population.

Contact: $C$. Bruce Tarter, Administration (510) 422-4168, or Dennis K. Fisher, Plant Operations (510) 422-3342. 
From two Fermi Award winners to numerous individuals honored for their public and community service this year, Laboratory men and women continue to distinguish themselves for outstanding achievements in science, technology, and public work.

'ory Director Harold Brown, 'he 1992 Enrico Fermi

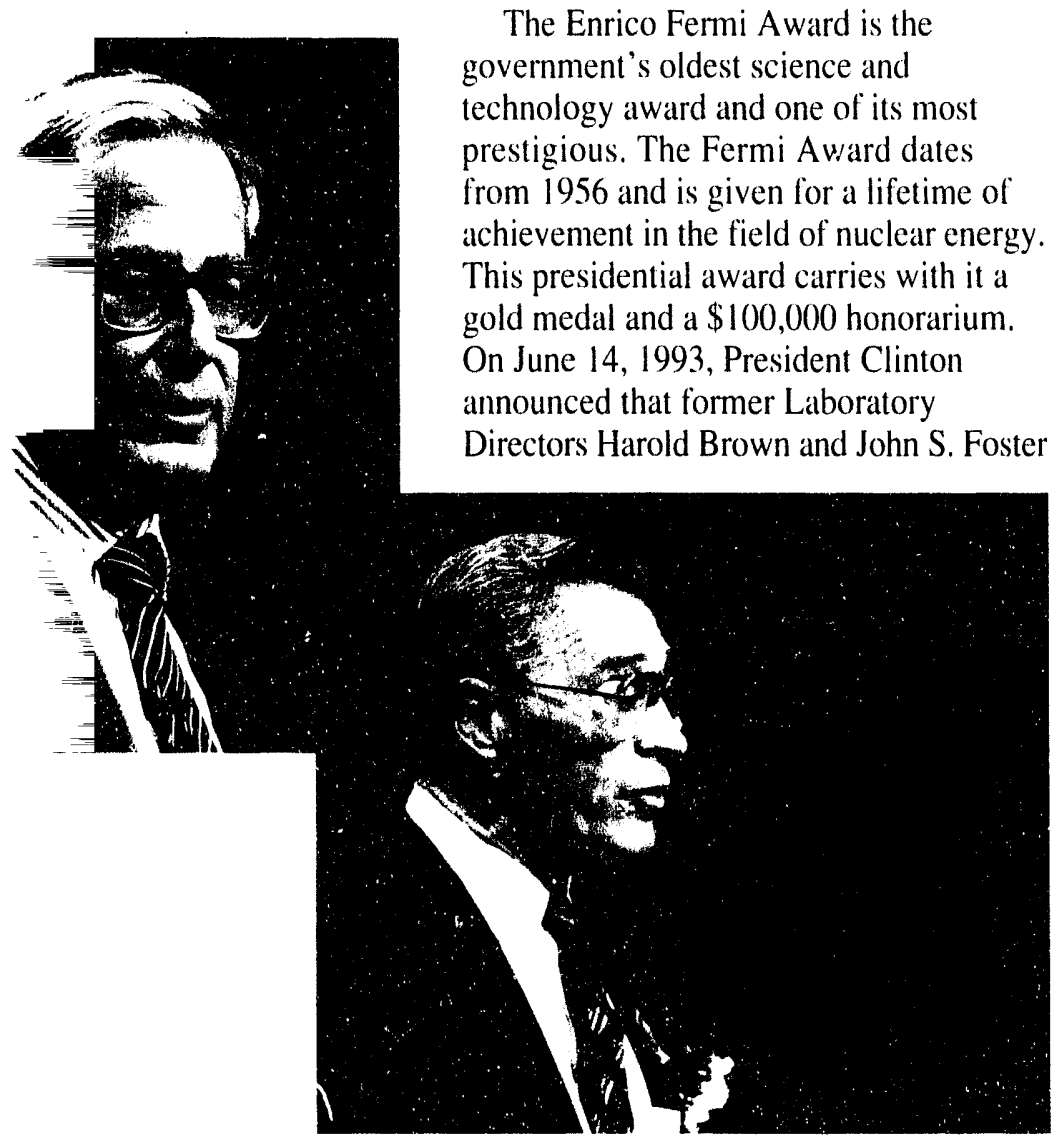

Former Laboratory Director John S. Foster, joint winner of the 1992 Enrico Fermi Award. were winners of the 1992 Enrico Fermi Award. As joint winners for careers that have been intertwined, they will share the $\$ 100,000$ honorarium. The other winner this year was Leon M. Lederman of Hyde Park, Illinois. "It is extremely fitting," said Secretary of Energy Hazel R. O"Leary, "that these scientists be honored for continuing Fermi's tradition of selfless contribution to science."

Brown received his award "for his outstanding contributions to national security: in technical leadership in the development of nuclear weapons; in leadership of Lawrence Livermore National Laboratory in its formative years; in leadership in formulating nuclear deterrence policy during the difficult Cold War period; and for excellent service and continued counsel to government." Brown is a counselor at the Center for Strategic and International Studies, a Washington D.C. think tank.

Foster received his award "for his outstanding contributions to national security: in technical leadership in the development of nuclear weapons; in leadership of Lawrence Livermore National Laboratory in its formative years; in technical leadership in the defense industry; and for excellent scrvice and continued counsel to government." Foster, until recently, chaired the Defense Science Board of the Department of Defense.

\section{Edward Teller Medal}

The Teller Medal, first awarded in 1991, at the International Conference on Laser Interactions and Related Plasma 
Phenomena, commemorates the achievements in fusion energy of Laboratory Director Emeritus Edward Teller. More specifically, this medal honors pioneering research and leadership in the use of lasers and ion particle beams to produce high-energy density matter for scientific research and for controlled thermonuclear fusion. On October 26, 1993, Laboratory physicist John D. Lindl, a deputy program leader for the Inertial Confinement Fusion (ICF) Program, received the Teller Medal in recognition of his research. Lindl's work spans a wide range of topics, including high-gain target design, hydrodynamic instabilities in ICF, implosion symmetry and hohlraums, and the physics of compression and ignition. Lindl, who joined the Laboratory in 1972, is currently the leader of the ICF Target Physics Program and is responsible for a collaborative program between LLNL and Lawrence Berkeley Laboratory to develop induction accelerators for ICF applications.

\section{Fellows}

At its annual meeting in Seattle, the American Physical Society (APS) announced the election of two Laboratory researchers to fellowship. Richard A. London, associate X-Division leader for Advanced Technology and member of the APS Division of Plasma Physics, was recognized for his landmark contribution to the physics of $x$-ray lasers and other work "including elegant and useful models of target evolution, beam propagation, and coherence." Election to fellowship was described by X-Division leader Mordecai D. Rosen as "special recognition for special people." According to Rosen, London's work in determining the optimal wavelength for biological holography or taking a picture inside a cell "turned conventional wisdom on its head."

David V. Anderson, a computational physicist at the National Energy Research
Supercomputer Center (NERSC) and member of the APS Division of Computation Physics, was recognized for his work with complex computational models of plasma. Anderson is currently developing a hybrid-ordered particle simulation (HOPS) code designed to run efficiently on massively parallel computing systems. A HOPS code can be applied to simulate the use of plasmas in chip fabrication.

Tai-Gang Nieh, a metallurgist in Chemistry and Materials Science, was named a fellow of the American Society for Metals. Nieh, who is 41 and perhaps the youngest fellow in the society, was recognized "for outstanding contribution to the development of advanced aerospace materials, including metal matrix composites, intermetallic alloys, and ceramics." Edward Teller Medal winner for 1993,
John D. Lindl.

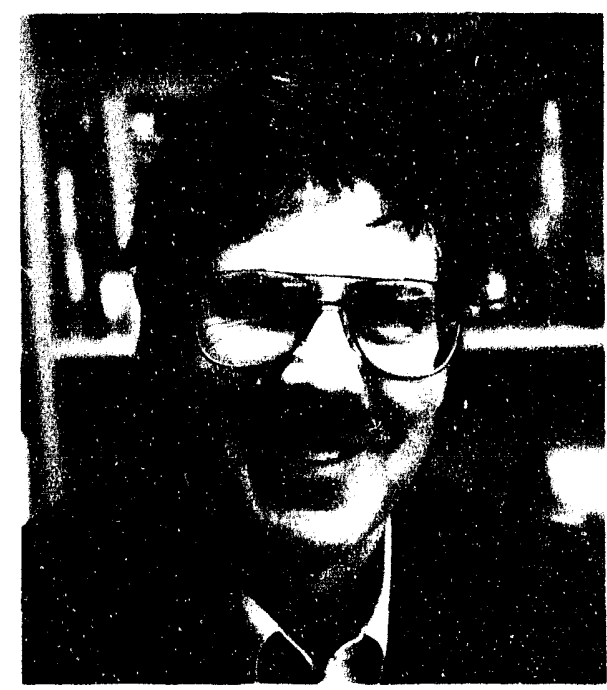

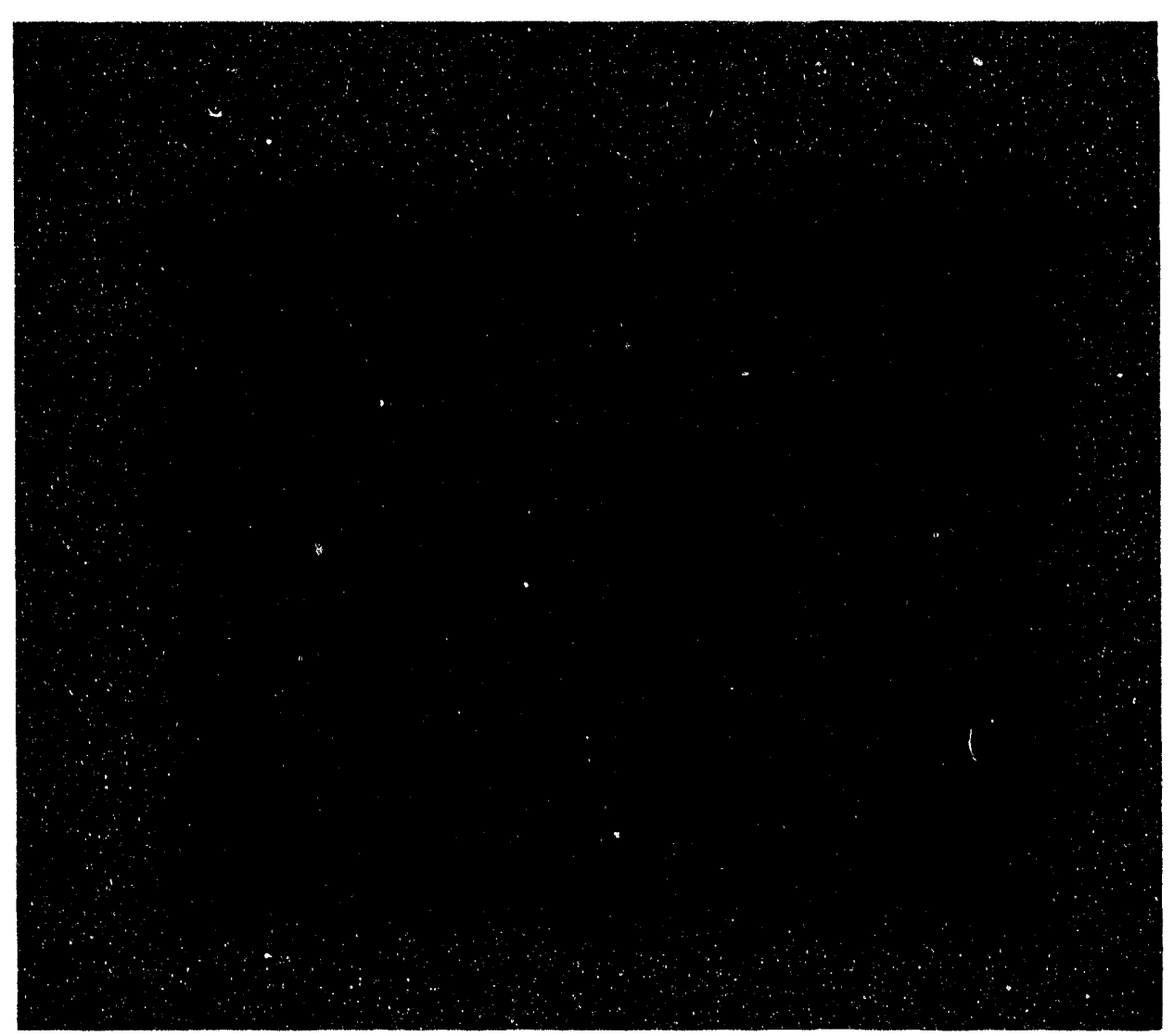


William F. Krupke and John R. Murray of the Laser and Environmental Programs were named fellows of the Optical Society of America. Of the 12,000 members of this society, 935 are fellows. Krupke is deputy associate director for Laser and Environmental Programs, and Murray is a senior scientist.

Ralph W. Moir of the Energy Program was elected chairman of the American Nuclear Society's Fusion Energy Division. His one-year term as chairman for the 1100-member organization is effective until June 1994.

\section{R\&D 100 Awards}

\section{Director John Nuckolls (left) congratulates astrophysicist Charles R. Alcock (right) on winning a 1993 R\&D 100 award for the MACHO camera.}

The goal of taking scientific innovations and turning them into new and improved products has been pursued at the Laboratory for over four decades and is also recognized by private industry.

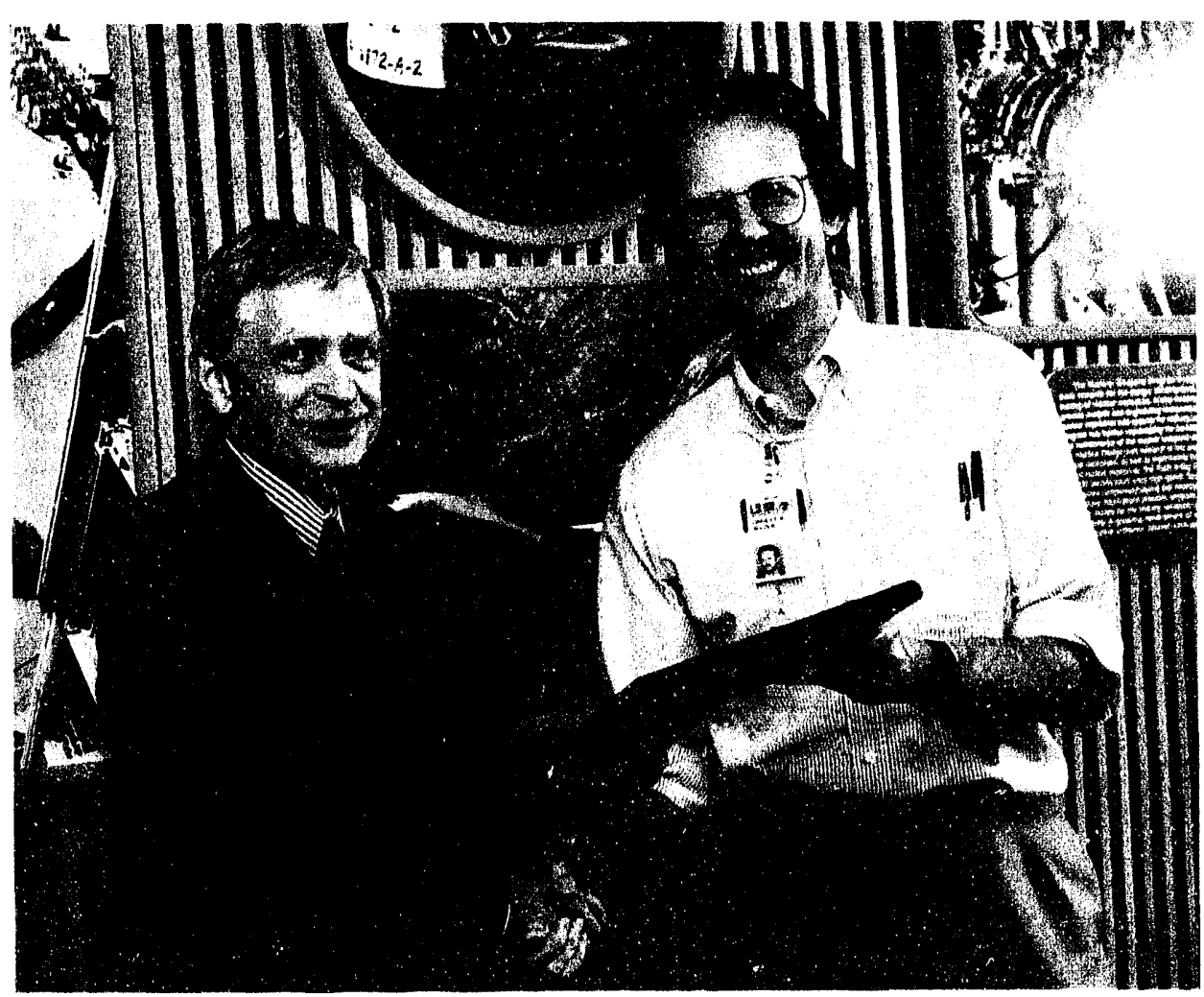

Each year, $R \& D$ Magazine selects 100 outstanding achievements in science and technology and honors the individuals responsible for them with the $R \& D 100$ award. Since 1978, the Laboratory has won 50 of these awards.

In late 1992, John C. Whitehead received the R\&D 100 award for his work as the principal developer of a compact propulsion system for small spacecraft. His new liquid rocket propulsion features miniature pumps that can turn on and off and change speed without delay to meet a wide range of thrust requirements. Propellant is stored at relatively low pressure in a lightweight metal tank. The pumped system reduces the total effective engine mass by more than one-half and cuts tank mass to as little as one-fifth previous values. Whitehead's new propulsion system allows small spacecraft to go faster and farther with less total weight and gives designers the option of increasing payload or reducing launch costs.

On September 9, 1993, three R\&D 100 awards were presented to Laboratory researchers at the Museum of Science and Industry in Chicago. Astrophysicist Charles R. Alcock (left) shared in winning the award for helping to develop the MACHO camera. The extremely powerful MACHO system integrates into one package image taking, image analysis, and data storage and archiving. MACHO is the leader in the search for the dark matter of the universe. William J. Benett, Barry L. Freitas, and Raymond J. Beach of the Laser program were recognized for creating a cooling system that allows lasers to be operated at five times greater power than was previously possible. Their modular, high-power, laser-diode array is a revolutionary jump in the packaging of lasers. The array is about seven times lower in cost than other competing cooling technologies. Thomas E. McEwan and Joseph D. Kilkenny, also of the Laser Program, received their award for a system 
that electronically records electrical signals as short as 30 trillionths of a second.

Their single-shot transient digitizer has applications in high-speed physics, telecommunications, and testing highspeed digital computer chips. It uses lowcost, off-the-shelf components and is an inexpensive replacement for oscilloscopes.

\section{Individual Honors}

Richard M. Christensen, a senior scientist in Chemistry's Materials Division, received the American Society of Mechanical Engineer's highest award and was also named Honorary Member of that society. The award cites Christensen "for distinguished contributions to mechanical engineering through original research, conceptual design of materials, and service to the profession and governmental laboratories." In addition to his latest honor, Christensen, who joined LLNL in 1976, has garnered many other awards, including the Worcester Reed Warner Gold Medal (1988), the Society of Engineering Science's William Praeger Medal (1989), and the University of Delaware Medal of Excellence in Composite Materials (1989).

Physicist Marvin J. Weber of the Chemistry and Materials Science Department is the winner of the 1993 International Conference on Luminescence Prize. This prize, given every three years, recognizes its recipient "for the fundamental studies of dynamical processes in solids which affect luminescence efficiency and the application of that knowledge to laser and scintillator materials." Weber, who has received other awards for his research on fluorescence and stimulated emission in laser glass, is the discoverer of scintillation in bismuth germanate, a crystalline material widely used to detect high-energy particles and radiation. He is currently collaborating with researchers at Lawrence Berkeley
Laboratory on scintillator materials for medical imaging.

Laboratory associate Ray E. Kidder and former LLNL Associate Director Roy D. Woodruff received the 1993 Szilard

Barry L. Freitas, Raymond J. Beach, and William J. Benett (left to right), co-winners of a $1993 R \& D 100$ award.
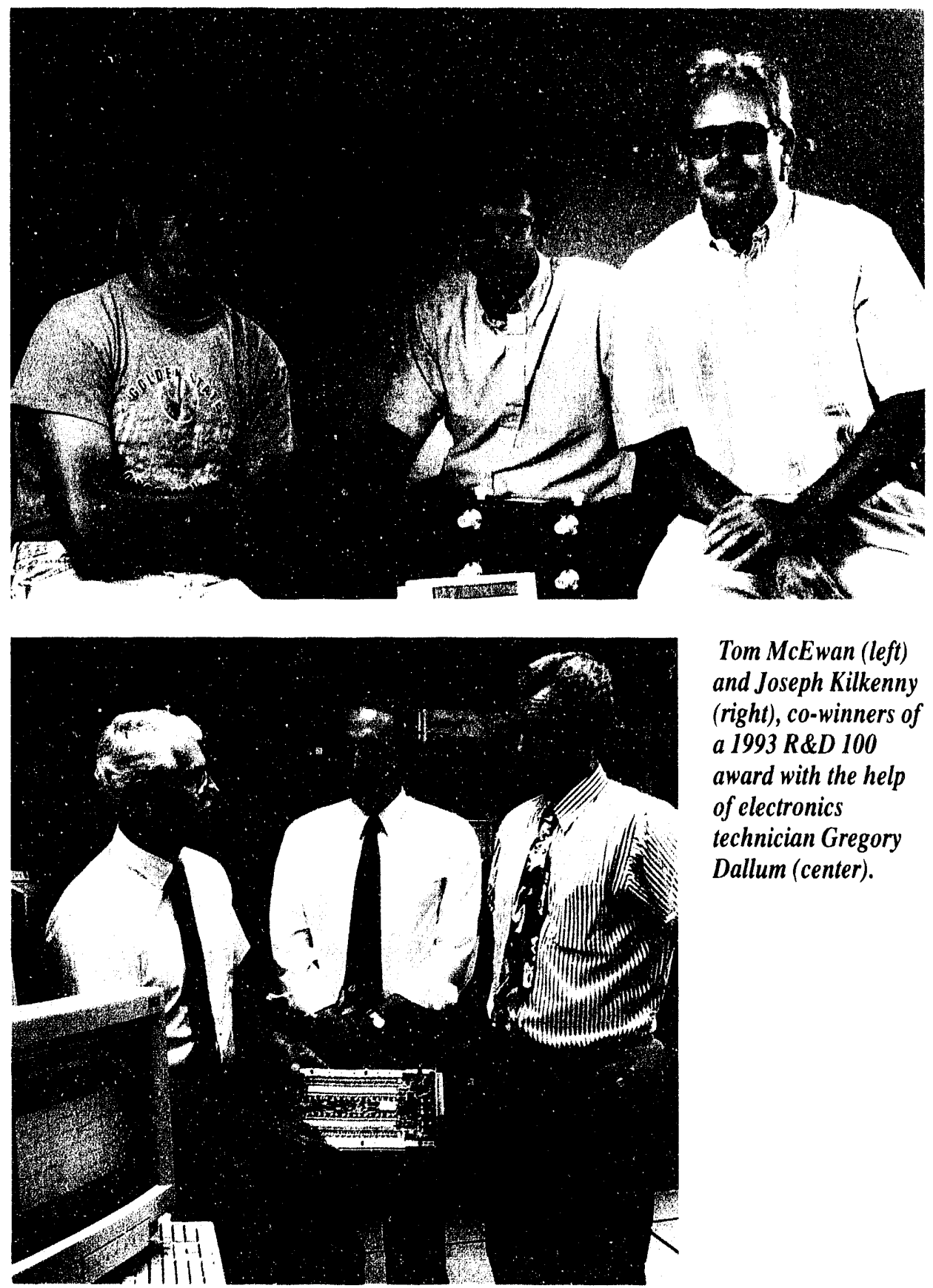

Tom McEwan (left) and Joseph Kilkenny (right), co-winners of a 1993 R\&D 100 award with the help of electronics technician Gregory Dallum (center). 


\section{Laboratory Protective Service Officers donated teddy bears and blankets to the California Highway Patrol for use to help comfort children involved in auto accidents. Here, Lab Employee Reserve Police Officer Doug Trimble and CHP Officer Steve Creel load the blankets and bears into Officer Creel's CHP cruiser.}

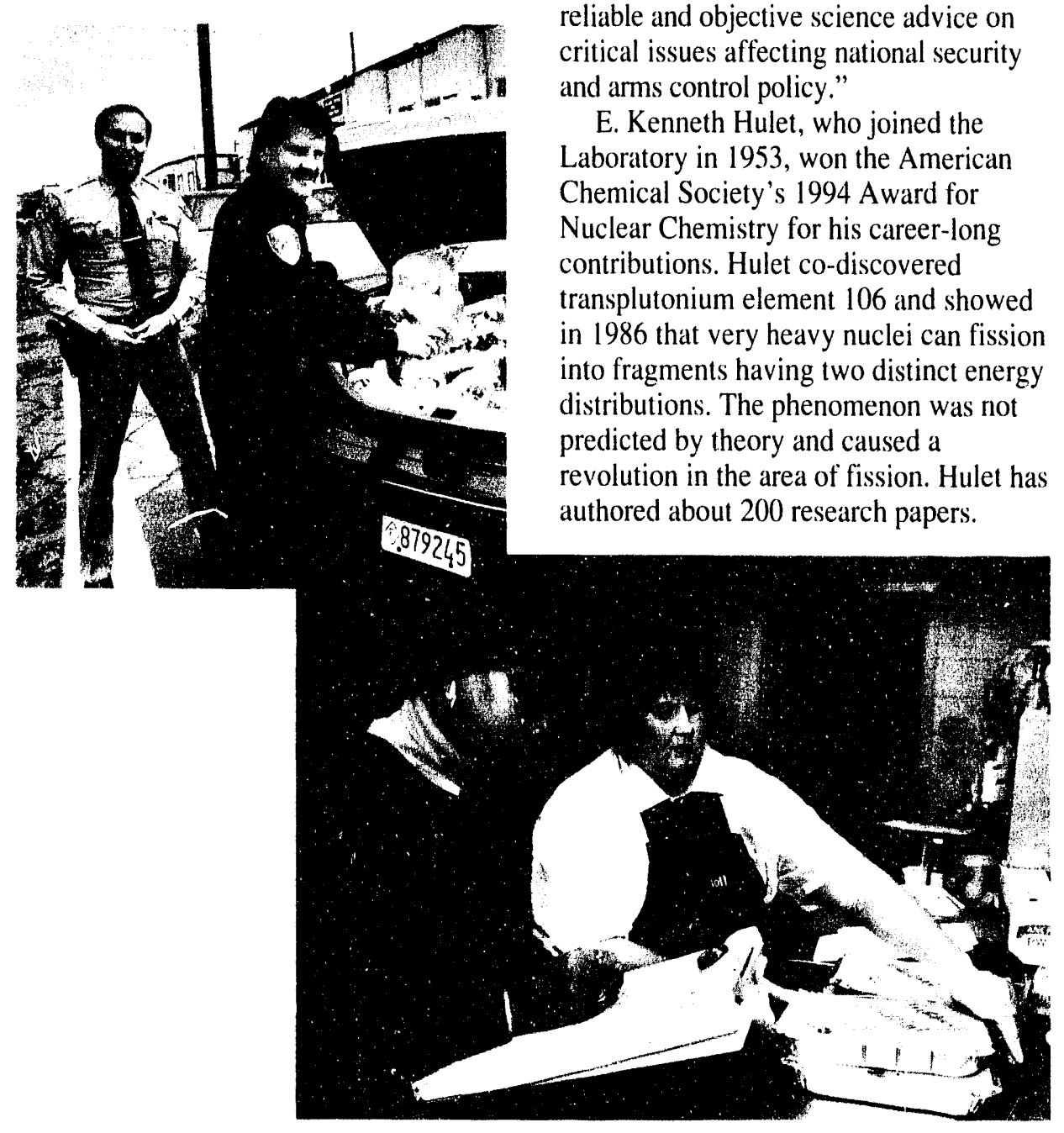

This year, $L L N L$ food vendor, Marriot Corp., worked with the Contra Costa Food Bank to save and donate excess food from the Laboratory's cafeterias.

award from the American Physical Society (APS). Kidder directed the Laboratory's Inertial Confinement Fusion program for the first ten years of its existence and recommended that the Laboratory pursue its current program in Atomic Vapor Laser Isotope Separation. Woodruff left the LLNL in 1990 for the Los Alamos National Laboratory, where he became program director for nonproliferation and arms control. The citation accompanying the award, presented by the APS in Washington D.C. reads, "For courageous efforts to provide the government with reliable and objective science advice on critical issues affecting national security nd arms control policy."

E. Kenneth Hulet, who joined the Laboratory in 1953, won the American Chemical Society's 1994 Award for Nuclear Chemistry for his career-long ered ransplutonium element 106 and showed ission phergy revolution in the area of fission. Hulet has authored about 200 research papers.
Although he retired recently, he still conducts research at the Laboratory parttime and lectures here and abroad.

William B. Durham, an experimental geophysicist in Earth Sciences, won a prestigious Alexander von Humboldt Foundation Senior U.S. Scientist Award for a year's study in Germany. (This award program was started in 1972 by West German Chancellor Willi Brandt; von Humboldt, born in 1769 in Prussia, is considered by many to have been the last great science generalist.) Durham, an LLNL scientist since 1977, received a von Humboldt fellowship for young scientists 8 years ago, in which he studied solid-state thermodynamics with a top German materials scientist. With this new award, he plans to spend 12 months at the University of Bayreuth in Bavaria, which recently established an institute for experimental geochemistry and geophysics. Durham will study deformation of the mantle's main component, olivene, at the extreme pressures that exist at the Earth's interior. He will subject olivene to pressures up to 130,000 times atmospheric pressure to test its mechanical properties. The results of these experiments will have implications for our understanding of continental drift and the convective flow of materials in the mantle.

Michael E. Glinsky is a post-doctoral fellow who joined the Lab in 1991 to work in X Division and lasers. In June, 1993, Glinsky received the Simon Ramo Award from the American Physical Society for the best doctoral thesis in plasma physics. Glinsky's dissertation is entitled "Temperature Equilibration and ThreeBody Recombination in Strongly Magnetized Pure Electron Plasmas." He is currently working on electron transport in fast igniter ICF target design.

Several Laboratory researchers earned international recognition this year for their work in scientific visualization. Computation's Nelson L. Max and Roger A. Crawfis captured a first-place 
award from the International Multimedia Association for their film "Global Climate Visualization." Experimental physicist Larry Shaw, who works in B Division, received the 1992 Photo-Sonics

Achievement Award for his "outstanding contributions in the development of highspeed imaging systems."

Twenty-five Lab employees were presented with the DOE Weapons Recognition of Excellence Awards in April 1993. The awards were for contributions made in 1991 and 1992.

The employees cited for their efforts were Dan W. Patterson, Glenn L. Mara, David R. Goosman, James V. Tyler, William J. Quirk. Dana P. Rowley, Richard C. Baxter, James E. Hanafee, Ronald D. Streit, Eugene W. Burke, Mark E. Lowry, Franklin Roeske Jr., Walter V. Morgan, Dean A. Beckedahl, Paul D. Sargis, Ronald E. Haigh, Charles F. McConaghy, Daniel C. Nelson, Donald A. Masquelier, Jack L. Robbins, Terry R. Lindman, Lawrence E. Valby, Mark S. Strauch, and William L. Robison.

\section{Public Service and Community Awards}

This year, the California Governor's Committee for Employment of Disabled Persons named James L. Willows, Jr., employee of the year. Willows, a software engineer in the Safeguards, Security Engineering, and Computation Division, has been a Laboratory employee since 1954 and blind for the past 32 years. Willows is a member of the Advisory Committee on Services for the Blind, the first vice president of the National Federation of the Blind of California, and a member of the Laboratory's Advisory Committee on Disability. Gregory E. Davis, deputy associate program leader of the Fission Energy System Safety Program, described Willows as a role model for Livermore employees who have become disabled and an inspiration to all. "He has facilitated and promoted employment opportunities for the blind and disabled persons and has encouraged the blind and disabled to seek new or maintain current employment."

For saving the Laboratory an estimated $\$ 500,000$ during the last fiscal year and for implementing projects that will save an additional $\$ 780,000$ annually, the Utilities and Electric Utilities Divisions earned the Federal Energy Efficiency Award. This award for outstanding contributions to energy management and integrated resource planning was presented to Laboratory representatives on October 30, 1992, at the Russell Senate Office Building in Washington D.C.

In April 1993, the Laboratory's Plating Shop in Building 332 was given the California Water Pollution Control Association Certificate of Merit for its outstanding achievement in waste water management. Since the shop's waste minimization effort began in 1990, the amount of water discharged to the sewer went from 2.8 million gallons each year to zero.

The Labor Department's Office of Federal Contract Compliance Programs presented an Exemplary Voluntary Effort

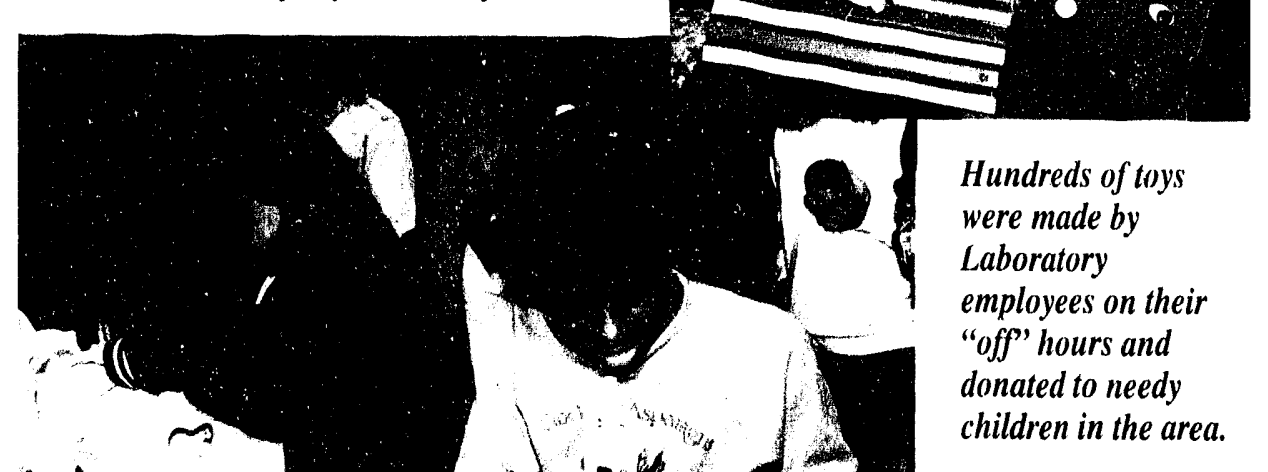

Award to the Laboratory for implementing innovative programs to increase employment for minorities, women, veterans, and the disabled.

More than a score of Laboratory employees were honored in April 1993 for their volunteer service to the community. Those individuals singled out by the Corporate Volunteer Council, a coalition of valley businesses, were Sharlene Londin, Elvis Spencer, Ken Williams, Walt Lindquist, Jackie McBride, Chelle Clements, Norma Mc'Tyler, Arnic Warshawsky, Don Ryder, Joe Shinn, Donna Chato, Jim Travis, Nick Brazell, Lynn Throckmorton, Fred Allen, Donna Almanza, Janice Lawson, Betty Klino, Roger Werne, Amy Sands, Bill Dunlop, Jim Caywood, and Joan Bennett.

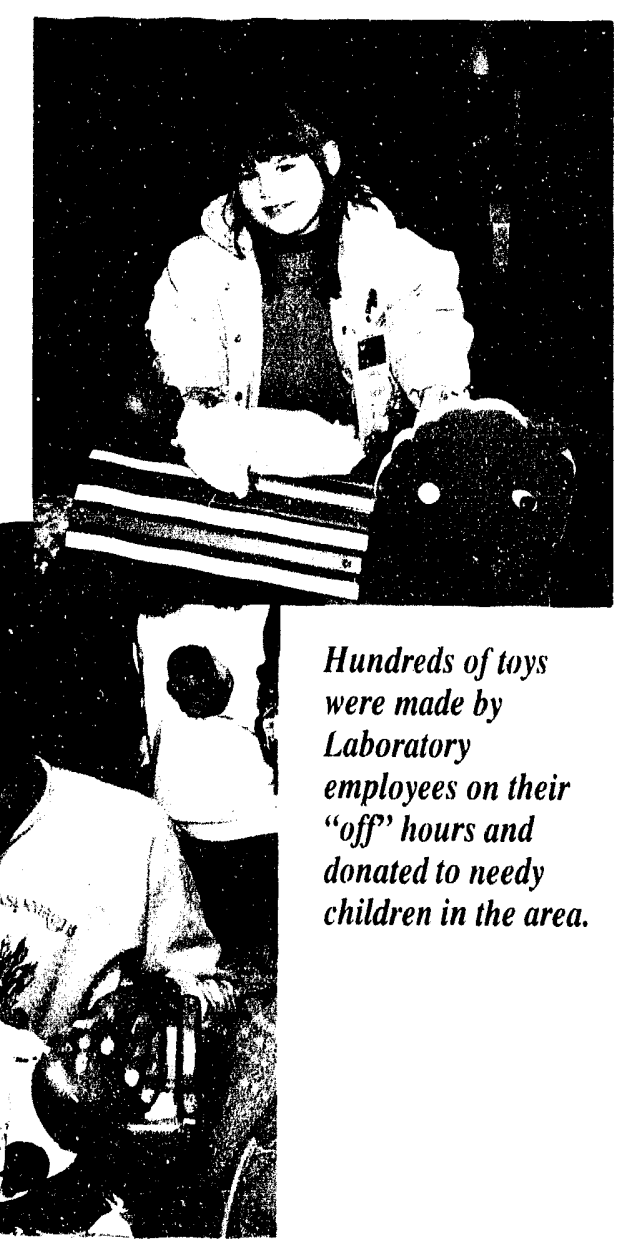




$\begin{array}{ll}\text { AFM } & \text { atomic force microscopy } \\ \text { AGS } & \text { Alternating Gradient Synchrotron } \\ \text { AIS } & \text { Administration Information Systems } \\ \text { AlGaAs } & \text { aluminum gallium arsenide } \\ \text { ANN } & \text { artificial neural network } \\ \text { ARAC } & \text { Atmospheric Release Advisory Capability } \\ \text { AVI } & \text { automatic vehicle identification } \\ \text { AVLIS } & \text { atomic vapor laser isotope separation }\end{array}$

BASTEC Bay Area Science and Technology Education Collaboration

CALIOPE Chemical Analysis by Laser Interrogation of Proliferation Effluents

CAMS Center for Accelerator Mass Spectrometry

CCD charge-coupled device

CDF channel-dropping filter

CFCs chlorofluorocarbons

CIAC Computer Incident Advisory Capability

C\&MS Chemistry and Materials Science

CMTC California Manufacturing Technology Center

COP certification of process (gauge)

COTP California-Oregon Transnission Project

CQI continuous quality improvement

CRADA Cooperative Research and Development Agreement

DAS Department of Applied Science

DHS Department of Health Services (State of California)

DNA Defense Nuclear Agency

DOD Department of Defense

DOE Department of Energy

EBIT electron beam ion trap

EC Electronic Commerce

ECX extrusion cast explosive

EOS equation of state

EPA Environmental Protection Agency

ESnet Energy Sciences Network

ES\&H Environment, Safety, and Health

EYH Expanding Your Horizons (program)

FENIX Fusion Engineering International Experiment

FSU former Soviet Union

FXR flash $x$-ray (facility)

GaAs gallium-arsenide

GATEC Government Acquisition through Electronic Commerce

GPA glycophorin A (assay)

HBCUs Historically Black Colleges and Universities

HE high explosive

HEPA high-efficiency particulate air (filter) 


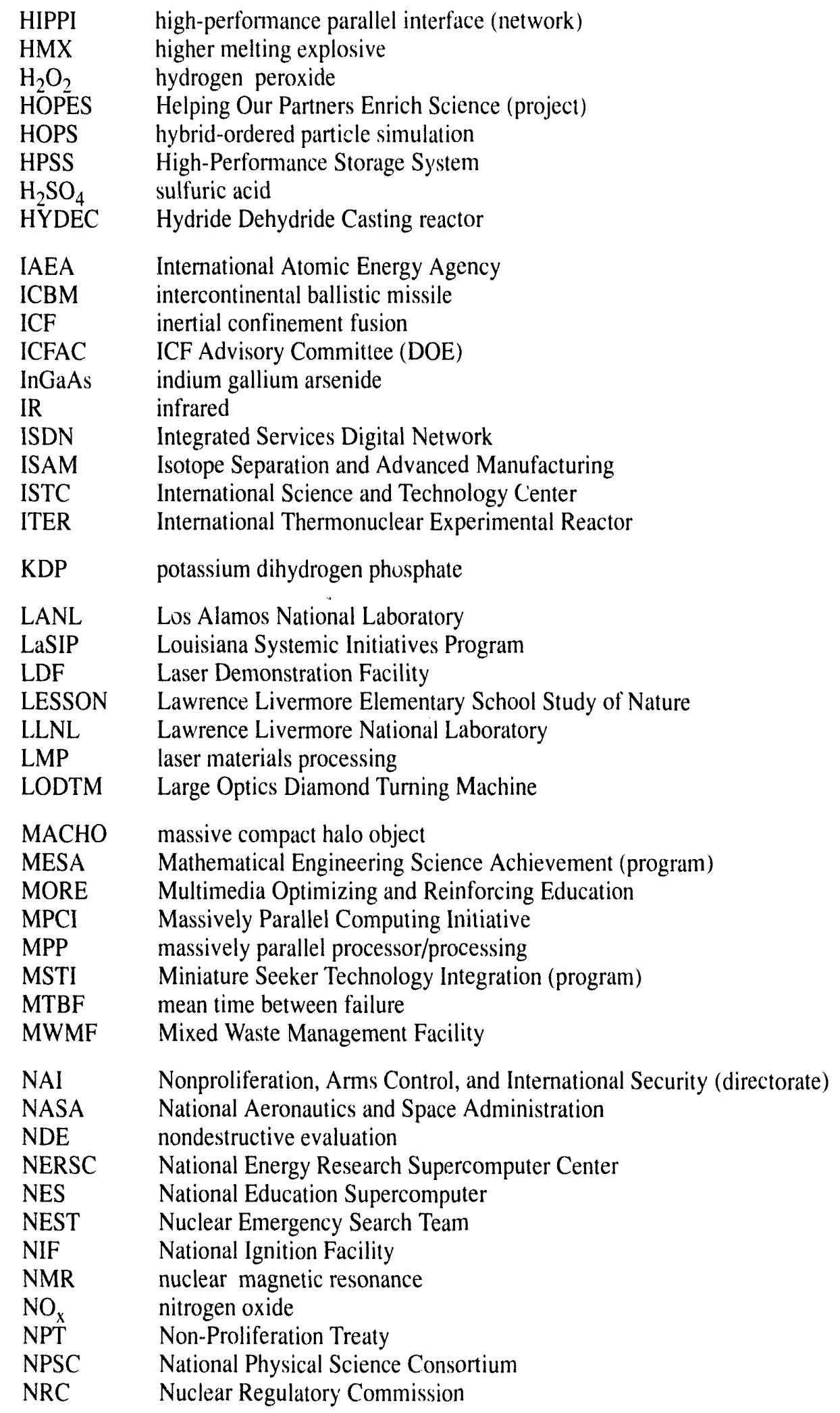


NSL National Storage Laboratory

NTES Nuclear Test and Experimental Science (directorate)

OES Office of Emergency Services (State of California)

PALS Principals for the Advancement of Leadership in Science

PC

PCE personal computer

PCR polymerase chain reaction

PDDP parallel data-distribution preprocessor

PETE Partnership for Environmental Technology Education

PG\&E Pacific Gas and Electric (company)

PLANET Pumps Layout and Evaluation Tool

QGP quark-gluon plasma

R\&D research and development

RHIC Relativistic Heavy Ion Collider

RISC restricted instruction set computer

ROMAC Remote Optical Measurement and Calibration

SEC Science Education Center

SERS Science and Engineering Research Semester

$\mathrm{SO}_{3} \quad$ sulfur trioxide

$S$ O.S. $\quad$ Science on Site

SSC Superconducting Super Collider

START Strategic Arms Reduction Talks

STM scanning tunneling microscopy

TAHRS Tire, Accident, Handling, and Roadway Safety (project)

TAISIR Temperature and Imaging System Infrared

TATB triaminotrinitrobenzene

TCE trichloroethylene

TMOS tetramethoxy silane

TPX Tokamak Physics Experiment

TQM total quality management

TTBT Threshold Test Ban Treaty

UDS Uranium Demonstration System

USEC U.S. Enrichment Corporation

UV ultraviolet

VISTA Vehicle Impact Simulation Technology Advancement (program)

VMS Virtual Machine System (computer operating system)

WESVA Weapon Safety Value Assessment

WIMP weakly interactive massive particle

WTVC Wavelength Tunable Video Camera

XP xeroderma pigmentosum 


\section{Visiting the \\ Lawrence Livermore National Laboratory}

Visiting the Lawrence Livermore National Laboratory is easy. The Visitors Center is located at the East Gate on Greenville Road just three miles south of Interstate 580. It is in an open area of the Laboratory, so no badges or identification are needed and parking is available. All services of the Visitors Center are free of charge. The Center provides an overview of LLNL's current research programs and a glimpse of their applications. The Center's relaxed, self-guided format encourages visitors to examine the displays and videos at their own pace. The Center is open weekdays.

\section{The Visitors Center staff provides:}

- Tour Programs. The Visitors Center offers a community tour of parts of the Laboratory on the first and third Mondays of each month at 1:00 pm. Visitors must reserve a place on a tour at least a week in advance. You need to be 18 years of age or older.

Student classes or other special-interest groups may arrange a tour of parts of the Laboratory on weekdays other than Monday.

- Community Outreach at the Laboratory includes working with community organizations, governmental agencies, and individuals to show that the Laboratory is a good neighbor. The Laboratory offers employee volunteers to nonprofit and governmental organizations to help accomplish their chosen programs.

- The Speakers Bureau schedules Laboratory personnel to speak to schools, community organizations, and professional groups about work at the Laboratory.

- The Information Line is a telephone number you can call with questions about the Laboratory or about the research that is done here.

For information on the Visitors Center or its programs, call (510) 422-9797.

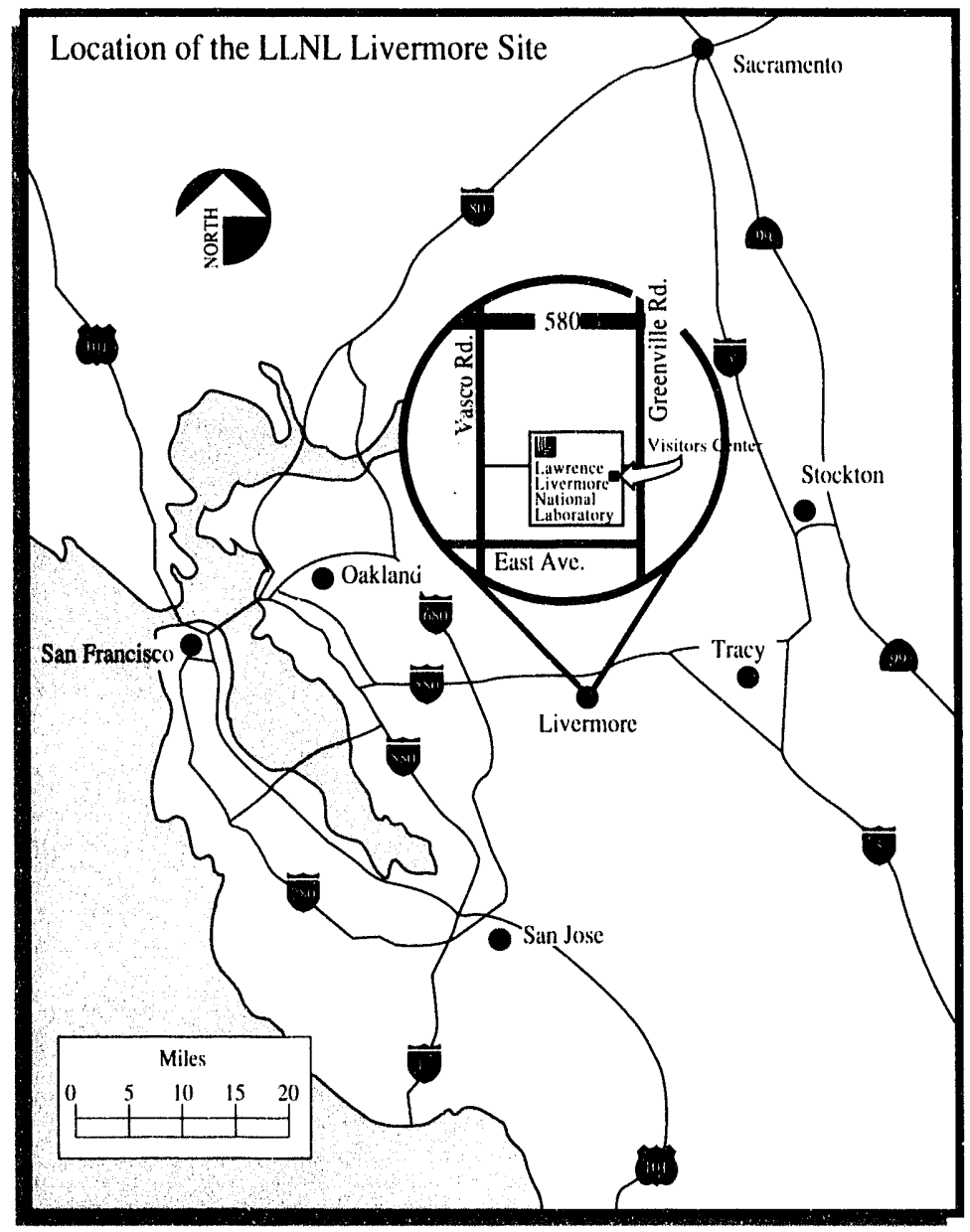



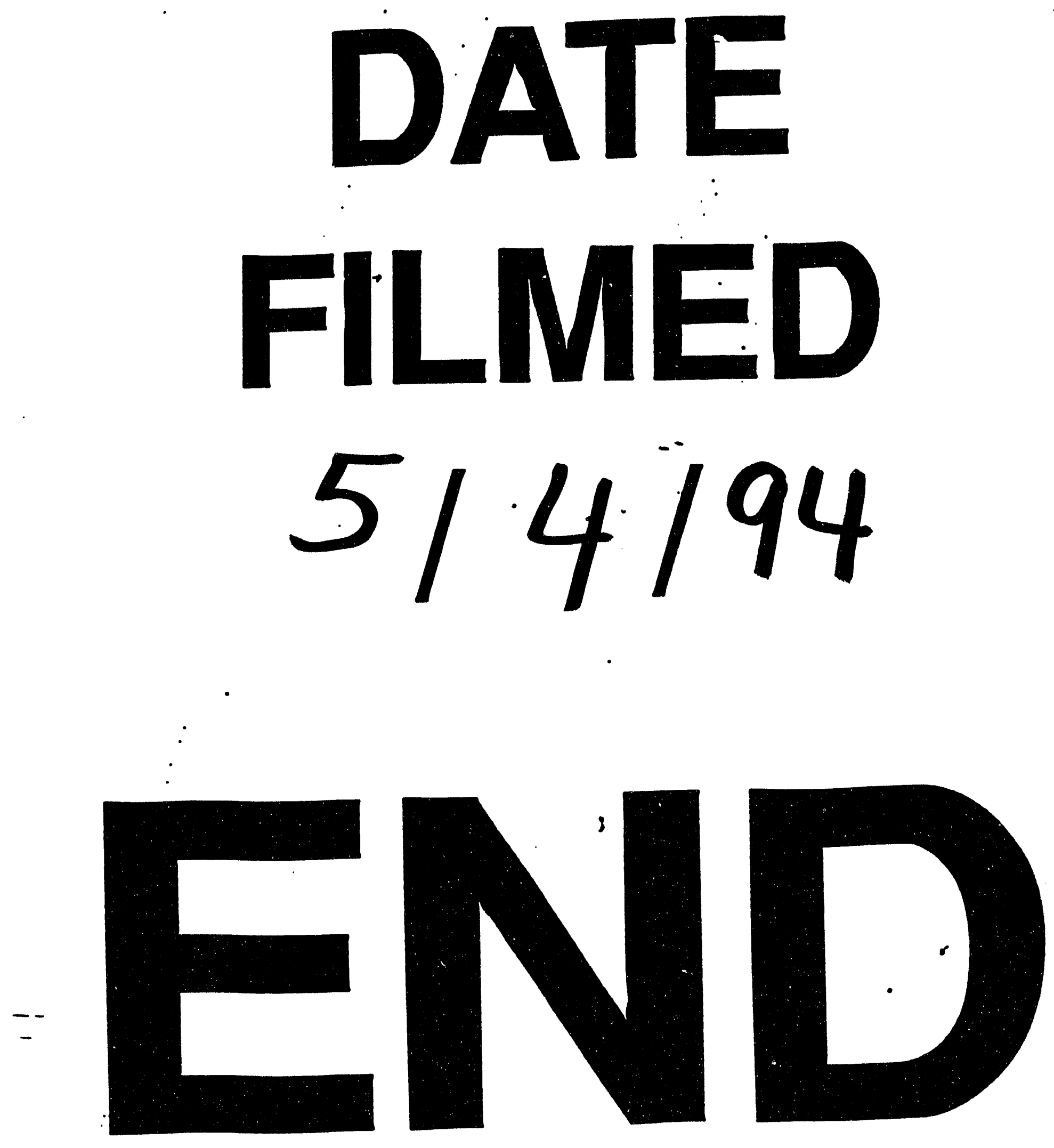
